\title{
National Register Testing of Nine Archeological Sites at Waco Lake, McLennan County, Texas
}

Ann M. Scott

Prewitt and Associates, Inc.

Karl W. Kibler

Cross Timbers Geoarcheological Services

Marie E. Blake

Prewitt and Associates, Inc.

Follow this and additional works at: https://scholarworks.sfasu.edu/ita

Part of the American Material Culture Commons, Archaeological Anthropology Commons, Environmental Studies Commons, Other American Studies Commons, Other Arts and Humanities Commons, Other History of Art, Architecture, and Archaeology Commons, and the United States History Commons

Tell us how this article helped you.

This Article is brought to you for free and open access by the Center for Regional Heritage Research at SFA ScholarWorks. It has been accepted for inclusion in Index of Texas Archaeology: Open Access Gray Literature from the Lone Star State by an authorized editor of SFA ScholarWorks. For more information, please contact cdsscholarworks@sfasu.edu. 
National Register Testing of Nine Archeological Sites at Waco Lake, McLennan County, Texas

\section{Creative Commons License}

\section{(c) (1) $\Theta(9$}

This work is licensed under a Creative Commons Attribution-NonCommercial-No Derivative Works 4.0 International License. 


\title{
NATIONAL REGISTER TESTING OF NINE ARCHEOLOGICAL SITES AT WACO LAKE, MCLENNAN COUNTY, TEXAS
}

\author{
by \\ Ann M. Scott \\ Karl W. Kibler \\ and \\ Marie E. Blake \\ Co-Principal Investigators: Karl W. Kibler and Ross C. Fields
}

REPORTS OF INVESTIGATIONS, NO. 132

\author{
Submitted to \\ U.S. Army Corps of Engineers \\ Fort Worth District \\ by \\ Prewitt and Associates, Inc. \\ Cultural Resources Services \\ Austin, Texas
}

J anuary 2002 

TABLE OF CONTENTS

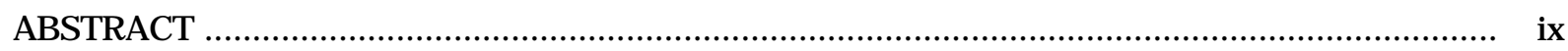

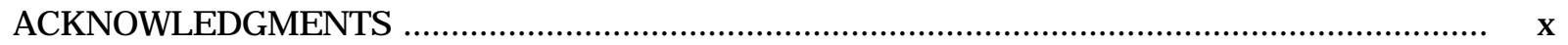

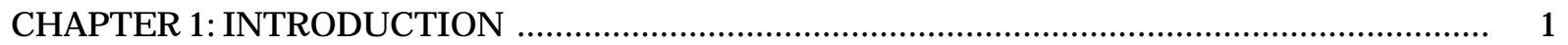

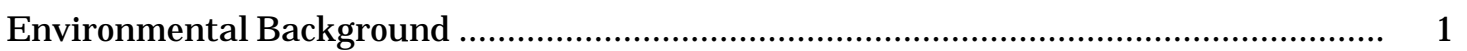

Geology, Geomorphology, and Soils ........................................................... 1

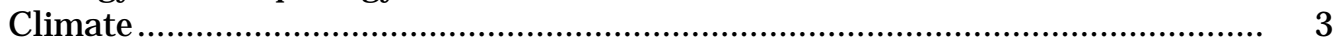

Flora and Fauna ............................................................................ 3

Previous Archeological I nvestigations ......................................................................... 3

CHAPTER 2: ARCHEOLOGICAL AND HISTORICAL BACKGROUND ..................................... 7

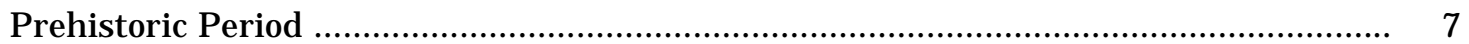

Paleoindian Period ….............................................................................. 7

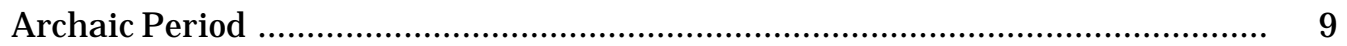

Late Prehistoric Period ........................................................................ 10

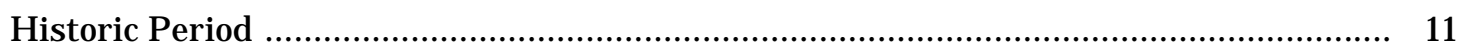

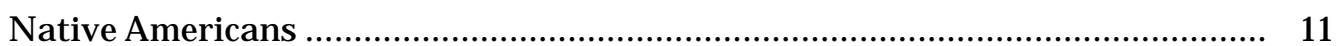

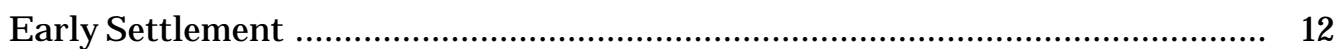

Civil War and Reconstruction .................................................................. 13

Agricultural Recovery and Success ......................................................... 14

World War I and Camp MacArthur ............................................................ 14

The 1920s to the Present ..................................................................... 14

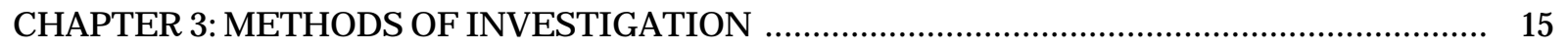

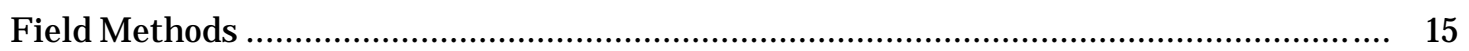

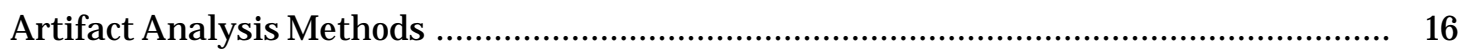

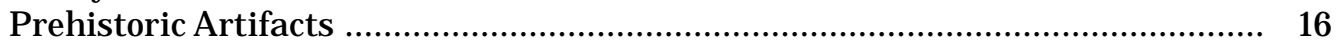

Chipped StoneArtifacts ........................................................... 16

Other Tools and Materials ............................................................ 18

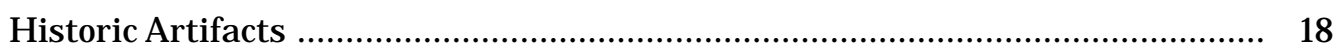

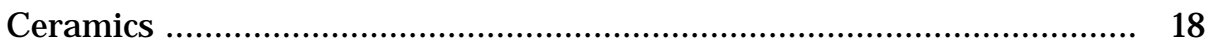

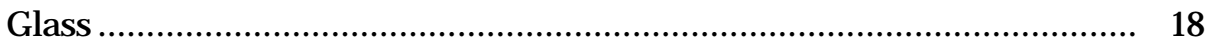

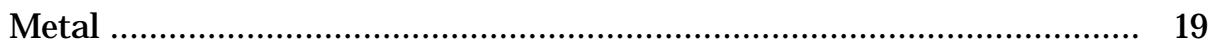

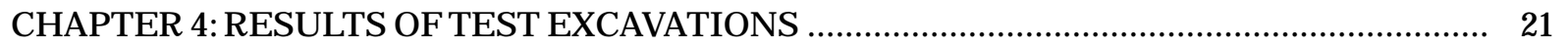

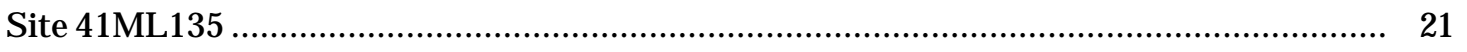

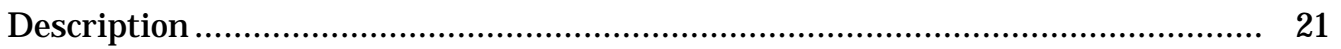

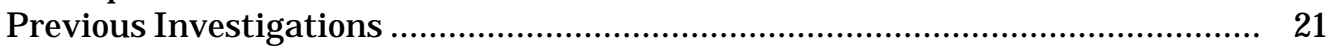

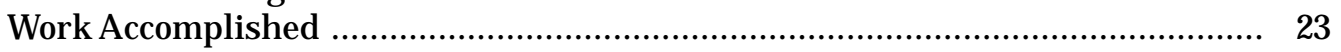

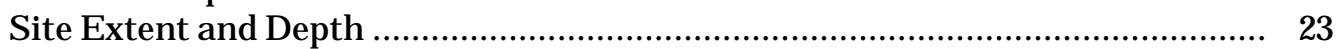

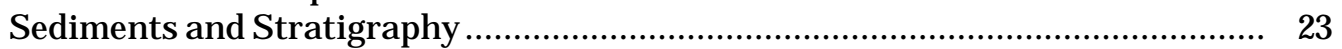

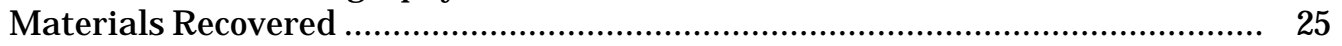

Chronology and Components ..................................................................... 26

Summary and Assessment .................................................................. 26

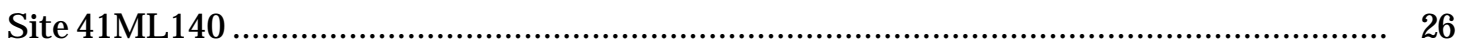

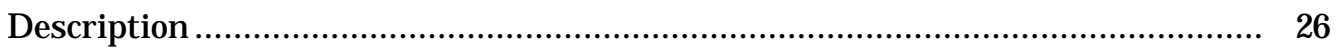

Previous I nvestigations ...................................................................... 26 


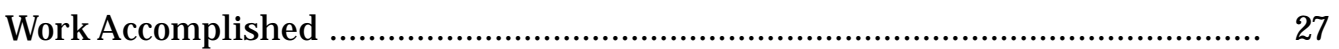

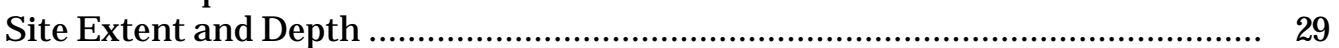

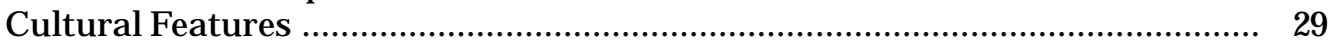

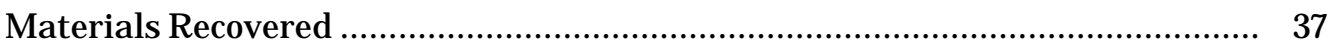

Chronology and Components ......................................................................... 44

Summary and Assessment ..................................................................... 45

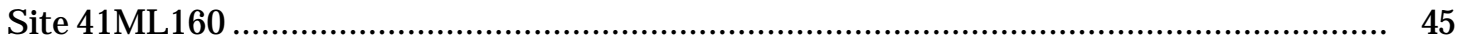

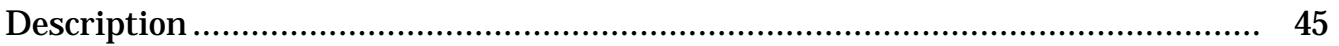

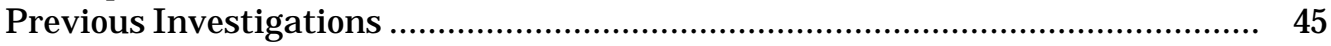

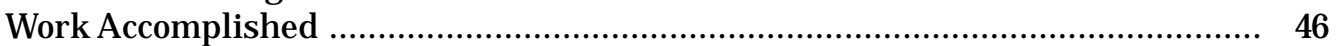

Site Extent and Depth .......................................................................... 46

Sediments and Stratigraphy ................................................................... 46

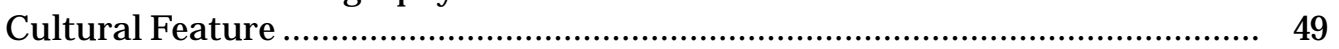

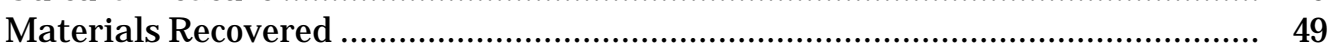

Chronology and Components ................................................................ 52

Summary and Assessment .......................................................................... 52

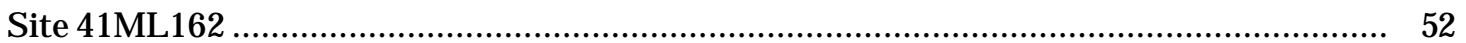

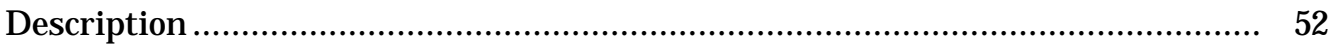

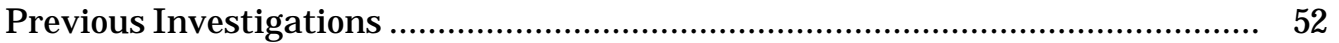

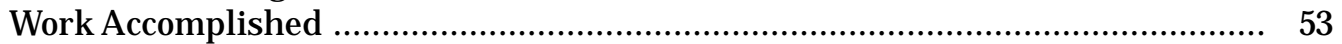

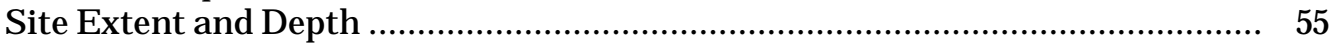

Sediments and Stratigraphy ..................................................................... 55

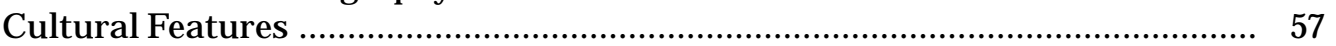

Materials Recovered ............................................................................. 58

Chronology and Components ................................................................... 69

Summary and Assessment ................................................................. 71

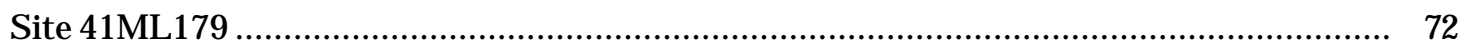

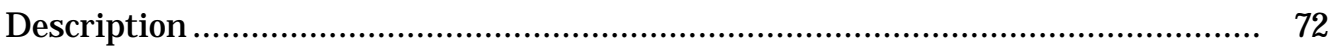

Previous I nvestigations .......................................................................... 72

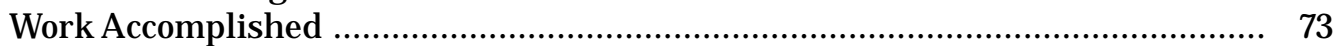

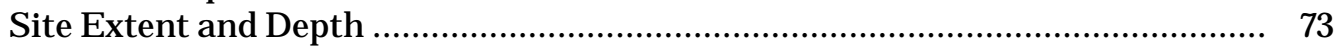

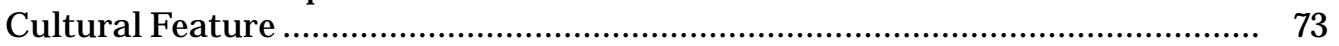

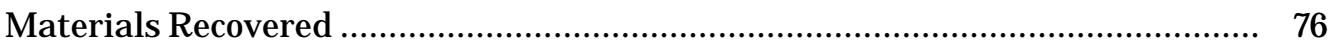

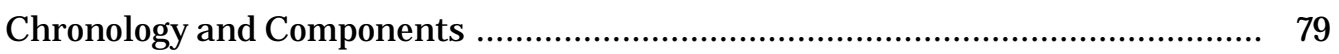

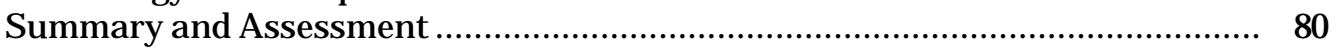

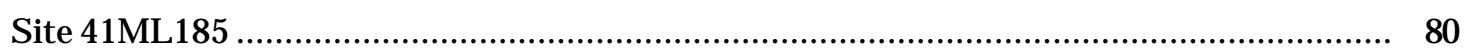

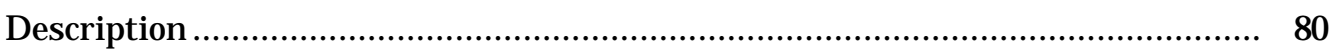

Previous I nvestigations .......................................................................... 80

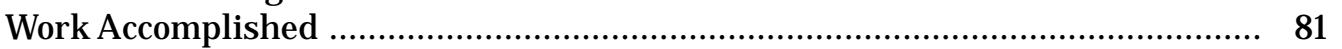

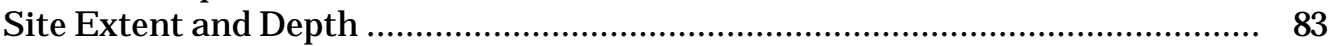

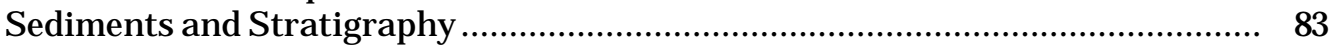

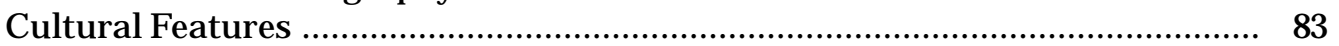

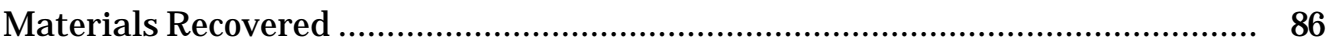

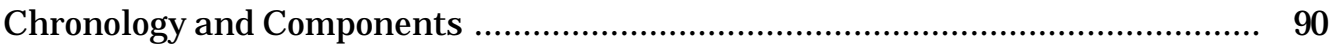

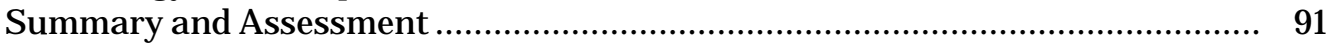

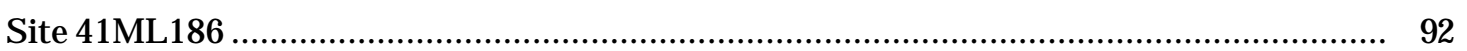

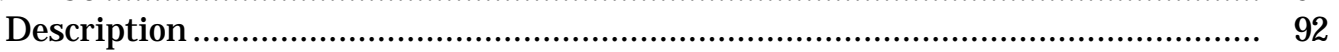

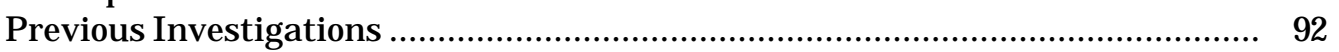

Work Accomplished .................................................................................. 92

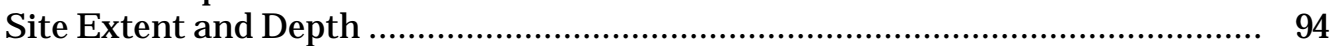

Sediments and Stratigraphy ..................................................................... 94 


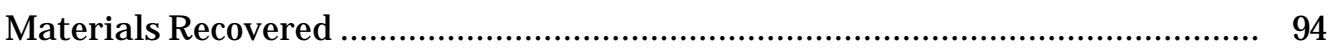

Chronology and Components ................................................................... 96

Summary and Assessment .................................................................... 96

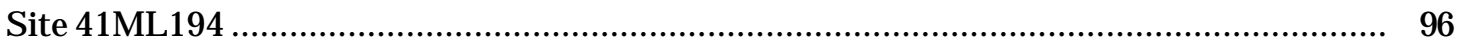

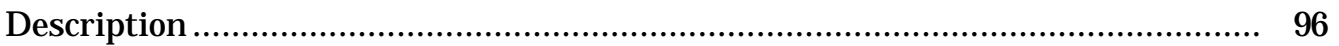

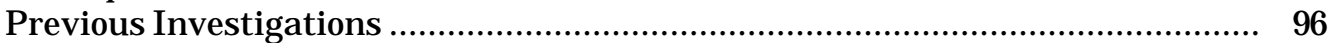

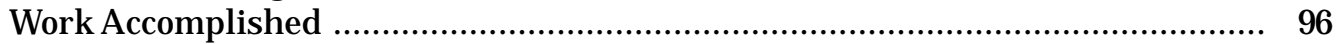

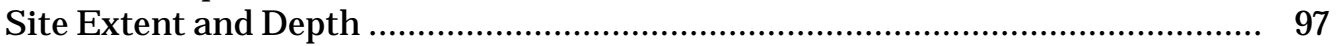

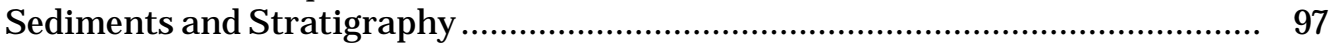

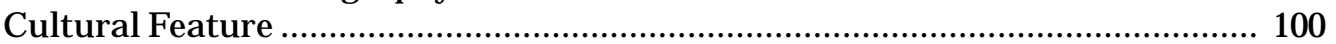

Materials Recovered .................................................................................. 100

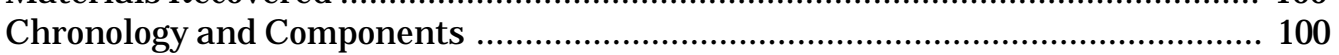

Summary and Assessment ................................................................ 100

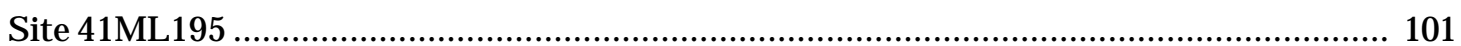

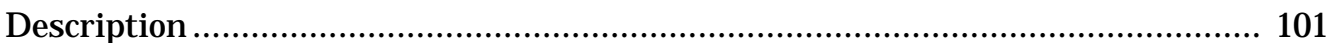

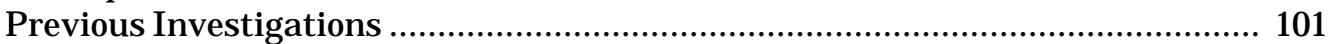

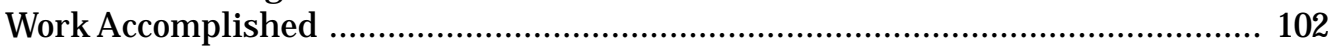

Site Extent and Depth ............................................................................. 102

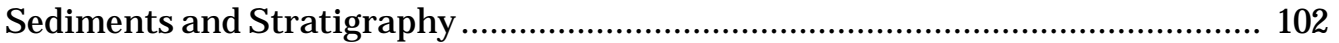

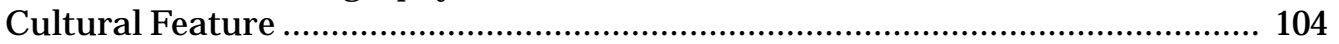

Materials Recovered ................................................................................. 104

Chronology and Components ..................................................................... 109

Summary and Assessment ...................................................................... 110

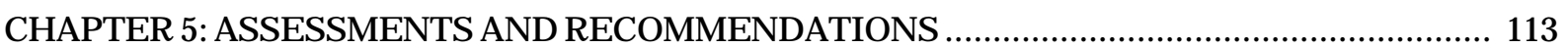

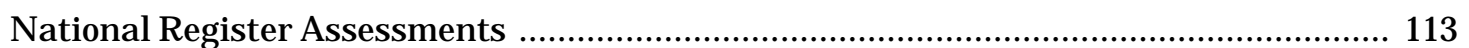

Data Recovery Recommendations and General Research I ssues at Waco Lake............... 114

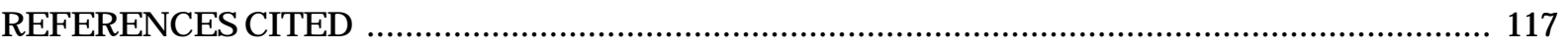

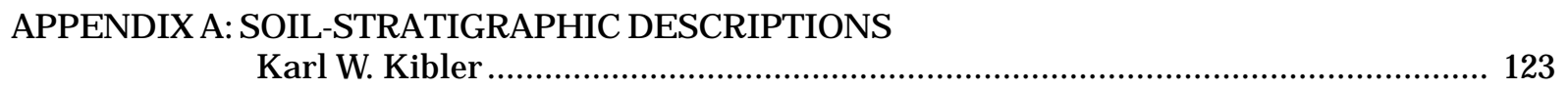

APPENDIX B:INVERTEBRATE FAUNAL ANALYSIS

Karen M. Gardner ............................................................................... 135

APPENDIX C:VERTEBRATE FAUNAL ANALYSIS

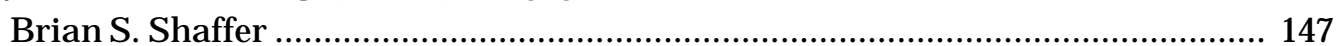

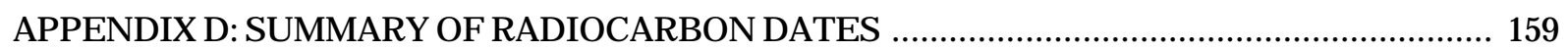




\section{LIST OF FIGURES}

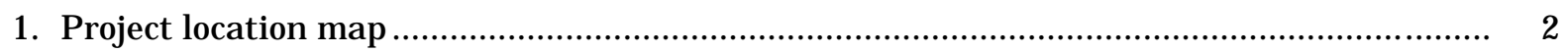

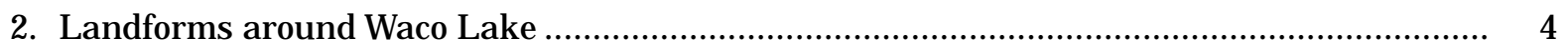

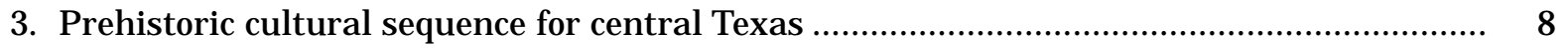

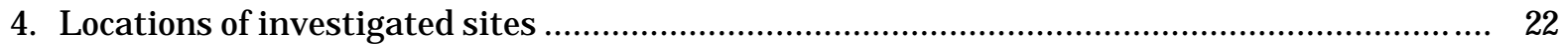

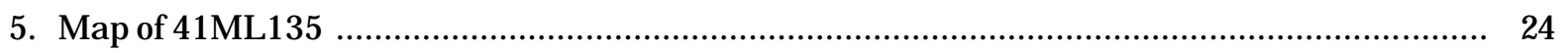

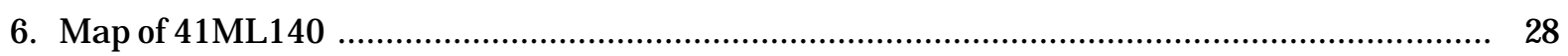

7. Plan view of Feature 1 at the Erath/McLennan House, 41ML140 ..................................... 30

8. Plan view of Feature 2 at the Erath/McLennan House, 41ML140 ................................... 31

9. Photograph of Feature 2 as exposed in Test Unit 2 (Level 2) ........................................... 32

10. Plan view of Feature 3 at the Erath/McLennan House, 41ML140 ................................... 33

11. Photograph of Feature 4 at the E rath/M cLennan House, 41ML 140 ................................. 34

12. Plan view of Feature 5 at the Erath/M cLennan House, $41 \mathrm{ML} 140$....................................... 35

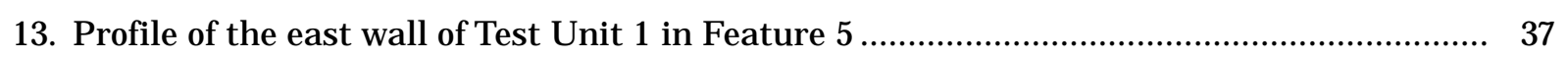

14. Photograph of Feature 6 as exposed in Test Unit 5 (Level 1) ............................................ 38

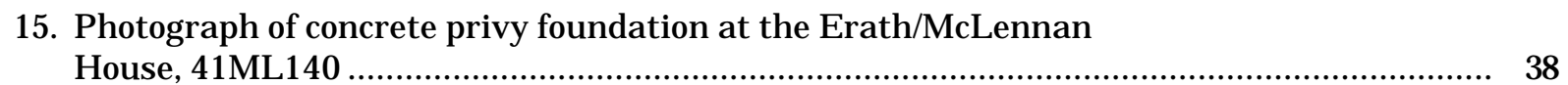

16. Photograph of concrete pad and galvanized water tank at the E rath/McLennan

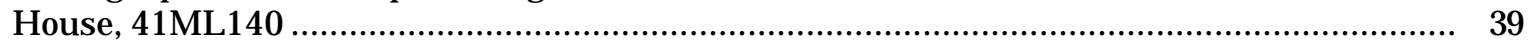

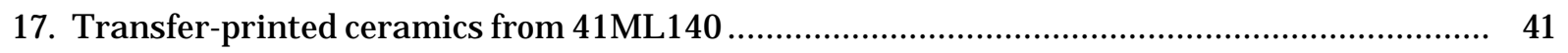

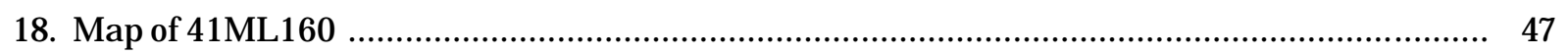

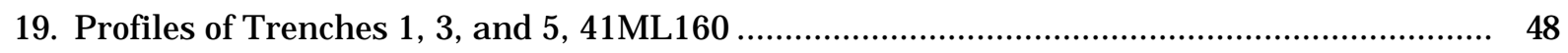

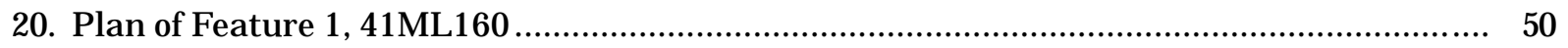

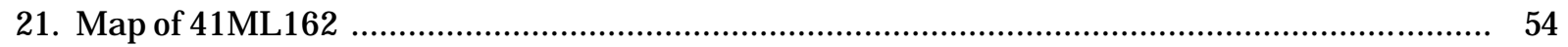

22. Profiles of Trenches 1, 3, and 4, 41ML162 ............................................................. 56

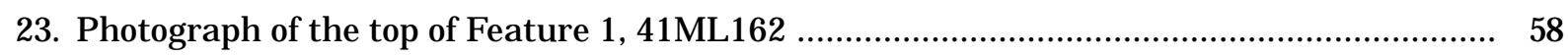

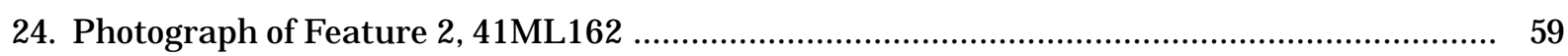

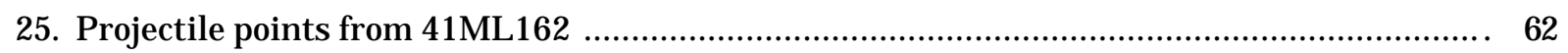

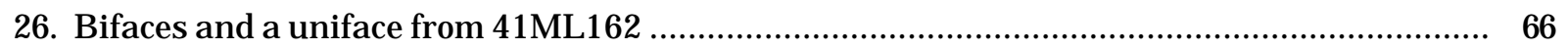

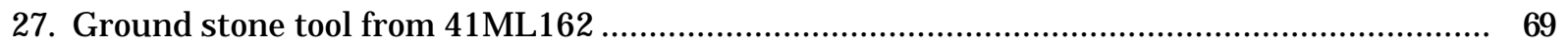

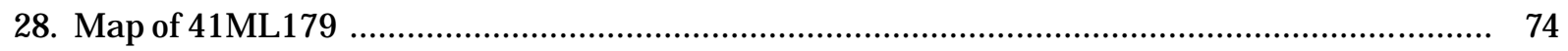

29. Plan view of Feature 1 at the Sneed Farmstead, 41ML 179 .......................................... 75

30. Photograph of Feature 1 as exposed in Test Units 1 and 2 (Level 4) ................................ 77

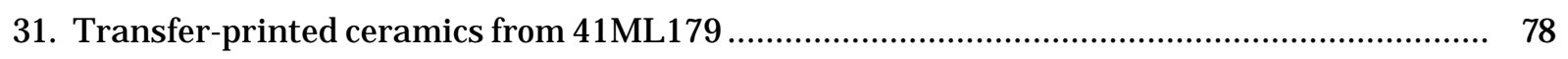

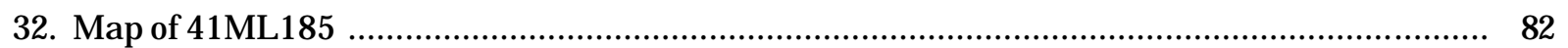

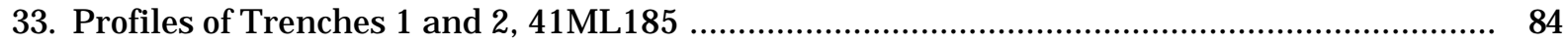




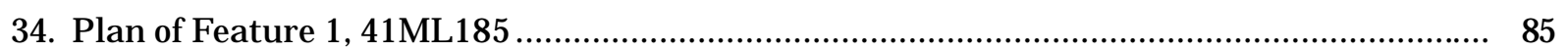

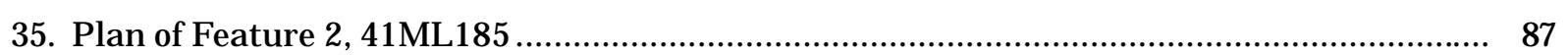

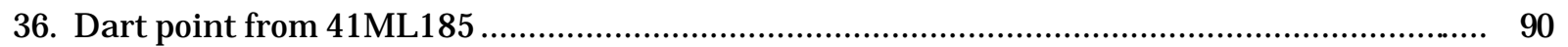

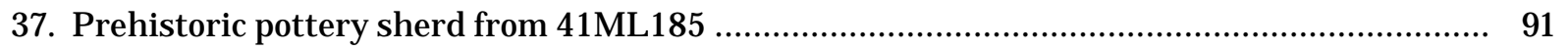

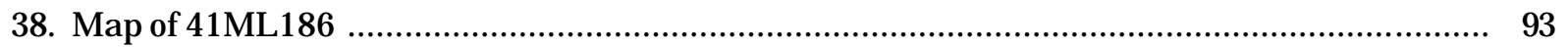

39. Profiles of Backhoe Trenches 1, 2, and 5, 41ML 186 ........................................................ 95

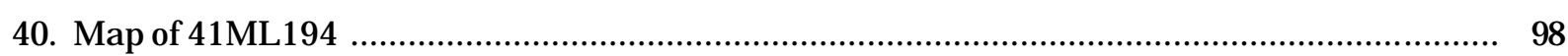

41. Profiles of Trenches 2, 3, and 6, 41ML194 ................................................................... 99

42. Photograph of Feature 1, Test U nits 3 and 4, 41ML 194 ................................................. 101

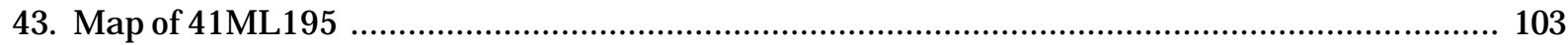

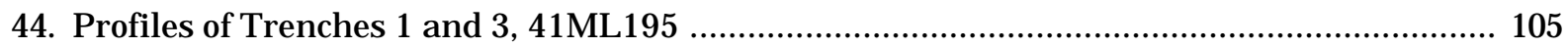

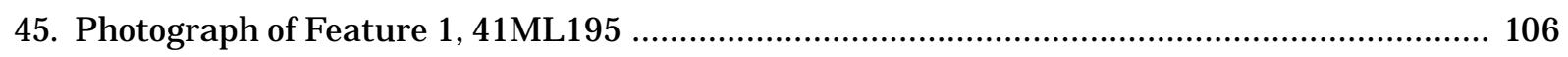

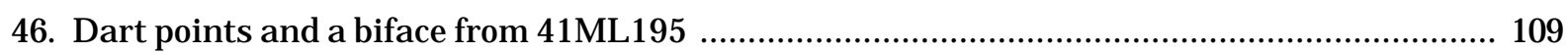




\section{LIST OF TABLES}

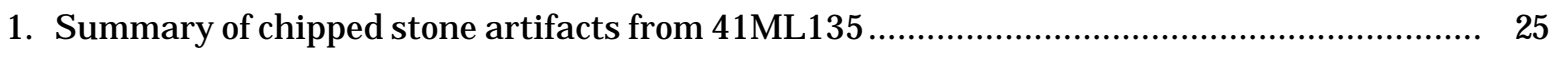

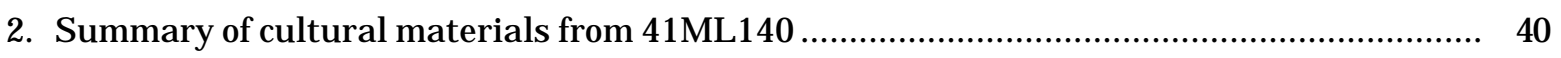

3. Summary of cultural materials from 41ML 160 ..................................................... 51

4. Summary of cultural materials from 41ML162 ........................................................ 60

5. Provenience and metric data for projectile points from 41ML 162 ................................. 63

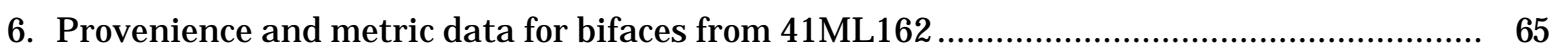

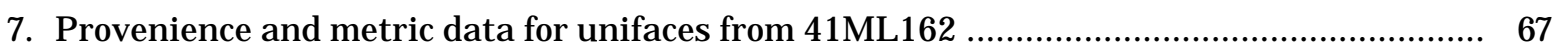

8. Provenience and metric data for cores from 41ML162 .................................................. 67

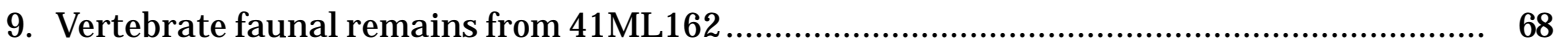

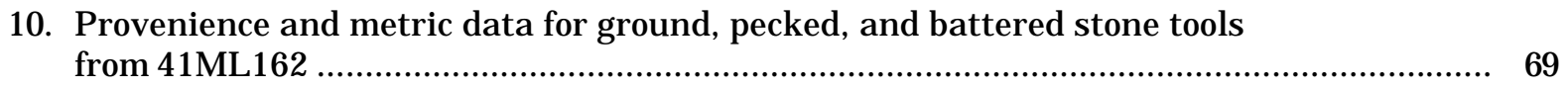

11. Summary of cultural materials from 41ML 179 ..................................................... 78

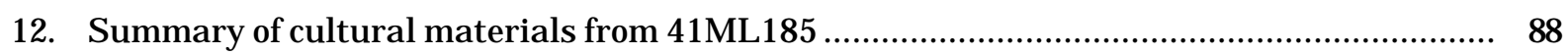

13. Provenience and metric data for bifaces from 41ML 185 ........................................... 91

14. Provenience of mussel shells from 41ML186 .......................................................... 96

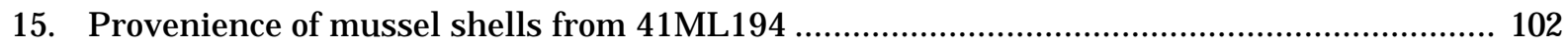

16. Summary of cultural materials from 41ML 195 ...................................................... 107

17. Provenience and metric data for dart points from 41ML 195 ....................................... 110

18. Provenience of invertebrate faunal remains ................................................................ 138

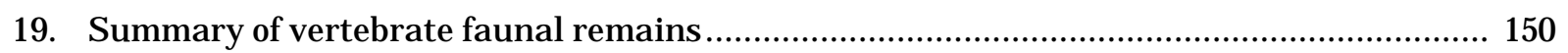

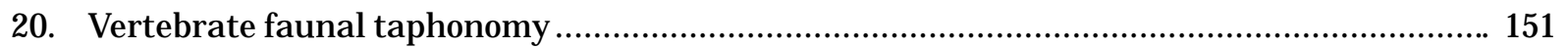

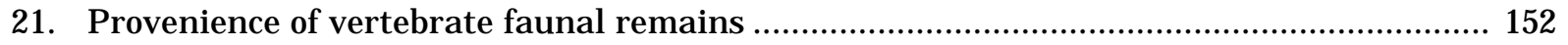

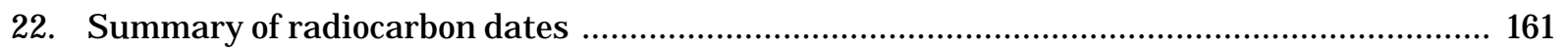




\section{ABSTRACT}

From October 2000 to February 2001, Prewitt and Associates, Inc., conducted National Register of Historic Places eligibility testing of ninesites located at Waco Lake in McLennan County, Texas. The U.S. Army Corps of Engineers, Fort Worth District, sponsored the project as a result of the proposed plan to raise the conservation pool level of the lake by $7 \mathrm{ft}$. Of the nine sites, two are historic (41ML 140 and 41ML 179), six are prehistoric (41ML160, 41ML162, 41ML 185, 41ML186, 41ML 194, and 41ML 195), and one contains both prehistoric and historic components (41ML 135). Testing at 41ML 135 investigated only the prehistoric component, since the proposed raising of the lake will not impact the historic one.

Four prehistoric sites-41ML 160, 41ML 162, 41ML 185, and 41ML 195-havethe capacity to contribute important information and are considered el i gible for $\mathrm{N}$ ational Register listing based on their good contextual integrity and the presence of stratigraphically isolablecomponents with sufficient quantities of artifacts and other materials for interpretation. Data recovery excavations are recommended at the two most-productive and best-dated of these-41ML 162 and 41ML 195-along with two National Register-eligible sites-41ML 35 and 41ML37-tested previously. Prehistoric sites 41ML 135, 41ML 186, and 41ML 194 are judged to be inel igible for National Register listing because they yielded so few artifacts and other cultural materials that they lack the capacity to yield any important information. The two historic sites are considered ineligible for National Register listing because of the sparseness of contexts containing isolable early assemblages at 41ML140, the scarceness of diagnostic attributes useful for interpretation in the assemblage from 41ML 179, and the inability at both sites to address issues rel ated to overall plantation/farmstead layout. 


\section{ACKNOWLEDGMENTS}

The completion of this project would not have been possible without the hard work and cooperation of many individuals. Ann M. Scott served as Project Archeologist with the guidance of Co-Principal Investigators, Ross C. Fields and Karl W. Kibler. Historic Archeol ogist Marie E. Blake offered advice and supervised aspects of the field operations at the historic sites. Mr. Kibler also served as Project Geomorphologist. Appreciation is extended to the crew for their perseverance in the face of numerous delays during the project. Project crew members wereArdi Eggleston, Timothy P. Everette, Timothy Gibbs, and Rob Thrift. Mr. Thrift performed the site mapping with a total station.

Additional individuals who aided in the completion of this project include personnel from the U.S. Army Corps of Engineers, Waco Lake Office and Fort Worth District Office, and the City of Waco Water Utilities Department. Billy Haferkamp and Kathy Gately of the Waco Lake Project Office provided land access and logistical assistance. J ames Sexton and Danny J ackson, of the City of Waco, coordinated backhoe and trackhoe operations. Steve Bradbury conducted the initial trenching. J ohn McMillan, who skillfully excavated trenches at most of the sites, replaced Mr. Bradbury. J ohn's contributions, and servings of venison sausage, are greatly appreciated. Dr. J ay R. Newman, U.S. Army Corps of Engineers, Fort Worth District, served as Technical Representative and supervised the coordination required for the project.

The staff at Prewitt and Associates provided their expertise through comments and advice throughout all phases of the project. Most of the background information for this report was borrowed from ReLocati on and U pdated Recordation of 44 Archeol ogi cal Sites at Waco Lake, McLennan County, Texas, by Kimberly K. Kvernes, Marie E. Blake, Karl W. Kibler, J ennifer K. McWilliams, E. Frances Gadus, and Ross C. Fields.

Mr. Fields and Mr. Kibler offered constructive comments during field operations and report production. Artifacts were washed and cataloged by J onathan Grant and Mr. Thrift under the supervision of Laboratory Director Karen M. Gardner. Ms. Gardner also examined the mussel shell collection for identifiable specimens and tabulated the results. EIton R. Prewitt typed the projectile points. Brian J. Wootan prepared the illustrative materials. J ack Rehm conducted the artifact photography. Consultants who contributed to the data analysis are Brian S. Shaffer (analysis of vertebrate fauna) and Dr. J. Phil Dering (identification of macrobotanical specimens). Mr. Fields and Audra L. Pineda edited the report, and Ms. Pineda produced it. 


\section{INTRODUCTION}

From October 2000 to February 2001, personnel from Prewitt and Associates, Inc., conducted National Register of Historic Places eligibility testing of nine sites located at Waco Lake in McLennan County, Texas. The U.S. Army Corps of Engineers, Fort Worth District, sponsored the project as a result of the proposed plan to raise the conservation pool level of the lake by $7 \mathrm{ft}$ to $462 \mathrm{ft}$ above mean sea level.

Waco Lake is located in central McLennan County, Texas, on the west side of the City of Waco (Figure 1). It is on the Bosque River, with the dam lying ca. $6.6 \mathrm{~km}$ upstream from where the Bosque flows into the Brazos River. Two arms extend west and south from the main body of the lake following the North Bosque and South Bosque Rivers. Two major tributaries, Hog Creek and the Middle B osque River, enter the southern arm from the west. No major streams feed the lake from the east. The original dam was completed in 1929, and at an elevation of $430 \mathrm{ft}$, the lake covered ca. 2,700 acres. In 1965, a new dam was finished and the level raised to $455 \mathrm{ft}$, with the new conservation pool covering ca. 7,300 acres.

\section{ENVIRONME NTAL BACKGROUND}

\section{Geology, Geomorphology, and Soils}

Waco Lake lies at the eastern edge of the Grand Prairie, which is separated from the Blackland Prairie farther to the east by the Balcones Fault Zone (Hill 1901:72). The eastern shore of the lake is bordered by the westward-facing White Rock escarpment or cuesta, consisting of outcrops of the Upper Cretaceous South Bosque, Lake Waco, and Austin Chalk Formations (Hayward 1988:332; Hill 1901:331-
332; Proctor et al. 1970). The first two formations consist of limestone and shale, while the third is composed of chalk and marl. This escarpment, which rises ca. $60 \mathrm{~m}$ above the level of Waco Lake, constitutes the western edge of the Balcones Fault Zone (Burket 1965:158). The west side of Waco Lake and the inundated valleys of the North Bosque River, Hog Creek, Middle Bosque River, and South Bosque River are set in Lower Cretaceous marls, shales, and limestones of the Grayson, Main Street, Pawpaw, Weno, Denton, Fort Worth, and Duck Creek Formations (Proctor et al. 1970). I n general, the Grand Prairie landscape associated with these lithological units consists of flat to gently rolling uplands, with the major streams and rivers being entrenched and often bordered by limestone cliffs.

The streams of the larger valleys, such the North Bosque, Hog Creek, Middle Bosque, and South Bosque, areflanked by terraces and floodplains of lateQuaternary alluvium. In addition, late Quaternary deposits of colluvium flank some of the lower slopes of these valleys, merging and interfingering with the alluvial deposits. In 1984 and 1985, Collins and Holliday (1985) conducted a geomor phol ogical reconnaissance of Waco Lake. The primary thrust of this study was to identify the potential of various landforms around the margins of the lake to contain archeological sites of varying ages and in varying geomorphic contexts. Three basic settings were identified: lower alluvial surfaces, higher alluvial surfaces, and colluvial slopes.

Lower alluvial surfaces composed of Holocene alluvium were found to be well represented along the $\mathrm{N}$ orth and South Bosque Rivers at the upstream ends of the lake. J udging from the geologic map of the area (Proctor 
National Register Testing of NineArcheol ogical Sites at Waco Lake

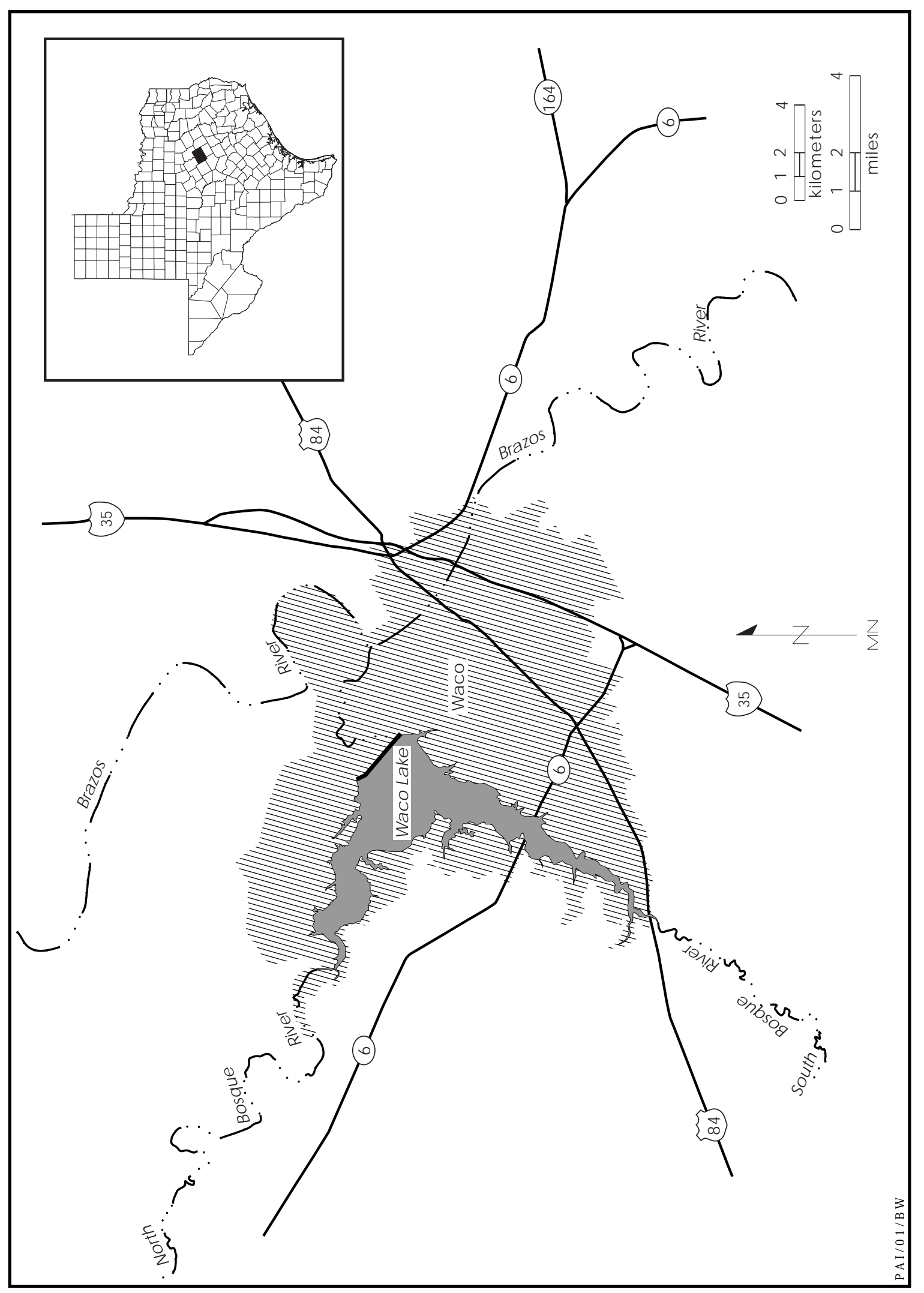

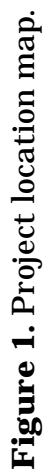


et al. 1970), comparable deposits extend up the Middle Bosque River and Hog Creek as well (Figure 2). The deposits tend to be silty and clayey sediments reflecting a variety of depositional settings, including levees, point bars, and floodplains (Collins and Holliday 1985:36). These deposits can be several meters thick, and while in many exposures they look at least moderately youthful (i.e., no older than the late Holocene) it is almost certain that older sediments are encompassed within theselandforms. Mapped soils on the lower alluvial surfaces belong to the Catal pa series and are described as "grayish-brown to dark grayish-brown calcareous alluvial soils made up of little-altered recent stream sediments" (Templin et al. 1958:47). The lower alluvial surfaces are known to contain stratified archeological deposits with the capacity to yield abundant valuable information.

Higher alluvial surfaces are extensivealong the west and north sides of the lake (see Figure 2). They consist of weathered, often gravelly deposits that usually are considered to be of Pleistocene age, although it has been suggested that some of these deposits could be young enough to host Paleoindian archeological materials (Collins and Holliday 1985:36). While it appears that these sediments areassociated primarily with the North Bosque River (Collins and Holliday 1985:36), contribution from the Brazos River is possible north of the lake. Mapped soils belong mostly to the Lewisville, Bell, and Payne series (Templin et al. 1958). Archeol ogical sites on these landforms are uniformly thin ( $50 \mathrm{~cm}$ or less) and often multicomponent. Because of this, they have a relatively limited capacity to contribute important information.

Colluvial slopes occur most consistently along the eastern side of the lake. Where slopes are steep, little sediment accumulation occurs. However, some areas contain substantial Holocene colluvial deposits. These are likely to be complex depositional situations, with colluvium perhaps interfingering with alluvial deposits from the North and South Bosque Rivers and/ or small streams that drain the slopes east of the lake. While such areas with thick Holocene colluvium are not extensive and, thus, have not been mapped as distinct soils, they have the potential to contain stratified archeological deposits in good geomorphic contexts. As observed by Kvernes et al. (2000), however, parts of the eastern lakeshore with Holocene colluvial deposits have suffered from severe erosion.

\section{Climate}

The McLennan County area has a humid, subtropical climate with an average growing season of 248 days (Natural Fibers I nformation Center 1987:343). The average daily maximum and minimum temperatures are $78^{\circ}$ and 56\%, while monthly means range from 46\% in J anuary to 86\% in J uly and August. Precipitation comes almost entirely in the form of rainfall and has an annual mean of 31.0 inches. Typically, all months have nearly 2.0 inches or more of rain, but the wettest months are April, May, September, and October, which have means of $3.8,4.7,3.2$, and 3.1 inches.

\section{Flora and Fauna}

Waco Lake, at the eastern edge of the Grand Prairie, is in an area characterized by grasslands and post oak savannah, with riparian woodlands along stream channels. The area supports floral and faunal communities common to both the Texan and Balconian biotic provinces (Blair 1950). Dominant native grass species include big bluestem, little bluestem, and Indiangrass, while trees include oaks, pecan, elm, and hackberry. Today, both junipers and mesquites are much more common than they were in the past. The region is home to 57 species of mammals, 16 lizards, 39 snakes, 7 urodeles, and 13 anurans (Blair 1950:100-101, 112-115). Probably among the more-important animals prior to modern times were whitetailed deer, bison, rabbits and other small mammals, turkey, mussels, and a variety of fish that occupied the $\mathrm{N}$ orth, Middle, and South Bosque Rivers and Hog Creek.

\section{PREVIOUS ARCHE OLOGICAL INVESTIGATIONS}

Waco Lake was constructed prior to professional archeological investigations in that specific area. However, avocational archeologists associated with the Central Texas Archeological Society conducted investigations in the general vicinity before the lake was built. Frank Bryan $(1936,1937)$ was interested in identifying deeply buried sites along streams in the 
National Register Testing of NineArcheol ogical Sites at Waco L ake

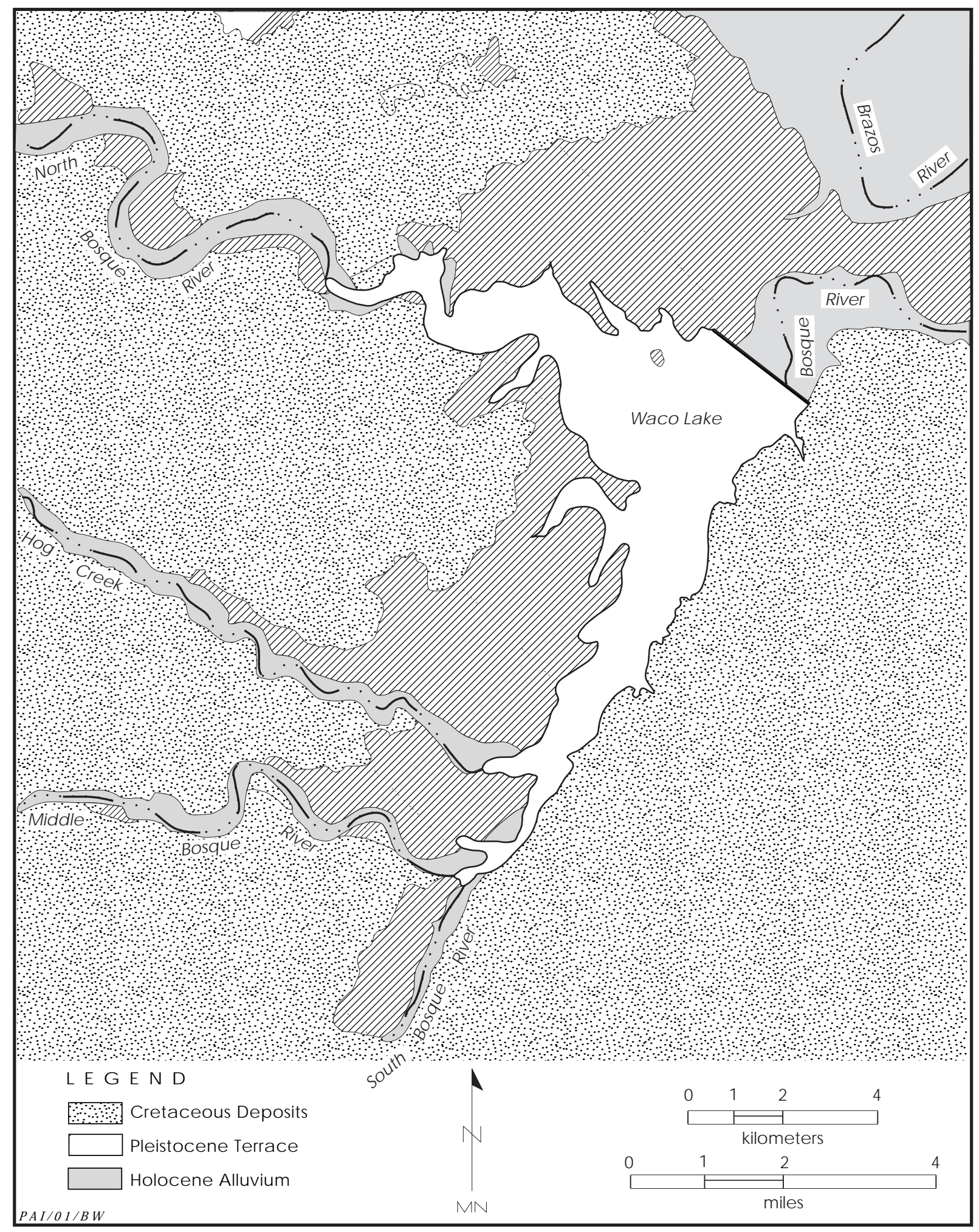

Figure 2. Landforms around Waco Lake. 
area. Frank H. Watt was especially prolific, with articles on several important sites published from the late 1930s to the 1970s. These include Aycock Shelter (Watt 1936), the Chupik site (Watt 1941), the Asa Warner site (Watt 1956), the Clark site (Watt 1965), the Waco Indian Village site (Watt 1969), and Horn Shelter No. 2 (Watt 1978).

Two expansions of the flood pool at Waco Lake were preceded by professional archeol ogical work. In the 1950s, a survey identified 23 sites, most of which appeared to have Archaic components (Duffield 1959). Two of the most significant sites subsequently tested were the Baylor and Britton sites. Both had deep stratified deposits that were used to help establish the cultural chronological sequence for the central Brazos area and central Texas in general (Story and Shafer 1965).

The Baylor site was divided into two areas, with Area $A$ representing the southern area within recent alluvium and Area B representing the northern, higher alluvial surface. Test excavations consisting of 25 units ( $5 \times 5 \mathrm{ft}$ ) revealed that deeply buried cultural deposits were present in Area A, with Area B containing only surface deposits. Excavations in Area $A$ reveal ed cultural materials to a depth of $3.6 \mathrm{~m}$. Artifacts diagnostic of the Austin and Toyah phases were found at $0.45-0.81 \mathrm{~m}$ bel ow the surface, as were six stone-lined hearths. At 0.60-1.00 m, Late Archaic diagnostics were recovered. Middleand LateArchaic artifacts occurred from 1.00 to $1.80 \mathrm{~m}$ (Story and Shafer 1965:72). The Area A test excavations also produced bones, mussel shell artifacts, and ceramic sherds.

At the Britton site, artifacts were observed in 5.5-m-thick alluvial deposits. Testing consisted of 11 hand-dug units ( $5 \times 5 \mathrm{ft}$ ) and 20 backhoe trenches (Story and Shafer 1965). The trenches were excavated to a maximum depth of $3 \mathrm{~m}$, whilethe hand-dug units were excavated to maximum depths of 0.3 to $5.2 \mathrm{~m}$, with little excavation below $3.0 \mathrm{~m}$. The excavations encountered stratified cultural deposits to at least $3.0 \mathrm{~m}$, with only scattered charcoal found at greater depths. Diagnostic artifacts from the upper $3 \mathrm{~m}$ indicate occupations primarily during the Late Archaic period (Story and Shafer 1965:132-136). In addition to diagnostic artifacts, the excavations produced modified mussel shells and bone artifacts, as well as unmodified faunal remains. The 49 features recorded include ash lenses, hearths, mussel shell concentrations, and a possible multiple dog burial. Four radiocarbon assays yielded ages ranging from 1865 to 2330 B.P., confirming occupations within the Late Archaic period.

Archeological investigations were initiated in 1984 by another plan to raise the level of the flood pool. This work entailed an intensive survey of the impact area, providing an overview of all known sites. A total of 83 previously recorded and newly recorded sites were evaluated, and test excavations were conducted at 16 sites (Prikryl and J ackson 1985; Prikryl and Prewitt 1984). Prehistoric sites ranged in age from Early Archaic through the Late Prehistoric Toyah phase and consisted of both shallowly buried occupations on old landforms and sites, such as Baylor and Britton, buried within Holocene alluvium. Part of the survey focused on the identification of 41 sites with historic materials ranging in age from the 1840s to the 1960s. Included in this survey was the central core and outlying farmsteads/housesites of the community of Speegleville. Conducted partly in conjunction with this survey was a geoarcheological study that identified the archeological potential of various landforms in the project area, as well as locating a number of archeological sites that subsequently were visited by the survey crew (Collins and Holliday 1985).

After a hiatus of almost a decade and a half, renewed plans to raise the lake level led to limited archeological investigations in 1999 (Kvernes et al. 2000). This project consisted of a re-location survey of 44 previously recorded sites (41 assessed as eligible or potentially eligible for listing in the National Register of Historic Places as a result of the 1984- 1985 survey, along with 3 sites not addressed during that project) to assess their current condition, rerecord them, and reassess the $\mathrm{N}$ ational Register eligibility of each site. Two sites with prehistoric components (Baylor and Britton) were recommended as being eligible for listing in the National Register, while 14 were considered ineligible. Theremaining 14 sites with prehistoric components were of unknown eligibility, with additional testing required before a determination could be made. Seven of these sites appeared to be the best candidates for further work based on their el evations and the impacts anticipated as a result of raising the lake level (these are the 7 prehistoric sites tested during 
National Register Testing of NineArcheol ogical Sites at Waco Lake

the project reported in this volume). Four sites with historic components were considered to be of unknown eligibility, pending additional field investigations and/or archival research; 2 of these appeared to be the best candidates for further work based on their elevations and the anticipated impacts (testing of these 2 sites is reported in this volume). The remaining 12 sites with historic components were considered ineligible for listing in the National Register. 


\section{ARCHEOLOGICAL AND HISTORICAL BACKGROUND}

\section{PREHISTORIC PERIOD}

The prehistoric archeological record of the middle Brazos River valley and Waco area traditionally has been viewed as part of the central Texas archeological region (e.g., Prewitt 1981; Suhm 1960). This region is recognized based on decades of investigations at various stratified sites throughout areas of the E dwards Plateau, its highly dissected eastern and southern margins, and the margins of physiographic regions to the east and south (see Collins [1995] for review). The Waco area is on the periphery of the central Texas archeological area, and the archeological record and projectile point style sequences contain el ements that suggest influences and contacts to varying degrees over time with areas to the east and northeast (Collins 1995; J ohnson and Goode 1994). A better understanding of the area's archeological record has been obtained through several large-scale projects, including Waco Lake (Collins and Holliday 1985; Duffield 1959; Prikryl and J ackson 1985; Prikryl and Prewitt 1984; Story and Shafer 1965). Other nearby large-scale projects-primarily reservoir salvage projectsinclude Whitney Lake (J elks 1953, 1962; Stephenson 1947, 1970) and Aquilla Lake (Brown 1987; Lynott and Peter 1977; Skinner et al. 1978; Skinner and Henderson 1972) to the northwest and north; Hog Creek Reservoir (Hays and Kirby 1977; Henry 1995; Henry et al. 1980; Larson and Kirby 1976; Larson et al. 1975; Shafer 1977) to the west; and Stillhouse Hollow Reservoir (Sorrow et al. 1967), Belton Lake (Miller and J elks 1952; Shafer et al. 1964), and Fort Hood (Abbott and Trierweiler 1995; Kleinbach et al. 1999; Mehalchick et al. 1999, 2000; Trierweiler 1994, 1996) to the southwest.
K vernes et al. (2000:7-12) provide summaries of these projects. These projects as well as others aided in establishing the prehistoric cultural sequence that we understand and recognize today for the region. Generally, this sequence is divided into three periods: Paleoindian, Archaic, and Late Prehistoric (Figure 3).

\section{Paleoindian Period}

Paleoindian (11,500-8800 B.P.) occupations of the central Texas region are represented by surficial and deeply buried sites, rockshelter sites, and isolated artifacts. The period often is described as having been characterized by small, highly mobile bands of foragers who were specialized hunters of Pleistocene megafauna. However, a more-accurate view of Paleoindian lifeways probably includes the utilization of a much wider array of resources. Recent investigations at the Wilson-Leonard site (41WM235) and the Aubrey Clovis site (41DN479) support this view and have challenged the fundamental defining criterion of the Paleoindian period, that of artifacts in association with late Pleistocene megafauna (Collins 1998; Ferring 2001).

Collins (1995) divides the Paleoindian period into early and late subperiods. Two projectile point styles, Clovis and Folsom, areincluded in the early subperiod. Clovis chipped stone artifact assemblages, including the diagnostic fluted lanceolate Clovis point, were produced by bifacial, flake, and prismatic-blade techniques on high-quality and oftentimes exotic lithic materials (Collins 1990). Along with chipped stone artifacts, Clovis assemblages include engraved stones, bone and ivory points, stone bolas, and ochre (Collins 1995:381; Collins et al. 1992). Clovis, as well as a number of later 
National Register Testing of NineArcheol ogical Sites at Waco L ake

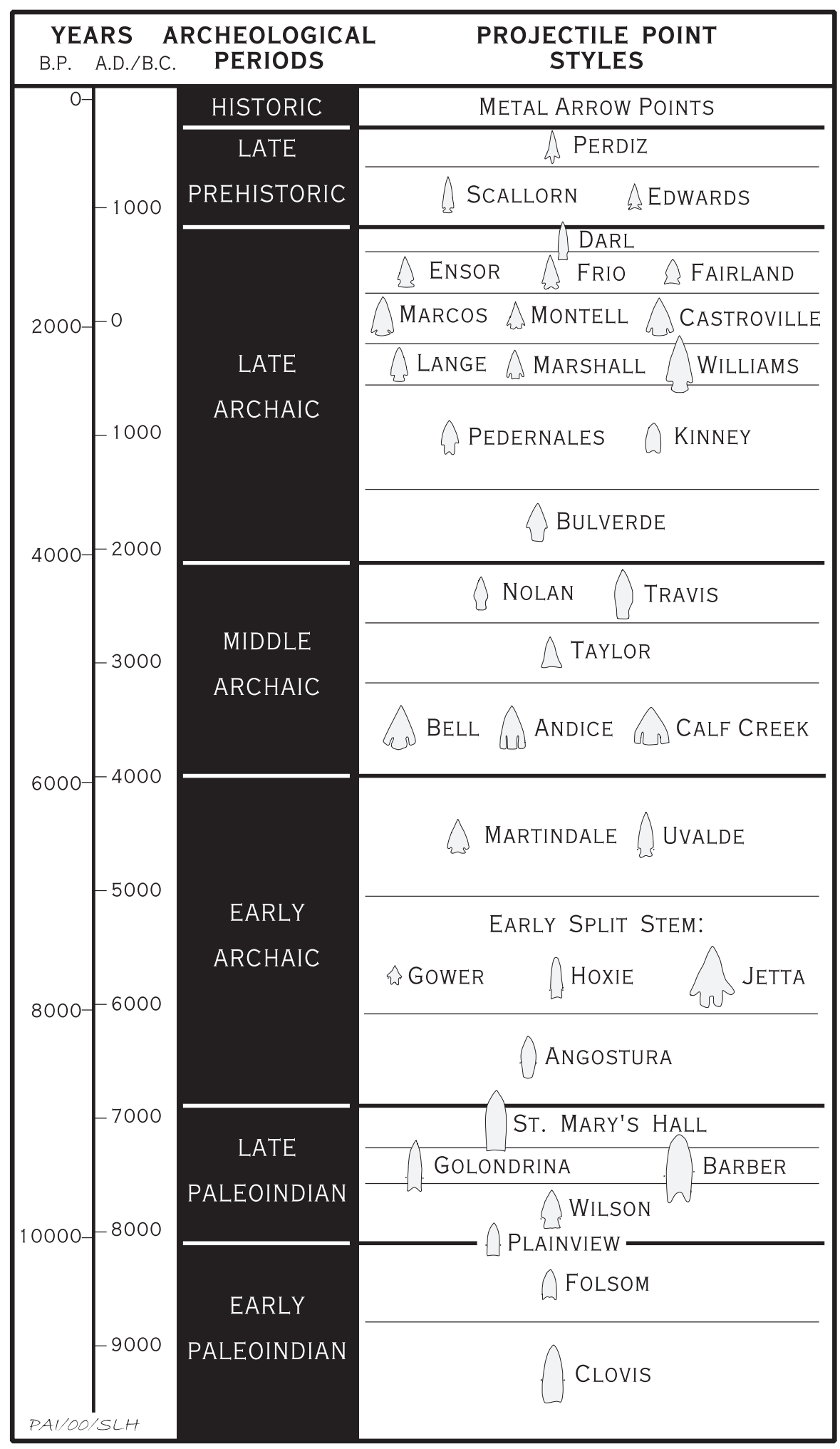

Figure 3. Prehistoric cultural sequence for central Texas (modified from Collins 1995:Table 2). 
Paleoindian dart points, have been recovered from the Gault site in Bell County (Collins and Brown 2000) and the Triple S Ranch site in Hamilton County (Hatfield 1997). Probable Clovis polyhedral blade cores have been found in Hamilton County (Goode and Mallouf 1991). Analyses of Clovis artifacts and site types suggest that Clovis peoples were well-adapted, generalized hunter-gatherers who had the technology to hunt larger game but did not rely solely on such resources. In contrast, Fol som tool kits, consisting of fluted Folsom points, thin unfluted (Midland) points, large thin bifaces, and end scrapers, are more indicative of specialized hunting, particularly of bison (Collins 1995:382). Folsom points have been recovered from Horn Shelter No. 2 al ong the Brazos River (Redder 1985; Watt 1978).

Postdating Clovis and Folsom points in the archeological record are a series of dart point styles for which the temporal, technological, or cultural significance is unclear. Several of these styles were recovered from Horn Shel ter No. 2 and include Plainview, Scottsbluff, Dalton, and San Patrice (Watt's [1978] Brazos Fishtail points). Often the Plainview type name is given to any unfluted, lanceol ate dart point, however, Collins (1995:382) has noted that many of these points typed as Plainview do not parallel Plainview type-site points in thinness and flaking technology. Also problematic are the chronological position and cultural significance of Dalton and San Patrice dart points. Components and artifact and feature assemblages of the later Paleoindian subperiod appear to be Archaic-like in nature and in many ways may represent a transition between the early Paleoindian period and succeeding Archaic period (Collins 1995:382).

\section{Archaic Period}

The Archaic period for central Texas dates from ca. 8800 to 1300-1200 в.P. (Collins 1995). The Archaic period generally is believed to represent a shift toward the hunting and gathering of a wider array of animal and plant resources and a decrease in group mobility (Willey and Phillips 1958:107-108). In the eastern and southwestern U.S. and on the Great Plains, the Archaic period was succeeded by the devel opment of horticultural-based, semisedentary to sedentary societies. In theseareas, the Archaic truly represents a developmental stage of adaptation as Willey and Phillips (1958) define it. For central Texas, this notion of the Archaic is somewhat problematic. An increasing amount of evidence suggests that Archaiclike adaptations were in place prior to the Archaic (see Collins 1995:381-382; Collins 1998; Collins et al. 1990) and that these practices continued into the succeeding Late Prehistoric period (Collins 1995:385; Prewitt 1981:74). In fact, the Archaic period of central Texas is not a developmental stage, but an arbitrary chronological construct and projectile point style sequence. Collins (1995) and J ohnson and Goode (1994) divide this sequence into three parts-early, middle, and late-based on perceived (though not fully agreed upon by all scholars) technological, environmental, and adaptive changes.

Early Archaic (8800-6000 в.P.) sites are small and their tool assemblages are diverse (Weir 1976:115-122), suggesting that populations were highly mobileand densities low (Pre witt 1985:217). It has been noted that Early Archaic sites are concentrated along the eastern and southern margins of the Edwards Plateau (J ohnson and Goode 1994; McKinney 1981). This distribution may be indicative of climatic conditions at the time given that these environments have reliable water sources and a diverse resource base. Early Archaic projectile point styles include Angostura, Gower, Hoxie, Wells, Martindale, and Uvalde. Manos, metates, hammerstones, Clear Fork and Guadalupe bifaces, and a variety of other bifacial and unifacial tools are common in Early Archaic assemblages. The construction and use of rock hearths and ovens reflect a specialized subsistence strategy (possible exploitation of roots and bulbs) during the Early Archaic. These burned rock features most likely represent the technological predecessors of the larger burned rock middens that later devel oped extensively in the Archaic period (Collins 1995:383). Significant Early Archaic sites include the Youngsport site in Bell County (Shafer 1963), which yielded Gower and Wells dart points from deeply buried contexts.

During the Middle Archaic period (60004000 в.P.), the number and distribution of sites, as well as site size, increased due to probable increases in population densities (Prewitt 1981:73; Weir 1976:124, 135). Macrobands may have formed at least seasonally, or an increased 
number of small groups may have utilized the same sites for longer periods of time (Weir 1976:130-131). A greater reliance on plant foods is suggested by the presence of burned rock middens toward the end of the MiddleArchaic, although tool kits still imply a strong reliance on hunting (Prewitt 1985:222-226). MiddleArchaic projectile point styles include Bell, Andice, Taylor, Baird, Nolan, and Travis. Bell and Andice points reflect a shift in lithic technology from the preceding Early Archaic Martindale and Uvaldepoint styles (Collins 1995:384). J ohnson and Goode (1994:25) suggest that the Bell and Andice darts were parts of a specialized bisonhunting tool kit. They also suggest that the beginning of the Middle Archaic was marked by an influx of bison and bison-hunting groups from the Eastern Woodland margins during a slightly more-mesic period. Bell points and bison remains were recovered from the $L$ andslide site in Bell County (Sorrow et al. 1967). Bison disappeared, or were reduced in number, as more-xeric conditions returned during thelater part of the MiddleArchaic. Later MiddleArchaic projectile point styles represent another shift in lithic technology (Collins 1995:384; J ohnson and Goode 1994:27). Prewitt (personal communication 2000) postulates that the production and morphology of Travis and Nolan points are similar to those of projectile points from the Lower Pecos region. Such characteristics as bevel ed stems and overall morphology may have originated in the Lower Pecos, since these elements appeared earlier there than they did in central Texas. Shafer's (1963:67) surprise that Nolan points, which are more common in sites to the south and west, were not found in greater numbers at the Youngsport site might support the idea that bearers of these darts came out of the Lower Pecos and moved into adjacent portions of central Texas, but did not utilize all portions of central Texas equally. At the same time, a shift to more-xeric conditions accompanied the development of burned rock middens, the masses of burned rocks left over from multiple episodes of baking and cooking with hot rock hearths and ovens. J ohnson and Goode (1994:26) believe that the dry conditions promoted the spread of xerophytic plants, such as yucca and sotol, which were collected and cooked in large rock ovens by late Middle Archaic peoples.

During the succeeding Late Archaic period
(4000 to $1300-1200$ в.P.), populations continued to increase (Prewitt 1985:217). Within stratified Archaic sites, such as Youngsport, the Baylor and Britton sites in McLennan County (Story and Shafer 1965), and the Steele site in Hill County (Stephenson 1970), the Late Archaic components contain the densest concentrations of cultural materials. The establishment of large cemeteries suggests strong territorial ties by certain groups (Story 1985:40). A variety of projectile point styles appeared throughout the Late Archaic period. J ohnson and Goode (1994:29-35) divide the Late Archaic into two parts, Late ArchaicI and Late Archaic II, based on increased population densities and perceived evidence of Eastern Woodland ceremonial rituals and religious ideological influences. Middle Archaic subsistence technol ogy, including the devel opment of burned rock middens, continued into the Late Archaic period. Collins (1995:384) states that, at the beginning of the Late Archaic period, the construction and use of burned rock middens reached its zenith and that their use declined during the latter half of the LateArchaic. However, there is mounting data that midden formation and use culminated much later and that this high level of use continued into the early Late Prehistoric period (Black et al. 1997:270284; Kleinbach et al. 1995:795). A picture of prevalent burned rock midden development in the eastern part of the central Texas region after 2000 B.P. gradually is becoming clear. This scenario parallels the widely recognized occurrence of post- 2000 в.P. middens in the western reaches of the Edwards Plateau (see Goode 1991). The use of rock hearths and ovens and subsequent development of burned rock middens appears to have been a major part of the subsistence strategy, as a decrease in the importance of hunting-inferred from the low ratios of projectile points to other tools in site assemblages-may have occurred (Prewitt 1981:74).

\section{Late Prehistoric Period}

The Late Prehistoric period (1300-1200 to 300 в.P.) was marked by the introduction of the bow and arrow and, later, ceramics into central Texas. Population densities appear to have dropped considerably from their Late Archaic peak (Prewitt 1985:217), but the reasons for this 
remain obscure. Subsistence strategies did not differ greatly from the preceding period, although bison became an important economic resource during the later part of the Late Prehistoric period (Prewitt 1981:74). As noted above, the use of rock hearths and ovens for plant food processing (?) and the resulting development of burned rock middens continued throughout the Late Prehistoric period (Black et al. 1997; Kleinbach et al. 1995:795). Horticulture came into play very late in the region and was of minor importance to overall subsistence strategies (Collins 1995:385).

In central Texas, the Late Prehistoric period generally is associated with theAustin and Toyah phases (J elks 1962; Prewitt 1981:82-84). Story (1990:364), in her overview of the middle Brazos River basin, argues for a period/horizon characterized by Alba points and Early Caddoan-like pottery intermediate between the Austin and Toyah phases. Evidence of this proposed archeological manifestation was found at the Chupik site in McLennan County (Watt 1953). Much of what we know about the Austin and Toyah phases comes from rockshelter sites in and around Whitney Lakein Bosque and Hill Counties (J elks 1962; Stephenson 1970). Austin and Toyah phase horizon markers (ScallornE dwards and Perdiz arrow points, respectively) are distributed across most of the state. The introduction of Scallorn and Edwards arrow points into central Texas often is marked by evidence of violence and conflict, as many excavated burials contain these point tips in contexts indicating they were the cause of death (Prewitt 1981:83). Subsistence strategies and technologies (other than use of the bow and arrow) did not change much from the preceding Late Archaic. This continuity is recognized by Prewitt's (1981) use of the term "Neoarchaic." In fact, J ohnson and Goode (1994:39-40) and Collins (1995:385) state that the break between the LateArchaic and the LatePrehistoric could be represented easily and appropriately by the break between the Austin and Toyah phases.

Around 1000-750 B.P., slightly more-xeric or drought-prone climatic conditions returned to the region and bison returned in large numbers (Huebner 1991; Toomey et al. 1993). Utilizing this vast resource, Toyah peoples were equipped with Perdiz point-tipped arrows, end scrapers, four-beveled-edge knives, and plain bone-tempered ceramics. The technology and subsistence strategies of the Toyah phase represent a completely different tradition than the preceding Austin phase. Contact with Caddoan groups to the east and northeast is represented by the presence of Caddoan ceramics in site assemblages, particularly in the eastern peripheral areas of central Texas (e.g., Stephenson 1970). Collins (1995:388) states that burned rock middens fell out of use, as bison hunting and group mobility obtained a level of importance not witnessed since Folsom times. While the importance of bison hunting and high group mobility can hardly be disputed, the cessation of burned rock midden devel opment during the Toyah phase is tenuous. A recent examination of Toyah-age radiocarbon assays and assemblages by Black et al. (1997) suggests that their association with burned rock middens represents more than a "thin veneer" capping Archaic-age features. Black et al. (1997) claim that rock hearth and oven use resulting in the development of burned rock middens, while not as prevalent as in earlier periods, played a role in the adaptive strategies of Toyah peoples.

\section{HISTORIC PERIOD}

\section{Native Americans}

Historical accounts of Native Americans and their interactions throughout the region with the Spanish, the Republic of Mexico, the Texas Republic, and the United States are provided by Hester (1989), J elks (1970), and Newcomb (1961). The beginning of the late seventeenth and early eighteenth centuries marked an era of more-permanent contact between Europeans and Native Americans as the Spanish moved northward out of Mexico to establish settlements and missions on their northern frontier. There is littleavailable information on aboriginal groups and their ways of life except for the fragmentary data gathered by the Spanish missionaries. The inevitable and disastrous impacts to native social structures and economic systems by disease and hostile encounters with E uropeans and intruding groups, such as the A pache, were al ready under way at this time. Historically, three groups occupied the Waco area: Wichita-speaking groups consisting of the Tawakoni, Waco, and Kichai; Caddoan tribes comprised of the Anadarko, Hasinai, and Kadohadacho; and the Tonkawa. The Apaches 
and Comanches also were present, but later. Athanase de Mézières's expedition along the Brazos River in the 1770 s encountered two large Tawakoni villages al ong a stretch from presentday Waco to the vicinity of the Nolan River ( elks 1970; Krieger 1996). Based on archeological evidence and historical documents, the Stansbury site near Whitney Lake was occupied by the Tawakoni in the 1770s to 1780s ( elks 1970). By the mid-1830s, the site was occupied by the Caddoan-speaking Hasinai, but the village moved in 1846 approximately 10 miles up the Brazos near the locale that would becomeF ort Graham in 1849. Fort Graham was established to provide protection for the growing number of Euro-American settlements in the area from Native American hostilities. It was only briefly occupied by the United States military and was abandoned in 1853 ( $\mathrm{J} \mathrm{el} \mathrm{ks}$ 1970). Tonkawa groups seeking protection from Comanche raids moved near there.

The Native American presence and hostilities precluded Euro-American settlement of the Waco area until the 1840 s and 1850 s despite its location within the 1825 Mexican colonization grant given to Robert Leftwich. In 1844 and 1845, formal talks between the Republic of Texas and Native American groups occurred, but settlement remained sparse as only 17 percent of the land area had been surveyed by 1845 , and no permanent settlements were established until Texas was annexed by the United States (Prikryl and J ackson 1985:28-29; Smryl 1996a:431). The removal of Native American groups, first to a reservation in Texas in 1854 and then to Indian territory (Oklahoma) in 1859 , opened the area to widespread settlement (Smryl 1996a:431).

\section{Early Settlement}

A history of the settlement and development of the Bosque River valley during the years 1700-1984 is provided by J ackson (1984) and Prikryl and J ackson (1985). More-complete histories of MCLennan County and the Waco area are provided by Baker (1936), Kelly (1972), Poage (1981), and Horne (n.d.).

Under the governments of the Republic of Texas and the State of Texas, the location of surveys in the Waco area was carried out at a slow but regular pace. One of the first land grants on the N orth and Middle Bosque Rivers in the Waco Lake area was issued on April 26, 1832, to Thomas J efferson Chambers, a surveyor and notorious land speculator (Smryl 1996a:431). Other surveyors in the north-central Texas region included George B. Erath and Neil McLennan, both of whom later returned and established residences on the land they had surveyed. Neil McLennan built a cabin and took up residency in 1845, and George B. Erath was one of the surveyors who helped lay out the townsite of Waco in 1849. When a new county was established on J anuary 20 , 1850 , it was named M CLennan in honor of the first permanent settler (Kelly 1972:174; Smryl 1996a:431).

Neil McLennan, a native of the Scottish I sle of Skye, immigrated with his extended family and a group of friends in 1801, first to N orth Carolina and then to Florida. They left Florida for Texas in 1834 and settled initially at Pond Creek in the Robertson Colony. In 1836, McLennan's brother (Laughlin), sister-in-law, and mother were killed by Indians, who also captured Laughlin's three children. The survivors moved to a safer location, but despite this effort, McLennan's other brother, J ohn, was killed by Indians in 1838. It was after these tragedies that Neil McLennan joined George B. Erath in surveying the Waco area. In 1845, McLennan exchanged his land at Pond Creek for land in the Waco area and relocated his family. MCLennan died in his family home in 1867 (Smryl 1996a:430). The Neil McLennan cabin survived until 1934 when it burned down. Its location was threatened by the expansion of Waco Lake in 1961, and when archeologists re visited the site in 1985, they found that extensive gravel mining had disturbed the area (Prikryl and J ackson 1985:30).

The home of Duncan McLennan, Neil's son, also was identified within the project area and desi gnated as $41 \mathrm{ML} 140$. The site was reported by local informants to have been occupied by George B. Erath as well. Archival research confirms this association. By 1851, George B. Erath had established a 600-acrefarm on the Farnash Survey where he had a house, 3 slaves, and 2 horses. By 1860, his operation had expanded to include 11 slaves, 19 horses, 740 cattle, and 260 sheep. In 1868 and 1869, Duncan McLennan bought this property from George B. Erath (Prikryl and J ackson 1985:30-31).

George Bernard Erath was a native of 
Vienna, Austria, where he was educated. He immigrated to the New Orleans area in 1832 and left for the Robertson Colony in 1833. Although his initial ties were to Waco as a surveyor in 1849 and as a landowner through the late 1860 s, the bulk of his notable career was spent elsewhere in other capacities, primarily military and political. Simultaneous with his service as a surveyor, Erath was a member of ranger companies in 1835 and the early 1840s, assembled in an effort to control I ndian activities. In 1858, he was instrumental in organizing the Texas Ranger group under Captain J ohn S. Ford, although Erath was not a member himself. Instead, in 1861 he became member of a committee that arbitrated disputes between the State of Texas and the Native Americans on reservations in the state. Other military duty consisted of service in the Texas Revolution (including participation in the Battle of San J acinto) and the Civil War. Erath's ill health sent him home to Waco at the beginning of the war, but by 1864 he was in command of a regiment that defended his home region. Erath's other major activity was politics. Hewas a member of Congress during the Texas Republic, a member of the first statelegislature, and a senator in 1857 to 1861 and again in 1874 (Cutrer 1996:880).

Another early settler in the Bosque valley was I srael Washington Speegle. Speegle was born in North Carolina in 1813 and moved from Missouri to Texas with his wife, Susanna, and family in 1849. Once in the Waco area, he started farming and set up shop as a blacksmith. In 1859, Speegl e was a successful sheep farmer. The Speegle family also maintained peach and apple orchards. During the 1860s, wheat, corn, and oats were of principal importance to the needs of settlers in general and their livestock. I srael Speegle's blacksmithing shop served as a focal point for the community. As the community began to develop in the antebellum period, a store, the Speegl eville Cemetery, and several churches already had been established (Speegle 1985). During the postbellum era, the area continued to develop into a small town. In 1879 Speegleville got its first post office, and I srael Speegle became its first postmaster. A cotton gin was built in 1885, which was the same year that Israel Speegle died (Buice 1985; Prikryl and J ackson 1985:3438, 195; Smryl 1996b:24).

\section{Civil War and Reconstruction}

In J anuary 1861, a representative from McLennan County voted for secession, and he was overwhel mingly supported by the population in the county. During the Civil War, 1,500 men (including 6 generals) from McLennan County joined in the struggle. Despite their effort, the cause was lost, and the City of Waco was occupied by U.S. troops for a short period during Reconstruction. Friction between troops and local residents was common (Smryl 1996a:431).

After the war, veterans returned to their homes and farms to resume their lives as best they could. However, during Reconstruction, McLennan County suffered a great economic decline, as did much of the South. The wealth once gained from agricultural production now was lost. A variety of factors contributed to this. The emancipation of slaves equated to a loss of both their labor and value to their former owners. This combi ned with a trend toward smaller farm size, as well as a devaluation of acreage and livestock. Without these valuable agricultural assets, tax revenues for McLennan County decreased sharply. An inadequate transportation infrastructure exacerbated the problem. U pon emancipation, a large number of formerly enslaved African Americans stayed in McLennan County. Some remained as laborers on plantations, some sought work in Waco, and some moved to their own farms and established communities. Over time, the African American population slowly grew (Smryl 1996a:432). For blacks and whites alike during Reconstruction, cash crop farming and sharecropping became a new way of life (Prikryl and J ackson 1985:34).

The isolated Sneed homestead is a good representative of typical Reconstruction settlement. It was identified during survey in 1984 and designated 41ML 179 (Prikryl and J ackson 1985:38). Nicholas Sneed was born in Williamson County, Tennessee, in 1826. He was educated in Alabama and then returned to his home state to become a teacher (Lewis Publishing Co. 1893:788). Sneed moved to Texas in 1850 and continued to ply his trade as a teacher, first in Navarro County and then in Waco, where he established the town's first school in 1851. Sneed taught in Waco until 1853 but then returned to Navarro County until called away for 
duty at the advent of the Civil War. Sneed was commissioned as a lieutenant and later promoted to captain. Although Nicholas Sneed survived the war, he returned to Texas not only as a veteran but also a widower. His wife had died while he was away (Prikryl and J ackson 1985:38-39).

By October 1865, Sneed had met and married J ennett Hubby, the widow of a Waco merchant. Upon her previous husband's death, J ennett had inherited 80 acres of land located on Hog Creek. In 1866, Sneed and his new wife moved to the property and established a farm. J ennett died shortly after, in 1868 , but Nicholas continued to raise J ennett's children on the farm until 1877. In that year, the Sneed house burned down, and Nicholas sold the property and moved to a new location. The property was never reoccupied. Instead, it became grazing land as part of a large cattle operation owned by the McLennan family (Prikryl and J ackson 1985:230-231).

\section{Agricultural Recovery and Success}

The hardships experienced in the Waco Lake area during Reconstruction began to improve in the late 1870s. The primary factors causing change were the influx of capital from the north, the increase of immigration by $\mathrm{Eu}$ ropeans, and improved access to transportation via the railroad. In the 1880 s, five major rail lines were constructed in McLennan County. Waco became a primary junction and a large center of urban devel opment (Smryl 1996a:432).

By the 1880s, horses and mules replaced sheep and oxen, and cotton was the primary cash crop. The average farm size in the Waco Lake area was 144 acres, but by 1900 the average had dropped to 89 acres for landowning farmers (Prikryl and J ackson 1985:39). Access to markets and rail road transportation allowed for a transition from subsistence farming to a single commercial cash crop. Farmers stopped growing subsistence crops and began to rely moreheavily on goods supplied by the rail roads. A nationwide distribution system allowed all farmers to concentrate on a single cash crop as opposed to growing a series of subsistence crops. During the years of 1918 and 1919, cotton prices soared and the Speegleville community's cotton gin provided an important source of revenue for the county. Cotton agri- culture dominated the area until the advent of World War I brought diversification to the local economy.

\section{World War I and Camp MacArthur}

In 1917, the United States Army purchased land to the west of Waco near the edge of the Bosque valley and built a training camp for American efforts in World War I. Much of the area where the camp once existed is now residential neighborhoods of Waco. Camp MacArthur served to further stimulate the local economy and also caused a shift toward more urban development. Many of the military personnel who had been stationed at the camp during the war chose to remain in Waco, which in turn contributed to a continuation of economic growth. Industrial ventures became an increasingly important part of the economy alongside agriculture (Smryl 1996a:432).

\section{The 1920s to the Present}

For the small farmers of central Texas, the Great Depression was preceded by a severe drought in 1925. As a result, Speegl eville cotton farmers suffered dramatic losses (Prikryl and J ackson 1985:45). Relatively few new buildings were constructed during these difficult economi c times, and black cotton land that sold for $\$ 150$ per acre in 1920 sold for $\$ 25$-30 per acre during the 1930s (Poage 1981:117).

The construction of the Waco Lake dam in 1929 offered hope of economic recovery to impoverished farmers. Investors such as W. H. Forrester began buying lakeshore property in 1928 for residential and recreational developments (Prikryl and J ackson 1985:45). Further devel opment of the Waco Lake area was halted with the expansion of the lake in 1962. The Corps of Engineers purchased most of the shore line property and constructed a larger dam to allow for the impoundment of the additional water needed to supply the growing City of Waco. The Corps of Engineers removed, and in some cases relocated, any structures that were standing after purchasing the lakeshore property. The east side of the lake near the White Rock Escarpment consists mainly of Waco suburbs, while most of the western side has been devel oped by the Corps as camping, boating, and picnicking areas. 


\section{METHODS OF INVESTIGATION}

\section{FIELD METHODS}

Formal testing of nine sites at Waco Lake consisted of re-locating each site, site reconnaissance, trenching (prehistoric sites only), manual excavation of test units, recordation of soilstratigraphic profiles, and mapping. This was done over ca. 69 work days between October 2000 and February 2001, requiring 347 persondays of effort. Using information from previous investigations, each site was re-located, and the ground surface and cutbank exposures (where present and accessible) were examined for cultural materials. On the seven prehistoric sites, the general strategy for testing consisted of opening up two to six trenches within the site limits as recorded in 1984 (because the lake level was much lower in 1984, cutbanks and the cultural materials within them were more visible than in 2000-2001), followed by the placement of four to six test units (often in 1x2-m configurations) adjacent to and within the trenches to sample the cultural deposits. On the two historic sites, the strategy focused on using four to six test units to explore cultural features visible on the surface, as well as areas between and around features.

Trenching was conducted on prehistoric sites to provide exposures of soil stratigraphy, assess site geomorphology, and provide access to deeply buried deposits requiring manual excavation. The City of Waco's Water Utilities Department supplied the machinery needed for trenching (a standard backhoe, a small trackhoe, and a large trackhoe, depending on the anticipated depth of excavation at each site, soil conditions, accessibility, and machine availability) and a skilled operator. The 30 trenches excavated varied greatly in sizeand depth, with smaller trenches sufficing at the shallowly buried sites and larger trenches required at the sites with deeply buried deposits. The trenches ranged from 2.1 to $8.6 \mathrm{~m}$ in length, 1.0 to $4.0 \mathrm{~m}$ in width, and 0.6 to $4.5 \mathrm{~m}$ in depth (mean length $=4.8 \mathrm{~m}$; mean width $=2.4 \mathrm{~m}$; mean depth $=2.7 \mathrm{~m}$ ). As with placement of the trenches, depth was determined to a large extent by what had been recorded in 1984, when good cutbank visibility allowed the depths of the cultural deposits to be determined. Thus, for each site, a target depth for trenching/test unit excavation was identified at the beginning of the project. Not surprisingly, actual testing results differed in some cases from the depth estimates derived from the 1984 data, resulting in the need for strategic adjustments at some sites (e.g., removal of sterile overburden without screening, deeper excavations than planned, etc.).

Backdirt from the trenches was not screened; however, it was examined cursorily for cultural materials. Trench excavations were monitored by the project archeol ogist or geomorphologist, and the trench walls were examined for the presence of cultural remains. When deeply buried cultural materials or features were encountered in a trench wall, a safety bench was excavated within the trench to serve as a working platform for deep manual excavations. The soil stratigraphy was described for representative trenches by the Project Geomorphologist. Soil-stratigraphic descriptions and the methods used are presented in A ppendix A. When appropriate, diagnostic artifacts or special samples, such as charcoal or bulk sediment, were collected from the trenches. Each sample was assigned a unique al phanumeric designation based on the sample type (e.g., the first 
charcoal sample was designated $\mathrm{C} 1$, the first sediment sample S1, etc.). All samples were numbered consecutively for each site and recorded on an Inventory of Samples Collected form.

Forty-two $1 \times 1-m$ test units encompassing $65.5 \mathrm{~m}^{3}$ of sediment (32 units and $60.2 \mathrm{~m}^{3}$ at the seven prehistoric sites, and 10 units and $5.3 \mathrm{~m}^{3}$ at the two historic sites) were excavated to sample buried cultural deposits. The locations of the units were determined by the findings of previous investigations, trenching results, evidence in cutbanks, and the locations of surface features (on the historic sites). Most units on prehistoric sites were along or within trenches, while the units on historic sites were unaccompanied by trenches. All units were excavated in arbitrary 10-cm levels, with the ground surface of the highest corner used as a datum for vertical control. In cases where test units were excavated on safety benches within trenches or where culturally sterile overburden was removed and not screened, the numbering of excavation levels began at the prepared surface. A datum point was placed at the highest corner of the test unit for vertical control, and the distance from the ground surface to the datum point was noted for the first level on the Excavation Level Record form.

Manually excavated fill was dry screened through $1 / 4$-inch-mesh hardware cloth. Artifacts were collected and bagged by level and noted on an Artifact F requency Distribution Summary form. Charcoal recovered from the screen was collected by level and given a sample number. Materials such as mussel shell fragments, feature-associated burned rocks, snail shells (Rabdotus sp.), and intrusive modern debris were only counted (burned rocks also were weighed) and not collected. An Excavation Level Record form was completed for each level, and an inventory of artifact bags was maintained for every test unit. Selected test unit profiles were drawn in cases where features were present or unusual stratigraphy was observed.

Discrete cultural features typically were excavated as entities. Features were described and recorded on Feature Data forms, as well as photographed and mapped in plan and profile. If possible, charcoal samples were collected directly from the fill of prehistoric features. Often, a feature's entire matrix was collected as a flotation sample. Otherwise, theremaining matrix was screened through 1/4-inch-mesh hardware cloth.

All sites were mapped using a Sokkia electronic total station. For each site, a datum marked by rebar or a wooden stake in the ground was established and assigned an arbitrary el evation of $100.00 \mathrm{~m}$. Site maps included the natural topography, cultural features exposed on the surface, all mechanical and manual excavations, datum points, natural and manmade landmarks, and, in many cases, the edge of Waco Lake.

In addition to recordation using the forms mentioned above, the Project Archeologist maintained field records including a daily journal. F urthermore, the excavations were documented through photography. Black-and-white photographs and col or slides were taken to document the investigations including site overviews, backhoe trench and test unit profiles, and cultural features.

\section{ARTIFACT ANALYSIS METHODS}

Thecultural materials recovered during the testing are grouped into two broad categoriesprehistoric and historic artifacts. Each category is subdivided into different artifact types and described below.

\section{Prehistoric Artifacts}

\section{Chipped Stone Artifacts}

Analysis of the chipped stone artifacts utilizes a technological and functional framework composed of seven classes of tools and artifacts: projectile points, bifaces, unifaces, cores, cobble tools, edge-modified flakes, and unmodified flakes. The methods of analysis for each class are discussed below, and descriptions of the materials and illustrated examples can befound in Chapter 4.

\section{PROJ ECTILE POINTS}

Projectile points are divided into arrow points and dart points. No preforms of either category were identified. Tool completeness and measurements are recorded for each specimen. The nine categories of tool completeness are intact or nearly complete specimens and proximal, medial, distal, stem, longitudinal, barb, wedge, and indeterminate edge fragments. 
Measurable attributes, including maximum length, maximum blade width, neck width, base width, haft length, and overall thickness are recorded when possible. All measurements are in millimeters. EIton R. Prewitt, with reference to the type descriptions of Suhm and J elks (1962) and Turner and Hester (1993), assigned all typological identifications.

\section{BIFACES}

Bifaces are categorized by their stage of reduction (early, middle, late, finished, or indeterminate), biface function or tool class, and tool completeness. Measurements of overall length, width, and thickness are given when possible.

Early stage reduction bifaces exhibit the nature of the raw material blank from which they were made (e.g., cortex, stream cobble, or tabular chert morphologies). The biface is in an initial stage of percussion shaping, exhibiting large, deep percussion flake scars, irregular cross sections, and irregular margins. Percussion thinning is not evident. Middle stage reduction bifaces show evidence of initial percussion thinning. The percussion flakescars are more evenly spaced and tend to run al most all the way across the surface of the biface. Margin regularizing is accomplished with fine percussion flaking, and platform preparation is more distinct and carefully executed. Latestage reduction bifaces have apparent final percussion thinning and margin regularizing. The percussion flake scars are well spaced. They overlap only slightly with contiguous flake removals, and they tend to terminate at the medial ridge of the biface, often with step or hinge fractures, which are met by similar flaking from the opposite edge. Evidence of careful platform preparation is present, with many of the platforms having been isolated, possibly by pressure flaking. A finished-stage biface exhibits careful, selective pressure flaking al ong the margins. The high ridges between the percussion flakes have been removed, producing a sharp and regular margin. The tool is carefully pressure thinned across both faces, and use wear is evident.

Bifaces may fall into seven tool classes: adze, drill, graver, gouge, knife, scraper, and indeterminate biface. Adzes are chopping or cutting implements that presumably were hafted to a handle. Drills are characterized by a long ta- pered bit, usually blunted or dulled at the tip. Gravers are small, carefully chipped tools with beaklike protrusions. Gouges, while similar in morphology to adzes, probably functioned as planing and shaving tools rather than chopping or cutting ones. Knives are thin, sharp-edged bifaces presumably used for cutting. Scrapers are described bel ow in the uniface category.

\section{UNIFACES}

Unifaces are categorized as end scrapers, side scrapers, end/side scrapers, knives, gravers, adzes, gouges, spokeshaves, and indeterminate unifaces. Tool completeness also is noted. Many of these tool categories are mentioned above in the biface category; those remaining are described below. The presence or absence of cortex and measurements, including overall length, width, and thickness, are given for each specimen.

Scraping tools consist of end and side scrapers or a combination of both. End scrapers are trimmed to a steep convex bit at the end of the long axis. Side scrapers are trimmed on the lateral edges of the blank. The end/side scrapers show trimming on both the lateral and distal ends. Use-related microflaking appears on the dorsal sides of scrapers. Spokeshaves are specialized scraping tools with unifacially retouched notches or concavities along a unifacially worked tool edge.

\section{CORES}

Cores are classified according to the number and orientation of flakeremoval scars. Measurements for both cores and core fragments are overall length, width, and thickness.

\section{COBBLE TOOLS}

Cobble tools are cobbles that retain a cortex-covered surface opposite a working edge. They are grouped into wedges or choppers based primarily on size and presumed function. Wedges are smaller specimens with working edges that have relatively acute angles. Choppers are larger with working edges that are primarily blunt. Recorded attributes are tool completeness, the presence or absence of cortical backing, and overall thickness, length, and width. 


\section{EDGE-MODIFIED FLAKES}

Flakes with consistent unifacial and/or bifacial microflake scars, as opposed to items with intentional retouching or postdepositional alterations, are classified as edge-modified flakes. Edge-modified debitage attributes are flake type, dorsal cortex percentage, maximum dimension, and number of modified edges. The different flake types are: completeflakes, which have striking platforms and hinged or feathered terminations; proximal fragments, which have striking platforms but lack hinged or feathered terminations; chips, consisting of only medial or distal fragments without striking platforms; and chunks, angular debris that lacks flake attributes altogether. Evidence of burning or crazing, such as potlids or discoloring, also is noted.

\section{UNMODIFIED DEBITAGE}

Unmodified debitage is classified into the same types as edge-modified flakes. Similarly, the percentage of cortex present and maximum dimension are recorded. Evidence of burning or crazing also is noted.

\section{Other Tools and Materials}

Other tools and materials recovered from the prehistoric sites are burned rocks; pottery; ground, pecked, and battered stonetools; burned clay lumps; and floral and faunal remains. Burned rocks from feature contexts, which were not collected, were counted and weighed in the field.

Recorded pottery sherd attributes are vessel part, temper, interior and exterior surface finish, decorative technique and el ement or design, maximum dimension, and wall thickness. Ground, pecked, and battered stone tools are examined in terms of raw material, general shape, wear type and location, and the length and width of the working surface. Measurements recorded are weight, maximum length, width, and thickness. Burned clay lumps were counted and weighed.

Faunal remains consist of freshwater mussels and vertebrates. Freshwater mussels are identified by taxon, counted, and presented by provenience in Appendix B. Vertebrate faunal materials, al so counted and identified by taxon, are presented in A ppendix C. F lotation samples taken in the field yielded little in terms of botanical materials. A few larger pieces of charred wood are large enough for taxonomic identification.

\section{Historic Artifacts}

All historic materials were sorted to determine which artifacts have interpretive value, and those that could provide information relevant to temporal and/or functional questions were selected for detailed analysis. As many artifacts were identified as possible, although some have insufficient diagnostic attributes to allow for functional identifications. In such cases, material type identifications are utilized. All artifacts are quantified by count. The major artifact categories are ceramics, glass, metal, faunal, and other.

\section{Ceramics}

In general, ceramic as a material is extremely durable and survives well in archeological contexts. Therefore, diagnostic attributes that allow for dating usually are present. Also, there are copious published comparative data on ceramics of all sorts, making them that much more useful during analysis.

All sherds are identified by ware/paste type, glaze type, and decoration. These diagnostic characteristics determine classification within recognized ware types, including whiteware, stoneware, and bone china (Majewski and O'Brien 1987). Particular attention is paid to sherds with temporally diagnostic features. A primary focus is placed on whiteware sherds decorated with transfer-printed patterns, which can indicate a manufacturer, date range, and origin. An attempt is made to identify all transfer-printed patterns with referenceto published volumes (Blake and Freeman 1998; Pollan et al. 1996; Williams and Weber 1998). However, some patterns cannot be identified.

\section{Glass}

Glass also survives well in archeological contexts. All glass is sorted to distinguish between container glass, table glass, window glass, and other glass. All glass al so is classed by col or, which can sometimes aid in indicating function 
(such as milk glass jar lid liners) and age (such as nineteenth-century ol ive green glass or turnof-the-century solarized glass). Table glass was exposed to black light under an ultraviolet lamp to test for fluorescence. An ice-blue fluorescence in col orless glass indicates it is lead glass, which is mid-nineteenth century in date.

\section{Metal}

A variety of artifacts found on historic archeological sites are made from metal, prima- rily ferrous and white metals. Ferrous (and other) metal is a somewhat problematic material. Because of rust and corrosion, it does not survive as well as ceramics and gl ass in archeological contexts, and diagnostic attributes often are lost. Metal also continues to degrade over time. Metal that is highly fragmented or unidentifiable due to rust has little interpretive value, and such items were not considered worthy of close examination. Objects classed in the metal category consist primarily of cut and wire nails and food containers, such as tin food cans. 



\section{RESULTS OF TEST EXCAVATIONS}

This chapter presents the results of testing of nine archeological sites at Waco Lake. The locations of the nine sites are shown in Figure 4.

\section{Site 41ML 135 \\ Description}

Site 41ML 135 contains both prehistoric and historic components. The site is on the eastern shore of Waco Lake opposite where Hog Creek enters the lake (see Figure 4). It is situated on a Holocene alluvial terrace at ca. 455-470 ft above mean sea level. This terrace was developed, at least in part, by the South Bosque River or perhaps the intermittent stream that bordered the site on the south prior to impoundment of the lake (this stream now forms an inlet of the lake). The eastern part of the site where the historic component is located extends above $470 \mathrm{ft}$ and may consist of colluvial deposits from the steep slopes to the east. Prior to impoundment, a meander loop of the river lay just southsouthwest of the site, with the floodplain lying at an elevation of ca. $440 \mathrm{ft}$. A reed-covered cutbank ranging from 1 to $2 \mathrm{~m}$ in height is located to the west and east of the site. Vegetation consists primarily of willows and buttonbushes along the shoreline and a dense forest of oaks, elms, hackberries, and mesquites upslope on the terrace surface.

\section{Previous Investigations}

Site 41ML 135 was recorded in 1984 (Prikryl and J ackson 1985:70-75, 169-170). The investigations included surface survey and testing. The prehistoric component was recognized based on 10-15 flakes found over a distance of ca. $75 \mathrm{~m}$ along the shore. The materials appeared to have eroded out of the upper meter of the cutbank. Surface inspection yiel ded a comparable number of flakes and several burned rocks. These items were scattered throughout an area measuring $150 \mathrm{~m}$ northwest-southeast by $80 \mathrm{~m}$ northeast-southwest in the western part of the site. The historic component was evidenced by a scatter of glass, ceramics, and metal in an area measuring $100 \times 50 \mathrm{~m}$ at the southeastern end of the site next to the upland slope. Purple glass and patinated olive glass, possibly indicative of a late-nineteenth- or earlytwentieth-century occupation, were noted, in addition to a scatter of bricks and shaped limestone slabs that could indicate a house location.

Testing consisted of the excavation of three shovel tests, one 1x1-m unit, and two profile cuts. Shovel Test 1 was at the northwestern edge of the site $30 \mathrm{~m}$ north of the cutbank. No cultural materials were recovered from this unit, which was excavated to $75 \mathrm{~cm}$. Shovel Test 2 was $18 \mathrm{~m}$ north of the cutbank and $50 \mathrm{~m}$ eastsoutheast of Shovel Test 1. Excavated in 15-cm levels to $60 \mathrm{~cm}$, this unit produced two pieces of lithic debitage from Level $1(0-15 \mathrm{~cm})$ and one chert chip from Level $3(30-45 \mathrm{~cm})$. The second and fourth levels produced no cultural materials. Shovel Test 3 was 5 m north of the cutbank and $70 \mathrm{~m}$ southeast of Shovel Test 2 at the southeastern end of the site. Artifacts recovered from Level $1(0-15 \mathrm{~cm})$ consisted of one chert biface fragment, a bottle cap, and two glass fragments. Onemetal fragment was found in thethird level $(30-45 \mathrm{~cm})$, and the fourth level $(45-60 \mathrm{~cm})$ yielded two glass fragments. The second level (15$30 \mathrm{~cm}$ ) produced no cultural materials.

A 1.0-m-wide by 0.9-m-high profile cut was excavated on the cutbank directly south of 
National Register Testing of NineArcheol ogical Sites at Waco Lake

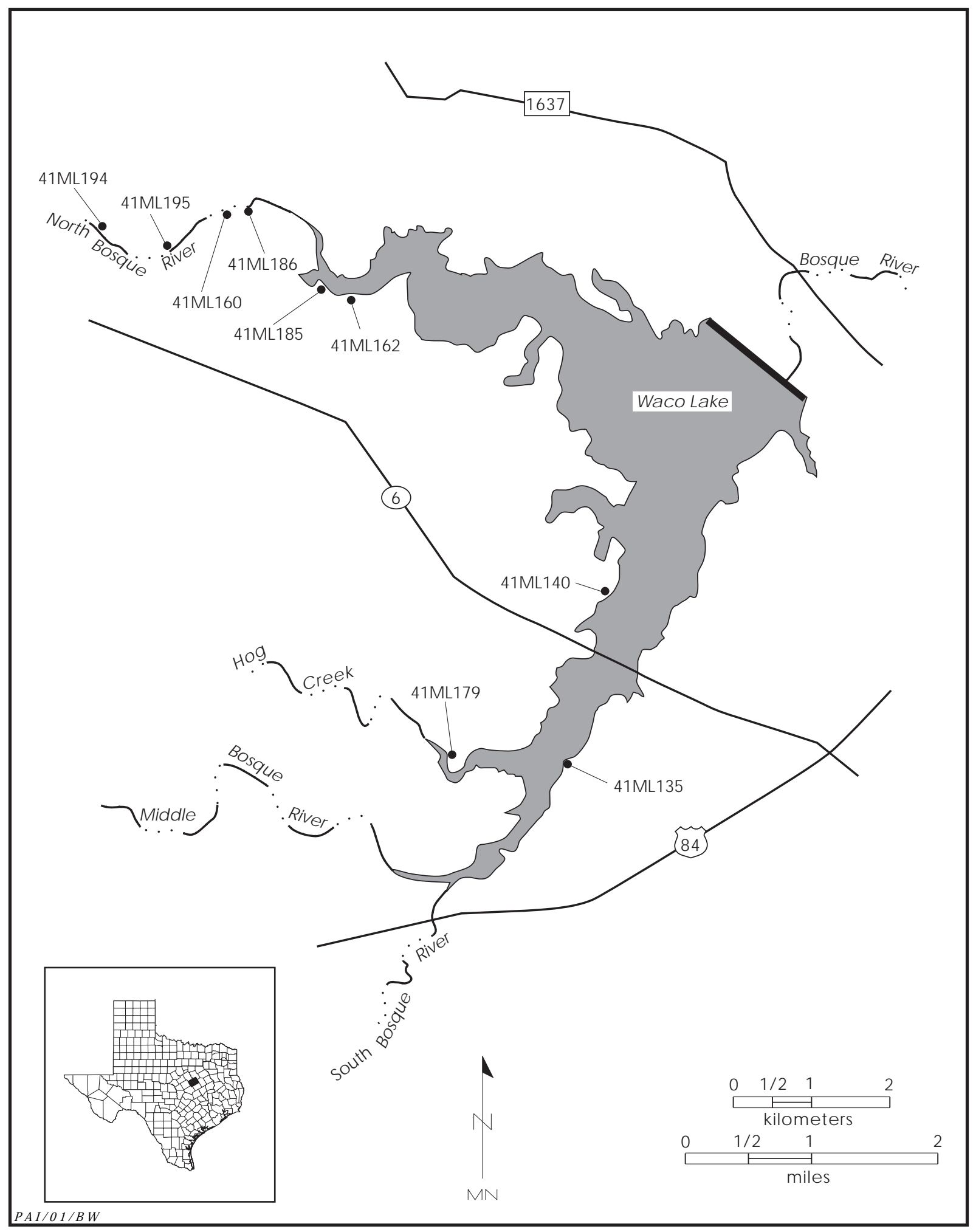

Figure 4. Locations of investigated sites. 
Shovel Test 1. Two chert flakes were observed in the profile at approximately 2 and $50 \mathrm{~cm}$ bel ow the surface, A second profile cut, $1 \mathrm{~m}$ high, was excavated south of Shovel Test 2. Except for a flake observed on the surface, this cut yielded no cultural materials.

A $1 \times 1-m$ test unit was placed just east of Shovel Test 2 and excavated in $10-\mathrm{cm}$ levels to a depth of $30 \mathrm{~cm}$. This unit was intended to explore the possibility that the absence of artifacts in Level 2 of Shovel Test 2 indicated a separation of components evidenced in Levels 1 and 3. The first level of the test pit yielded a Perdiz point, 8 pieces of chert debitage, and 15 burned rocks. The second level produced 2 pieces of chert debitage, and the third level contained only 1 chert chip and several burned rock fragments. The profile cuts, shovel tests, and test unit all exposed similar profiles.

Site 41ML 135 was revisited, surveyed, and shovel tested in 1999 as part of a sitere-location and reassessment effort ( $K$ vernes et al. 2000:34-36). I nspection of the site revealed that recent flooding had deposited substantial debris. Therefore, surface visibility was poor. The lake level was higher in 1999 than in 1984 making the cutbank unobservable. A 250x100-m area was surveyed for the identification of both prehistoric and historic artifacts. The scattered bricks and limestone slabs possibly representing the housesite were rediscovered, but no specific identification of the structural design or elements could be ascertained. Because of the abundant flood debris obscuring the ground, survey of the prehistoric component involved shovel testing. Two shovel tests were excavated to $40 \mathrm{~cm}$, and neither produced any artifacts.

\section{Work Accomplished}

The 2000-2001 investigations focused on the prehistoric component, as the historic component is in the upslope part of the site and will not be affected by the proposed raising of the lake. A datum nail was set in the base of a bois d'arc tree located in the north-central part of the site. It represents the primary datum and was given an arbitrary elevation of $100.00 \mathrm{~m}$. A secondary rebar datum was placed ca. $7 \mathrm{~m}$ northeast of the primary datum.

Five trackhoe trenches were excavated (Figure 5). None was deeper than $1 \mathrm{~m}$. They were ca. $1 \mathrm{~m}$ wide and 2.5-3.5 m long. No cultural materials or features were observed in any of the trenches.

Trench 1 was excavated in the eastern part of the site at an orientation of $72^{\circ}$. Trench 2 was oriented at $344^{\circ}$ and situated 66 m northwest of Trench 1 . Trench 3 was excavated $19 \mathrm{~m}$ due north of Trench 2 and aligned at $356^{\circ}$. Trench 4 , oriented at $22^{\circ}$, tested the western part of the site. It was located $36 \mathrm{~m}$ southwest of Trench 3. Trench 5, al igned at $340^{\circ}$, was located 20 m northeast of Trench 2 and 53 m northwest of Trench 1. Trench 5, al ong with Trenches 2 and 3, tested the central part of the site.

Four test units were excavated. All were placed adjacent to trenches, and L evel 1 in each of the units began at the modern ground surface. All of the units were terminated at $60 \mathrm{~cm}$. Test Unit 1 was on the south side of Trench 1. Test Units 2 and 3 were arranged on the east si des of Trenches 2 and 3, respectively. Test U nit 4 was on the west side of Trench 4 . In total, $2.4 \mathrm{~m}^{3}$ were hand excavated.

\section{Site Extent and Depth}

Based on the 1984 observations, the prehistoric component covers ca. $12,000 \mathrm{~m}^{2}$. Waco Lake borders this component to the south and west. Cultural materials were encountered in each of the four test units to a depth of $60 \mathrm{~cm}$. However, at $50 \mathrm{~cm}$, artifacts decreased in number, while gravels increased. The cultural zone appears to be about $40 \mathrm{~cm}$ thick with a few artifacts being displaced deeper from bi oturbation. The first level $(0-10 \mathrm{~cm})$ in each unit encountered modern and possible historic materials (e.g., wire nails, container glass, flat glass, a metal belt buckle, whiteware, wire, a button, a shell casing, a metal bottle cap, and plastic); however, in Test Unit 1 in the eastern portion of the site, the recovery of historic materials continued into Level $3(20-30 \mathrm{~cm})$. These materials were not collected because they are nondiagnostic and because they reflect, at least in part, modern debris deposited around the margin of the lake. Test U nit 4, located on the point to the west, produced the highest recovery of prehistoric cultural materials ( $n=31$ ).

\section{Sediments and Stratigraphy}

Thesediments and stratigraphy at 41ML 135 
National Register Testing of NineArcheol ogical Sites at Waco Lake

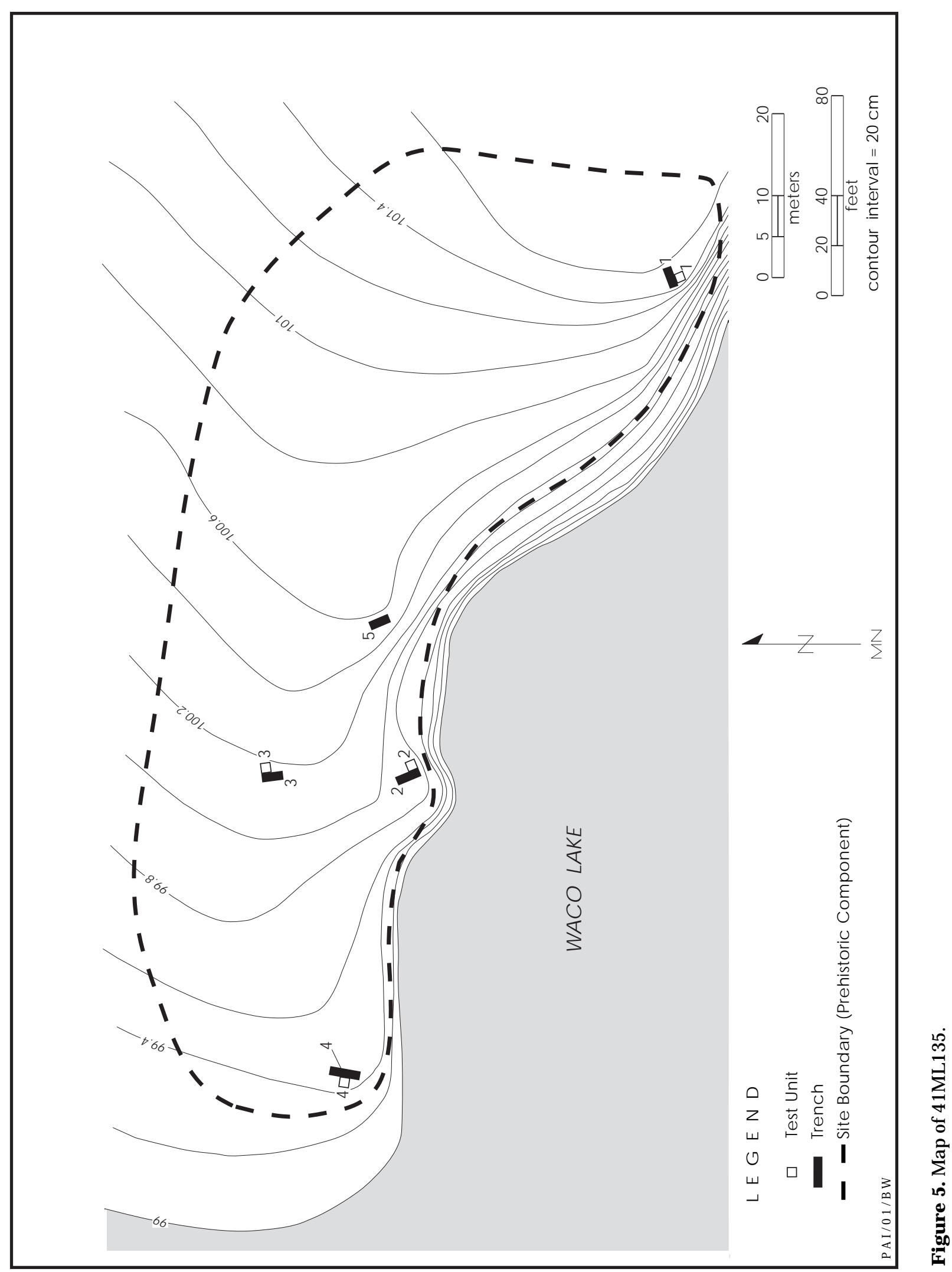


were examined through the profiles of five trenches and descriptions of the soil stratigraphy of two of the trench profiles (see Appendix A). The site is situated on an alluvial terrace, which (prior to inundation) stood ca. $9 \mathrm{~m}$ above the South Bosque channel. Soils on the terrace surface are mapped as part of the Catalpa se ries, which consist of dark grayish brown silty clay or clay soils formed on recent alluvium (Templin et al. 1958).

The alluvial deposits of Trench 1 are imprinted with an A-Bw soil profile. The A horizon $(0-29 \mathrm{~cm})$ is a dark grayish brown clay loam with 1 percent limestone gravels. The Bw horizon $(29-81+\mathrm{cm})$ is a light ol ive brown silty clay loam with 2 percent limestone gravels. The profile of Trench 4 is similar. It exhibits an A-Bw soil profile. The A horizon is a very dark gray clay with 1 percent limestone gravels, while the Bw horizon is a dark grayish brown silty clay loam with 10 percent limestone gravels.

The shallow trenches did not afford a look at the deeper deposits at 41ML135, but Collins and Holliday (1985:34) noted the presence of gravel beds and stringers interbedded with finer clastic sediments underlying the surficial deposits within a high cutbank exposure at the site. At the time, Collins and Holliday (1985:35) were uncertain of the age of these gravels, as data from other localities suggested that fine-grained sediments predominate the Holocene alluvium in the lower Bosque basin. However, based on the recovery of a Perdiz point by Prikryl and J ackson (1985) and the degree of soil development observed in Trenches 1 and 4, it is clear that the alluvial deposits (at least the upper ca. $1 \mathrm{~m}$ ) composing the terrace are late Holocene in age. The underlying gravel beds and stringers are probably the source of the matrix-supported, subrounded to rounded gravels observed throughout the trench profiles during the current investiga- tions. Their dispersal throughout the surficial fine-grained deposits is probably the result of biological agents.

\section{Materials Recovered}

The materials recovered from 41ML 135 consist of 57 chipped stone artifacts, 4 vertebrate faunal specimens, and 2 invertebratefaunal remains. Also recovered were a few burned rocks. None of the test units encountered any cultural features.

\section{CHIPPED STONE ARTIFACTS}

A total of 57 chipped stone artifacts were recovered (Table 1 ). This assemblage consists of 1 biface, 1 core, and 55 pieces of unmodified debitage.

Table 1. Summary of chipped stone artifacts from 41ML 135

\begin{tabular}{|c|c|c|c|c|}
\hline Provenience & Biface & Core & $\begin{array}{c}\text { Unmodified } \\
\text { Debitage }\end{array}$ & Totals \\
\hline \multicolumn{5}{|l|}{ TEST UNIT 1} \\
\hline Level $1(0-10 \mathrm{~cm})$ & - & - & 1 & 1 \\
\hline Level $2(10-20 \mathrm{~cm})$ & - & - & 3 & 3 \\
\hline Level $4(30-40 \mathrm{~cm})$ & 1 & - & 1 & 2 \\
\hline Level 6 (50-60 cm) & - & - & 1 & 1 \\
\hline Subtotals & 1 & 0 & 6 & 7 \\
\hline \multicolumn{5}{|l|}{ TEST UNIT 2} \\
\hline Level 2 (10-20 cm) & - & - & 2 & 2 \\
\hline Level $3(20-30 \mathrm{~cm})$ & - & - & 1 & 1 \\
\hline Level $6(50-60 \mathrm{~cm})$ & - & - & 1 & 1 \\
\hline Subtotals & 0 & 0 & 4 & 4 \\
\hline \multicolumn{5}{|l|}{ TEST UNIT 3} \\
\hline Level $1(0-10 \mathrm{~cm})$ & - & - & 2 & 2 \\
\hline Level $2(10-20 \mathrm{~cm})$ & - & - & 2 & 2 \\
\hline Level $3(20-30 \mathrm{~cm})$ & - & - & 2 & 2 \\
\hline Level $4(30-40 \mathrm{~cm})$ & - & - & 4 & 4 \\
\hline Level $5(40-50 \mathrm{~cm})$ & - & - & 2 & 2 \\
\hline Level $6(50-60 \mathrm{~cm})$ & - & - & 3 & 3 \\
\hline Subtotals & 0 & 0 & 15 & 15 \\
\hline \multicolumn{5}{|l|}{ TEST UNIT 4} \\
\hline Level $1(0-10 \mathrm{~cm})$ & - & - & 20 & 20 \\
\hline Level 2 (10-20 cm) & - & 1 & 3 & 4 \\
\hline Level $3(20-30 \mathrm{~cm})$ & - & - & 6 & 6 \\
\hline Level $6(50-60 \mathrm{~cm})$ & - & - & 1 & 1 \\
\hline Subtotals & 0 & 1 & 30 & 31 \\
\hline TOTALS & 1 & 1 & 55 & 57 \\
\hline
\end{tabular}


Biface

A single longitudinal fragment of a biface was recovered from Test U nit 1. The fragment is in the late stage of reduction. It is $4.1 \mathrm{~mm}$ thick.

Core

A core was recovered from Test U nit 4. With most of the cortex remaining, only four bidirectional flake scars are present on the chert specimen. The core measures $65.8 \mathrm{~mm}$ long by $71.1 \mathrm{~mm}$ wide by $37.8 \mathrm{~mm}$ thick.

Unmodified Debitage

Fifty-five pieces of unmodified debitage were collected. Of those, 44 percent $(n=24)$ are complete flakes, 18 percent $(n=10)$ are proximal flakes, 22 percent $(n=12)$ are chips, and 16 percent $(n=9)$ are chunks. Cortex is present on 4 of the chunks and 20 flakes. Most of the flakes are small with 74 percent $(n=41)$ being $2 \mathrm{~cm}$ or less in maximum dimension. Most of these small flakes al so lack cortex. Only 1 large complete flake (with cortex), measuring $4-5 \mathrm{~cm}$ in maximum dimension, was recovered. None of the flakes appear to have been utilized as expedient tools. Chert colors vary from a dark and/or mottled gray to a brown or mottled tan. A few specimens are light gray or almost white in color.

\section{VERTEBRATE FAUNAL REMAINS}

Vertebrate faunal remains are few and recovered fromTest Unit 4, Level 1. The four specimens were identified as unburned, large to medium-sized Mammalia (see Appendix C). It is unclear whether the specimens are historic or prehistoric in age.

\section{INVERTEBRATE FAUNAL REMAINS}

Invertebrate faunal remains consist of two small fragments of unidentifiable freshwater mussel shells (seeAppendix B). These two fragments are from Test Unit 4, Level 1.

OTHER MATERIALS

About $20-25$ small $(<5 \mathrm{~cm})$ burned lime- stone rocks were observed. These occurred in all four test units; no concentrations indicative of features were found.

\section{Chronology and Components}

Stratigraphically separable cultural zones or components were not observed at 41ML135. Although a Perdiz point, suggesting a Toyah phase component, had been recovered during previous investigations (Prikryl and J ackson 1985:74-75), no other diagnostics were discovered during the current investigations to strengthen that assessment.

\section{Summary and Assessment}

Whilea Toyah phase component apparently is present at 41ML 135, it appears to have little capacity to contribute important information. This is based on the overall sparseness of cultural materials, the lack of diagnostic artifacts or datable materials in the 2000-2001 excavations that would allow confirmation of the Toyah age assessment, the apparent lack of cultural features, and the lack (or extreme sparseness) of materials such as faunal and macrobotanical remains. It is recommended that the prehistoric component at 41ML 135 be considered ineligible for listing in the National Register of Historic Places.

\section{Site 41ML 140}

\section{Description}

Site 41ML 140 consists of the remains of a housesite once occupied by George Erath and Duncan McLennan. Situated at an elevation of $465 \mathrm{ft}$ on a high, old alluvial terrace on the west side of the South Bosque River valley (see Figure 4), the site is approximately $60 \mathrm{~m}$ northwest of the shore of Waco Lake. It is in a heavily wooded area adjacent to a previously cultivated field. The entire area resides in the Corps of Engineers Speegleville Park. Hackberries, chinaberries, elms, oaks, mesquites, and various tall grasses and weeds are present in and around the site.

\section{Previous Investigations}

The initial investigations at 41ML140 in 
1984 included survey, limited testing, and archival research (Prikryl and J ackson 1985:175178). Structural remains and scattered historic artifacts were noted over an area measuring $65 \mathrm{~m}$ north-south by $35 \mathrm{~m}$ east-west. The housesite was recorded in the center of this area. Two large mounds of bricks and sandstone rubble were thought to represent two chimneys at the ends of the house. Halfway between the rubble mounds were two sandstone and brick footings interpreted as chimney foundations for an earlier house. Artifacts collected from the surface included ceramics (alkaline-glazed stoneware, flow blue whiteware, blueshell edge, blue transfer-printed ware, ironstone, decalcomania, porcelain, and molded blue stoneware); perfume, olive oil, and patent medicine bottles; ornamental pressed glass sherds; and miscellaneous metal artifacts such as buttons, a spoon, and cut nails.

A single shovel test was excavated to a depth of $15 \mathrm{~cm}$ and produced cut nails, window and bottle glass, a shell button, a metal fragment, and several burned bone fragments from 0 to $10 \mathrm{~cm}$. These artifacts and those recovered from the surface indicated mid-nineteenth- to early-twentieth-century occupations (Prikryl and J ackson 1985:176).

Additional investigations included archival research. McLennan County deed and tax records indicated that the site represents the former homes of McLennan and Erath. George Erath established a large plantation around 1850-1851 and then sold it to Duncan McLennan in 1868. Nannie Sinclair purchased the property from Duncan McLennan in 1930, but tax records indicate that she probably never occupied the property (Prikryl and J ackson 1985:177). She sold it to the Corps of Engineers in 1962. The only improvements listed for the property at the time it was acquired by the Corps were an abandoned building and a barn.

Site 41ML 140 was revisited in 1999 as part of a site re-location and reassessment effort (K vernes et al. 2000:36-38). I nvestigations consisted of re-locating the features, surface inspection, and shovel testing. Features at the site were examined to determine if any disturbances had occurred since their recording in 1984. They were found to be in similar conditions as originally reported. Four shovel tests were excavated. Each one was placed near a feature. Feature 1 (the brick-lined well/cistern) was cleared and found to be filled with earth and rubble. No shovel tests were excavated in the well. However, Shovel Test 99-1 was dug near Features 2 and 3. A single piece of clear glass was recovered from 20 to $40 \mathrm{~cm}$. Shovel Test 99-2 was excavated in the vicinity of Feature 4 and yielded three pieces of container glass, a burned button, and tin can fragments in the upper $20 \mathrm{~cm}$. From 20 to $40 \mathrm{~cm}$, a whiteware sherd and a charcoal fragment were recovered. Shovel Test 99-3 was excavated adjacent to Feature 5 and yiel ded one cl ear glass fragment from 20 to $40 \mathrm{~cm}$. Finally, Shovel Test 99-4 was placed east of Feature 6 and recovered two glass sherds. The two remaining features at the site are a twentieth-century privy foundation and a metal water tank with associated foundation. No shovel tests were excavated near them. Most of the artifacts observed on the surface in 1999 or recovered from shovel tests were found to date to the late nineteenth or early twentieth centuries. A few mid-nineteenth-century artifacts were observed on the surface. They included handmade bridks, bl own-glass tableware, and a rim sherd from an undecorated ironstone chamber pot.

\section{Work Accompl ished}

During the 2000-2001 investigations, a long rebar stake was used as the primary datum and was given an arbitrary elevation of $100.00 \mathrm{~m}$. The datum was placed ca. 22 m east of the edge of the woods and ca. $8 \mathrm{~m}$ southwest of Feature 1 , the well/cistern. A second datum (rebar) was placed near a large oak tree in the northern area of the site, ca. $14 \mathrm{~m}$ south of the edge of the woods and ca. $18 \mathrm{~m}$ almost due north of Feature 1.

After initial identification of the various features, each feature was swept to remove leaf debris and then photographed, drawn in plan view, and subjected to testing. Four auger tests were excavated in Feature 1, while one test unit each was excavated in Features 2, 3, 4, and 6 (Figure 6). Two test units were placed in Feature 5.

Four auger tests were dug in Feature 1. Auger Tests 1 and 2 reached 40 and $45 \mathrm{~cm}$, while Auger Tests 3 and 4 terminated at 60 and $75 \mathrm{~cm}$, respectively. Each auger test was stopped by a blockage of bricks.

Test Unit 1 was on the east edge of Feature 5. 


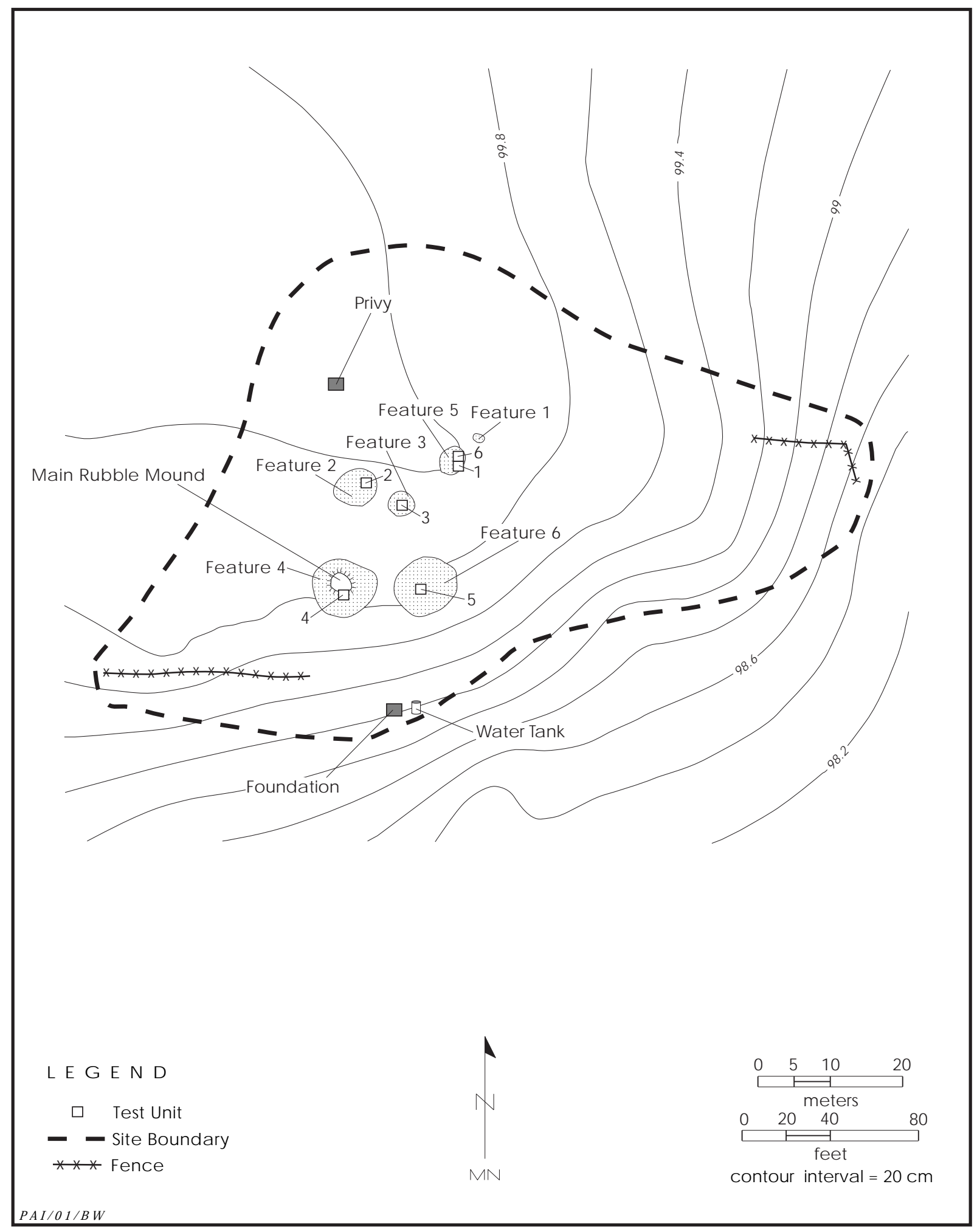

Figure 6. Map of 41ML140. 
Excavation was terminated at Level 8. Test Unit 2 was on the east side of Feature 2, hitting one of the large rocks to the north. Excavation was completed at Level 4. Test Unit 3 was situated adjacent to a large flat rock on the western side of Feature 3. Level 4 also was the last level excavated in this test unit. Located on the southern slope of the large pile of rubble designated as Feature 4, Test Unit 4 was excavated to Level 9. The first few levels were smaller than 1x1 m because of the sloping nature of the rubble mound. Test U nit 5 was near the southern center of the brick rubble pile of Feature 6 . Work was completed in this unit at Level 4. Finally, Test Unit 6 was placed adjacent (north) to Test Unit 1 in Feature 5 to follow out a gray ashy lens found in the first unit. As with Test Unit 1 , Test Unit 6 was finished at Level 8. A total of $3.4 \mathrm{~m}^{3}$ was excavated at 41ML 140 .

\section{Site Extent and Depth}

Based on the features and artifacts visible on the surface, $41 \mathrm{ML} 140$ covers ca. $6,300 \mathrm{~m}^{2}$. The features indicate that the surface of the landform at the time of occupation approximated the current surface, although all of the investigated features and substantial artifact deposits extend below the modern surface within a ca. 20-40-cm-thick matrix of dark brown silty clay loam over sterile reddish brown clay to clay loam. Sixty-eight percent of the 1,950 artifacts from the test pits are from the upper $20 \mathrm{~cm}$. Almost all of the remainder are from 20 to $60 \mathrm{~cm}$, with most coming from the subsurface component of Feature 5 in Test U nits 1 and 6 . Artifact yiel ds varied significantly. The units with the highest yields are Test Unit $5(n=$ $669)$, Test Unit $1(n=498)$, and Test U nit $6(n=$ 438).

\section{Cultural Features}

Eight features were documented at 41ML 140 (see Figure 6). Six are assigned number designations, while two relatively recent features are not.

\section{FEATURE 1}

Feature 1, located northeast of the house, is a brick-lined cistern (or possibly a well) filled with earth and rubble (Figure 7). It measures 1.0x0.7 m and has been damaged on the northern side by the growth of a tree. Surface manifestations of the feature consist of the lining of machine-made bricks, most of which have a mortar veneer covering them. The center of the circular opening is filled with sediment. Artifacts observed around the feature include a condensed milk can, modern beer bottles, sanitary cans, and metal roofing.

Four 15-cm-diameter auger tests were dug in the sediment-filled opening. The sediments were not screened, and none of the artifacts recovered were collected. Each test was terminated after encountering tightly packed bricks. Auger Test 1 stopped at $40 \mathrm{~cm}$ and recovered a plastic soda bottlelabel, a piece of glass, a stoneware sherd, and an earthenware sherd. Auger Test 2, dug to $45 \mathrm{~cm}$, recovered another piece of the plastic label, two mortar fragments, charcoal and brick fragments, and a wire nail. Excavated to $60 \mathrm{~cm}$, Auger Test 3 encountered numerous charcoal flecks and brick fragments. Auger Test 4, terminated at $75 \mathrm{~cm}$, recovered more of the plastic label, charcoal flecks, brick fragments, a wire nail, a fragment of rusted sheet metal, and a stoneware sherd. None of the materials appear to be early in age, and it is unclear if the feature contains cultural deposits beneath the brick fill. Based on the presence of machine-made brick, it appears that Feature 1 is not associated with the initial E rath occupation of $41 M L 140$, unless the visible portion represents repairs to an early cistern/well.

\section{FEATURE 2}

Located in the western part of the site, Feature 2 consists of large, flat, cut sandstone blocks in an L-shaped configuration around which numerous other sandstone and machine-made brick fragments are scattered (Figure 8). The scatter measures about $3.5 \mathrm{~m}$ north-south by 4.0 m east-west. Artifacts observed on the surface include container glass, window glass, milk glass, porcelain, and sheet metal fragments. Test Unit 2 was placed in the eastern portion of the feature. Excavations revealed that the large tabular stones continue $38 \mathrm{~cm}$ bel ow the surface, consisting of three more courses of tabular stones averaging ca. $15 \mathrm{~cm}$ in thickness (Figure 9). Artifacts recovered during excavation consist of animal bones, a ceramic sherd, a 
National Register Testing of NineArcheol ogical Sites at Waco Lake

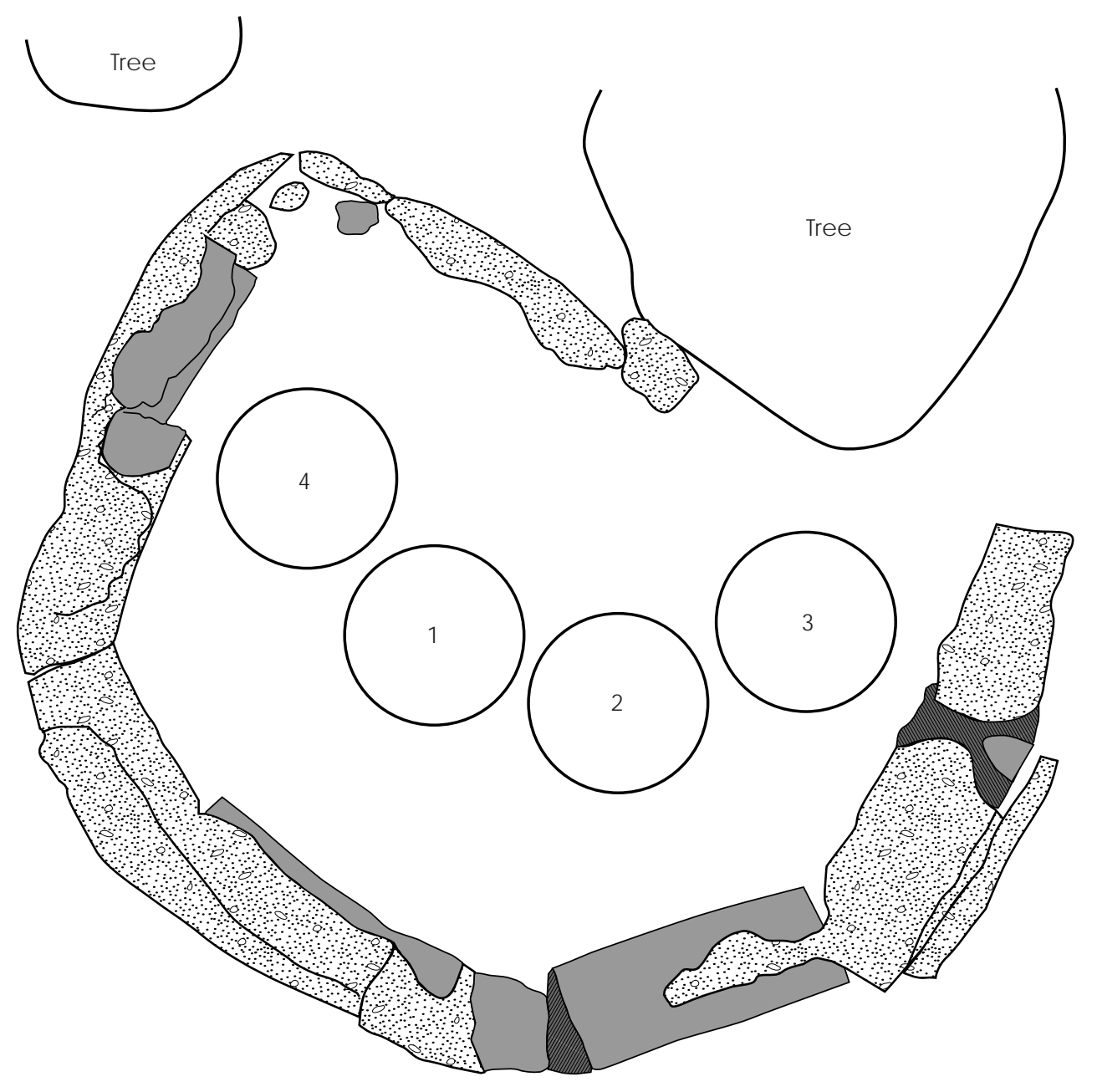

LE G E N D
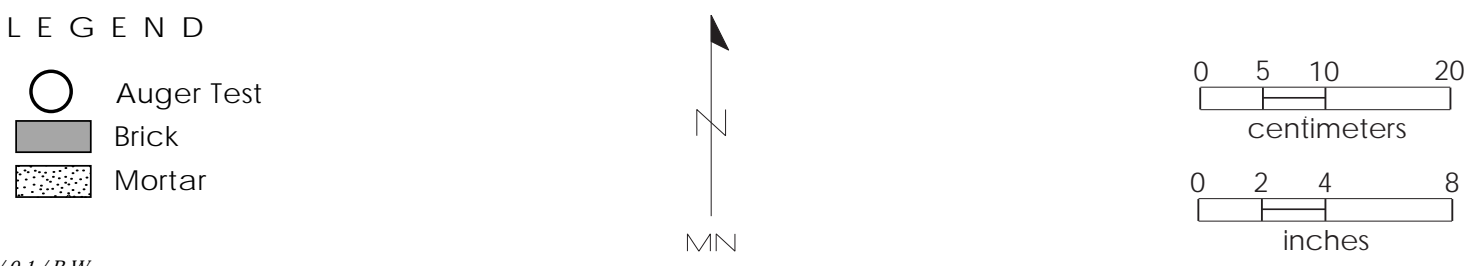

Figure 7. Plan view of Feature 1 at the Erath/McLennan House, 41ML140. 


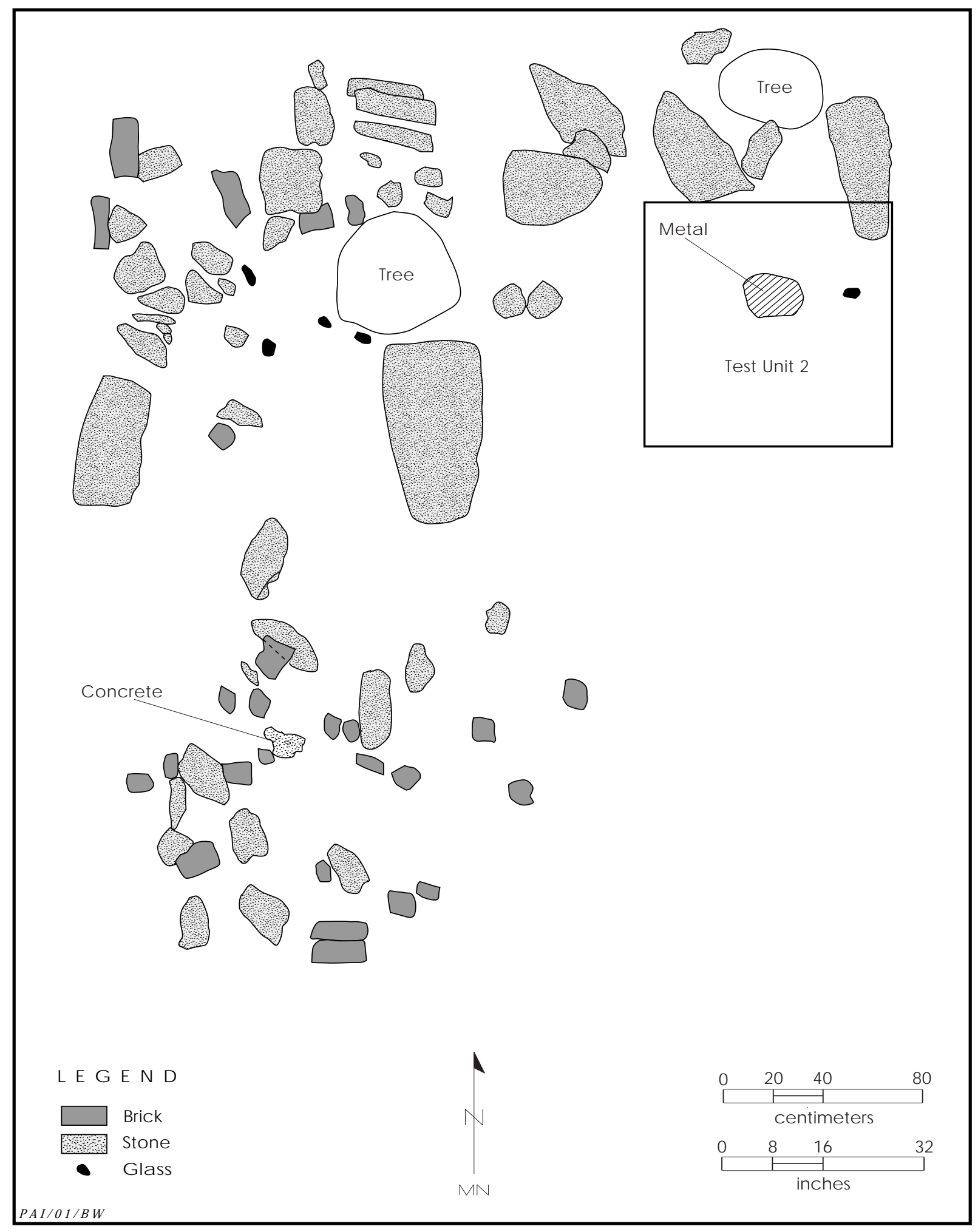

Figure 8. Plan view of Feature 2 at the Erath/McLennan House, 41ML140. 


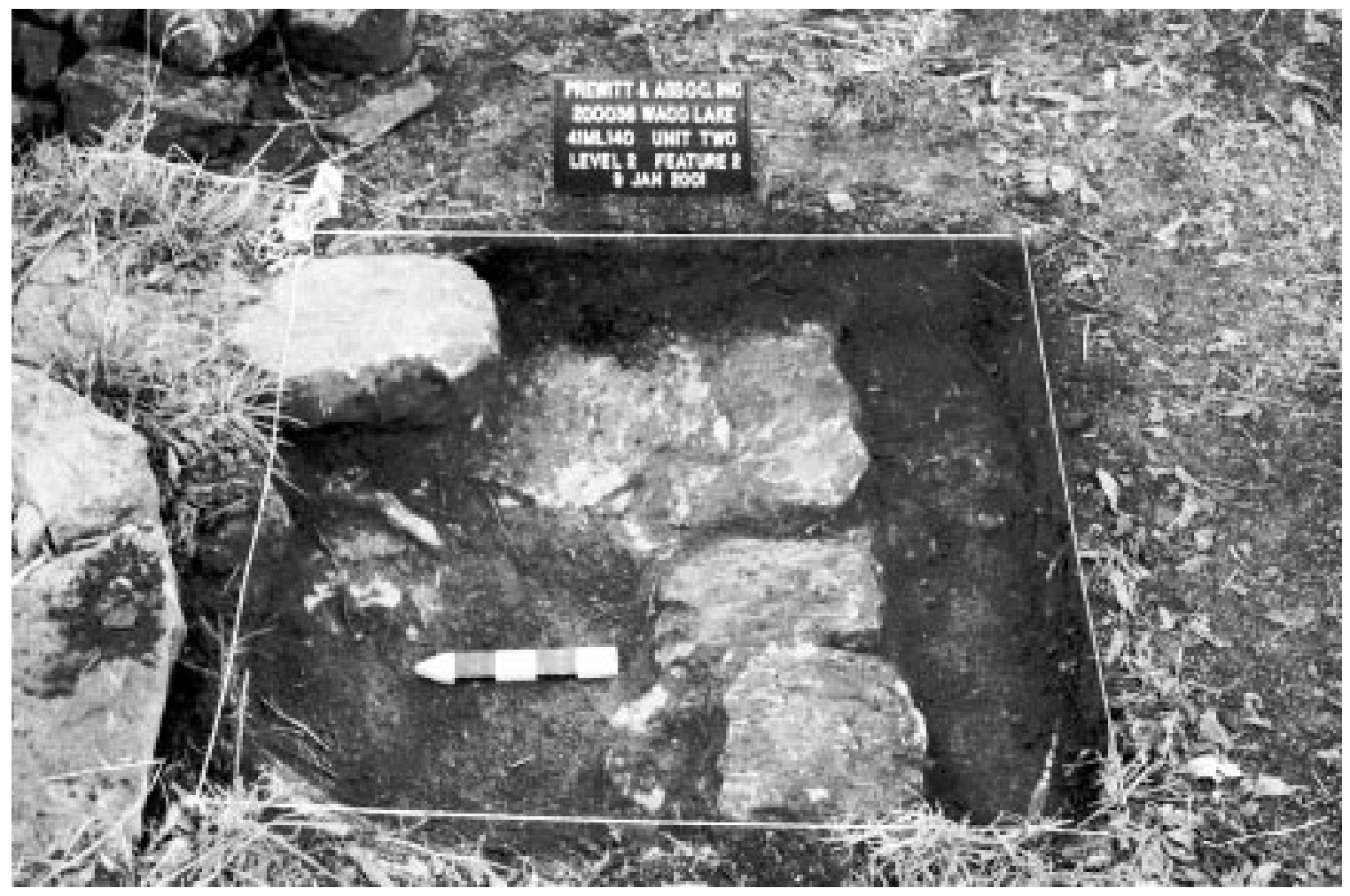

Figure 9. Photograph of Feature 2 as exposed in Test Unit 2 (Level 2) at the Erath/M CLennan House, 41ML140. View to the east.

small bottle, and glass fragments. Feature 2 appears to be a partially intact foundation. While no evidence of a pit could be seen in the walls of Test Unit 2, the subsurface extent of the rocks indicates that the foundation was placed in a builder's trench. Although no ash or charcoal was recovered, it is suspected that the foundation was for a chimney based on its size and shape.

\section{FEATURE 3}

Feature 3, which lies ca. $3 \mathrm{~m}$ southeast of Feature 2, is another configuration of tabular sandstone rocks (Figure 10). It measures ca. $2.6 \mathrm{~m}$ north-south by 2.5 m east-west. The large rocks are arranged in a U-shaped pattern. Scattered around them are smaller fragments of sandstone, concrete, and machine-made bricks. Other artifacts observed on the surface include melted clear glass, a metal table knife, corrugated metal roofing, and a fragment of metal chain. Test Unit 3 was placed at the southern end of the feature to include the westernmost large rock. Excavations reveal ed that this rock is not underlain by others, unlike Feature 2. Cultural materials were recovered from the first three levels $(0-30 \mathrm{~cm})$; they consist of nails, ceramics, glass, a canning jar lid liner, bones, teeth, numerous charcoal fragments, and a 1-inchdiameter pipe traversing the unit, which indicates disturbance. Based on the degree of disturbance (especially the underlying water pipe) and the fact that the rocks apparently are resting on the modern ground surface, Feature 3 appears to represent materials displaced from Feature 2 nearby, or perhaps footing stones for the house. In either case, it has little integrity.

\section{FEATURE 4}

Feature 4, located in the southwest part of the site, is a large pile of sandstone rocks, bricks, and concrete fragments. The rubble pile covers about $6 \mathrm{~m}$ north-south by $7 \mathrm{~m}$ east-west and is about 0.75-1.0 $\mathrm{m}$ high (Figure 11). Five trees are present in and around the pile. Scattered 


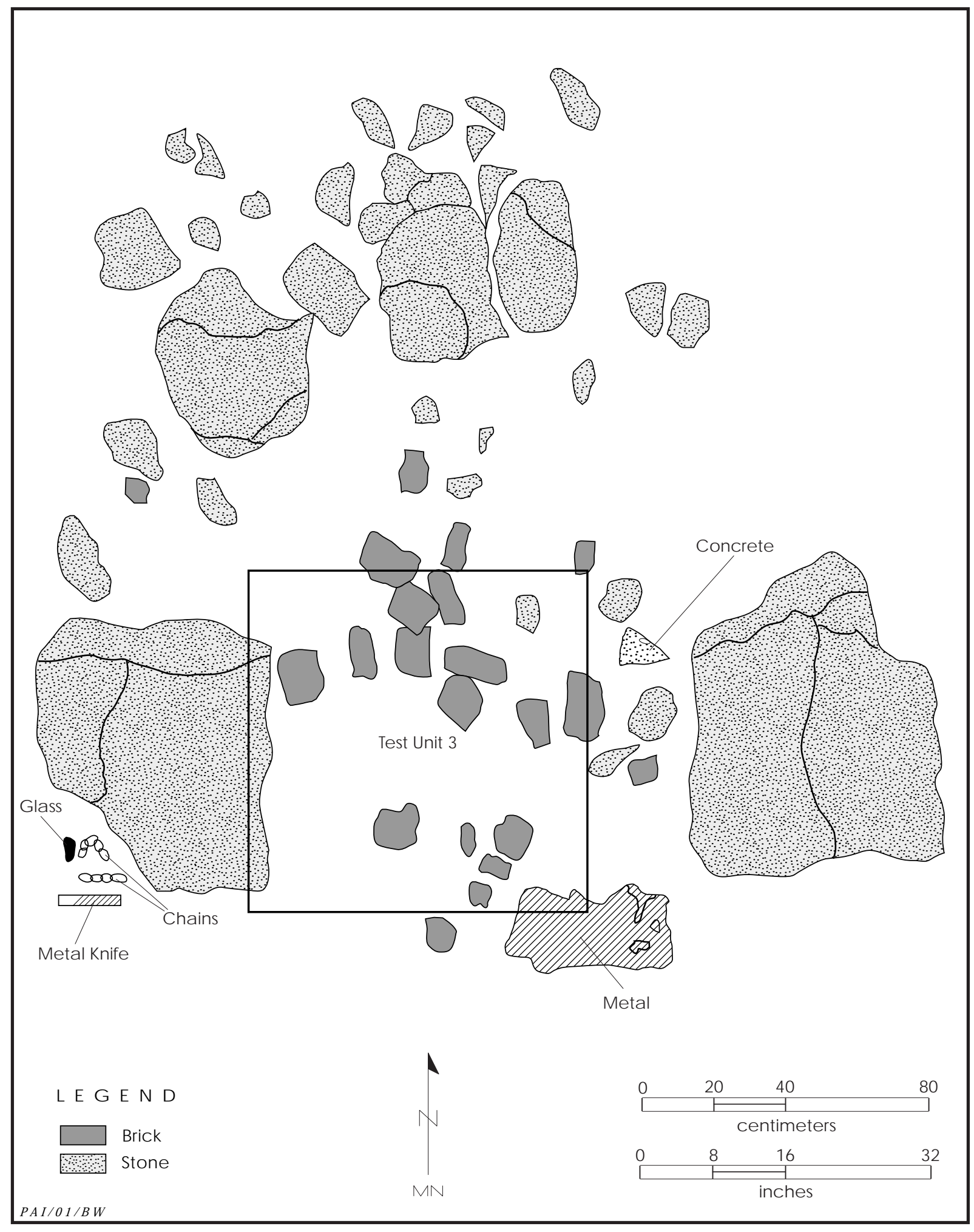

Figure 10. Plan view of Feature 3 at the Erath/M cLennan H ouse, 41ML140. 


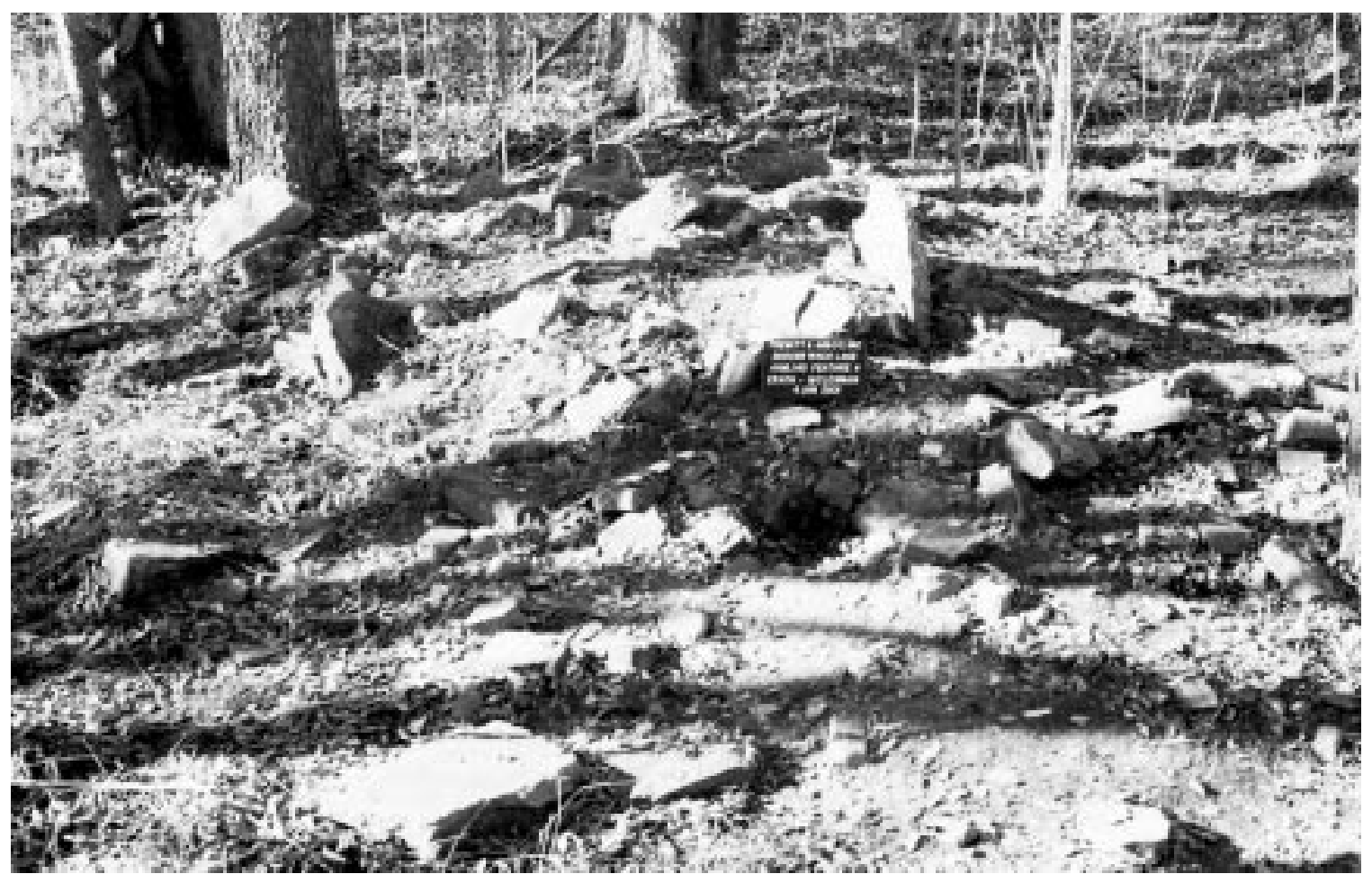

Figure 11. Photograph of Feature 4 at the Erath/M LLennan House, 41ML140. View is northwest.

among the stone rubble are window glass sherds, a blue transfer-print sherd, and various bricks, three of which have makers' marks. These marks are: "BUTLER" made by the Mike Butler Brick Company in Harris County, 18921915; “A. P. GREEN F. B. CO. / EMPIRE D. R." made by the A. P. Green Refractories in Sulpher Springs, Hopkins County, 1954 to present; and "WACO B. CO." made by the Waco Brick Company in Waco, McLennan County, 1907-? (Steinbomer 1982). Initially, two stones in the rubble pile appeared to be in situ on the south side; therefore, this is where Test Unit 4 was placed to test the integrity of the feature. However, excavation revealed jumbled rubble in a brown loam matrix. A 5-cm-thick charcoal lens was encountered and likely associated with a collapsed, rusty stovepi pe situated in the eastern part of the unit. The thickest part of the rubble was $0.9 \mathrm{~m}$, and no intact deposits were discovered. Artifacts from the unit include stones, machine-made bricks, nails, miscellaneous metal, glass fragments, a complete bottle, and a shell button. Prikryl and J ackson (1985:176) suggest that this feature is a col- lapsed chimney, but the current investigations indicate that the feature is a push pile of rubble.

\section{FEATURE 5}

Feature 5 lies approximately $4 \mathrm{~m}$ southwest of Feature 1. It is a low $(20 \mathrm{~cm})$ mounded area with artifacts scattered across the surface, covering about $2.4 \mathrm{~m}$ north-south by $2.2 \mathrm{~m}$ eastwest (Figure 12). Cultural materials present on the surface include container glass; window glass; brick, concrete, and stone fragments; a metal rod; a drill bit; and a porcelain doll. Another small $(1.5 \times 1.5 \mathrm{~m})$ artifact scatter is located ca. $2 \mathrm{~m}$ to the south. This scatter consists of items similar to those at the surface of Feature 5, such as container glass, window glass, miscellaneous metal, and brick fragments.

Test $U$ nits 1 and 6 were placed on the eastern part of Feature 5 . The test units formed a 1×2-m arrangement with Test Unit 6 to the north. The upper $30 \mathrm{~cm}$ of the units consisted of dark brown silty clay loam sediments with abundant artifacts (74 percent of the total from these two units), especially cut and wire nails, 


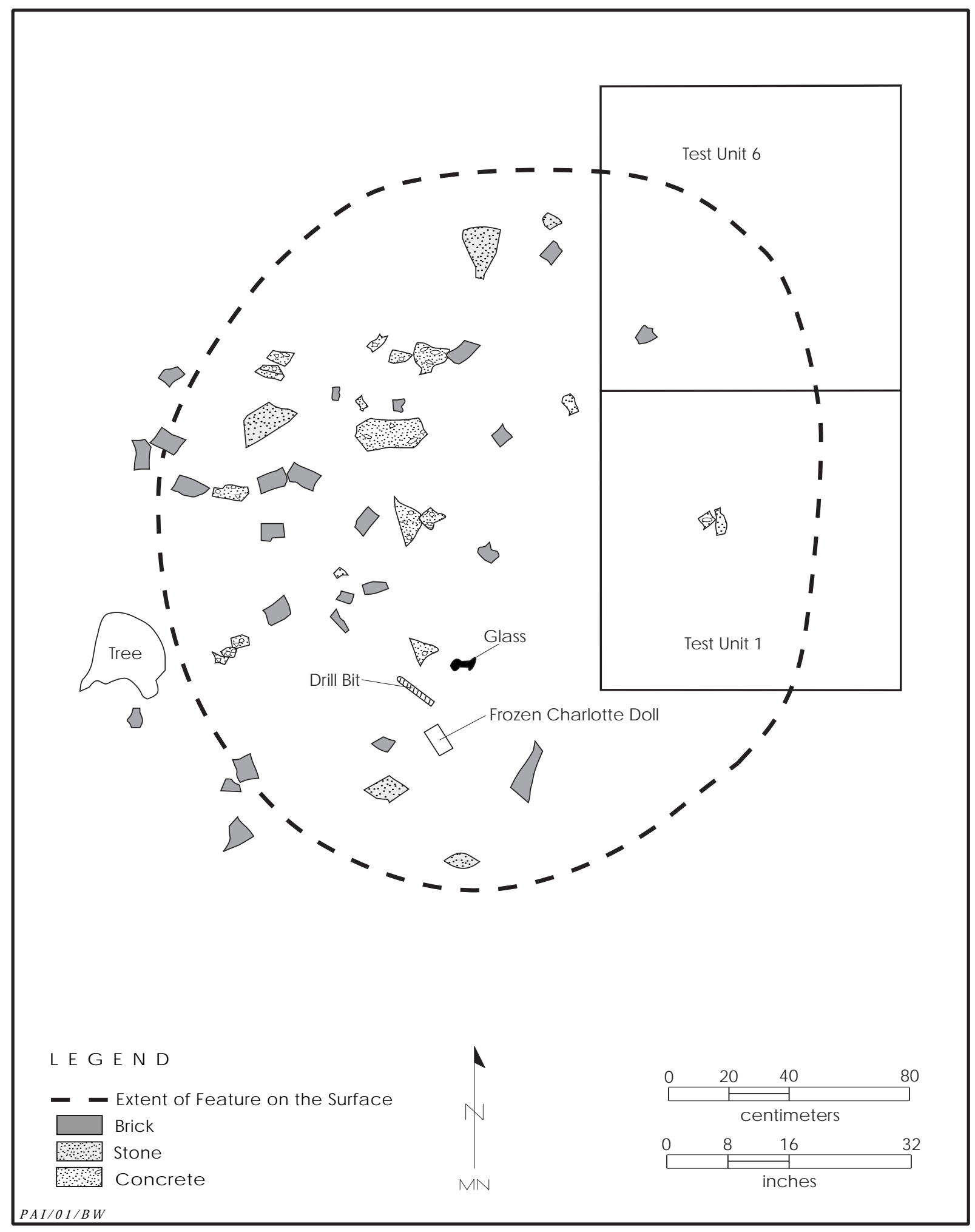

Figure 12. Plan view of Feature 5 at the Erath/M cLennan House, 41ML140. 
window glass, and container glass, along with charcoal and small numbers of rodks, brick fragments, and animal bones. In Level 4, a concentration of ca. 25 largely flat-lying rocks, some as large as $30-35 \mathrm{~cm}$ and some exhibiting pink thermal discoloration, was encountered. These rocks were most frequent in the northeastern quarter of Test U nit 1, but some occurred in the central and south-central parts of this unit and throughout the east half of Test Unit 6; no particular arrangement of the rocks could be discerned. Artifacts were recovered in smaller numbers than the overlying levels, along with charcoal and bones. In Level 5 and extending into Level 7, a roughly circular deposit of ash and charcoal was encountered. It measured ca. $90 \mathrm{~cm}$ north-south (ca. $20 \mathrm{~cm}$ in the southern part of Test U nit 6 and $70 \mathrm{~cm}$ in the northern part of Test Unit 1) by $75 \mathrm{~cm}$ east-west, extending into the east walls of both units. About 13 rocks ( $5-40 \mathrm{~cm}$ in diameter) were present beyond the ash deposit or on its edges, mostly in the northeastern quadrant of Test Unit 6. Other artifacts, induding faunal remains, occurred in small numbers. Level 8 below the ash deposit was culturally sterile reddish brown day loam.

The ash and charcoal deposit in Levels 5-7 and the high densities of artifacts, including faunal remains, suggest that Feature 5 represents a locus of trash disposal. Though pit boundaries were not visible in the dark brown surface sediments, the thin ash lens with charcoal at its base along the bottom of the feature hints that a pit may have been dug slightly into the reddish brown clay loam subsoil (Figure 13), and that trash may have been burned in this pit. The relative concentration of faunal remains (63 percent) in Levels 5 and 6 and the fact that most of the obviously burned artifacts (both of the burned ceramic sherds and 17 of the 19 pieces of melted glass) were found in Levels 13 suggest that these initial burning episodes may have involved food refuse rather than discarded domestic debris. As discussed bel ow, the diagnostic artifacts from the lower levels of Test Units 1 and 6 indicate that thesetrash disposal activities began during the early occupations of thesite, with the upper levels containing earlytwentieth-century remains as well. The mounded nature of Feature 5 on the surface presumably reflects the continued use of this part of the site for trash discard during thelater occupations.

\section{FEATURE 6}

Located ca. 3 m east of Feature 4 is a broad surface scatter of bricks designated Feature 6. The scatter measures about $7 \mathrm{~m}$ north-south by $5 \mathrm{~m}$ east-west. Cultural materials noted on the surface consist of container glass, window glass, stoneware, ironstone, machine-made brick fragments, and a few sandstone rocks. Test Unit 5 was placed in the central part of the scatter in an area where possibly in situ bricks were noted. The surface bricks were mapped and re moved, revealing a second layer of mortared bricks lying on their sides in Level 1 (Figure 14). The orientation and alignment of the bricks indicate collapse in an east-west direction. Near the bottom of Level 1 , beneath the brick layer, were fragments of decomposing wood along with numerous nails, glass sherds, and other household debris, most of which exhibited evidence of burning. Below these materials at ca. $19 \mathrm{~cm}$ was sterile reddish brown clay loam. No cultural materials were observed bel ow $20 \mathrm{~cm}$. Feature 6 appears to represent a fallen brick chimney.

\section{UNNUMBERED FEATURES}

The last two features have not been assigned numbers. These are a concrete foundation for a two-hole privy in the northern part of the site and a collapsed galvanized metal water tank and associated concrete foundation in the southern part of the site. The privy consists of poured concrete creating two separate rectangular sections (Figure 15). Dimensions of the feature are $1.4 \times 1.25 \mathrm{~m}$. No excavations were conducted here. The surrounding artifact scatter covers an area ca. $15 \mathrm{~m}$ north-south by $10 \mathrm{~m}$ east-west. The artifacts consist of container glass, Bristol-gl azed stoneware, a paint can lid, and sanitary cans. Largefragments of displaced concrete-possibly from the privy-were found south of the foundation.

The dented and semicollapsed, corrugated, galvanized metal water tank is lying on the ground ca. $10 \mathrm{~m}$ south of Features 4 and 6. Manufacturer's writing is present on the west side of the tank ("...nam Machine's") (Figure 16). The adjacent concrete feature appears to be the base that supported the superstructure for the tank. It measures $1.4 \times 1.2 \mathrm{~m}$. Threaded metal bolts and nuts are 


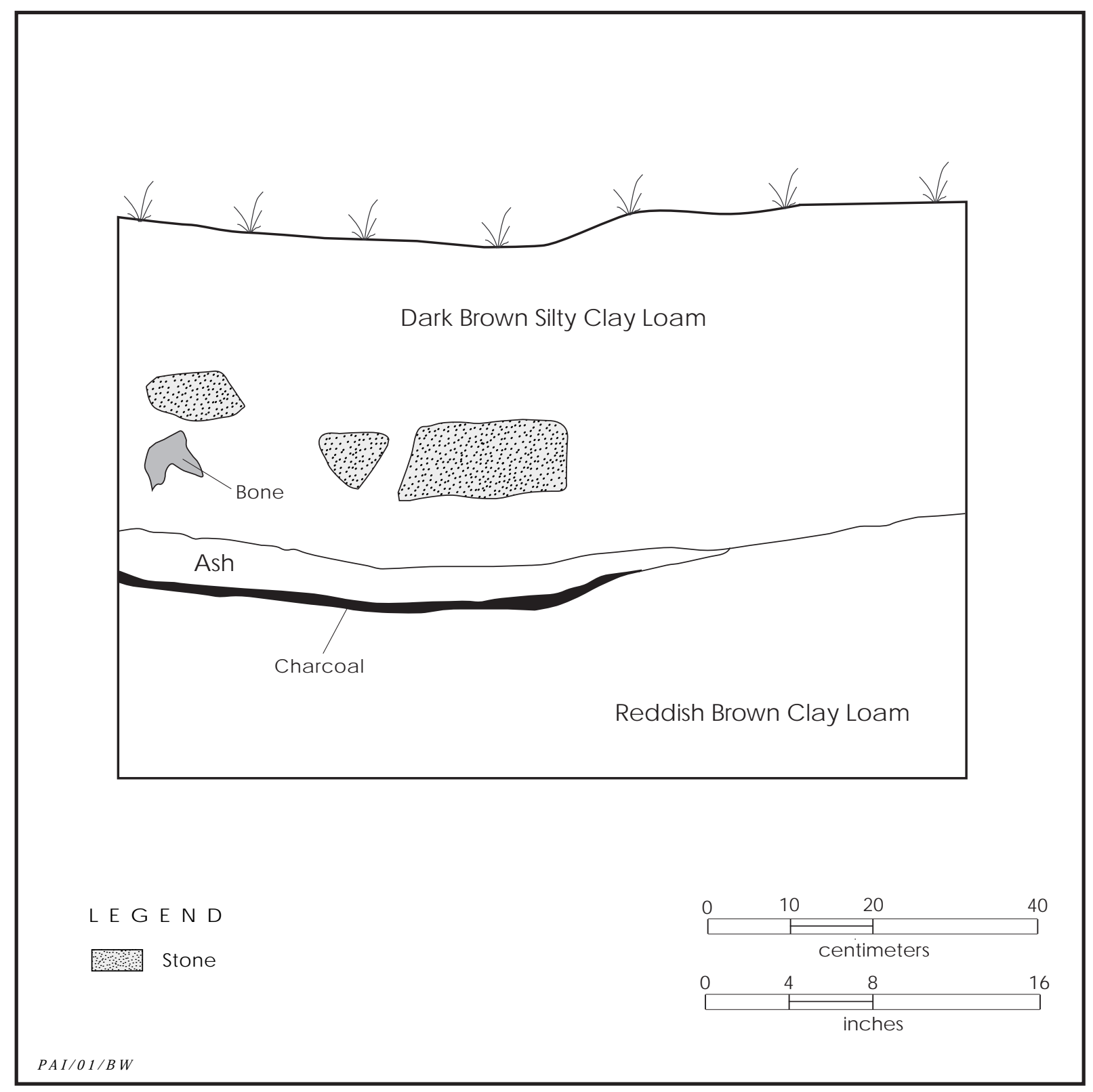

Figure 13. Profile of the east wall of Test Unit 1 in Feature 5 at the Erath/M cLennan House, 41ML140.

present at all four corners of the pad, and portions of graffiti ("CAB" and "RB") etched in the surface are readable. The pad appears to have been displaced from its original location, although its association with the tank suggests that the original location was nearby. The drilled well that likely provided water for the tank is not evident on the surface. No excavations were conducted near these features.

\section{Materials Recovered}

The artifacts recovered from the excavations at 41ML 140 consist mostly of ceramics ( $n=103)$, glass $(n=679)$, metal $(n=958)$, and faunal remains $(n=200)$ (Table 2 ). Small amounts of other materials recovered consist of buttons ( $n=2)$, mortar $(n=3)$, a charcoal pencil $(n=1)$, and miscellaneous materials $(n=6)$. 


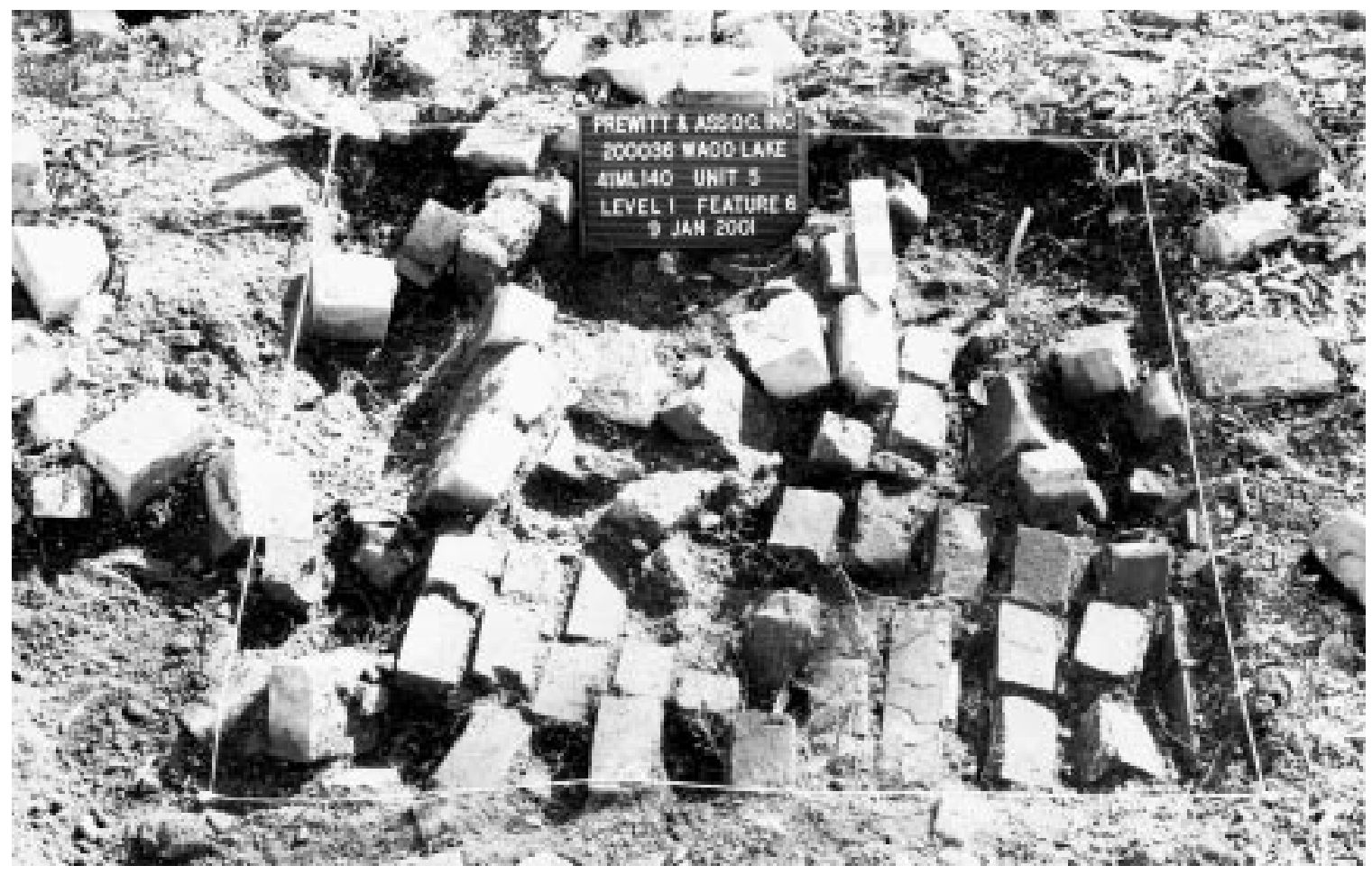

Figure 14. Photograph of Feature 6 as exposed in Test Unit 5 (Level 1) at the Erath/McLennan House, 41ML140. View is south.

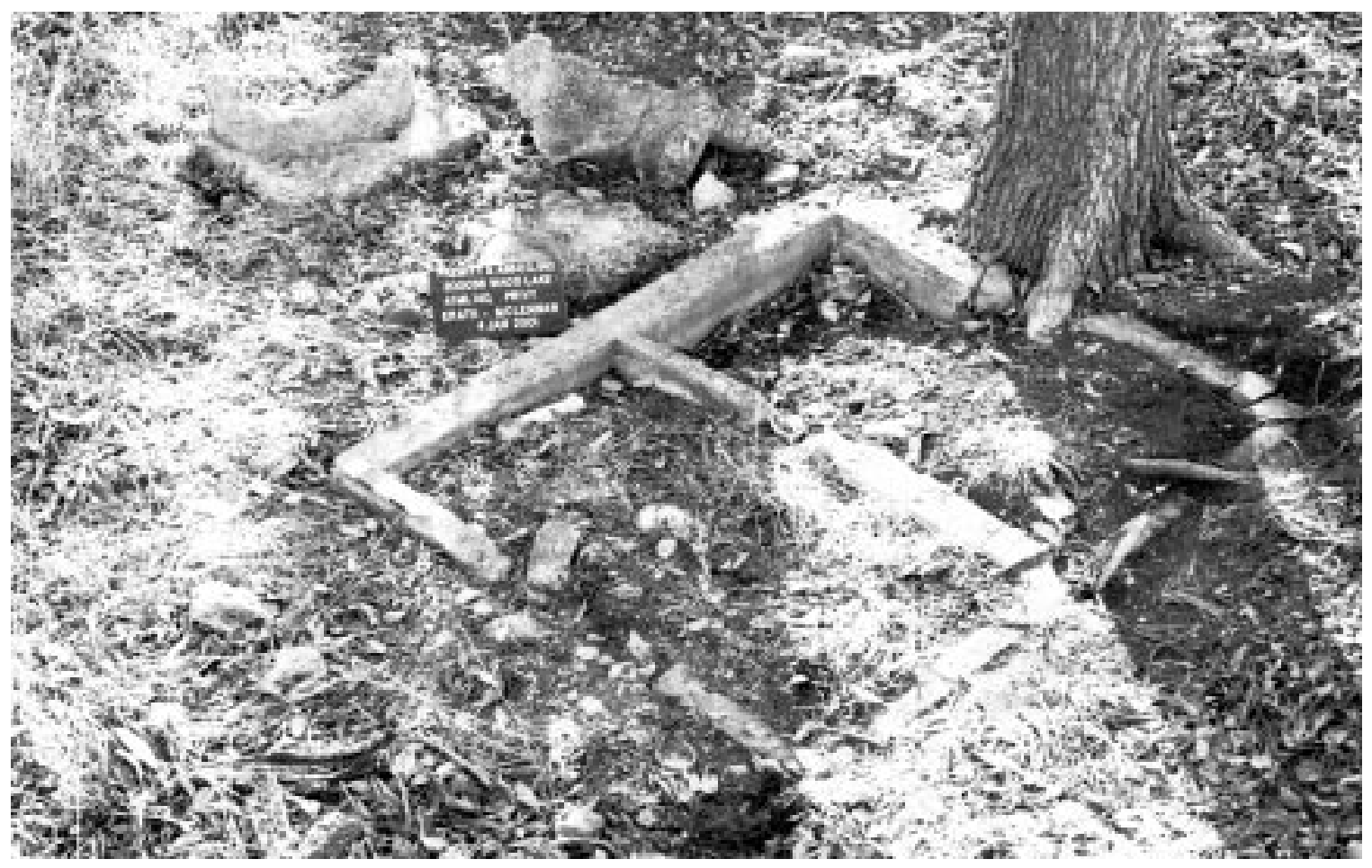

Figure 15. Photograph of concrete privy foundation at the E rath/M CLennan House, 41ML 140. View is southwest. 


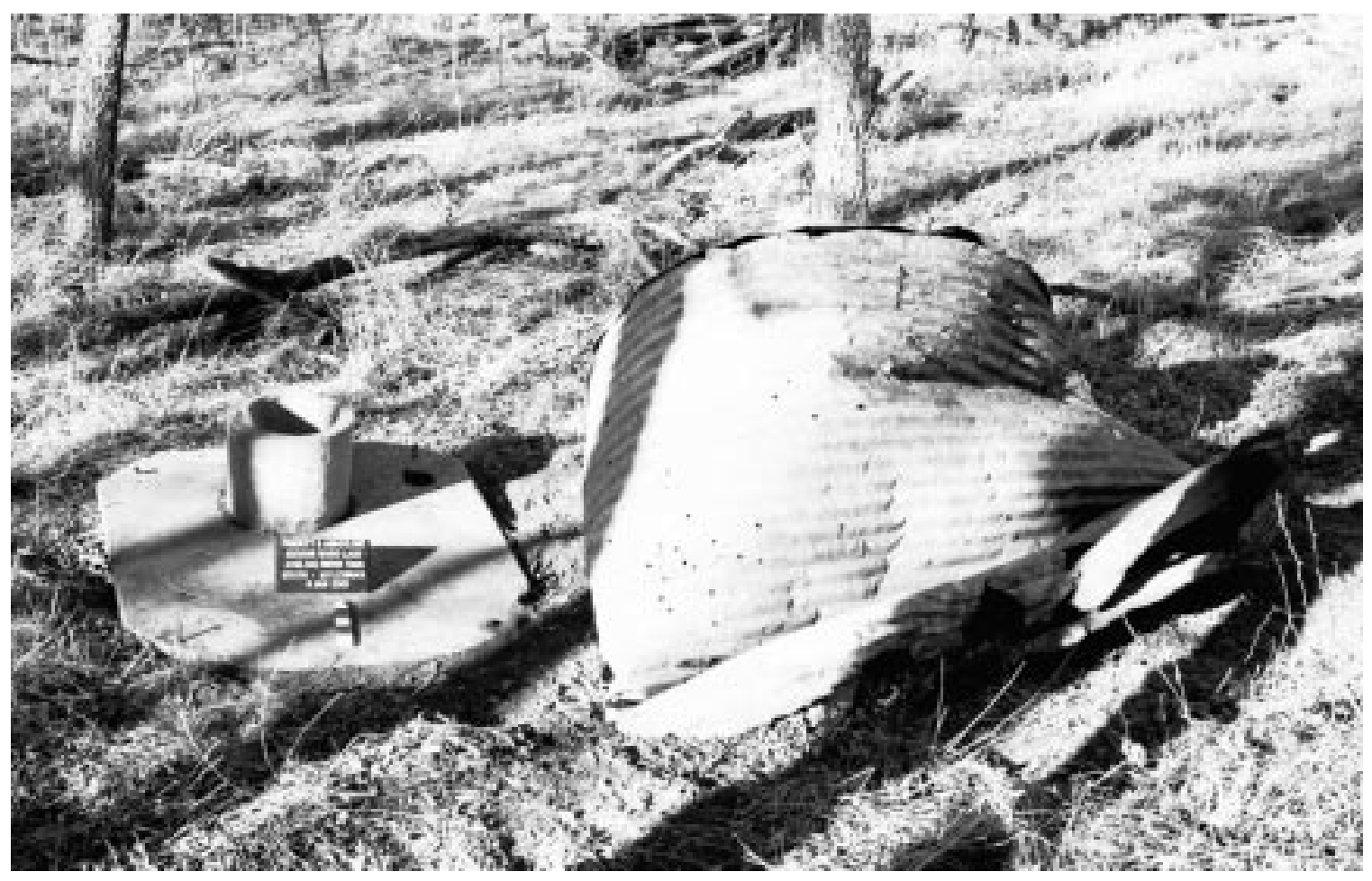

Figure 16. Photograph of concrete pad and galvanized water tank at the E rath/McLennan House, $41 \mathrm{ML} 140$. View is north.

\section{CERAMICS}

Of the 103 ceramic sherds, 85 are whiteware, 7 are stoneware, 8 are porcelain, and 3 are other miscellaneous ceramic objects.

\section{Whiteware}

The 85 whiteware sherds exhibit the following decorative types: undecorated ( $n=46)$, molded ironstone $(n=11)$, molded and gilded $(n=2)$, decalcomania $(n=1)$, transfer printed $(n=15)$, transfer printed and enameled $(n=1)$, flow blue $(n=2)$, handpainted $(n=5)$, and annular ware $(n=2)$. Most diagnostic are the transfer-printed whiteware sherds (Figure 17). With the exception of a single sherd recovered from the surface, all are associated with Feature 5, a refuse disposal deposit.

Transfer-printed ceramics are highly diagnostic because they can be dated accurately to short spans of time. I dentified patterns consist of: Columbia, a blue transfer print made by William Adams \& Sons, ca. 1842-1858 (Blake and F reeman 1998:48); Florilla, green enamel on a purple transfer print, made by $E d w a r d$ Challinor, 1842-1867 (Blake and Freeman 1998:62); L ozere, a bluetransfer print also made by Edward Challinor, 1842-1867 (Blake and Freeman 1998:78); Sirius, recovered in both blue and brown transfer prints, made by $\mathrm{J}$ ames and Thomas Edwards, 1839-1841 (Pollan et al. 1996:70); and Colonna, a purple transfer print made by Thomas Goodfellow, ca. 1828-1859 (Williams and Weber 1998:13). Due to the early dates of these artifacts, some of the materials deposited in Feature 5 clearly are associated with occupation and activities by George E rath who established his plantation ca. 1850-1851 and sold it in 1868.

\section{Stoneware}

Although only seven sherds of stoneware were recovered, they represent five different types, and at least that many vessels. Stoneware glaze types consist of Bristol $(n=1)$, Bristol and Albany $(n=1)$, Albany $(n=2)$, salt glazed and Albany $(n=1)$, and salt glazed $(n=2)$. With 
National Register Testing of NineArcheol ogical Sites at Waco L ake

Table 2. Summary of cultural materials from 41ML 140

\begin{tabular}{|c|c|c|c|c|c|c|}
\hline Provenience & Ceramics & Glass & Metal & Faunal & Other & Totals \\
\hline Surface & 2 & - & - & - & - & 2 \\
\hline \multicolumn{7}{|l|}{ TEST UNIT 1} \\
\hline $\begin{array}{l}\text { Level } 1(0-10 \mathrm{~cm}) \\
\text { Level } 2(10-20 \mathrm{~cm}) \\
\text { Level } 3(20-30 \mathrm{~cm}) \\
\text { Level } 4(30-40 \mathrm{~cm}) \\
\text { Level } 5(40-50 \mathrm{~cm}) \\
\text { Level } 6(50-60 \mathrm{~cm}) \\
\text { Level } 7(60-70 \mathrm{~cm})\end{array}$ & $\begin{array}{r}4 \\
11 \\
4 \\
5 \\
5 \\
4 \\
3\end{array}$ & $\begin{array}{r}14 \\
93 \\
38 \\
9 \\
5 \\
4 \\
-\end{array}$ & $\begin{array}{r}38 \\
104 \\
51 \\
2 \\
5 \\
3 \\
3\end{array}$ & $\begin{array}{r}- \\
23 \\
8 \\
7 \\
36 \\
14 \\
2\end{array}$ & $\begin{array}{l}1 \\
2 \\
- \\
- \\
- \\
- \\
-\end{array}$ & $\begin{array}{r}57 \\
233 \\
101 \\
23 \\
51 \\
25 \\
8\end{array}$ \\
\hline Subtotals & 36 & 163 & 206 & 90 & 3 & 498 \\
\hline \multicolumn{7}{|l|}{ TEST UNIT 2} \\
\hline $\begin{array}{l}\text { Level } 1(0-10 \mathrm{~cm}) \\
\text { Level } 2(10-20 \mathrm{~cm}) \\
\text { Level } 3(20-30 \mathrm{~cm})\end{array}$ & $\begin{array}{l}1 \\
- \\
-\end{array}$ & $\begin{array}{r}14 \\
13 \\
2\end{array}$ & $\begin{array}{l}- \\
- \\
-\end{array}$ & $\begin{array}{r}1 \\
14 \\
10\end{array}$ & $\begin{array}{l}- \\
- \\
-\end{array}$ & $\begin{array}{l}16 \\
27 \\
12\end{array}$ \\
\hline Subtotals & 1 & 29 & 0 & 25 & 0 & 55 \\
\hline \multicolumn{7}{|l|}{ TEST UNIT 3} \\
\hline $\begin{array}{l}\text { Level } 1(0-10 \mathrm{~cm}) \\
\text { Level } 2(10-20 \mathrm{~cm}) \\
\text { Level } 3(20-30 \mathrm{~cm})\end{array}$ & $\begin{array}{r}10 \\
4 \\
2\end{array}$ & $\begin{array}{r}21 \\
5 \\
-\end{array}$ & $\begin{array}{r}104 \\
1 \\
1\end{array}$ & $\begin{array}{l}1 \\
6 \\
2\end{array}$ & $\begin{array}{l}- \\
- \\
-\end{array}$ & $\begin{array}{r}136 \\
16 \\
5\end{array}$ \\
\hline Subtotals & 16 & 26 & 106 & 9 & 0 & 157 \\
\hline \multicolumn{7}{|l|}{ TEST UNIT 4} \\
\hline $\begin{array}{l}\text { Level } 1(0-10 \mathrm{~cm}) \\
\text { Level } 3(20-30 \mathrm{~cm}) \\
\text { Level } 4(30-40 \mathrm{~cm}) \\
\text { Level } 5(40-50 \mathrm{~cm}) \\
\text { Level } 6(50-60 \mathrm{~cm}) \\
\text { Level } 7(60-70 \mathrm{~cm}) \\
\text { Level } 8(70-80 \mathrm{~cm})\end{array}$ & $\begin{array}{l}- \\
- \\
- \\
1 \\
1 \\
- \\
-\end{array}$ & $\begin{array}{r}1 \\
- \\
- \\
16 \\
11 \\
3 \\
3\end{array}$ & $\begin{array}{r}- \\
6 \\
10 \\
25 \\
48 \\
5 \\
1\end{array}$ & $\begin{array}{l}- \\
- \\
- \\
- \\
- \\
- \\
-\end{array}$ & $\begin{array}{l}- \\
- \\
- \\
1 \\
- \\
- \\
1\end{array}$ & $\begin{array}{r}1 \\
6 \\
10 \\
43 \\
60 \\
8 \\
5\end{array}$ \\
\hline Subtotals & 2 & 34 & 95 & 0 & 2 & 133 \\
\hline \multicolumn{7}{|l|}{ TEST UNIT 5} \\
\hline $\begin{array}{l}\text { Level } 1(0-10 \mathrm{~cm}) \\
\text { Level } 2(10-20 \mathrm{~cm})\end{array}$ & $\begin{array}{l}4 \\
1\end{array}$ & $\begin{array}{l}184 \\
143\end{array}$ & $\begin{array}{l}210 \\
116\end{array}$ & $\overline{5}$ & $\begin{array}{l}4 \\
2\end{array}$ & $\begin{array}{l}402 \\
267\end{array}$ \\
\hline Subtotals & 5 & 327 & 326 & 5 & 6 & 669 \\
\hline \multicolumn{7}{|l|}{ TEST UNIT 6} \\
\hline $\begin{array}{l}\text { Level } 1(0-10 \mathrm{~cm}) \\
\text { Level } 2(10-20 \mathrm{~cm}) \\
\text { Level } 3(20-30 \mathrm{~cm}) \\
\text { Level } 4(30-40 \mathrm{~cm}) \\
\text { Level } 5(40-50 \mathrm{~cm}) \\
\text { Level } 6(50-60 \mathrm{~cm}) \\
\text { Level } 7(60-70 \mathrm{~cm})\end{array}$ & $\begin{array}{r}- \\
10 \\
9 \\
5 \\
3 \\
13 \\
1\end{array}$ & $\begin{array}{r}5 \\
50 \\
27 \\
12 \\
2 \\
4 \\
-\end{array}$ & $\begin{array}{r}4 \\
104 \\
65 \\
16 \\
18 \\
17 \\
1\end{array}$ & $\begin{array}{r}- \\
5 \\
20 \\
4 \\
19 \\
21 \\
2\end{array}$ & $\begin{array}{l}- \\
- \\
1 \\
- \\
- \\
- \\
-\end{array}$ & $\begin{array}{r}9 \\
169 \\
122 \\
37 \\
42 \\
55 \\
4\end{array}$ \\
\hline Subtotals & 41 & 100 & 225 & 71 & 1 & 438 \\
\hline TOTALS & 103 & 679 & 958 & 200 & 12 & 1,952 \\
\hline
\end{tabular}




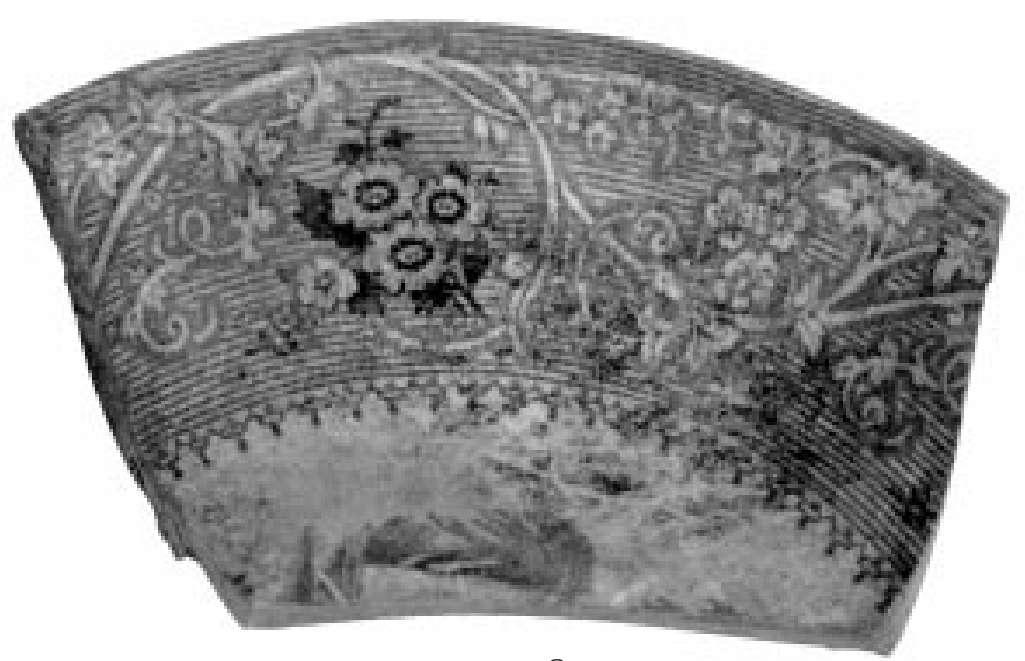

a

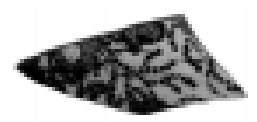

d

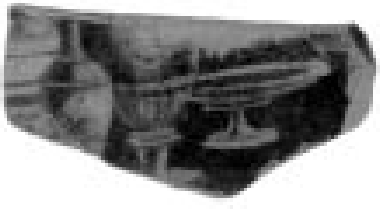

e

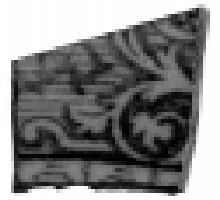

C

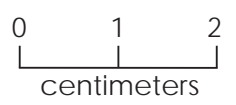

\section{b}

,
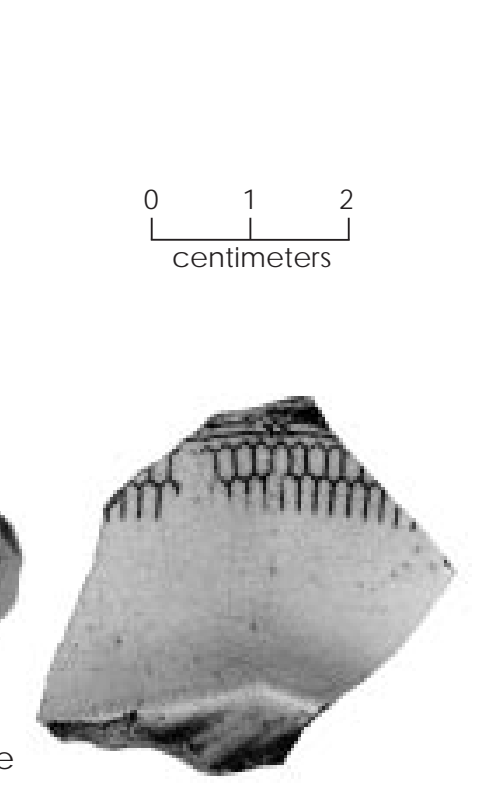

Figure 17. Transfer-printed ceramics from 41ML 140. (a) Columbia; (b) Florilla; (c) Lozere; (d) Sirius; (e) Colonna.

only a single exception, all stoneware sherds were recovered from Feature 5 . This probably correlates with a higher reliance on stoneware for the storage of preserved foodstuffs in the mid-nineteenth century, before the advent of readily available glass canning jars (Lebo 1987:121).

\section{Porcelain}

Only eight sherds of porcelain were recovered. All are bone china, a kind of soft-paste porcelain commonly manufactured in the nineteenth century and later (Majewski and O'Brien 1987:126-127). All but one of the bone china sherds were recovered from contexts other than Feature 5, perhaps reflecting the increasing availability and affordability of bone china over time.
Other Ceramics

The remainder of the ceramics assemblage consists of a porcelain doll, an industrial ceramic disk of unknown function, and an unrefined earthenware marble (possibly homemade).

\section{GLASS}

Glass artifacts recovered fall into five general categories: table glass $(n=20)$; kerosene lamp chimney glass $(n=25)$; container glass $(n=$ 254); window glass ( $n=212)$; and unidentified/ melted or other glass ( $n=168)$.

\section{Table Glass}

Table glass is defined as "glassware used on the table and associated with food and drink, 
as well as some items of decorative glassware, such as vases" (J ones and Sullivan 1989:127). The 20 sherds recovered consist of opaque white/milk glass $(n=6)$, lead glass $(n=8)$, clear/ colorless glass ( $n=4)$, and solarized glass $(n=$ 2). Of particular note is the lead glass tableware, most commonly found on sites predating 1860 (J ones and Sullivan 1989:12). All of the lead glass tableware sherds are from Feature 5 .

\section{Kerosene Lamp Chimney Glass}

Twenty-five sherds of glass from the chimney portion of kerosene lamps were recovered. Both lead glass $(n=8)$ and clear, nonlead glass $(n=17)$ specimens are represented. Although lead glass was replaced by soda lime glass in the 1860s for the manufacture of tableware, lead glass continued to be used for making lamp chimneys through thelatter portion of the nineteenth century and even into the early twentieth century (Woodhead et al. 1984:61).

\section{Container Glass}

A total of 254 sherds of container glass (primarily from bottles and jars) were recovered. Colors represented are aqua $(n=48)$, clear/colorless ( $n=162)$, brown $(n=28)$, solarized $(n=$ $4)$, blue $(n=3)$, green $(n=4)$, and olive $(n=5)$. Most of the colors are not diagnostic because of their extended use in container production. Exceptions are solarized glass, which was made primarily from ca. 1875 to 1914 (J ones and Sullivan 1989:13), and olive green glass, which became increasingly uncommon after the $1860 \mathrm{~s}$ (J ones 1986:10). All olive glass recovered from 41ML 140 came from Feature 5.

\section{Window Glass}

A total of 212 window glass sherds were recovered. Although window glass was present across the site, the greatest concentration occurred in association with Feature 6, which is interpreted as a collapsed chimney.

\section{Unidentified/Melted or Other Glass}

Of the 168 artifacts in this category, 2 represent canning jar lid liners, 1 made of clear glass and the other of opaque white glass. The rest of the artifacts are glass fragments that have been melted or otherwise distorted by fire so that identification beyond material type is impossible.

\section{METAL}

Metal artifacts constitutethe largest group of artifacts recovered. Artifact types consist of door hardware $(n=2)$, cut nails $(n=561)$, wire nails ( $n=187)$, screws $(n=4)$, wire $(n=19)$, fencing staples $(n=19)$, tin can fragments $(n=$ 20), clothing fasteners $(n=4)$, ammunition ( $n=$ $7)$, unidentified metal $(n=108)$, and miscellaneous metal $(n=27)$.

\section{Door Hardware}

Both a hinge and portion of a metal doorknob were recovered. These relate to doors that were part of the house, or perhaps to furniture items (such as hutches, cupboards, etc.) that might have served as furnishings inside the house.

\section{Cut Nails}

Of the fasteners used in constructing the house at $41 \mathrm{ML} 140$, cut nails $(n=561)$ represent the most common type. I nitial occupation of the property reportedly took place in 1851, and it is likely that the initial episode of construction took place at that time. Additional construction also probably occurred after Duncan MCLennan acquired the property in 1868. The presence of cut nails in large numbers is consistent with this.

\section{Wire Nails}

In comparison, only 187 wire nails were recovered from the site. They most probably represent later expansion and repairs to the existing structure under the ownership of Duncan McLennan.

Screws

Four pointed-tip wood screws were recovered, all associated with the upper $30 \mathrm{~cm}$ of Feature 5. Such screws could have been used either in construction of the house or as fasteners for furniture or other items. 
Wire

Wire fragments ( $n=19)$ of a variety of types and gauges (including plain and barbed) were recovered. Used for a multitude of tasks on a farm, wire would have been used heavily in the late nineteenth century, and later, for fencing off the house and yard from cultivation and livestock areas.

\section{Fencing Staples}

Directly related to the use of wire for fencing are staples to secure wire to vertical support posts. Nineteen fencing staples were recovered, with a fairly tight correlation be tween the horizontal distribution of wire fragments and fencing staples.

\section{Tin Can Fragments}

A fairly small number $(n=20)$ of identifiabletin can fragments were recovered. All came from deposits no deeper than $30 \mathrm{~cm}$. The surprisingly small number of tin can fragments, usually copious in sites occupied in the late nineteenth century, suggests that dumping of bulk refuse might have taken place at a location away from the main habitation.

\section{Clothing Fasteners}

Four metal clothing fasteners were recovered from Lev!el 2 of Test Unit 6 in Feature 5. All are components from overalls and consist of a slide buckle, two rivets, and a metal button/rivet face stamped "TEN WHEELER."

\section{Ammunition}

Seven fragments of ammunition were re covered, with a widely dispersed horizontal distribution pattern. Ammunition types include both shotgun shell heads and metal cartridge casings.

All shotgun shell heads have manufacturers' marks. The three recovered are: Winchester Ranger 16 gauge, which is a twentieth-century type; Peters High Velocity 16 gauge, 1897-1935; and Union Metallic Cartridge Company New Club 10 gauge, ca. 1936 (Vinson 1968:91-93). A singlebrass .410 Remington Express casing was recovered as well. Two .22-caliber short car- tridges manufactured by the U nion Metallic Cartridge Company after 1885 were recovered, as was one Super $X$.22-caliber short cartridge manufactured by the Western Cartridge Company, postdating 1927 (Barber 1987:48, 86).

\section{Unidentified Metal}

Artifacts identifiable to material type (ferrous metal) only and for which no functional identifications are possible are assigned to the category of unidentified metal $(n=108)$. Although distributed widely both horizontally and vertically, the largest concentration of unidentified metal $(n=29)$ was in Level 6 of Test Unit 4 in Feature 4, which is interpreted as a push pile of rubble.

\section{Miscellaneous Metal}

Metal artifacts that are identifiable functionally but do not fit easily into any of the other established categories are classed as miscellaneous metal $(n=27)$. These are a can key, buckles $(n=2)$, a lead fragment, a bayonet, fragments of zinc canning jar lid $(n=6)$, a cotter pin, bottle caps $(n=3)$, a horse bit, a ferrule, a gear, a corkscrew, a bol t lock fastener, a metal brace, fragments of window screen $(n=2)$, an eye hook, a pocket knife blade, a handle, and a farm implement part.

\section{MISCELLANEOUS ARTIFACTS}

Artifacts that are identifiable in material and/or function but do not fit easily into any of the other established categories are classed as miscellaneous ( $n=212$ ). This category contains a charcoal pencil, vertebrate faunal remains $(n=$ 183), invertebrate faunal remains ( $n=17)$, mortar fragments $(n=3)$, buttons $(n=2)$, and miscellaneous materials $(n=6)$.

\section{Charcoal Pencil}

A single fragment of a charcoal pencil was recovered from Level 1 of Test Unit 5.

\section{Vertebrate Faunal Remains}

Although bones were recovered from across the entire site area, vertebrate faunal remains 
( $n=183$ ) were concentrated in Test U nits 1 and 6 in Feature 5. I dentified taxa are Vertebrata (vertebrates, $n=24$ ), Bufo sp. (toads, $n=1$ ), Aves (duck/turkey-sized, $\mathrm{n}=3$ ), Mammalia (canid/ deer-sized, $\mathrm{n}=102$ ), Mammalia (deer/bisonsized, $n=24$ ), Artiodactyla (goat/deer-sized, $n=$ 2), Sus scrofa (pig, $n=25$ ), Bos/ Bison (cow/bison, $\mathrm{n}=1$ ), and Ovis/ Capra (sheep/goat, $\mathrm{n}=1$ ) (seeAppendix C). The 144 bones recovered from Feature 5 probably represent food remains.

\section{Invertebrate Faunal Remains}

None of the 17 shell fragments collected are sufficient for taxonomic identification (see Appendix B). Although they are exclusively from Feature 5, few conclusions can be drawn about their presence.

\section{Mortar}

Three fragments of mortar were collected as samples.

\section{Buttons}

Two shell sew-through-type buttons are in the assemblage.

\section{Miscellaneous Materials}

A small number $(n=6)$ of other materials were recovered. Although most are cultural, they are not historic or otherwise related to the historic occupations at 41ML 140. They are a mud dauber nest, debitage $(n=3)$, a plywood fragment, and a piece of asphalt.

\section{Chronology and Components}

The chronol ogy for 41ML 140 is based on the artifacts recovered, the features documented, and archival evidence of activity on the property. Two primary components are present at the site. The earlier component is defined most certainly by thelower part of Feature 5 (a refuse disposal area), and perhaps by Feature 1 (a cistern/well) and Feature 2 (a chimney foundation). Based on the strong correlation between the archivally documented occupation by George Erath (ca. 1850-1868) and the manufacture date range (ca. 1828-1867) of the transferprinted ceramics recovered from Feature 5, the early component clearly is associated with Erath's activities.

The surface manifestati on of Feature 5 appeared to be a late-nineteenth-century rubble mound with little indication that it was associated with an early occupation. U pon investigation, however, it appears that the area had been established early as a dumping locale and continued to function as such. Within the feature, an ash and charcoal deposit with faunal materials and mid-nineteenth-century artifacts was encountered. The upper perimeter of this refuse pit was obscured, perhaps by a lack of contrast with surrounding soils and continued later use for trash disposal. The bottom part of this feature appears to represent the most direct and undisturbed evidence of Erath's activity at 41ML 140.

The later historic component dates to the period of purchase in 1868 and subsequent use by Duncan MCLennan and presumably tenants of Nannie Sinclair. This activity is represented by Feature 4 (a push pile), Feature 6 (collapsed chimney), and the two unnumbered features (a privy and a metal water tank with associated foundation). Based on the construction materials in the surface features, the surface artifacts, and the artifacts recover ed from excavation, the secondary component dates from the late nineteenth century (ca. 1870s) until the early twentieth century (1920s) and later. The house and outbuildings were expanded and updated, as evidenced by the presence of bricks, concrete, galvanized metal, and wire nails among the construction debris.

While most of the features can be associated with one or another of the two components, it is difficult to get a clear picture of the layout of the house and immediately surrounding area for either component. This is because few intact features directly related to the house (e.g., chimney bases and foundation footings) survived clearing activities that presumably accompanied Corps acquisition of thesite in 1962. The report on the 1984 survey during which the site was recorded (Prikryl and J ackson 1985:33) includes an artist's reconstruction of the house based on a photograph in a 1954 volume on historic log cabins in McLennan County, but it is impossible to correlate the archeological features with elements shown on this depiction, which indicates a large Lor T-plan house with three chimneys. 
Chapter 4: Results of Test Excavations

F urther, the documented features represent a small portion of what must have been much larger agricultural complexes. The various components related to crop and livestock production, particularly outbuildings and the domestic quarters for Erath's slaves, are not represented at this site. Only the simplest of activities can be interpreted from these features. The remains of Erath's original home and later additions to it are present, as are two water sources and a refuse pit. Artifact recovery indicates the use and discard of a common assortment of domestic goods, including table ceramics and container glass, as well as the cooking and consumption of domestic and wild animals. Beyond these simple conclusions, however, little can be said.

\section{Summary and Assessment}

Site $41 M L 140$ is the location of the housesite occupied by George Erath (18501868) and Duncan McLennan (1868-1930) and probably subsequently by tenants of Nannie Sinclair. It has at least eight cultural features and numerous artifacts associated with this occupation span. However, only part of one investigated feature (a trash disposal area) yielded intact, archeologically important, midnineteenth-century deposits of artifacts and faunal remains. Approximately two-thirds of this feature was excavated during testing, leaving little potential for it to yield additional information. Elsewhere on the site, the cultural materials representing the various occupations are mixed together, offering little opportunity to isolate early assemblages that could contribute important information. The features provide limited information on the general layout of the immediate house area, and 41ML 140 represents only the core habitation; the larger plantation/farming complex of which the residence was a part remains unidentified archeologically and perhaps is partly under the waters of Waco Lake. Hence, 41ML 140 has little capacity to contribute important information concerning the use of space and activity areas. The sparseness of contexts containing isolable early assemblages and the inability to address issues related to overall plantation/farmstead layout render the site ineligible for $\mathrm{N}$ ational Register listing under Criterion D.

\section{Site 41ML 160}

\section{Description}

Site 41ML 160 is a deeply buried prehistoric site on the southwestern bank of the North B osque River near the upper end of Waco L ake (see Figure 4). It is situated within Holocene terrace deposits, with cultural materials recorded at elevations of 458 to $467 \mathrm{ft}$. A flood chute cuts east-west across the terrace south of the site. Oak, elm, and pecan trees dominate the vegetation in the area, with a dense understory consisting of junipers, greenbriers, and shrubs.

\section{Previous Investigations}

Site $41 M L 160$ was recorded in 1984, at which time the lake level was lower than normal at $450 \mathrm{ft}$ (Prikryl and J ackson 1985:87-91, 209-210). Initial investigations included inspection of a 120 -m segment of the cutbank, where 20-25 mussel shells, 5- 10 burned rocks, 2 pieces of debitage, and a few animal bones were observed at various depths between 1.0 and $5.0 \mathrm{~m}$ bel ow the surface in the 6-m-high cutbank. One mussel shell fragment with an intentionally modified edge was collected, as was a bone fragment identified as a thoracic vertebra of a deer. Subsequent investigations included the cleaning and profiling of a 2-m-wide and 2-m-high section of the cutbank in a location where at least 1-2 $\mathrm{m}$ of the upper deposits had been lost to slumping. Two stratigraphic zones were identified in this profile. The upper one extended to $1.3 \mathrm{~m}$ bel ow the top of the profile and consisted of grayish brown silty clay loam, with a lens of mussel shells and charcoal flecks at 1.0-1.1 m below the top of the profile. It was separated from the lower zone, consisting of culturally sterile alternating deposits of grayish brown clayey silt and light brown sandy silt, by 2-8 cm of oxidized organic clay that also appeared to be culturally sterile. The oxidized lens was found about $3.7 \mathrm{~m}$ below the ground surface.

Site 41ML 160 was revisited by boat in 1999 as part of a site re-location and reassessment effort (Kvernes et al. 2000:53-54). I nvestigation was limited to inspection of $150 \mathrm{~m}$ of the cutbank exposure; no shovel tests were excavated because of the depth of the cultural deposits. The lake level was $455 \mathrm{ft}$, and the ex- 
posed cutbank extended about $4.5 \mathrm{~m}$ above the water. It was noted that slumping of the cutbank had continued since 1984. Burned rocks, mussel shells, and bones were observed in the cutbank at a depth of approximately $3 \mathrm{~m}$ below thesurface. Thetwo natural stratigraphic zones recorded in 1984 were visible with some discoloration to the lower zone, probably because of the fluctuating lake level.

\section{Work Accomplished}

During the 2000-2001 investigations, a long rebar stake was used as the primary datum and was given an arbitrary elevation of $100.00 \mathrm{~m}$. The datum was placed ca. $12 \mathrm{~m}$ east of the cutbank edge and ca. $5 \mathrm{~m}$ northeast of Trench 2. A second datum (rebar) was placed near a large oak tree in the northern area of the site ca. 2.5 m east of Trench 4 .

Fivetrackhoe trenches were excavated ( $F$ igure 18). Trench 1 was placed at the southern end of the site area near the upstream end of the flood chute and close to the lake edge. It measured $8.2 \times 2.8 \times 3.8 \mathrm{~m}$ and was aligned at $284^{\circ}$. Mussel shells were noted in the south wall at $215 \mathrm{~cm}$, while charcoal was observed at ca. $385 \mathrm{~cm}$. Trench 2 , oriented to $274^{\circ}$ and placed $12 \mathrm{~m}$ north of Trench 1 , displayed no observable cultural materials. This trench measured $8.3 \times 2.9 \times 4.2 \mathrm{~m}$. Trench 3, excavated in the central part of the site area, was oriented to $282^{\circ}$ and measured $8.0 \times 2.7 \times 4.2 \mathrm{~m}$. Burned rocks and mussel shells were observed in the south wall at $270 \mathrm{~cm}$. A thin gravel lens was present at $286 \mathrm{~cm}$. Trench 4 was excavated ca. $20 \mathrm{~m}$ north of Trench 3. It measured $7.7 \times 3.1 \times 4.5 \mathrm{~m}$ and was oriented at $302^{\circ}$. A single burned rock was discovered in the wall at $260 \mathrm{~cm}$. Finally, Trench 5, aligned at $314^{\circ}$ and measuring 8.3 $\times 3.3 \times 4.2 \mathrm{~m}$, encountered no cultural materials. This trench was situated ca. $25 \mathrm{~m}$ northeast of Trench 4.

Four test units were hand excavated. Test Units 1 and 2 were on the south side of Trench 1 . These units went from the modern ground surface to deep into the alluvial deposits. Excavations were terminated at Level $35(350 \mathrm{~cm})$. Test Units 3 and 4 were on the south side safety bench of Trench 3. Thefirst levels in these units began $130 \mathrm{~cm}$ below the modern ground surface, and the excavations ceased at Level $22(350 \mathrm{~cm})$. In total, $11.4 \mathrm{~m}^{3}$ of fill were excavated.

\section{Site Extent and Depth}

Site 41ML 160 originally was recorded by boat survey in 1984 (Prikryl and J ackson 1985:87-91, 209-210). Cultural materials (bones, debitage, and burned rocks) were observed at various depths $(1.0-5.0 \mathrm{~m})$ along a ca. 120-m stretch of cutbank of the North B osque River. Subsequent investigations found a shorter stretch of the cutbank intact because slumping had occurred since 1984. These investigations also noted cultural materials at $3 \mathrm{~m}$ below the ground surface in the cutbank (K vernes et al. 2000:53-54). Trenching in 20002001 covered an area ca. $80 \mathrm{~m}$ in length adjacent to the cutbank. Deeply buried cultural materials were restricted to the southern ca. $55 \mathrm{~m}$ of this area. Testing recovered cultural materials, mainly lithic debitage, from depths of 260 to $330 \mathrm{~cm}$. Although no lithic materials were encountered deeper than $330 \mathrm{~cm}$, mussel shells were collected from 330 to $350 \mathrm{~cm}$.

\section{Sediments and Stratigraphy}

The sediments and stratigraphy at 41ML 160 were examined through the profiles of five trenches and descriptions of the soil stratigraphy of three of the trench profiles (see Appendix A). The site is located on the inside of a meander and situated on a Holocene alluvial terrace that stands ca. 4-5 $\mathrm{m}$ above the North Bosque channel. A flood chute, which diverts floodwaters from the channel bypassing the meander loop, cuts across the terrace surface isolating thesiteand terracefrom thelarger broad terrace that flanks the channel in this part of the North Bosque River valley. Soils on the terrace surface bel ong to the Catal pa series (Templin et al. 1958). Catalpa soils are calcareous grayish brown to dark grayish brown clay loam to clayey soils formed on recent alluvium.

Thealluvial deposits composing the terrace consist of fine-grained point bar facies and overbank sediments (Figure 19). The terrace surface is mantled by very recent alluvial sediments that are pedogenically unaltered. This deposit ranges from $27 \mathrm{~cm}$ thick in Trench 3 to $32 \mathrm{~cm}$ thick in Trench 5 and consists of alternating horizontal beds and laminae of pale brown fine to medium sand and grayish brown to dark gray mud. Along the terrace edge at the southern end of the site, this deposit has been 


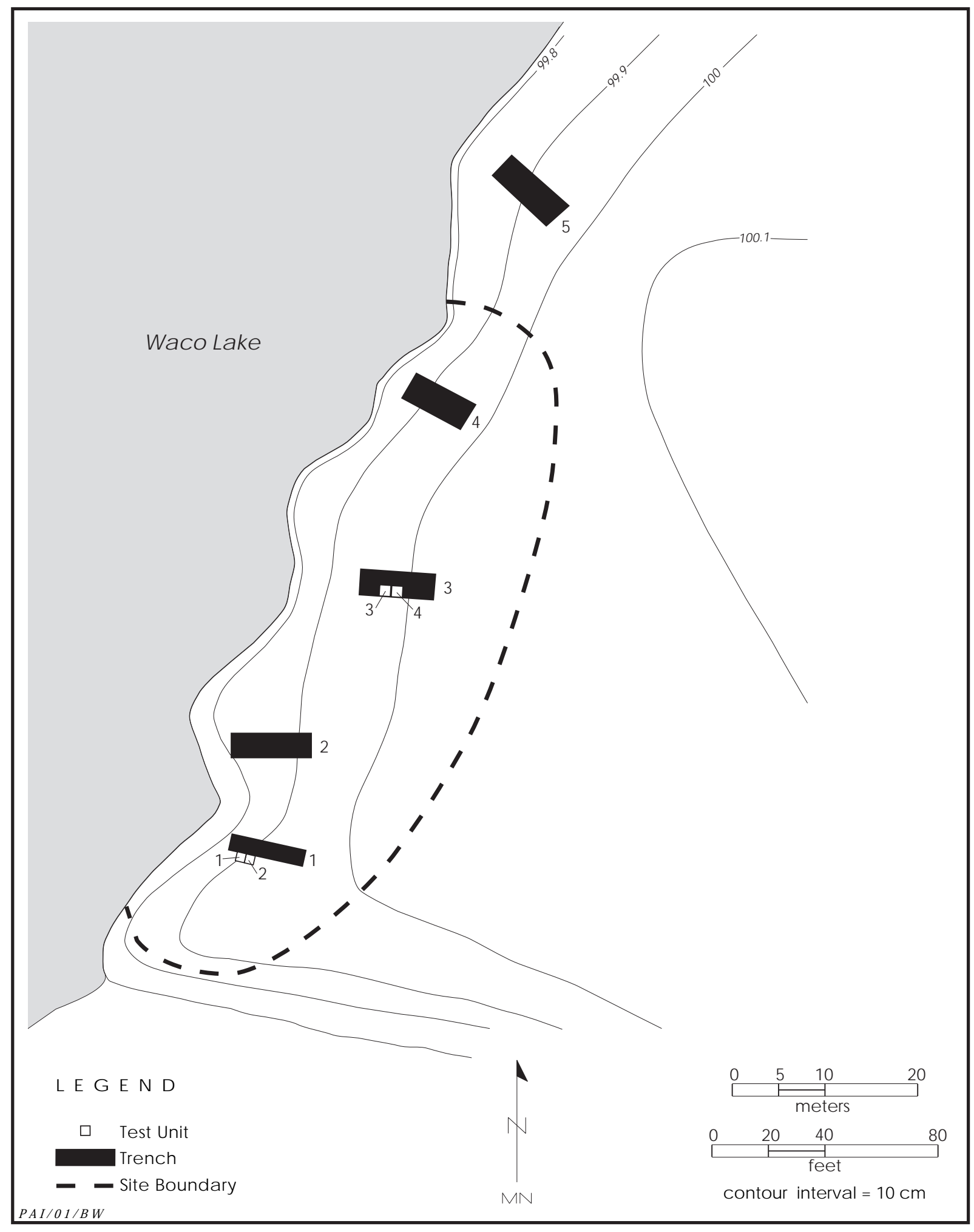

Figure 18. Map of 41ML 160. 


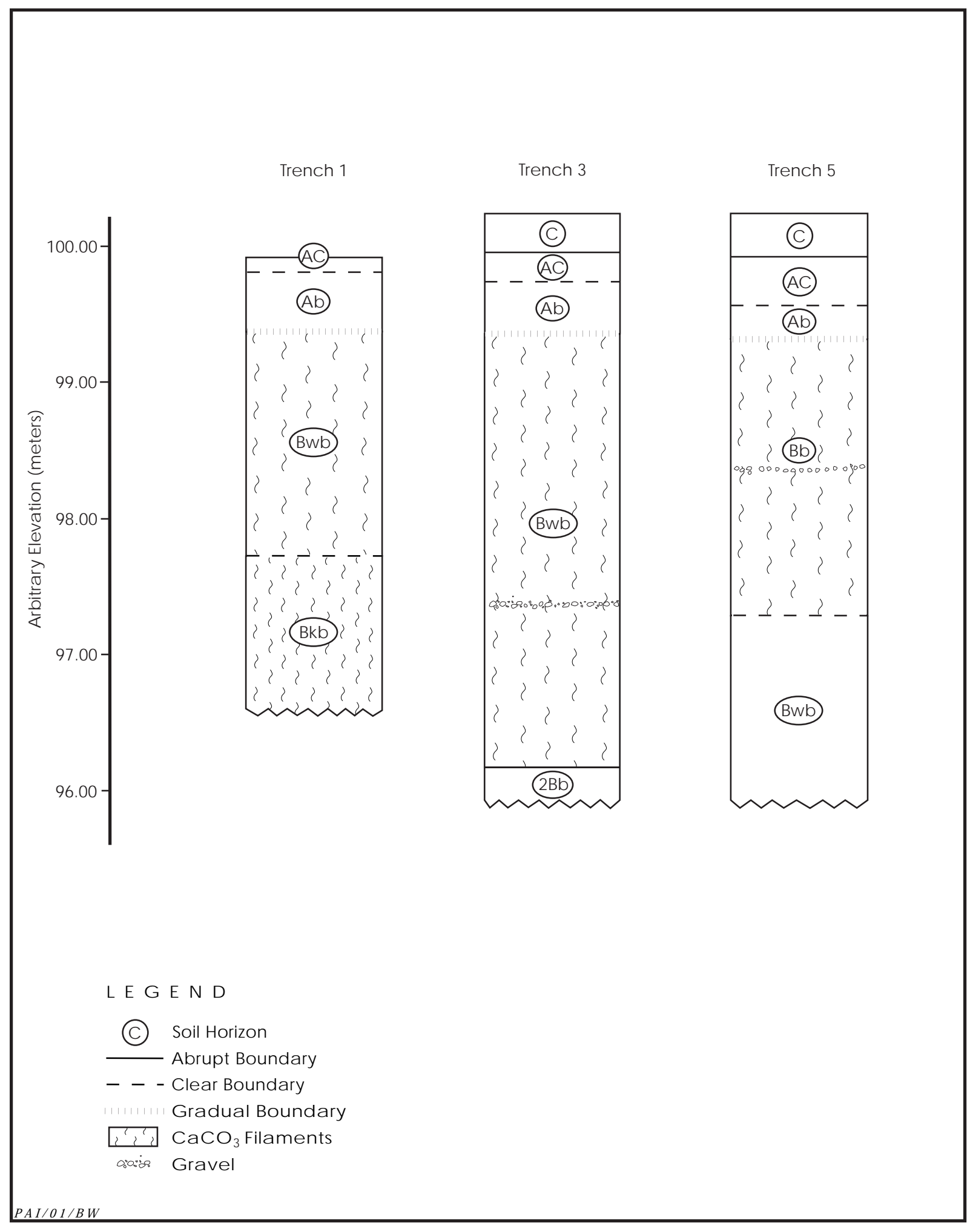

Figure 19. Profiles of Trenches 1, 3, and 5, 41ML 160. 
removed by erosion (see Figure 19, Trench 1 profile). Underlying the recent alluvial mantle is a thin $(11-36 \mathrm{~cm})$ bed of grayish brown to dark grayish brown silty clay loam to finesandy clay loam alluvium. This deposit is imprinted with a weak soil (AC horizon) and contains a few poorly preserved beds and laminae of sand and mud, suggesting that this deposit also is recent in age and probably dates to the historic period. This deposit mantles what is believed to be the presettlement or prehistoric terrace surface. The prehistoric alluvial deposits are composed of fine-grained point bar facies with rare gravel stringers (chute gravels). Based on the degree of soil development imprinted on these alluvial deposits, it is estimated that the sediments are late Holocene in age. The profile of Trench 3 is typical of the profiles observed and examined at the site. It displays an Ab-Bwb$2 \mathrm{Bb}$ soil profile. The $\mathrm{Ab}$ horizon $(50-86 \mathrm{~cm})$ is a very dark grayish brown silty clay loam. The Bwb horizon $(86-406 \mathrm{~cm})$ is a prismatic-structured brown silt loam with a thin bed of coarse to very coarse sand and gravel at $286 \mathrm{~cm}$. A very abrupt boundary separates the Bwb horizon from the $2 \mathrm{Bb}$ horizon $(406-420+\mathrm{cm})$. The $2 \mathrm{Bb}$ horizon is a brown clay loam with common reddish yellow mottles. The upper boundary, color, and mottling of this soil horizon suggest that it represents a separate stratigraphic unit and may predate the late $\mathrm{Hol}$ ocene.

\section{Cultural Feature}

One feature was encountered during testing. Feature 1, which was found in Test U nit 3, Levels 18-19 (304-313 cm), consists of burned or oxidized soil, charcoal, bone fragments, and burned rocks. The excavated portion measures about $70 \mathrm{~cm}$ north-south by $80 \mathrm{~cm}$ east-west; because it extends into the west and south walls of the unit, its full extent is unknown (Figure 20). Thethickness of the feature varies from 5 to $6 \mathrm{~cm}$, and its base is irregularly shaped in cross section.

N umerous bone fragments, 2 burned rocks, and charcoal were found in the feature. Two charcoal samples were collected from the same level-onefrom inside the featureand one from outside. The larger of the samples was submitted for radiocarbon assay but did not yield a sufficient amount of final carbon for dating. A few of the bone fragments show evidence of burning. Twoflakes werefound in association with thefeaturein theremaining test unit fill. Approximately 30.8 liters of sediment werecoll lected from the feature. Nine pieces of microdebitage and 21 bone fragments were recovered during flotation (see Materials Recovered).

The oxidized sediment and the presence of charcoal and burned bones suggest that the feature is a hearth. The feature likely represents a hearth on an unprepared surface, as evidenced by the lack of abundant burned rocks and pit or basin.

\section{Materials Recovered}

Twenty-six chipped stone artifacts, 44 invertebrate faunal remains, and 114 vertebrate faunal specimens were recovered from the hand excavations at 41ML160 (Table 3). Other materials consist of burned rocks, which were observed during excavation but not collected.

\section{CHIPPED STONE ARTIFACTS}

Of the 26 chipped stone artifacts, 25 are unmodified pieces of lithic debitage and 1 is an edge-modified flake.

\section{Unmodified Debitage}

The unmodified debitage consists of 52 percent $(n=13)$ complete flakes, 12 percent $(n=3)$ proximal flakes, 20 percent $(n=5)$ chips, and 16 percent $(n=4)$ chunks. Cortex is present on 3 of the specimens ( $2-5 \mathrm{~cm}$ maximum size), none of which are chunks. The majority of the flakes are small with 36 percent $(n=9)$ of the assemblage less than $1 \mathrm{~cm}$ in size. All of these specimens were recovered from flotation of Feature 1 fill. The remaining assemblage has 10 specimens $1-3 \mathrm{~cm}$ in size and 6 specimens $3-5 \mathrm{~cm}$ in size. Raw material varies from a light gray chert with white mottles to dark gray and light and dark brown cherts.

\section{Edge-modified Debitage}

The single edge-modified flake has two modified edges and a maximum dimension of 5-6 cm. Categorized as a proximal flake fragment, cortex is present on its dorsal side. The cortex is brown while the interior chert color is a dark mottled gray. 
National Register Testing of NineArcheol ogical Sites at Waco Lake

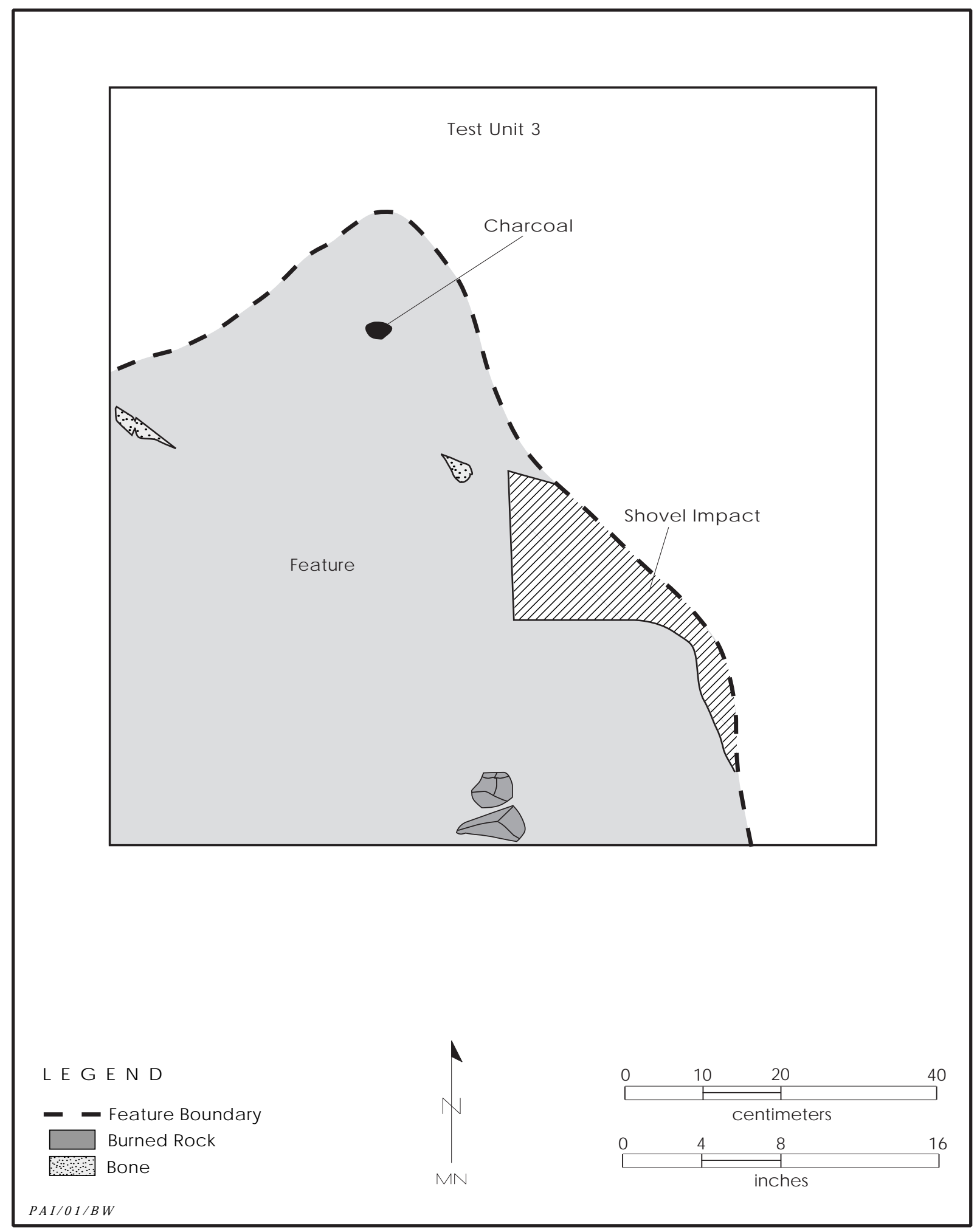

Figure 20. Plan of Feature 1, 41ML160. 
Table 3. Summary of cultural materials from 41ML160

\begin{tabular}{|c|c|c|c|c|c|}
\hline Provenience & $\begin{array}{c}\text { Edge-modified } \\
\text { Debitage }\end{array}$ & $\begin{array}{c}\text { Unmodified } \\
\text { Debitage }\end{array}$ & $\begin{array}{c}\text { Unmodified } \\
\text { Bones }\end{array}$ & $\begin{array}{c}\text { Unmodified } \\
\text { Mussel Shells }\end{array}$ & Totals \\
\hline \multicolumn{6}{|l|}{ TEST UNIT 1} \\
\hline Level $5(40-50 \mathrm{~cm})$ & _- & _- & - & 1 & 1 \\
\hline Level $10(90-100 \mathrm{~cm})$ & - & - & - & 2 & 2 \\
\hline Level $18(170-180 \mathrm{~cm}))$ & - & - & - & 1 & 1 \\
\hline Level $22(210-220 \mathrm{~cm})$ & - & - & - & 1 & 1 \\
\hline Level $27(260-270 \mathrm{~cm})$ & - & 1 & - & 2 & 3 \\
\hline Level $30(290-300 \mathrm{~cm})$ & - & - & - & 1 & 1 \\
\hline Level 34 (330-340 cm) & - & - & - & 3 & 3 \\
\hline Subtotals & 0 & 1 & 0 & 11 & 12 \\
\hline \multicolumn{6}{|l|}{ TEST UNIT 2} \\
\hline Level $32(310-320 \mathrm{~cm})$ & - & - & - & 2 & 2 \\
\hline Level $33(320-330 \mathrm{~cm})$ & - & 1 & - & - & 1 \\
\hline Subtotals & 0 & 1 & 0 & 2 & 3 \\
\hline \multicolumn{6}{|l|}{ TEST UNIT 3} \\
\hline Level $12(240-250 \mathrm{~cm})$ & - & - & - & 1 & 1 \\
\hline Level $14(260-270 \mathrm{~cm})$ & 1 & 4 & - & 4 & 9 \\
\hline Level $15(270-280 \mathrm{~cm})$ & - & 1 & - & 2 & 3 \\
\hline Level 16 (280-290 cm) & - & - & - & 2 & 2 \\
\hline Level $17(290-300 \mathrm{~cm})$ & - & 1 & - & - & 1 \\
\hline Level $18(300-310 \mathrm{~cm})$ & - & 2 & 33 & - & 35 \\
\hline F eature $1(304-313 \mathrm{~cm})$ & - & 9 & 27 & - & $36 *$ \\
\hline Level $21(330-340 \mathrm{~cm})$ & - & - & - & 3 & 3 \\
\hline Subtotals & 1 & 17 & 60 & 12 & 90 \\
\hline \multicolumn{6}{|l|}{ TEST UNIT 4} \\
\hline Level 5 (170-180 cm) & - & - & - & 1 & 1 \\
\hline Level $14(260-270 \mathrm{~cm})$ & - & 3 & - & 7 & 10 \\
\hline Level $15(270-280 \mathrm{~cm})$ & - & 1 & - & 1 & 2 \\
\hline Level $16(280-290 \mathrm{~cm})$ & - & 1 & - & 4 & 5 \\
\hline Level $18(300-310 \mathrm{~cm})$ & - & 1 & 54 & - & 55 \\
\hline Level $20(320-330 \mathrm{~cm})$ & - & - & - & 4 & 4 \\
\hline Level 21 (330-340 cm) & - & - & - & 1 & 1 \\
\hline Level $22(340-350 \mathrm{~cm})$ & - & - & - & 1 & 1 \\
\hline Subtotals & 0 & 6 & 54 & 19 & 79 \\
\hline TOTALS & 1 & 25 & 114 & 44 & 184 \\
\hline
\end{tabular}

* Nine pieces of debitage and 21 of the 27 bones were recovered from flotation processing.

INVERTEBRATE FAUNAL REMAINS

Thirty of the 44 mussel shells could be identified taxonomically (seeAppendix B). The taxa include Amblema plicata, Cyrtonaias tampicoensis, Leptodea fragilis, Quadrula petrina, Quadrula sp., and Tritogonia verrucosa.
The species A. plicata (threeridge mussel) is the most common taxon identified.

\section{VERTEBRATE FAUNAL REMAINS}

Bone preservation at $41 M L 160$ is good. All 114 bone specimens are from Test U nits 3 and 
4; of these, 93 were analyzed (see Appendix C). The remaining 21 bone fragments were retrieved during flotation processing. While none were included in the taxonomic analysis, general observations were made. The specimens range in size from 0.5 to $3.0 \mathrm{~cm}$, and 11 of the 21 are burned.

Although no species are identifiable in the vertebrate assemblage, 7 specimens were identified as Artiodactyla (medium- or goat/deersized). The remaining fragments are medium-sized to large (canid/deer-sized) Mammalia $(n=75)$ or Vertebrata $(n=11)$. Thirteen percent $(n=12)$ of the specimens are charred or calcined. Based on the quantity of medium to large mammal remains, it is likely that most of the faunal assemblage is made up of deer.

\section{OTHER MATERIALS}

Approximately 15 burned rocks were observed during hand excavations. Test Units 1 and 2 encountered ca. 4 small rocks, which in total weighed less than $1 \mathrm{~kg}$. Test U nits 3 and 4 contained ca. 11 burned rocks; these rocks collectively weighed ca. $2 \mathrm{~kg}$. Two of the rocks were found in situ within Feature 1.

\section{Chronology and Components}

One component is defined at the site by a small group of artifacts and a feature. The exact age of the component is unknown, since no diagnostics were recovered and the carbon submitted for dating was too small. The component is estimated to date to the early half of the $L$ ate Archaic period because the associated artifacts and feature occur between 260 and $330 \mathrm{~cm}$ in late Holocene alluvium.

The 70-cm-thick cultural zone yielded 26 chipped stone artifacts, 29 invertebrate faunal specimens, 114 vertebrate faunal remains, and Feature 1 (an unprepared heating/cooking surface). Based on analysis of the materials recovered, little interpretation of behaviors or activities during site occupation can be drawn. It does appear, however, that late bifacial reduction activities were performed, as evidenced by the sparseness of flakes with cortex. F urthermore, tool resharpening or expedient tool usage is suggested by the recovery of small pieces of debitage from Feature 1. Finally, with the recovery of numerous possible deer bone frag- ments both in and around Feature 1, it appears that activities such as large game processing and cooking took place. Site 41ML 160, therefore, may represent a short-term, specialized activity site (i.e., hunting camp).

\section{Summary and Assessment}

Site 41ML 160 is a deeply buried prehistoric site situated on the east bank of the North Bosque River. A total of 184 cultural materials-lithics, bones, and mussel shells-were collected. One hearth feature was encountered. Unfortunately, carbonized materials are sparse. While cultural materials are sparse, the site does appear to have a discrete occupation with good contextual integrity, probably dating to the early part of the Late Archaic period. Organic materials, particularly faunal remains, are well preserved. Based on these factors, it is believed the site has the potential to yiel d important data and should be considered eligible for National Register listing.

\section{Site 41ML 162}

\section{Description}

Site 41ML 162 is a multicomponent prehistoric site with stratified cultural deposits. It is situated in Holocene alluvial and colluvial deposits ca. $85 \mathrm{~m}$ south of the south bank of the North Bosque River arm of the lake (see Figure 4). The Holocene terrace surface rises from an elevation of ca. $458 \mathrm{ft}$ along the lakeshore to ca. $470 \mathrm{ft}$ on a rise at the southern valley wall, where colluvium from the adjacent slopes to the south appears to be present. Two intermittent tributaries to the N orth B osque mark the western and eastern boundaries of the site. A moderately dense forest of oak, elm, pecan, and hackberry trees covers the site area, in addition to a thick understory of greenbriers and poison oaks.

\section{Previous Investigations}

Site 41ML 162 was recorded and tested in 1984 (Prikryl and J ackson 1985:82-87, 211213). Cultural materials noted on the surface included sparse burned rocks, mussel shells, and debitage exposed in animal burrows and tree throws. Subsurface investigations consisted of 
three shovel tests and a single $1 \times 2-m$ test pit. Shovel Test 1, excavated to $35 \mathrm{~cm}$, was on the rise near the base of the upland slope. The sediments consisted of dark brown organically stained clay loam containing midden deposits with burned rocks, mussel shells, charcoal, bones, and a conch columella shell bead. Shovel Test 2 was ca. 10 m north of Shovel Test 1, doser to the river but still on the rise at the base of the upland slope. The first $30 \mathrm{~cm}$ of this test contained sterile clay loam. Below this to a depth of at least $60 \mathrm{~cm}$ were midden deposits similar to those in the first test. The third test was ca. $10 \mathrm{~m}$ farther downslope, on the Hol ocene terrace proper. The test was excavated through $40 \mathrm{~cm}$ of culturally sterileclay loam into a limestone gravel deposit at least $15 \mathrm{~m}$ thick.

Because no cutbanks were available for inspection, a test pit was excavated to explore the possibility of deeply buried components. This unit was 8-10 m west of Shovel Tests 2 and 3. The northern half was dug to a depth of $150 \mathrm{~cm}$, while the southern half reached a depth of $210 \mathrm{~cm}$. It was removed in 30-cm levels, with 25-75 percent of the fill screened to recover cultural materials.

Nine stratigraphic zones were identified, with the density of cultural debris being greatest in Zone 6 (for a more-detailed presentation of the stratigraphy, see Prikryl and J ackson [1985:82-87, 211-213]). The cultural deposit in Zone 6 contained burned rocks, mussel shells, bones, chipped stone debitage and tools, burned clay, charcoal, and two Late Archaic diagnostics (a Marcos dart point and an Erath biface). Part of this deposit, recorded as Zone 6a, consisted of a concentration of burned rocks along with a very high density of mussel shells, bones, charcoal, and debitage; it was interpreted as the edge of a midden or hearth area.

Site 41ML 162 was revisited in 1999 as part of a site re-location and reassessment effort (Kvernes et al. 2000:55-56). The small inlet recorded in 1984 as the western boundary of the site was easily relocated, as was a fence line near the eastern edge of the site. Surface visibility was extremely poor, and poison oaks, fallen trees, and leaf litter made surface inspection for cultural materials impossible. Two shovel tests were excavated at the southern end of the site on the rise at the base of the upland slope between elevations of ca. 460 and $470 \mathrm{ft}$. Shovel Test 99-1 was excavated in 20-cm levels to a depth of $40 \mathrm{~cm}$. Level 1, composed of a dark brown clay loam with 2-cm-diameter limestone rocks, produced only mussel shell fragments. Level 2 yiel ded a similar soil type and quantities of mussel shell fragments, but larger limestone cobbles $(>6 \mathrm{~cm}$ ) were noted at a depth of 35 to $40 \mathrm{~cm}$. Shovel Test 99-2 also was excavated to $40 \mathrm{~cm}$; it produced several pieces of burned limestone and a few mussel shell fragments. The soil was a dark brown clay loam.

\section{Work Accompl ished}

In the previous investigations of 1984 , a nail was set in the base of a bois d'arc tree located in the north-central part of the site. The secondary datum (rebar) for the 2000-2001 investigations was placed near that same tree. The primary datum (rebar) was given an arbitrary elevation of $100.00 \mathrm{~m}$ and placed near the center of the investigation area, about $10 \mathrm{~m}$ northwest of Trench 3 and $10 \mathrm{~m}$ southeast of Test Units 1 and 5.

Four trackhoe trenches were excavated to examine the colluvial toeslope, as well as the alluvial terrace deposits away from the base of the slope (Figure 21). In the central part of the site, Trench 1 was placed about $10 \mathrm{~m}$ northwest of the secondary datum on the alluvial terrace at an orientation of $60^{\circ}$. The trench measured $2.8 \times 2.6 \times 1.8 \mathrm{~m}$ and encountered both colluvial and alluvial deposits. This trench exemplified the interdigitation of late Holocene alluvium with the colluvial gravels from upslope. The colluvial gravels appeared to contain fragments of burned rocks.

Trench 2, aligned at $44^{\circ}$, was $45 \mathrm{~m}$ southeast of Trench 1 . It measured $2.1 \times 1.4 \times 1.5 \mathrm{~m}$ and encountered either bedrock or compact colluvial gravels near the base. Between 20 and $100 \mathrm{~cm}$, a few mussel shells, burned rocks, and charcoal flecks were observed. Trench 3 was situated $20 \mathrm{~m}$ southwest of Trench 2 and yielded similar results. From 19 to $93 \mathrm{~cm}$, burned rocks and a few mussel shell fragments were observed. The trench measured $2.7 \times 1.7 \times 1.5 \mathrm{~m}$ and encountered either bedrock or compact colluvial gravels.

Trench 4 examined the western part of the investigation area. Situated $21 \mathrm{~m}$ south of Trench 1 and $27 \mathrm{~m}$ west of Trench 3 , the trench measured $2.8 \times 1.7 \times 1.8 \mathrm{~m}$ and was oriented at $322^{\circ}$. The trench revealed well-strati- 


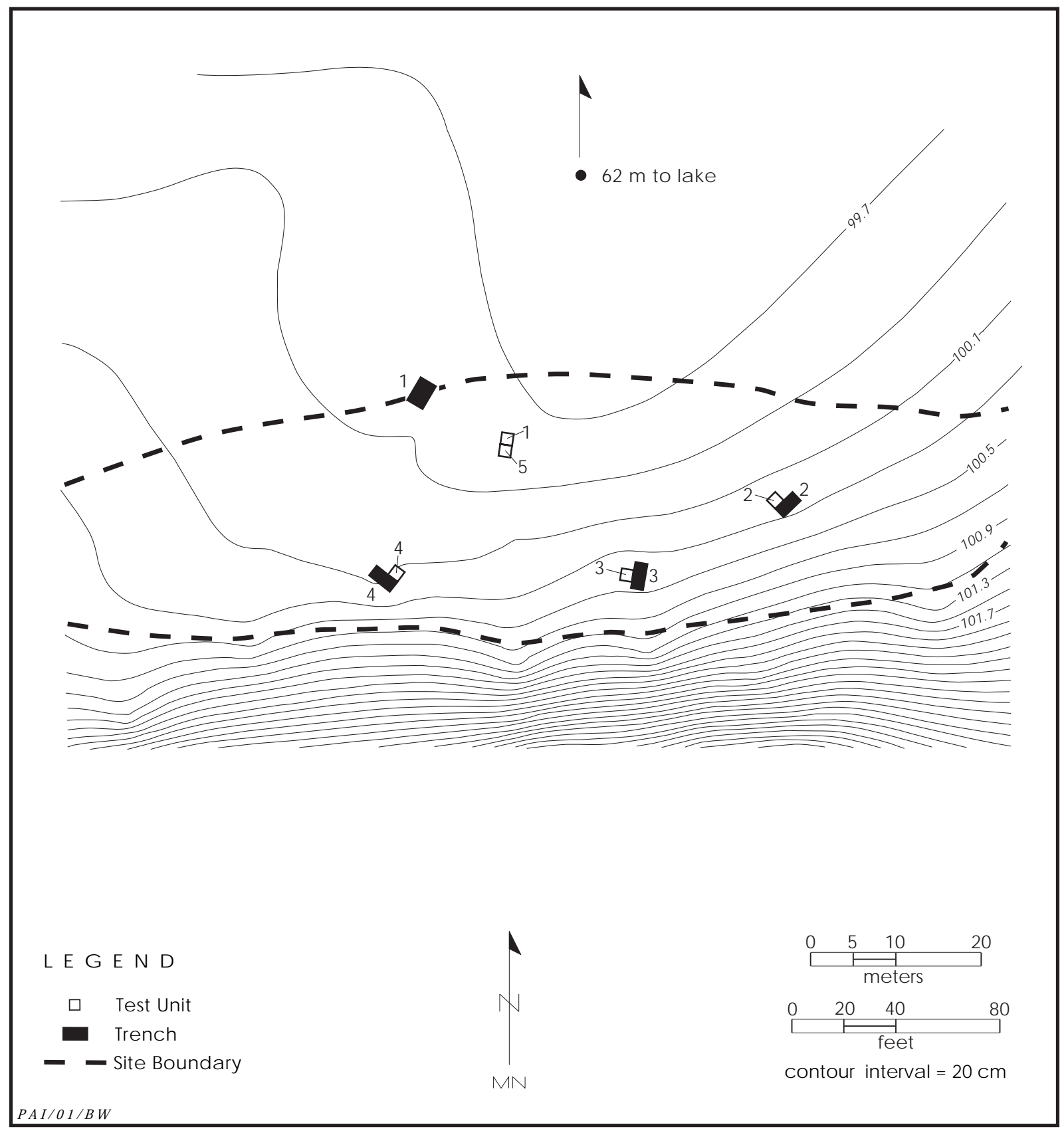

Figure 21. Map of 41ML162.

fied buried A horizons with cultural materials (e.g., mussel shells, burned rocks) at 18$77 \mathrm{~cm}, 105-127 \mathrm{~cm}$, and $153-180 \mathrm{~cm}$. The deeper half of the trench contained more colluvial gravels than the upper portion. Two bulk sediment samples for radiocarbon dating were collected from the wall at $50-60 \mathrm{~cm}$ and $107-117 \mathrm{~cm}$.
Five test units were excavated. Two were near the bois d'arc tree while the remaining three were adjacent to trenches. All of the units were excavated from the modern ground surface. All of the excavations were terminated when the water table was encountered or, in the case of Test U nit 1, when colluvial gravels were reached just above the water table. Because of 
the elevated water table, the anticipated target depth of $210 \mathrm{~cm}$ was not reached.

Test Unit 1 was set up in the area of the $1 \times 2-m$ unit excavated in 1984, east of the datum tree Excavation finished at Level $15(150 \mathrm{~cm})$. Test Unit 2 was placed on the west side of Trench 2. The water table was hit at Level 19 $(190 \mathrm{~cm})$. Test Unit 3 was on the west side of Trench 3. In this unit, the water table was encountered at $150 \mathrm{~cm}$. Test Unit 4 was set up on the east side of Trench 4. Eighteen levels were completed when the water table was encountered at $180 \mathrm{~cm}$. Finally, Test U nit 5 was placed on the south side of Test Unit 1 forming a $1 \times 2-m$ test pit. Excavation in this unit stopped at Level $14(140 \mathrm{~cm})$ because of the high water table. In total, $8.1 \mathrm{~m}^{3}$ were hand excavated.

\section{Site Extent and Depth}

Previous investigations at 41ML 162 measured the size of the site at ca. 160 by $50 \mathrm{~m}$, based on the distribution of surface artifacts (Prikryl and J ackson 1985:82-87, 211-213). These investigations al so noted cultural materials (burned rocks, debitage, and mussel shells) to a depth of $210 \mathrm{~cm}$ in a $1 \times 2-m$ test pit. Subsequent investigations noted heavy vegetation and large amounts of flood debris that obscured the surface, limiting observations about the site extent (Kvernes et al. 2000:56). Similarly, no surface artifacts were observed during the current investigations, and no new information on the east-west extent of the site was obtained. However, cultural materials were found in all of the excavations except for Trench 1, suggesting that the site extends only ca. $30 \mathrm{~m}$ northsouth from the toeslope out onto the terrace. Within most test units, artifacts and other cultural materials, though small in number, were recovered as deep as $150-180 \mathrm{~cm}$ when excavations were stopped at the water table; thus, the full depth of the site is not known.

\section{Sediments and Stratigraphy}

The sediments and stratigraphy at 41ML 162 were examined through the profiles of five trenches and descriptions of the soil stratigraphy of three trench profiles (see Appendix A). The site is located on the toeslope and terrace of the North Bosque River valley. Prior to the creation of Waco Lake, the terrace surface at this locality stood ca. 4-5 $\mathrm{m}$ above the N orth Bosque channel. Soils on the terrace surface belong to the Catalpa series (Templin et al. 1958). Catal pa soils are calcareous grayish brown to dark grayish brown clay loam to clayey soils formed on recent alluvium. Tarrant soils mantle the surface of the toesl ope and are dark calcareous stony clay soils.

Dueto the site's proximity to the valley wall, the deposits that underlie the surface are a mix of late $\mathrm{Hol}$ ocene alluvium and colluvium (Figure 22). A thin deposit of recent alluvium blankets much of the terrace surface. This deposit, designated an AC horizon, ranges in thickness from $18 \mathrm{~cm}$ in Trench 4 to $36 \mathrm{~cm}$ in Trench 1 and is composed of grayish brown to dark grayish brown to dark gray silty clay loam with some preserved horizontal structures. The $141-\mathrm{cm}-$ thick profile of Trench 1 best displays the interfingering of alluvium and colluvium. Below the recent alluvial mantle is a buried soil (Ab horizon, 36-52 cm) consisting of dark gray silty clay loam alluvium with 10 percent limestone gravels. The Ab horizon overlies a series of $\mathrm{Bw}$ horizons $(52-116 \mathrm{~cm})$ imprinted on interfingered deposits of alluvium and colluvium. The alluvial deposits pinch out to the south (toward the valley wall), while the colluvial deposits pinch out to the north (toward the North Bosque channel). The alluvial deposits typically are dark grayish brown silty clay loams, while the colluvial deposits consist of dark grayish brown gravelly sandy clay loams with angular to subrounded, granule to pebblesized gravels. The basal deposit (116-141+cm) is a dark grayish brown gravelly sandy clay loam and is designated a $C$ horizon.

Deposits at the toeslope were observed in Trench 3. The deposits below the recent alluvial cap are a mix of alluvium, colluvium, and deposits of anthropogenic origin. These are imprinted with an Ab-Bwb soil profile. The $A b$ horizon $(19-93 \mathrm{~cm})$ is formed on a black silty clay loam with 5 percent limestone gravels. Burned rocks are common throughout the horizon suggesting that the deposit on which the Ab horizon has formed al so contains an anthropogenic component. The Ab horizon grades into the B wb horizon (93-143+cm), a yel lowish brown silty clay with 2 percent limestone gravels.

The profile of Trench 4 also consists of a mix of alluvial and colluvial deposits below the recent alluvial veneer, but the profile displays 


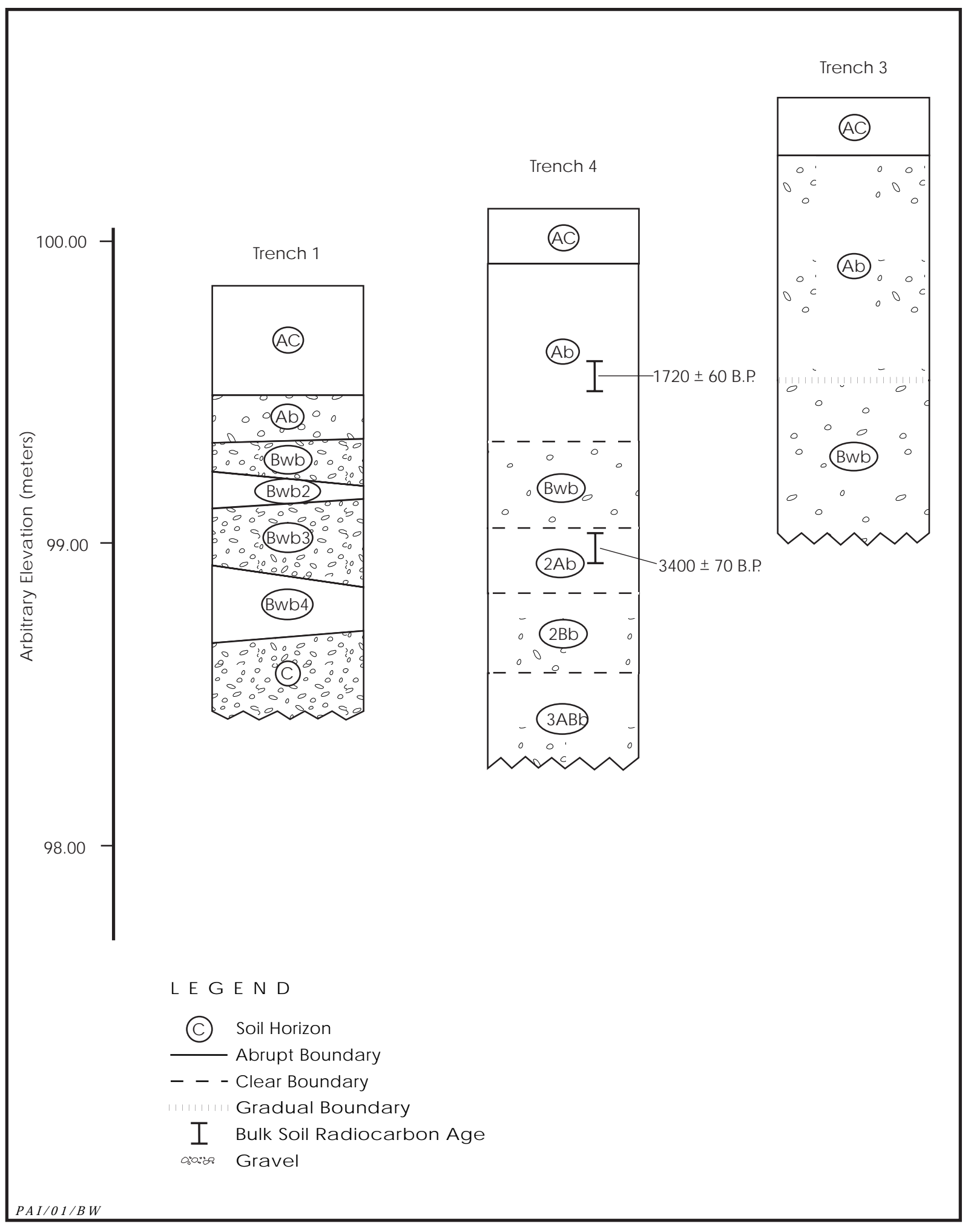

Figure 22. Profiles of Trenches 1, 4, and 3, 41ML 162. 
multiple buried soils. Thetrench exhibits an AbBwb-2Ab-2Bb-3ABb soil profile. The Ab horizon $(18-77 \mathrm{~cm})$ is a very dark gray silty clay loam with common freshwater mussel shell fragments and burned rocks. A bulk soil sample collected from 50 to $60 \mathrm{~cm}$ yielded a conventional radiocarbon age of $1720 \pm 60$ B.P. (Beta154293). The Bwb horizon $(77-105 \mathrm{~cm})$ is a dark grayish brown clay loam with 2 percent limestone gravels. The second buried soil (2Ab horizon at 105-127 cm) consists of a very dark grayish brown clay loam with many burned rocks, common freshwater mussel shells, and a few pieces of charcoal. A bulk soil sample collected from 107 to $117 \mathrm{~cm}$ produced a conventional radiocarbon age of $3400 \pm 70$ B.P. (Beta-154294). The accompanying 2Bb horizon $(127-153 \mathrm{~cm})$ is a brown silty clay loam with 5 percent limestone gravels. The third buried soil (3ABb horizon at $153-180+\mathrm{cm}$ ) consists of a dark grayish brown silty clay loam with 10 percent limestone gravels. Freshwater mussel shells are common throughout the soil. General observations of the profile revealed that the fre quencies of burned rocks, freshwater mussel shells, and charcoal peak strongly within the buried A horizons, clearly indicating that the terrace/floodplain surface was only occupied during periods of surface stability. The multiple soils were observed throughout the western part of the area investigated, suggesting that this part of the site witnessed more intervals of stability or lacunae in deposition than the area to the east, where only a singleA horizon (observed in Trenches 2 and 3) has formed atop alluvial and colluvial deposits.

\section{Cultural Features}

Two features were encountered during the test excavations. Both areburned rock features.

\section{FEATURE 1}

Feature 1, a buried burned rock midden, was discovered in Test Unit 3, Levels 5-10 (40$100 \mathrm{~cm}$ ) (Figure 23). The midden covered the entire test unit, and, ther efore, the feature's full dimensions and morphology are unknown. Its maximum thickness is ca. $60 \mathrm{~cm}$. No internal features were observed during excavation, though a few rocks appeared to be broken in place. While a large amount of rocks was found in Level 10 (90-100 cm), there was no pattern to the rocks to suggest that they represent a prepared base for a large hearth. No oxidized soil, charcoal, or ash was found in situ in the feature. Charcoal recovered from Level 6 (50$60 \mathrm{~cm}$ ) was identified as oak (Quercus sp.). This specimen was later submitted for radiocarbon dating and yiel ded a radiocarbon age of $1980 \pm$ 60 B.P. (Beta-154279).

Feature contents from the test unit consist of 395 burned rocks $(81 \mathrm{~kg}$ ), including 50 rocks $10 \mathrm{~cm}$ in size or greater, 120 rocks $5-10 \mathrm{~cm}$ in size, and 225 less than $5 \mathrm{~cm}$. Two dart points, 9 lithic tools, 229 pieces of debitage, 1 piece of pottery, 1 piece of burned clay, 37 pieces of bone, and 114 mussel shell fragments were collected.

About 4.5 liters of feature fill from Level 5 $(40-50 \mathrm{~cm})$ were collected for flotation. Flotation processing recovered ca. $0.4 \mathrm{~kg}$ of burned rocks, 18 pieces of lithic debitage, 18 pieces of bone, charred wood remains, and numerous fragments of snail and mussel shells (see Materials Recovered). Four mussel shell umbos recovered from flotation were included in the invertebrate faunal analysis. The bone specimens were not incor porated into the vertebrate faunal analysis. They vary in size from less than $0.5 \mathrm{~cm}$ to $2.0 \mathrm{~cm}$, and only one of the specimens is charred. Small to medium-sized vertebrates are represented.

Feature 1 represents the accumulation of burned rocks from hearths and baking features. While no internal features were observed during excavation, they may exist elsewhere in the midden. The development of the midden suggests repeated occupations focused on thesame or similar cooking and processing activities over time.

\section{FEATURE 2}

Feature 2 represents a discrete, single-layered cluster of burned rocks. It was first exposed in the northeast wall of Trench 4 and subsequently partially exposed during excavation of Test Unit 4. Found in Levels 7 and $8(62-75 \mathrm{~cm})$ at the base of the Ab horizon, Feature 2 is located in the west corner of the unit (Figure 24). In plan, the exposed portion resembles part of an oval and measures $49 \mathrm{~cm}$ northeast-southwest by $27 \mathrm{~cm}$ northwest-southeast. It is composed of ca. $7 \mathrm{~kg}$ of burned rocks ( 4 rocks greater than $10 \mathrm{~cm}$ in size, 17 rocks $5-10 \mathrm{~cm}$ in size, and 25 rocks less than $5 \mathrm{~cm}$ in size). The larger 


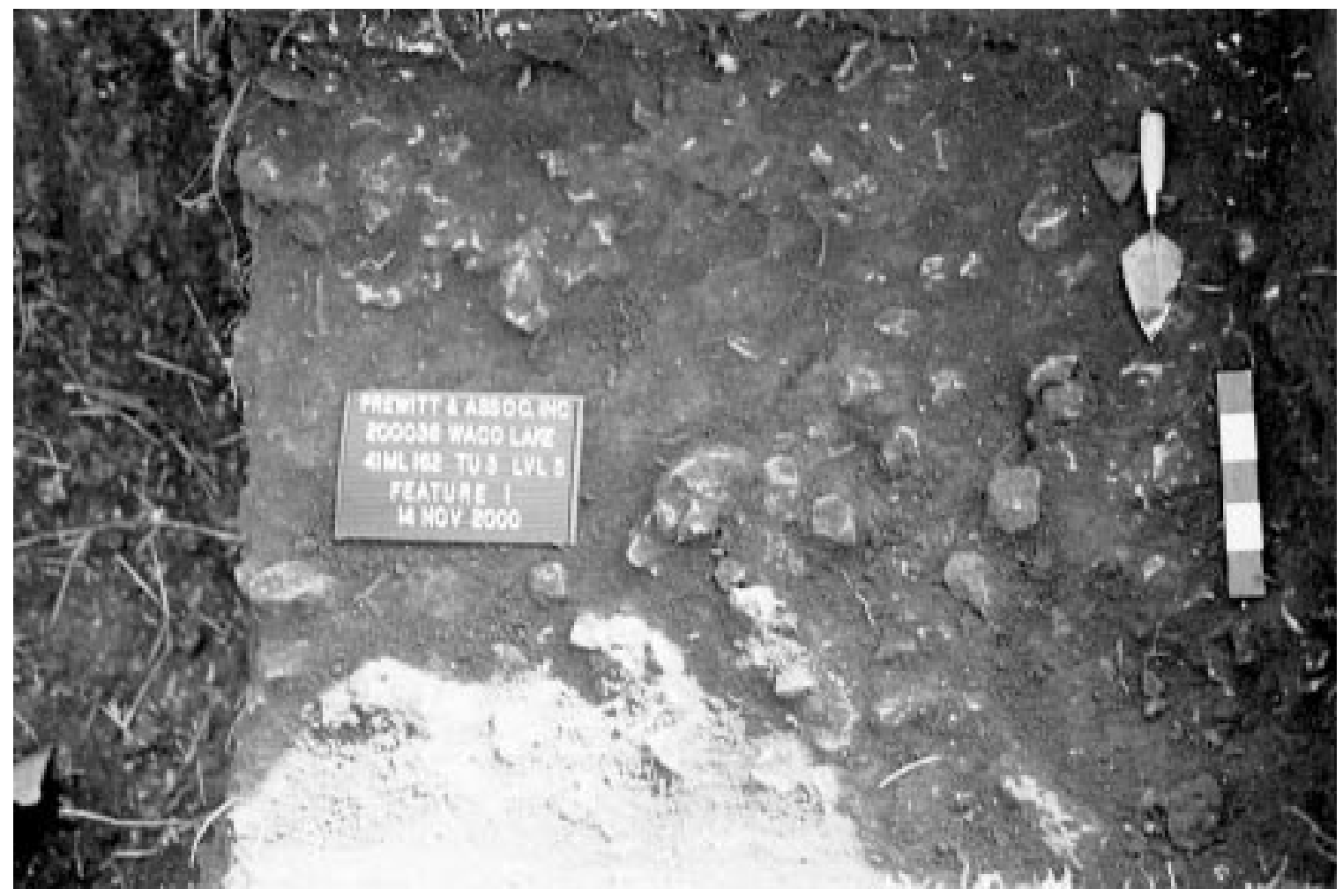

Figure 23. Photograph of the top of Feature 1, 41ML 162.

rocks, some of which are fractured in place, are toward the perimeter of the feature. In cross section the feature is basin shaped with rocks tilting slightly toward the center. While pieces of charcoal and charcoal flecking were observed, no oxidized sediment or ash was present. Two pieces of charcoal collected from the feature were submitted for radiocarbon dating. The first sample collected at $69 \mathrm{~cm}$ yielded a radiocarbon age of $2830 \pm 40$ B.P. (Beta-154280). The second sample collected at $72 \mathrm{~cm}$ produced a radiocarbon age of $2780 \pm 40$ B.P. (Beta-154281).

Approximately 4.5 liters of feature fill were collected for flotation. Flotation processing recovered $0.2 \mathrm{~kg}$ of burned rocks, seven pieces of lithic debitage, seven bone fragments, charcoal, and snail and mussel shell fragments. None of the mussel shell or bone fragments were included in the faunal analyses. The bone fragments are small $(<1 \mathrm{~cm})$, and only one specimen appears to be charred.

Feature 2 appears to have functioned as a cooking or baking pit. The basin-shaped cross section and rocks tilting toward the center sug- gest that a prepared surface was constructed on which a layer of rocks was placed. The feature probably was utilized to process and cook game as evidenced by the recovery of vertebrate faunal remains, some of which are charred. Radiocarbon dates suggest it was utilized during the early part of the Late Archaic period.

\section{Materials Recovered}

Test excavations at $41 \mathrm{ML} 162$ recovered 1,193 chipped stone artifacts; 820 invertebrate faunal remains; 261 vertebratefaunal remains; 1 piece of pottery; 4 ground, pecked, and battered stone tools; $1.0 \mathrm{~kg}$ of burned clay lumps; and numerous burned rocks. Provenience data for all of the materials recovered (except for the burned clay lumps and rocks) are summarized in Table 4.

\section{CHIPPED STONE ARTIFACTS}

The 1,193 chipped stone artifacts consist of 1 arrow point, 9 dart points, 22 bifaces, 7 unifaces, 


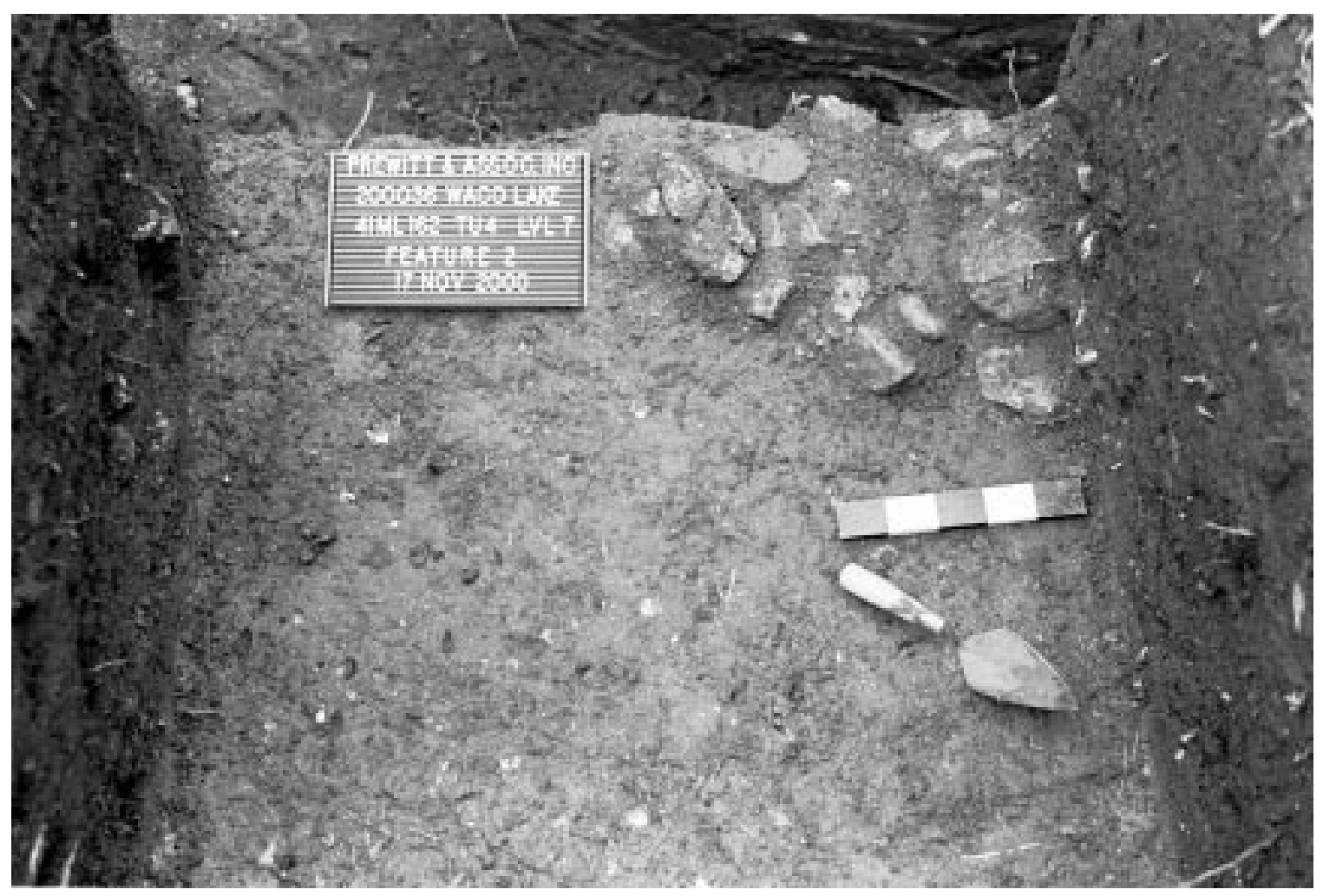

Figure 24. Photograph of Feature 2, 41ML 162.

6 cores, 1 cobble tool , 41 pieces of edge-modified debitage, and 1,106 pieces of unmodified debitage.

\section{Arrow Point}

One specimen is classified as a Perdiz arrow point (Turner and Hester 1993:227) (Figure 25a). The point is complete, retains its barbs and tapered tip, and is bifacially flaked. The stem is contracting with a gentle convex base. The material is an opaque brown chert. Provenience and metric data are presented in Table 5.

\section{Dart Points}

\section{Darl}

One specimen is identified as a Darl (Turner and Hester 1993:101) (Figure 25b). The dart point has an almost parallel-sided blade that is slightly bevel ed and serrated on one edge. The shoulders are weak, and the stem is straight with a slight bevel and lightly ground edges. The base is straight to slightly convex with no basal grinding. The material is a reddish brown chert.

\section{Ellis}

Three dart points are classified as Ellis (Turner and Hester 1993:113). The first specimen is a reworked Ellis point with a triangular blade (Figure 25c). The shoulders are weak, and the stem is expanding. A portion of the basehas been removed with a single blow to one corner, resulting in the removal of a tiny narrow flake from the basal edge. This basal modification also is applied to the two other Ellis points. The material is a speckled brown and tan chert that shows evidence of heat treatment through discol oration.

The second specimen has a long, slender triangular blade with serrated edges (Figure 25d). The shoulders are moderate, and the stem and base are highly modified. As with the first Ellis point, a portion of the base is missing. The material is a light tan chert with white speckled inclusions. 
Table 4. Summary of cultural materials from 41ML 162

\begin{tabular}{|c|c|c|c|c|c|c|c|c|c|c|c|c|c|}
\hline \multicolumn{14}{|l|}{ TEST UNIT 1} \\
\hline Level $4(30-40 \mathrm{~cm})$ & - & - & - & - & - & - & - & - & - & - & - & 1 & 1 \\
\hline Level $5(40-50 \mathrm{~cm})$ & - & - & - & - & - & - & - & - & - & - & 3 & - & 3 \\
\hline Level $6(50-60 \mathrm{~cm})$ & - & - & - & - & - & - & - & 1 & - & - & 2 & - & 3 \\
\hline Level $7(60-70 \mathrm{~cm})$ & - & - & - & - & - & - & - & 2 & - & - & 1 & 18 & 21 \\
\hline Level $8(70-80 \mathrm{~cm})$ & - & - & - & - & - & - & 1 & 2 & - & - & 4 & - & 7 \\
\hline Level $9(80-90 \mathrm{~cm})$ & - & - & - & - & - & - & - & 2 & - & - & 4 & - & 6 \\
\hline Level $10(90-100 \mathrm{~cm})$ & - & - & - & - & - & - & 1 & 8 & - & - & 8 & 1 & 18 \\
\hline Level $11(100-110 \mathrm{~cm})$ & - & - & 1 & 1 & 1 & - & 1 & 19 & - & 1 & 17 & 1 & 42 \\
\hline Level $12(110-120 \mathrm{~cm})$ & - & - & - & - & - & - & 1 & 16 & - & - & 3 & 1 & 21 \\
\hline Level $13(120-130 \mathrm{~cm})$ & - & - & - & - & - & - & - & 12 & - & - & 1 & 1 & 14 \\
\hline Level $14(130-140 \mathrm{~cm})$ & - & - & - & - & - & - & - & 3 & - & - & 3 & - & 6 \\
\hline Level $15(140-150 \mathrm{~cm})$ & - & - & - & - & - & - & - & 1 & - & - & 1 & - & 2 \\
\hline Subtotals & 0 & 0 & 1 & 1 & 1 & 0 & 4 & 66 & 0 & 1 & 47 & 23 & 144 \\
\hline \multicolumn{14}{|l|}{ TEST UNIT 2} \\
\hline Level $3(20-30 \mathrm{~cm})$ & 1 & - & 3 & - & - & - & - & 8 & _- & - & 5 & 27 & 44 \\
\hline Level $4(30-40 \mathrm{~cm})$ & - & 3 & 3 & 1 & 1 & - & 6 & 220 & - & & 57 & 42 & 333 \\
\hline Level $5(40-50 \mathrm{~cm})$ & - & 1 & 4 & 1 & - & - & 6 & 96 & - & 1 & 55 & 26 & 190 \\
\hline Level $6(50-60 \mathrm{~cm})$ & - & - & - & - & - & - & 1 & 4 & - & & 4 & 1 & 10 \\
\hline Level $8(70-80 \mathrm{~cm})$ & - & - & - & 1 & - & - & - & 2 & - & - & 1 & - & 4 \\
\hline Level $9(80-90 \mathrm{~cm})$ & - & - & - & - & 1 & - & - & 6 & - & - & - & - & 7 \\
\hline Level $10(90-100 \mathrm{~cm})$ & - & - & - & - & - & - & - & 1 & - & - & 2 & - & 3 \\
\hline Level $12(110-120 \mathrm{~cm})$ & - & - & - & - & - & - & - & 1 & - & - & 1 & - & 2 \\
\hline Level $14(130-140 \mathrm{~cm})$ & - & - & - & - & - & - & - & 1 & - & - & 3 & - & 4 \\
\hline Level $15(140-150 \mathrm{~cm})$ & - & - & - & - & - & - & - & 1 & - & - & - & - & 1 \\
\hline Subtotals & 1 & 4 & 10 & 3 & 2 & 0 & 13 & 340 & 0 & 1 & 128 & 96 & 598 \\
\hline \multicolumn{14}{|l|}{ TEST UNIT 3} \\
\hline Level $3(20-30 \mathrm{~cm})$ & - & - & 2 & - & - & - & - & 9 & - & - & 134 & 7 & 152 \\
\hline Level $4(30-40 \mathrm{~cm})$ & - & 1 & - & 1 & - & - & 2 & 29 & - & 2 & 30 & 8 & 73 \\
\hline Feature $1(40-50 \mathrm{~cm})$ & - & - & - & - & - & - & 1 & 45 & - & - & 34 & 32 & 112 \\
\hline Feature $1(50-60 \mathrm{~cm})$ & - & 1 & - & - & 1 & - & - & 27 & - & - & 12 & 10 & 51 \\
\hline Feature $1(60-70 \mathrm{~cm})$ & - & - & 2 & - & - & - & - & 23 & 1 & - & 34 & 8 & 68 \\
\hline Feature $1(70-80 \mathrm{~cm})$ & - & 1 & 1 & - & - & - & 3 & 53 & - & - & 28 & 4 & 90 \\
\hline Feature $1(80-90 \mathrm{~cm})$ & - & - & - & - & - & - & 1 & 77 & - & - & 6 & 2 & 86 \\
\hline F eature $1(90-100 \mathrm{~cm})$ & _- & - & - & - & - & - & - & 22 & _- & - & 4 & - & 26 \\
\hline Level $11(100-110 \mathrm{~cm})$ & - & - & - & - & - & - & - & 5 & - & - & 2 & - & 7 \\
\hline Level $12(110-120 \mathrm{~cm})$ & - & - & - & - & - & - & - & - & - & - & 1 & - & 1 \\
\hline Subtotals & 0 & 3 & 5 & 1 & 1 & 0 & 7 & 290 & 1 & 2 & 285 & 71 & 666 \\
\hline \multicolumn{14}{|l|}{ TEST UNIT 4} \\
\hline Level $3(20-30 \mathrm{~cm})$ & - & - & - & - & - & - & - & - & _- & - & 1 & - & 1 \\
\hline Level $4(30-40 \mathrm{~cm})$ & _- & _- & 1 & _ & _- & _ & 1 & 17 & _ & _- & 13 & 6 & 38 \\
\hline Level $5(40-50 \mathrm{~cm})$ & - & - & 1 & - & - & - & 2 & 63 & - & - & 33 & 13 & 112 \\
\hline Level $6(50-60 \mathrm{~cm})$ & _- & - & 2 & - & . & - & 3 & 108 & _- & - & 29 & 6 & 148 \\
\hline Level $7(60-70 \mathrm{~cm})$ & - & - & - & 1 & - & - & 2 & 75 & - & - & 54 & 4 & 136 \\
\hline Feature $2(65-72 \mathrm{~cm})$ & - & - & - & - & - & _ & - & 7 & _- & - & - & 7 & 14 \\
\hline
\end{tabular}


Table 4, continued

\begin{tabular}{|c|c|c|c|c|c|c|c|c|c|c|c|c|c|}
\hline Provenience & 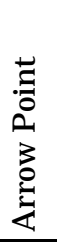 & 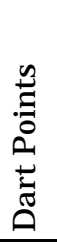 & 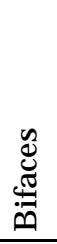 & 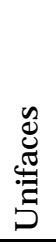 & ¿y & $\begin{array}{l}\overline{8} \\
\frac{0}{0} \\
\frac{0}{0} \\
0\end{array}$ & 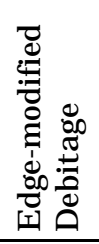 & 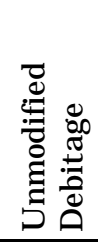 & 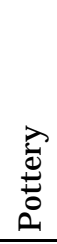 & 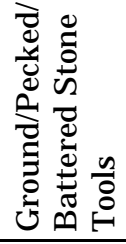 & 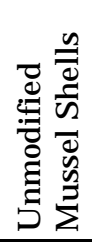 & 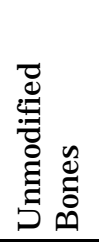 & $\begin{array}{l}\frac{n}{\pi} \\
\frac{0}{0} \\
\end{array}$ \\
\hline Level $8(70-80 \mathrm{~cm})$ & - & - & - & - & - & - & - & 1 & - & - & 1 & - & 2 \\
\hline Level $9(80-90 \mathrm{~cm})$ & - & - & - & - & - & 1 & 1 & - & - & - & 5 & - & 7 \\
\hline Level $10(90-100 \mathrm{~cm})$ & - & - & - & - & - & - & - & 7 & - & - & 5 & 3 & 15 \\
\hline Level $11(100-110 \mathrm{~cm})$ & - & - & - & 1 & - & - & 1 & 28 & - & - & 26 & - & 56 \\
\hline Level $12(110-120 \mathrm{~cm})$ & - & - & 1 & - & 2 & - & - & 12 & - & - & 31 & 1 & 47 \\
\hline Level $13(120-130 \mathrm{~cm})$ & - & - & - & - & - & - & - & 5 & - & - & 15 & - & 20 \\
\hline Level $14(130-140 \mathrm{~cm})$ & - & - & - & - & - & - & - & 7 & - & - & 14 & 12 & 33 \\
\hline Level $15(140-150 \mathrm{~cm})$ & - & - & - & - & - & - & 1 & 25 & - & - & 14 & - & 40 \\
\hline Level $16(150-160 \mathrm{~cm})$ & - & - & - & - & - & - & 1 & 17 & - & - & 24 & 3 & 45 \\
\hline Level $17(160-170 \mathrm{~cm})$ & - & - & - & - & - & - & 1 & 5 & - & - & 14 & 2 & 22 \\
\hline Level $18(170-180 \mathrm{~cm})$ & - & 1 & - & - & - & - & 1 & 7 & - & - & 22 & 6 & 37 \\
\hline Subtotals & 0 & 1 & 5 & 2 & 2 & 1 & 14 & 384 & 0 & 0 & 301 & 63 & 773 \\
\hline \multicolumn{14}{|l|}{ TEST UNIT 5} \\
\hline Level $4(30-40 \mathrm{~cm})$ & - & - & - & - & - & - & - & - & - & - & - & 2 & 2 \\
\hline Level $5(40-50 \mathrm{~cm})$ & - & - & - & - & - & - & - & 4 & - & - & 3 & 2 & 9 \\
\hline Level $6(50-60 \mathrm{~cm})$ & - & - & - & - & - & - & - & 1 & - & - & 6 & 1 & 8 \\
\hline Level $7(60-70 \mathrm{~cm})$ & - & - & - & - & - & - & - & - & - & - & 2 & 1 & 3 \\
\hline Level $8(70-80 \mathrm{~cm})$ & - & - & - & - & - & - & 1 & 4 & - & - & 1 & - & 6 \\
\hline Level $9(80-90 \mathrm{~cm})$ & - & 1 & - & - & - & - & 2 & 4 & - & - & 34 & 2 & 43 \\
\hline Level $10(90-100 \mathrm{~cm})$ & - & - & - & - & - & - & - & 7 & - & - & 9 & - & 16 \\
\hline Level $11(100-110 \mathrm{~cm})$ & - & - & - & - & - & - & - & 2 & - & - & 4 & - & 6 \\
\hline Level $12(110-120 \mathrm{~cm})$ & - & - & 1 & - & - & - & - & 4 & - & - & - & - & 5 \\
\hline Subtotals & 0 & 1 & 1 & 0 & 0 & 0 & 3 & 26 & 0 & 0 & 59 & 8 & 98 \\
\hline TOTALS & 1 & 9 & 22 & 7 & 6 & 1 & 41 & 1,106 & 1 & 4 & 820 & 261 & 2,279 \\
\hline
\end{tabular}

The third point has a triangular blade with serrated edges (Figure 25e). The shoulders are moderate to strong. The specimen displays the remnants of an expanding stem. The material is a dark gray to black chert with lighter colored inclusions. As with the previous specimens, the base is modified with evidence of two strikes to one corner to remove part of it. The result is a thick convex base. This may have been done to dull the base, a technique akin to basal grinding to prevent cutting or splitting the hafting material or shaft.

\section{Ensor}

One specimen is identified as an Ensor point (Turner and Hester 1993:114) (Figure 25f). The point has a triangular blade that displays alternately beveled edges and reworking. The shoul ders are moderatel y abrupt with some shallow side notching. The stem is expanding, and the base is straight. One ear or basal corner is missing. The material is a light brown/tan chert with lighter colored mottles.

\section{Marcos}

One specimen is classified as a Marcos (Turner and Hester 1993:147-148) (Figure25g). This proximal fragment displays the remnants of a broad, long, slightly triangular blade. The deep, inward corner notching results in abrupt barbed shoulders and an expanding stem with a straight base. 


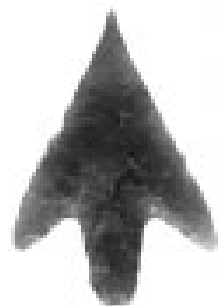

a

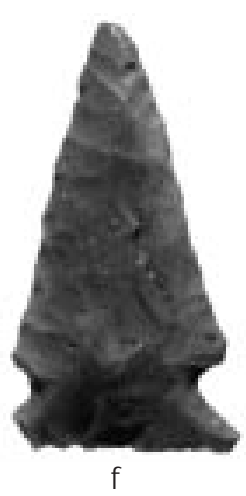

f

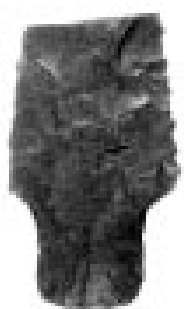

b

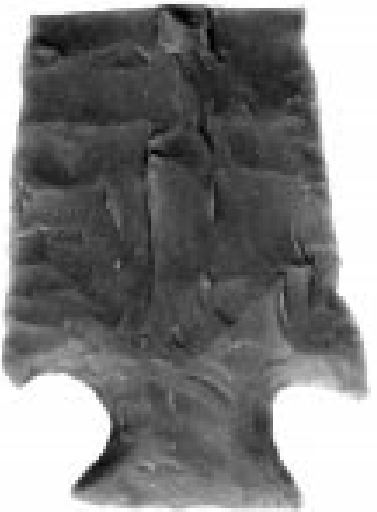

g

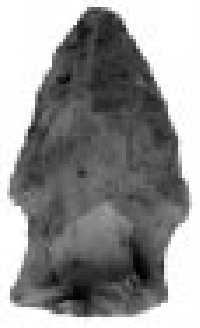

C

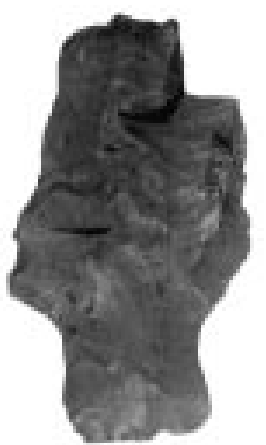

$\mathrm{h}$

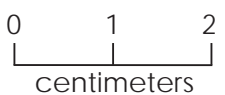

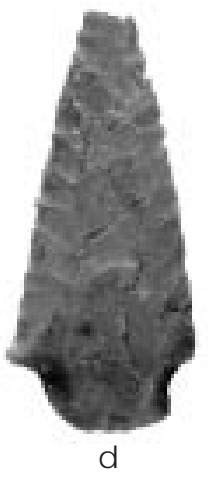
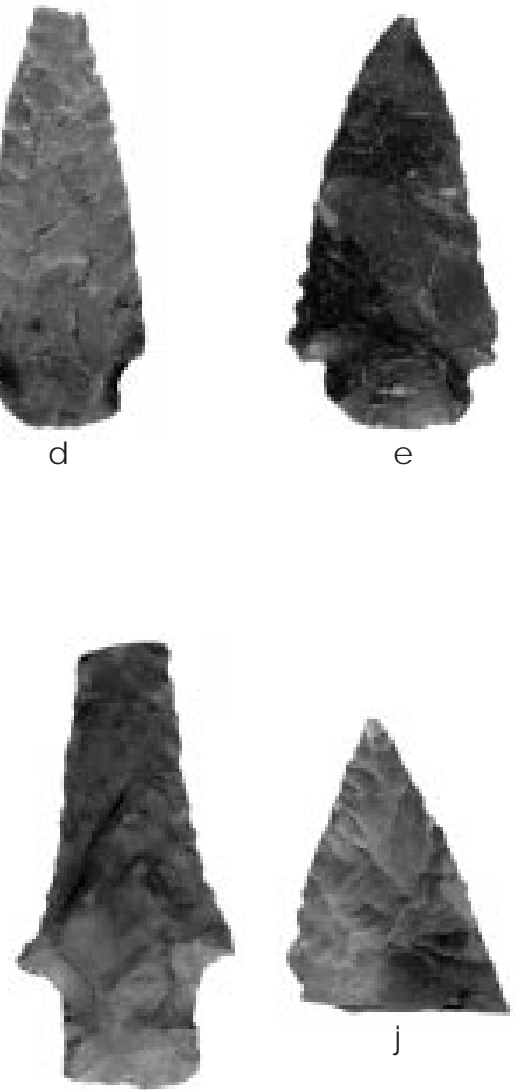

i

Figure 25. Projectile points from 41ML162. (a) Perdiz; (b) Darl; (c-e) Ellis; (f) Ensor; (g) Marcos; (h) Provisional Type 1 dart point; (i-j) untyped dart points.

Provisional Type 1

One specimen does not fall into a traditionally defined type (Figure 25h). The point has a reworked blade, which is broken. The shoulders are weak, and the slightly expanding stem has light to heavy edge grinding. The base is gently convex and not ground. The material is a light gray chert with lighter and darker colored inclusions.

This point closely resembles those specimens from Fort Hood and other areas in central Texas referred to by Kleinbach et al. (1999:335-344) as Provisional Type 1. Provisional Type 1 is best described as a point with straight to slightly convex blade margins, weak to strong shoulders (without barbs), a rectangular to slightly expanding stem with straight to subtle concave edges, and a straight to slightly convex base (Kleinbach et al. 1999:335). Radiocarbon dates associated with Provisional Type 1 points from Fort $\mathrm{Hood}$ range from 2400-2205 B.C. to <3335-3070 B.C. Kleinbach et al. (1999:337) suggest these points were utilized around 3000-2000 B.C. Although there are no radiocarbon ages directly associated with the specimen recovered from $41 M L 162$, it is from a context that is consistent with the 3000-2000 B.C. time span proposed by Kleinbach et al. (1999). The specimen, recovered from the 3ABb horizon at 170$180 \mathrm{~cm}$ in Test Unit 4, underlies two charcoal samples from $127 \mathrm{~cm}$ and $110-120 \mathrm{~cm}(2 \mathrm{Ab}$ horizon) that produced radiocarbon ages of 
Table 5. Provenience and metric data for projectile points from 41ML 162

\begin{tabular}{|c|c|c|c|c|c|c|c|c|}
\hline Provenience & Point Type & Tool Completeness & $\begin{array}{c}\text { Maximum } \\
\text { Length }\end{array}$ & $\begin{array}{c}\text { Maximum } \\
\text { Blade Width }\end{array}$ & $\begin{array}{c}\text { Haft } \\
\text { Length }\end{array}$ & $\begin{array}{l}\text { Neck } \\
\text { Width }\end{array}$ & $\begin{array}{c}\text { Base } \\
\text { Width }\end{array}$ & $\begin{array}{l}\text { Maximum } \\
\text { Thickness } \\
\end{array}$ \\
\hline \multicolumn{9}{|l|}{ TEST UNIT 2} \\
\hline Level 3 (20-30 cm) & Perdiz & intact & 30.5 & 20.5 & 9.2 & 6.4 & 5.0 & 2.7 \\
\hline Level 4 (30-40 cm) & Darl & proximal & - & 17.3 & 7.1 & 10.9 & 9.8 & 5.2 \\
\hline Level $4(30-40 \mathrm{~cm})$ & Ellis & intact/nearly complete & - & 18.3 & 6.3 & 13.8 & 15.7 & 5.7 \\
\hline Level 4 (30-40 cm) & Marcos & proximal & - & 37.1 & 10.1 & 16.2 & 23.4 & 8.0 \\
\hline Level $5(40-50 \mathrm{~cm})$ & Untyped Dart & proximal & - & 21.9 & 8.4 & 13.6 & 13.6 & 6.9 \\
\hline \multicolumn{9}{|l|}{ TEST UNIT 3} \\
\hline Level 4 (30-40 cm) & Ellis & intact/nearly complete & - & 19.4 & - & 12.4 & - & 5.1 \\
\hline F eature $1(50-60 \mathrm{~cm})$ & Ellis & intact/nearly complete & - & 20.8 & - & 14.1 & - & 6.0 \\
\hline F eature 1 (70-80 cm) & Untyped Dart & distal & - & - & - & - & - & 5.5 \\
\hline \multicolumn{9}{|l|}{ TEST UNIT 4} \\
\hline Level $18(170-180 \mathrm{~cm})$ & Provisional Type 1 & proximal & - & 24.3 & 10.9 & 13.6 & 13.9 & 8.3 \\
\hline \multicolumn{9}{|l|}{ TEST UNIT 5} \\
\hline Level $9(80-90 \mathrm{~cm})$ & Ensor & intact & 42.7 & 21.4 & 5.7 & 16.5 & - & 6.1 \\
\hline
\end{tabular}

Note: All measurements are in millimeters. 
$3490 \pm 40$ B.P. (Beta-154292) and $3600 \pm 40$ B.P. (Beta-154282), respectively. The two-sigma calibrated date ranges for these two radiocarbon ages are 3860 (3720) 3650 B.P. and 3990 (3900) 3830 B.P., or $1910-1700$ B.C. and $2040-1880$ B.C., respectively.

\section{Untyped}

Two points could not be typed (Figure $25 \mathrm{i}-$ j). The first specimen is a proximal fragment with the remnants of a substantially reworked blade. The blade is slender with slightly beveled, concave edges and strong shoulders. The shoulders may have been barbed at one point in time. The stem is straight with no edge grinding. The base is modified from having a portion removed, similar to the previously mentioned Ellis points. The material is a mottled brown chert.

The second specimen is a distal point tip. The remaining portion of the blade is a triangular specimen with some reworking on the edge. The material is brown chert with light tan mottles.

\section{Bifaces}

Twenty-two bifaces, mostly fragments, were recovered from $41 M L 162$. Provenience and metric data are provided in Table 6.

Six specimens (27 percent) are intact or nearly complete specimens. The remaining 16 (73 percent) are fragmentary. Early stage of reduction accounts for 50 percent $(n=11)$ of the specimens. The remainder represent middle $(n=1)$, late $(n=5)$, and finished stage $(n=4)$ bifaces, while 1 specimen is considered indeterminate in terms of reduction stage. Tool types consist of 2 knives (Figure 26a), 3 adzes (Figure 26b-c), 1 scraper, 1 graver, and 15 indeterminate bifaces (Figure 26d).

\section{Unifaces}

Seven unifaces were identified. Provenience and metric data are summarized in Table 7. J ust under half (43 percent, $n=3$ ) are intact or nearly complete artifacts. Most $(n=4)$ are scraping tools, including end and end/sidescrapers (Figure 26e). Two spokeshaves and 1 knife also are represented. Cortex is present on 71 percent $(n=5)$ of the assemblage.

\section{Cores}

Six cores were recovered. Provenience and metric data are presented in Table 8. All have more than three flake scars, and most $(n=4)$ display multiple directions of flake removal. The chert materials vary in col or from brown to light and very dark gray.

\section{Cobble Tool}

One cobble tool was found in Test Unit 4, Level $9(80-90 \mathrm{~cm})$. The tool is an intact wedge with use wear on one of its margins. Much of the nonworking edge of the tool is covered with cortex. The specimen measures $62.4 \mathrm{~mm} x$ $61.5 \mathrm{~mm}$, and it is $22.8 \mathrm{~mm}$ thick. The tool is made of a light tan chert.

\section{Edge-modified Debitage}

Forty-one pieces of edge-modified debitage were identified. Nineteen (46 percent) are complete flakes, 14 (34 percent) are proximal fragments, 7 (17 percent) are chips, and 1 (3 percent) specimen is a chunk. Twenty-six specimens (63 percent) have cortex on their dorsal surfaces. Most of the debitage $(n=21)$ has one modified edge, and 18 specimens have two modified edges. The remaining 2 pieces show three worked edges.

None of the specimens are smaller than $2 \mathrm{~cm}$ in size, and the largest piece is 6-7 cm. The two edge-modified flakes with three working edges are $2-3 \mathrm{~cm}$ in size. Overall, 44 percent ( $n=18)$ are $2-3 \mathrm{~cm}$ in size, and 34 percent $(n=14)$ are $3-4 \mathrm{~cm}$. The remaining 22 percent $(n=9)$ are $4-7 \mathrm{~cm}$. Raw material colors range from light brownish gray-the material used most frequently-to light and dark gray cherts.

\section{Unmodified Debitage}

A total of 1,106 pieces of unmodified debitage were recovered. Of those flakes, 249 (23 percent) are compl ete, 392 (35 percent) are proximal fragments, 373 (34 percent) are chips, and 92 (8 percent) are chunks. Cortex is absent on 59 percent $(n=652$ ) of the assemblage. Only 18 flakes ( $<2$ percent) have 100 percent dorsal cortex. The unmodified debitage ranges in size from less than 1 to $6 \mathrm{~cm}$. The $1-2-\mathrm{cm}$ size class 
Table 6. Provenience and metric data for bifaces from 41ML162

\begin{tabular}{|c|c|c|c|c|c|c|}
\hline Provenience & Tool Type & Completeness & Stage of Reduction & Length & Width & Thickness \\
\hline \multicolumn{7}{|l|}{ TEST UNIT 1} \\
\hline Level 11 (100-110 cm) & knife & distal & finished & - & - & 5.7 \\
\hline \multicolumn{7}{|l|}{ TEST UNIT 2} \\
\hline Level $3(20-30 \mathrm{~cm})$ & indeterminate & edge & late & - & - & 6.5 \\
\hline Level $3(20-30 \mathrm{~cm})$ & indeterminate & medial & finished & - & 36.7 & 7.2 \\
\hline Level $3(20-30 \mathrm{~cm})$ & indeterminate & edge & early & - & - & - \\
\hline Level 4 (30-40 cm) & indeterminate & distal & early & - & 25.3 & 16.3 \\
\hline Level $4(30-40 \mathrm{~cm})$ & indeterminate & medial & late & - & - & 4.1 \\
\hline Level 4 (30-40 cm) & indeterminate & wedge & late & - & - & 9.9 \\
\hline Level $5(40-50 \mathrm{~cm})$ & scraper & intact/nearly complete & early & 55.7 & 42.0 & 13.5 \\
\hline Level 5 (40-50 cm) & adze & intact/nearly complete & early & 66.4 & 43.8 & 18.3 \\
\hline Level 5 (40-50 cm) & indeterminate & intact/nearly complete & early & 48.5 & 39.0 & 16.5 \\
\hline Level 5 (40-50 cm) & knife & proximal & finished & - & 32.2 & 5.9 \\
\hline \multicolumn{7}{|l|}{ TEST UNIT 3} \\
\hline Level $3(20-30 \mathrm{~cm})$ & indeterminate & edge & indeterminate & - & - & 4.7 \\
\hline Level $3(20-30 \mathrm{~cm})$ & indeterminate & medial & early & - & 39.1 & 7.6 \\
\hline F eature $1(60-70 \mathrm{~cm})$ & indeterminate & intact/nearly complete & middle & 60.4 & 40.1 & 16.9 \\
\hline F eature $1(60-70 \mathrm{~cm})$ & adze & intact/nearly complete & late & 49.6 & 38.4 & 14.6 \\
\hline F eature 1 (70-80 cm) & indeterminate & barb & late & - & - & 6.5 \\
\hline \multicolumn{7}{|l|}{ TEST UNIT 4} \\
\hline Level $4(30-40 \mathrm{~cm})$ & graver & distal & finished & - & - & 6.4 \\
\hline Level $5(40-50 \mathrm{~cm})$ & indeterminate & edge & early & - & - & 18.0 \\
\hline Level 6 (50-60 cm) & adze & intact/nearly complete & early & 59.1 & 39.2 & 21.7 \\
\hline Level $6(50-60 \mathrm{~cm})$ & indeterminate & edge & early & - & - & 10.3 \\
\hline Level $12(110-120 \mathrm{~cm})$ & indeterminate & edge & early & - & - & 15.5 \\
\hline \multicolumn{7}{|l|}{ TEST UNIT 5} \\
\hline Level $12(110-120 \mathrm{~cm})$ & indeterminate & edge & early & - & - & 16.0 \\
\hline
\end{tabular}

Note: All measurements are in millimeters. 

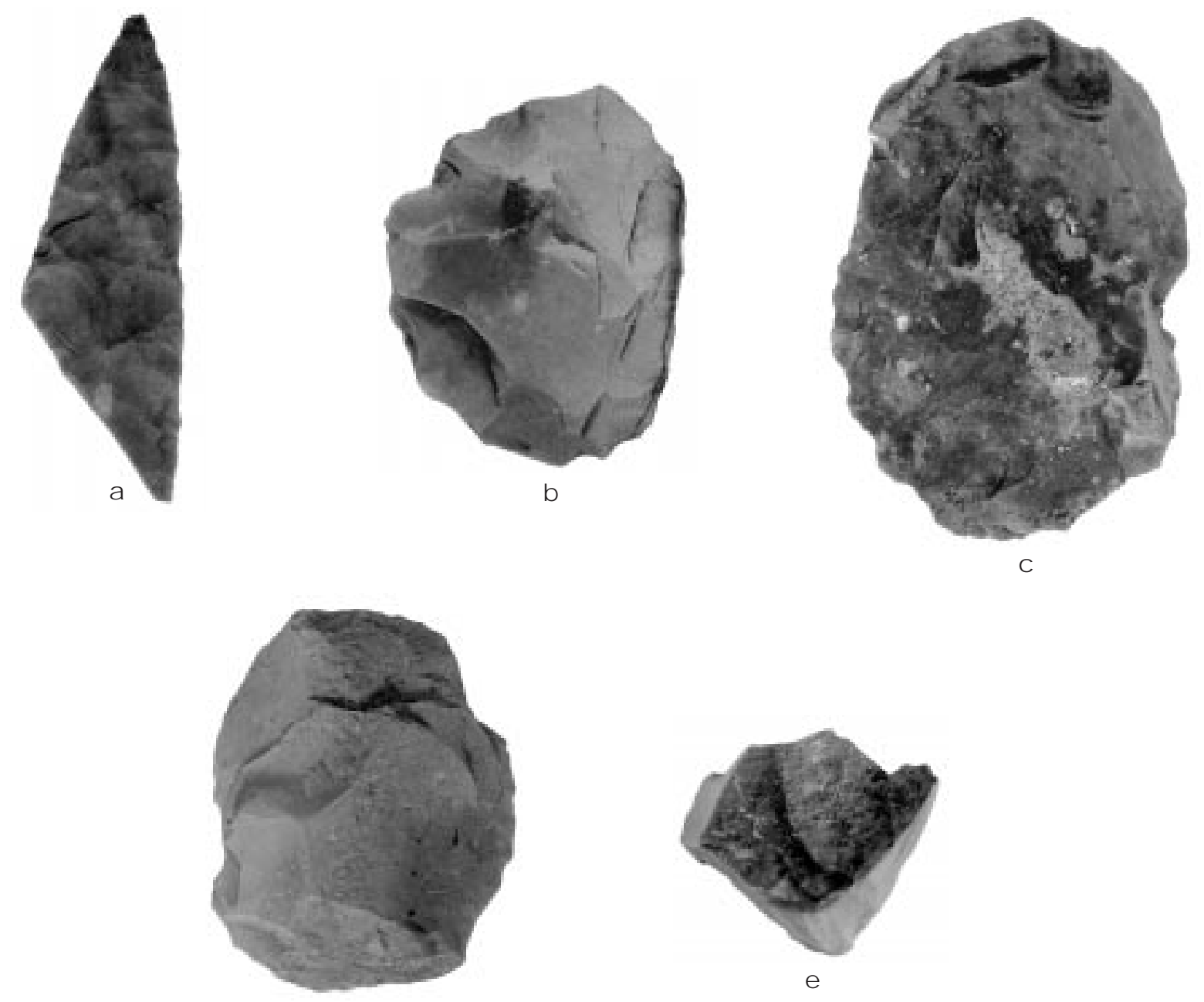

d

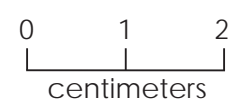

Figure 26. Bifaces and a uniface from 41ML 162. (a) Knife; (b-c) adzes; (d) indeterminate biface; (e) end/side scraper.

is represented by 53 percent $(n=590)$ of the debitage. The second most-frequent size class is $2-3 \mathrm{~cm}$, as represented by 28 percent $(n=303)$ of the assemblage. Seven percent $(n=77)$ of the debitage are less than $1 \mathrm{~cm}$ in size, and 12 percent $(n=136)$ are $3-6 \mathrm{~cm}$ in size. Raw material colors vary from light mottled gray or dark gray cherts, the more common color, to variations of brown. An almost black chert material was noted but is rare. Many flakes display a pinkish hue from thermal alteration.
INVERTEBRATE FAUNAL REMAINS

Four hundred sixty-four of the 820 mussel shells collected are complete enough for taxonomic identification (seeAppendix B). The taxa consist of Amblema plicata, Cyrtonaias tampicoensis, Leptodea fragilis, Potamilus purpuratus, Potamilus sp., Quadrula apiculata, Quadrula petrina, Quadrula sp., and Tritogonia verrucosa (one fossil oyster [Cretaceous] also was identified). By far the most common taxon ( $n=299$ ) is Amblema plicata (threeridgemussel). 
Table 7. Provenience and metric data for unifaces from $41 \mathrm{ML} 162$

\begin{tabular}{|c|c|c|c|c|c|c|}
\hline Provenience & Tool Type & Completeness & Cortex & 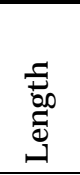 & $\frac{5}{\frac{1}{0}}$ & 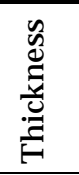 \\
\hline \multicolumn{7}{|l|}{ TEST UNIT 1} \\
\hline Level $11(100-110 \mathrm{~cm})$ & knife & medial & present & - & 21.4 & 8.6 \\
\hline \multicolumn{7}{|l|}{ TEST UNIT 2} \\
\hline $\begin{array}{l}\text { Level } 4(30-40 \mathrm{~cm}) \\
\text { Level } 5(40-50 \mathrm{~cm}) \\
\text { Level } 8(70-80 \mathrm{~cm})\end{array}$ & $\begin{array}{l}\text { spokeshave } \\
\text { end/side scraper } \\
\text { end scraper }\end{array}$ & $\begin{array}{l}\text { distal } \\
\text { proximal } \\
\text { distal }\end{array}$ & $\begin{array}{l}\text { absent } \\
\text { present } \\
\text { absent }\end{array}$ & $\begin{array}{l}- \\
-\end{array}$ & $\begin{array}{l}26.6 \\
22.3 \\
24.2\end{array}$ & $\begin{array}{l}5.3 \\
9.7 \\
4.1\end{array}$ \\
\hline \multicolumn{7}{|l|}{ TEST UNIT 3} \\
\hline Level 4 (30-40 cm ) & spokeshave & intact/nearly complete & present & 29.7 & 34.2 & 13.1 \\
\hline \multicolumn{7}{|l|}{ TEST UNIT 4} \\
\hline $\begin{array}{l}\text { Level } 7(60-70 \mathrm{~cm}) \\
\text { Level } 11(100-110 \mathrm{~cm})\end{array}$ & $\begin{array}{l}\text { end scraper } \\
\text { end/side scraper }\end{array}$ & $\begin{array}{l}\text { intact/nearly complete } \\
\text { intact/nearly complete }\end{array}$ & $\begin{array}{l}\text { present } \\
\text { present }\end{array}$ & $\begin{array}{l}20.1 \\
31.1\end{array}$ & $\begin{array}{l}27.6 \\
26.4\end{array}$ & $\begin{array}{r}4.8 \\
10.6\end{array}$ \\
\hline
\end{tabular}

Note: All measurements are in millimeters.

\section{VERTEBRATE FAUNAL REMAINS}

Bone preservation at 41ML 162 is good. Of the 261 specimens collected, 230 were analyzed (see Appendix C). The remaining unanalyzed fragments were either recovered from flotation ( $n=25$ ) (see Cultural Features) or inadvertently left out of the faunal analysis $(n=6)$. The 6 latter specimens vary in size from 1 to $3 \mathrm{~cm}$, and 3 appear to be burned.

Seventeen ( 7 percent) of the analyzed specimens could be identified at the genus/species or family level (Table 9). Bison, deer, cottontail rabbits, turtles, and drum are the species or families identified. At the order level, Artiodactyla is represented by 21 (9 percent) goat/deersized specimens and 3 (1 percent) cow/ bison-sized specimens. The class level consists

Table 8. Provenience and metric data for cores from $41 \mathrm{ML} 162$

\begin{tabular}{|c|c|c|c|c|c|}
\hline Provenience & $\begin{array}{l}\text { Number of } \\
\text { Flake Scars }\end{array}$ & $\begin{array}{l}\text { Direction of } \\
\text { Flake Scars }\end{array}$ & Length & Width & Thickness \\
\hline \multicolumn{6}{|l|}{ TEST UNIT 1} \\
\hline Level 11 (100-110 cm) & 8 & multidirectional & 63.3 & 50.2 & 28.2 \\
\hline \multicolumn{6}{|l|}{ TEST UNIT 2} \\
\hline $\begin{array}{l}\text { Level } 4(30-40 \mathrm{~cm}) \\
\text { Level } 9(80-90 \mathrm{~cm})\end{array}$ & $\begin{array}{l}3 \\
6\end{array}$ & $\begin{array}{l}\text { unidirectional } \\
\text { multidirectional }\end{array}$ & $\begin{array}{l}45.4 \\
93.4\end{array}$ & $\begin{array}{l}20.7 \\
43.1\end{array}$ & $\begin{array}{l}15.8 \\
29.9\end{array}$ \\
\hline \multicolumn{6}{|l|}{ TEST UNIT 3} \\
\hline F eature $1(50-60 \mathrm{~cm})$ & 9 & multidirectional & 43.5 & 31.2 & 25.7 \\
\hline \multicolumn{6}{|l|}{ TEST UNIT 4} \\
\hline $\begin{array}{l}\text { Level } 12(110-120 \mathrm{~cm}) \\
\text { Level } 12(110-120 \mathrm{~cm})\end{array}$ & $\begin{array}{l}3 \\
4\end{array}$ & $\begin{array}{l}\text { unidirectional } \\
\text { multidirectional }\end{array}$ & $\begin{array}{l}62.5 \\
87.9\end{array}$ & $\begin{array}{l}41.7 \\
47.5\end{array}$ & $\begin{array}{l}27.1 \\
21.6\end{array}$ \\
\hline
\end{tabular}

Note: All measurements are in millimeters. 
Table 9. Vertebrate faunal remains from 41ML 162

\begin{tabular}{lc}
\hline Taxa & Quantity \\
\hline Osteichthyes (medium-sized) & 2 \\
Sciaenidae (drum) & 1 \\
Testudinata (turtles) & 11 \\
Sylvilagus sp. (cottontail rabbits) & 2 \\
Odocoileus sp. (deer) & 2 \\
Bos/ Bison (cow/bison) & 1 \\
Artiodactyla (goat/deer-sized) & 21 \\
Artiodactyla (cow/bison-sized) & 3 \\
Mammalia (rabbit/canid-sized) & 1 \\
Mammalia (canid/deer-sized) & 114 \\
Mammalia (large/very large) & 26 \\
Vertebrata (vertebrates) & 46 \\
\hline TOTALS & 230 \\
\hline
\end{tabular}

of specimens of Osteichthyes (bony fishes) $(n=2)$ and Mammalia $(n=141)$. The Mammalia specimens consist of 1 rabbit/canid-sized, 114 canid/deer-sized, and 26 large/very large animals. This suggests that deer is probably the most common species represented in the assemblage. Twenty percent of the assemblage $(n=46)$ are only recognizable as Vertebrata.

\section{OTHER MATERIALS}

Other cultural materials recovered at thesite include pottery; ground, pecked, and battered stonetool s; burned clay lumps; and burned rocks. Because burned rocks from nonfeature contexts were not consistently quantified, detailed recovery summaries cannot be provided. However, nonfeature burned rock weights for entire test units consist of ca. $8 \mathrm{~kg}$ for Test Unit 1, ca. $41 \mathrm{~kg}$ for Test Unit 2, ca. $3 \mathrm{~kg}$ for Test Unit 3, ca. $34 \mathrm{~kg}$ for Test Unit 4, and ca. $1 \mathrm{~kg}$ for Test Unit 5.

\section{Pottery}

One small, undecorated pottery sherd was recovered from Feature 1 (Test U nit 3, Level 7 [60- $70 \mathrm{~cm}]$ ). Although the finished interior surface is not preserved, the exterior surface of the sherd is smoothed. It appears to be shell tempered. The sherd is less than $1 \mathrm{~cm}$ in size, and the vessel part cannot be determined. The maximum thickness of the sherd is $4.8 \mathrm{~mm}$.

Ground, Pecked, and Battered StoneTools

Four ground, pecked, and battered stone tools were recovered. All are of fineto medium-grained quartzite. Provenience and metric data are presented in Table 10. The first specimen, from Test Unit 1, is oblate or disk-shaped. It exhibits pecked and battered surfaces on both ends, suggesting it functioned as a hammerstone. The second artifact, from Test U nit 2, is a larger oblate tool that is ground smooth on one face. It may have functioned as a mano. The third tool, from Test Unit 3, is spheroidal. It has both pecked surfaces and small grinding facets on its faces and ends. This tool may have been used as a grinding stone as well as a hammerstone. The last specimen also is from Test Unit 3. It is oblate or disk-shaped (Figure 27). While there is pecking on the faces and ends, one end is heavily battered. This tool served as a hammerstone, and it may have been used for other purposes such as processing nuts.

\section{Burned Clay Lumps}

A total of $1.0 \mathrm{~kg}$ of burned clay lumps were recovered, the vast majority $(0.9 \mathrm{~kg})$ from Level $5(40-50 \mathrm{~cm})$ of Test Unit 2. Most are $1-3 \mathrm{~cm}$ in size and lack impressions, but a small number clearly display grass, twig, and stick impressions. It is possible that these specimens, as well as many of those lacking impressions, could be daub from a wattle-and-daub structure. Supporting this notion is the presence of a mud dauber nest in and amongst the many burned clay lumps recovered from Level 5 of Test U nit 2. In natural settings, mud daubers, or the common black and yellow wasp (Sceliphron sp.), build their nests in protective settings, such as under cliff overhangs and in hollow trees (Evans and E berhard 1970:102). Shelters and other human-built structures providesimilar protective settings that are used by mud daubers for the placement and construction of nests. At the Peerless Bottoms site (41HP175) in Hopkins County, several mud dauber nests with grass and small stick impressions were recovered from and around a hearth feature (see Fields 
Table 10. Provenience and metric data for ground, pecked, and battered stone tools from 41ML162

\begin{tabular}{|c|c|c|c|c|c|c|c|}
\hline Provenience & Wear Location and Type & 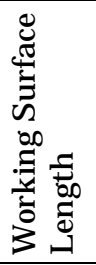 & 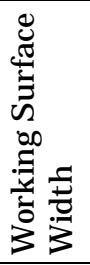 & $\begin{array}{l}\frac{\sigma}{5} \\
\frac{\sigma}{d} \\
\end{array}$ & $\frac{5}{\frac{1}{0}}$ & 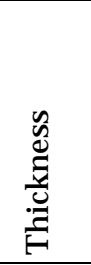 & $\begin{array}{l}\frac{+}{0} \\
\frac{0}{0} \\
3\end{array}$ \\
\hline \multicolumn{8}{|l|}{ TEST UNIT 1} \\
\hline Level 11 (100- $110 \mathrm{~cm})$ & both ends, pecked and battered & 36.5 & 15.5 & 68.1 & 55.8 & 23.7 & 139.2 \\
\hline \multicolumn{8}{|l|}{ TEST UNIT 2} \\
\hline Level $5(40-50 \mathrm{~cm})$ & one face, ground smooth & 80.8 & 78.7 & 109.0 & 81.9 & 52.1 & 668.0 \\
\hline \multicolumn{8}{|l|}{ TEST UNIT 3} \\
\hline Level 4 (30-40 cm) & $\begin{array}{l}\text { faces and ends, pecked and } \\
\text { ground }\end{array}$ & 60.5 & 40.6 & 61.7 & 46.9 & 43.8 & 158.0 \\
\hline Level 4 (30-40 cm) & faces and ends, pecked & 52.5 & 22.1 & 65.3 & 59.0 & 31.7 & 180.9 \\
\hline
\end{tabular}

Note: All measurements are in millimeters or grams.

et al. 1993:216-218). Based on the co-occurrence of burned clay lumps and other cultural materials and the behavioral aspects of mud daubers, Fields et al. (1993:218) make a convincing argument for the presence of sometype of structure, possibly of wattle-and-daub, at the site. The same might be said for $41 M L 162$, i.e., that the remains of some sort of wattle-and-daub structureare present in the vicinity of Test Unit 2; however, its dimensions, function, and age are not known at this time.

\section{Chronology and Components}

A combination of radiocarbon dates, temporally diagnostic artifacts (projectile points), and soil stratigraphy allows for the delineation of interpretable components and chronology at 41ML 162. I deally, deposition, when relatively concurrent with occupations, produces archeological sites in which the different occupations can be separated or isolated from one another for study (Ferring 1986). Thus, the eastern half of the site (Test U nits 2 and 3 ) should yiel d discrete components with good contextual integrity, given its history of more or less continuous aggradation. However, the cultural materials and chronological data recovered from bel ow the Ab horizon on the eastern half of the site are so limited that it is difficult to define any meaningful components. Even more difficult is de- lineating components for the cultural materials derived from the Ab horizon, even though the soil is cumulic in nature. Projectile point styles from this soil suggest that multiple components representing a time span encompassing the latter part of the Late Archaic through the Toyah phase are mixed and compressed within the soil. Conversely the western half of the site (Test Units 1, 4, and 5) with its multiple buried soils yielded enough cultural materials (including diagnostics) and chronological data in fairly discrete packages that meaningful and interpretable components can be defined. Therefore, the defined components do not represent all the cultural materials and features re covered at 41ML 162.

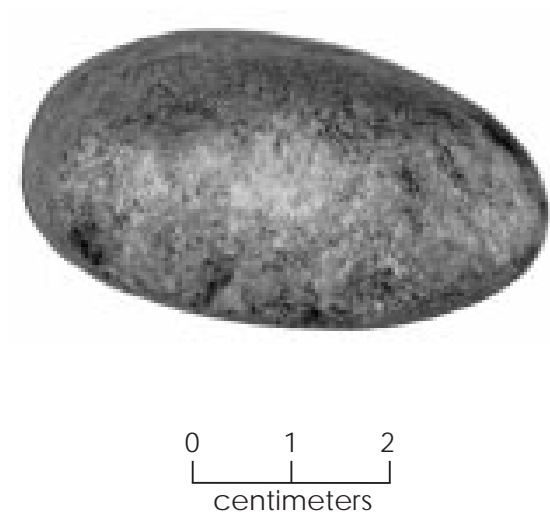

Figure 27. Ground stone tool from 41ML162. 
Five components are defined. The first, and most recent, consists of those artifacts and other materials recovered from the upper part of the Ab horizon (Levels 6-8 of Test Units 1 and 5, and Level 4 of Test Unit 4). No diagnostic artifacts are included in this component, but a radiocarbon age on oak wood charcoal from Test Unit 5, Level $8(72 \mathrm{~cm})$, produced a radiocarbon age of $810 \pm 40$ B.P. (Beta-154291), suggesting that the associated cultural materials are affiliated with the latter portion of the Austin phase or early Toyah phase. Artifacts and other materials associated with this $L$ ate Prehistoric component consist of 1 bifacial graver, 3 pieces of edge-modified debitage, 27 pieces of unmodified debitage, 29 mussel shells, and 26 pieces of bone. The small debitage assemblage suggests that cortical materials (chert cobbles) were reduced on site, probably for the production of bifacial tools. Flakes were utilized to complete expedient tasks, but these flakes probably were the byproducts of reduction rather than the final product. Other possible activities might include wood and bone engraving, based on the recovery of a graver. Though none of the vertebrate faunal remains are identified at the genus or species level, the specimens probably represent deer and bison, given the presence of medium-sized Artiodactyla, medium-sized to large mammals, and large to very large mammalian elements. The majority of the mussel shells are unidentifiable, and Amblema plicata (threeridge mussel) is the most common. Considering no Scallorn arrow points were recovered, the balance of the evi dence suggests that this component might represent an early Toyah phase occupation. A Perdiz arrow point was recovered from the mixed deposits on the eastern half of the site, and though not clearly identified, probablebison remains are part of the faunal assemblage. A subsistence strategy focused on bison hunting is often attributed to Toyah peoples, which is a radical departure from the subsistence practices attributed to the preceding Austin phase peoples (Collins 1995; Prewitt 1981).

The second component consists of artifacts and other materials also recovered from the $A b$ horizon (Levels 9-10 of Test Unit 1, Levels 910 of Test Unit 5, and Levels 5-6 of Test Unit 4). An Ensor dart point is the only diagnostic artifact associated with this component. A radiocarbon age on bulk soil $(50-60 \mathrm{~cm})$ yiel ded a radiocarbon age (1720 \pm 60 B.P., Beta-154293) that is consistent with Prewitt's (1981) Twin Sisters phase, of which the Ensor point is considered an index marker. It is probable that Feature 1 (the burned rock midden [or at least a portion of it]) and the Ellis points from the eastern half of the site are associated with this component based on the radiocarbon age from Feature 1 (1980 \pm 60 B.P., Beta-154279) and general age estimates for Ellis points (Prikryl 1990:56-57). The age estimate for this component based on the chronological data is ca. 20001400 B.P. Artifacts and other materials associated with this later Late Archaic component consist of 1 dart point (Ensor); 3 bifaces, including an adze; 8 edge-modified flakes; 192 pieces of unmodified debitage; 117 mussel shells; and 22 pieces of bone. The debitage assemblage indicates that the cortex of most materials probably was removed elsewhere, and raw materials may have been brought to the site as large blanks and preforms. The on-site reduction of raw materials probably was geared toward bifacial tool production. Flake byproducts appear to have been used occasionally for expedient tasks but were never the focus of tool production themselves. The bifacial tools along with the expedient tools indicate a variety of activities, such as hunting, game processing, and woodworking. The vertebrate faunal assemblage, consisting largely of medium-sized to large mammalian and medium-sized Artiodactyla el ements, suggests that deer were a large part of a diet that included turtles and mussels. If associated with this component, the burned rock midden indicates intensive processing of plant foods. Prewitt (1981:81) notes that a wide array of food sources was utilized during this time period.

The third component consists of artifacts, features, and other materials recovered from the base of the Ab horizon (Levels 11-12 of Test Units 1 and 5, and Levels 7-8 of Test Unit 4). Three radiocarbon ages are associated with this component. Two are from Feature 2 (see Cultural Features). The third is from charcoal collected from Level $12(112 \mathrm{~cm})$ of Test U nit 1, which produced a radiocarbon age of $2210 \pm$ 40 B.P. (Beta-154283). Though no diagnostic artifacts are part of this component, it is probable that the Marcos dart point from Test Unit 2 , Level 4, is associated with this component based on the age estimates for this point style (Collins 1995; J ohnson and Goode 1994; Prewitt 
1981, 1985). These chronological data date the component to ca. 3000 and 2000 B.P. Component artifacts and other materials consist of 2 bifaces, including a knife fragment; 2 unifaces consisting of a knife fragment and end scraper; 1 core; 4 pieces of edge-modified debitage; 124 pieces of unmodified debitage; 1 ground, pecked, and battered stone tool; 79 mussel shells; and 13 pieces of bone. The debitage assemblage indicates that some cortical materials were reduced initially at the site and that reduction strategies probably were geared toward the production of bifaces. Although the production of bifacial tools resulted in numerous flakes, few were utilized. Expedient flake tools and, more commonly, formal tools were used to complete a variety of tasks. Along with plant food processing suggested by the small burned rock feature (Feature 2), game and hide processing are two probable site activities. The small vertebrate faunal assemblage includes medium-sized to large mammalian el ements and one deer element. Some of the elements are burned and charred. Aside from deer, mussels also appear to have been a small part of the diet.

The fourth component consists of artifacts and other materials recovered from the $2 A b$ horizon (Levels 11-13 of Test Unit 4). Three radiocarbon ages are associated with this component. Two charcoal samples collected from Levels $12(110-120 \mathrm{~cm})$ and $13(127 \mathrm{~cm})$ produced radi ocarbon ages of $3600 \pm 40$ B.P. (Beta154282) and $3490 \pm 40$ B.P. (Beta-154292), respectively. The third radiocarbon age of 3400 \pm 70 B.P. (Beta-154294) is on bulk soil collected from the 2Ab horizon. No diagnostic artifacts are associated with this component, but the radiometric data appear to securely date the component to ca. 4000-3600 B.P., or the early LateArchaic. The component artifacts and other materials consist of 1 indeterminate early stage biface, 1 unifacial end/side scraper, 2 cores, 1 piece of edge-modified debitage, 45 pieces of unmodified debitage, 72 mussel shells, and 1 piece of bone. Though small, the chipped stone artifact assemblage suggests that cortex-covered chert cobbles were reduced initially at the site and that the reduction strategies probably focused on the production of bifaces. Flake byproducts appear not to have been used extensively for expedient tasks. The small formal tool assemblage does not offer many insights into what other tasks took place at the site, other than possibly hide and/or woodworking activities. Faunal remains indicate that mussels and a large to very large mammal (s) were consumed. The mussel shell assemblages in the three later components are dominated by the species Amblema plicata (threeridge mussel), but in the early Late Archaic component Quadrula sp. and A. plicata are equally dominant. Whether this dominance by a single species (A. plicata) later in time is an artifact of human preference or change in environment or habitat is not known, although the preferred habitats of both species are similar.

The fifth and earliest component consists of artifacts and other materials recovered from the $3 \mathrm{ABb}$ horizon (Levels 16-18, Test Unit 4). Dating of this component is tenuous, as no radiocarbon assays are available. However, a single projectile point (termed Provisional Type 1) suggests that the component dates to ca. 5000-4000 B.P., based on a similar point style from dated contexts at Fort Hood (see K leinbach et al. 1999:335-344). This timeframe places the component in the latter part of the Middle Archaic. Component artifacts and other materials consist of 1 dart point (Provisional Type 1 ), 3 pieces of edge-modified debitage, 29 pieces of unmodified debitage, 60 mussel shells, and 11 bone fragments. Though small, the debitage assemblage suggests that chert cobbles were reduced initially at the site. Tool production was probably geared toward the manufacturing of bifacial tools, and the flake byproducts occasionally were used to complete expedient tasks. What activities these bifacial tools might have been used for are difficult to say given the nearabsence of formal tools. Much of the vertebrate faunal assemblage is represented by mediumsized to large mammalian el ements (some burned), suggesting that deer was probably a large part of the diet. Turtles and mussels also were consumed at the site during this time period.

\section{Summary and Assessment}

The contextual integrity, stratigraphic separation, and preservation of many of theartifacts, features, and other materials recovered from 41ML162 are exceptional and, in conjunction with the chronological data, provide the necessary elements for the delineation of interpretable components or units of study. The 
components date from the latter part of the MiddleArchaic period (ca. 5000 B.P.) to theToyah phase. Inhabitants of the site during this time frame utilized the locality as a base camp, given the variety of activities and tasks indicated by the artifacts and features. How these activities and tasks changed or stayed the same over this ca. 4,500-year period is not fully understood at this time, though it is believed that the site has the capacity to yield data relevant to these questions. A more-specific issue that can be addressed is subsistence and diet throughout this time period, based on the preservation of faunal remains and other organic materials, which also may serve as proxy indicators of environmental change. The recovery of discrete tool assemblages from well-dated contexts would provide substantial data on thechanges (or stability) in tool kits over time and the potential ability to identify diagnostic assemblage characteristics. The same can be said for features at the site, in terms of their function, morphology, and composition, as well as how or why these attributes changed or stayed the same over time. For these reasons, it is recommended that 41ML 162 be considered el igi ble for listing in the National Register of Historic Places.

\section{Site 41ML 179}

\section{Description}

Site 41ML 179 consists of the structural remains of a farmstead established by Nicholas and J ennett Sneed in 1866. It is situated at an elevation of 460 to $462 \mathrm{ft}$ on a higher alluvial surface, probably representing a Pleistocene terrace, on the north side of Hog Creek near where the creek enters Waco Lake (see Figure 4). The site is ca. $75 \mathrm{~m}$ northeast of the creek. On the limestone creek bank opposite the site are two springs/seeps. Vegetation in the area consists of pecan, oak, elm, bois d'arc, and juniper trees with a thick understory of greenbriers and shrubs.

\section{Previous Investigations}

Site 41ML 179 was recorded, shovel tested, and subjected to archival investigation in 1984 (Prikryl and J ackson 1985:229-231). Scattered limestoneand sandstone rocks were noted al ong with sparse historic artifacts over a 115×35-m area. A clearing with a mound of limestone rubble in the west-central part of this area was interpreted as representing the former housesite.

Two shovel tests were excavated. The first was at the western end of the site and was excavated to a depth of $30 \mathrm{~cm}$. The soil was clayey, and artifacts (one ironstone sherd and one bottle glass fragment) were recovered only from the first $15 \mathrm{~cm}$. The second test was just east of the limestone rubble mound and was excavated to a depth of $23 \mathrm{~cm}$. Recovered artifacts included ironstone sherds, bottle and window glass fragments, a cut nail, and miscellaneous metal fragments.

Archival research revealed that the site occupies land that was once part of a 743-acre tract owned by William Badger, who sold portions of his estate to the Corps of Engineers in 1962. Badger acquired theland fromJ osephine McLennan, whoinherited the property from her father, Neil McLennan. Neil McLennan bought theland in 1877 from Nicholas Sneed after their home (which the site's structural remains apparently represent) burned in 1877. The home was not rebuilt after the fire.

Site 41ML 179 was revisited in 1999 (K vernes et al. 2000:57-58) as part of a site re-location and reassessment effort. It was found to be in much the same condition as originally reported. Nosign of additional disturbance or impacts was noted. The rubble mound was identified, and some of the stones were lying flat, suggesting that they represent an intact foundation feature. Very few surface artifacts were observed. Two shovel tests were excavated near the rubble mound to assess site integrity and date the deposits. As with the original shovel tests, brown clay loam soils were noted to a depth of $30 \mathrm{~cm}$. Shovel Test 99-1 yielded green transfer-printed whiteware $(n=5)$, undecorated ironstone $(n=1)$, aqua container glass $(n=2)$, window glass $(n=1)$, aqua glass slag $(n=$ $5)$, porcelain buttons $(n=2)$, cut nails ( $n=17)$, tin can fragments $(n=2)$, and a wire fragment $(n=1)$. Shovel Test 99-2 yiel ded undecorated ironstone $(n=2)$, brown container glass $(n=2)$, and clear container glass $(n=6)$.

All artifacts recovered were consistent with the suggested period of occupation, 1866-1877. No intrusive or later artifacts were discovered. Several ceramic sherds had scorch marks, melted glass was present, and 
one of the porcelain buttons had been partially warped due to exposure to fire, supporting the house fire indicated in the archival record. The five sherds of transfer-printed whiteware were uncovered lying adjacent to one another. All sherds crossmended, suggesting that they were lying where they fell when fire destroyed the house. Thus, the shovel testing suggested that an intact, buried component is present at 41ML179.

\section{Work Accomplished}

During the 2000-2001 investigations, a long rebar stake was used as the primary datum and was given an arbitrary elevation of $100.00 \mathrm{~m}$. The datum was placed ca. $6 \mathrm{~m}$ northwest of the center of Feature 1 (the rubble mound). A second datum (rebar) was placed near a large burr oak tree in the western part of the site, ca. $28 \mathrm{~m}$ southwest of the center of Feature 1.

The surface inspection yiel ded few artifacts since abundant leaf litter covers the area. Two ceramic sherds were found on the eastern edge of the site, while a clear bottle fragment was observed not far from Feature 1. Except for the obvious rubble pile making up Feature 1 , no other features were identified. Feature 1 was swept to remove the leaf debris, photographed, and drawn in plan view.

Four test units were hand excavated (Figure 28). All began at modern ground surface and were terminated at $30-60 \mathrm{~cm}$. Test Units 1 and 2 were placed on the eastern part of the Feature 1 rubble pile. Both units ended with Level 6 . Test Unit 3 was placed just off the mound area to the east among a surface scatter of stone structural debris. This test unit was ended at Level 3. Test Unit 4 was south of Test Unit 3 and southeast of the Feature 1 mound, adjacent to Shovel Test 99-1 excavated in 1999. Excavations ceased in Level 4 of this unit. No new features were encountered in either Test Unit 3 or 4 . In total, $1.9 \mathrm{~m}^{3}$ were hand excavated.

\section{Site Extent and Depth}

Whilethe property owned by the Sneed family encompassed a larger area, the site where the house once stood and its periphery cover ca. $700 \mathrm{~m}^{2}$. The cultural zone at the site averages ca. 30-40 cm in thickness. Sediments consist of a 30-40-cm-thick dark brown clay loam over a sterile darker brown clay loam with abundant gravels. Forty-five percent of the 814 artifacts recovered from the test pits werefrom the upper $20 \mathrm{~cm}$. Almost all of the remainder $(53$ percent, $n=429$ ) were from $20-40 \mathrm{~cm}$, with most materials coming from the subsurface component of Feature 1 in Test Units 1 and 2. That zone appears to represent a buried concentration of destruction debris. Test unit yields across the site are Test U nit $1(n=246)$, Test U nit 2 $(n=232)$, Test Unit $3(n=71)$, and Test U nit $4(n=265)$.

\section{Cultural Feature}

One feature, Feature 1, was identified and tested. It is represented by a low (ca. $35 \mathrm{~cm}$ ) rubble mound covering about $5 \mathrm{~m}$ north-south by 4.5 m east-west (Figure 29). Other than the various limestone and sandstone fragments, no artifacts are present on the surface. Test Units 1 and 2 made up a $1 \times 2-m$ unit on the eastern side of the mound. Test Unit 1 , to the south, examined the higher part of the mound, while Test Unit 2, to the north, examined the lower area on the mound periphery.

Excavation of Feature 1 revealed cut sandstone blocks, including large in situ foundation stones, and numerous artifacts. Many of the dressed blocks have mortar between them. Both limestone and sandstone were observed in the feature fill. Much of the material is burned. Recovery from the upper $10 \mathrm{~cm}$ of both units excavated in the feature consisted primarily of jumbled burned stone and mortar fragments in a loose, loamy fill deposit. At $10-20 \mathrm{~cm}$, the density of jumbled stones increased in Test Unit 1, as did artifact recovery. The rocks exhibited fire fractures, and large amounts of sediment were present between the stones. About half of Test Unit 2 was covered by intact chimney fall at this depth, with the linear alignment of the stones suggesting that the collapse fell in a northward direction.

By $20-30 \mathrm{~cm}$, many more of the stones uncovered appeared to be in situ, representing the upper portion of the intact base of the chimney feature. In Test U nit 1, stacked, mortared stones were observed across the entire unit but were concentrated in the southwestern quadrant. Few intrusive artifacts were recovered from amongst them. In Test Unit 2 to the north, a burned deposit with ash, many 
National Register Testing of NineArcheol ogical Sites at Waco L ake

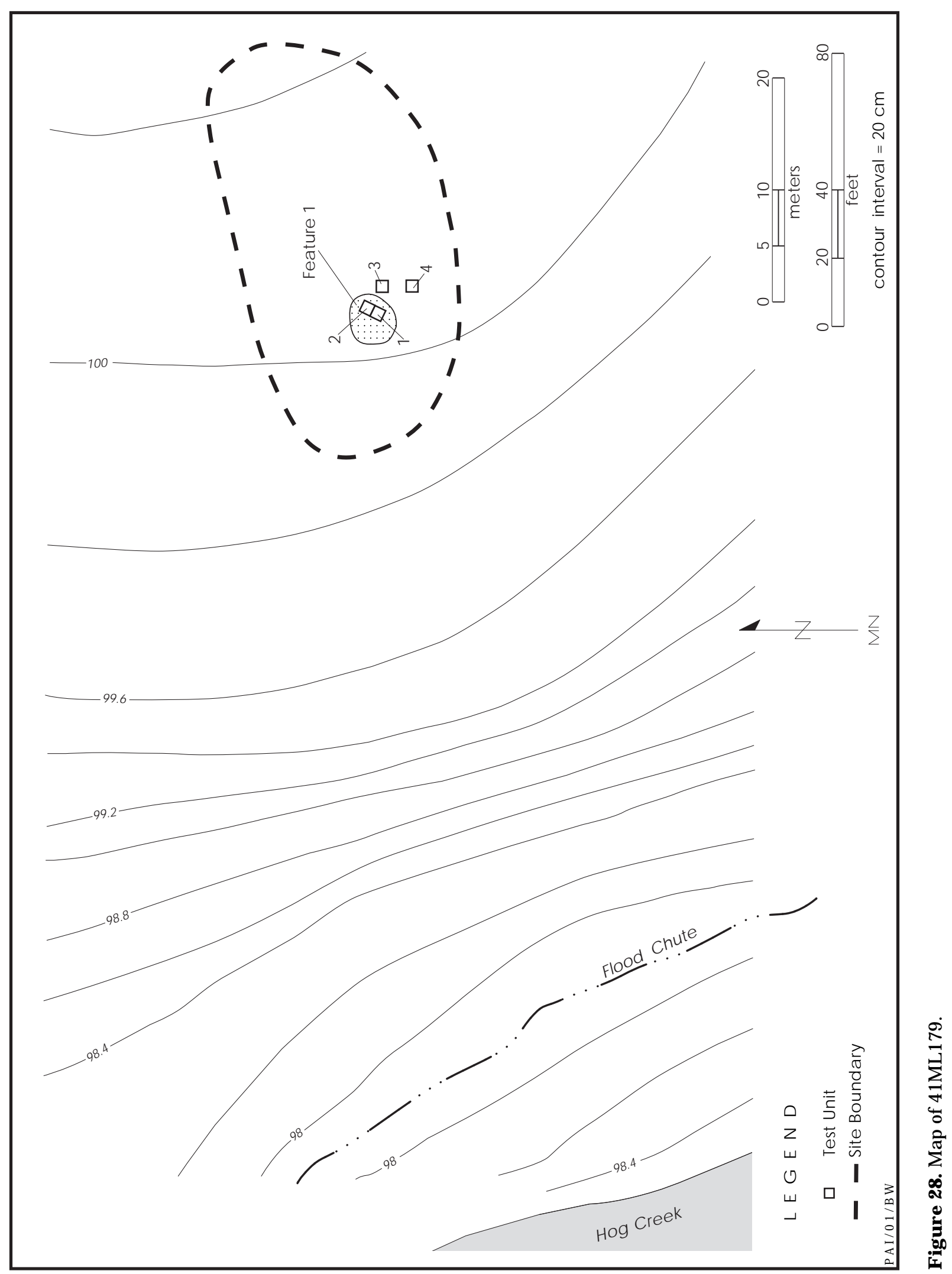


Chapter 4: Results of Test Excavations

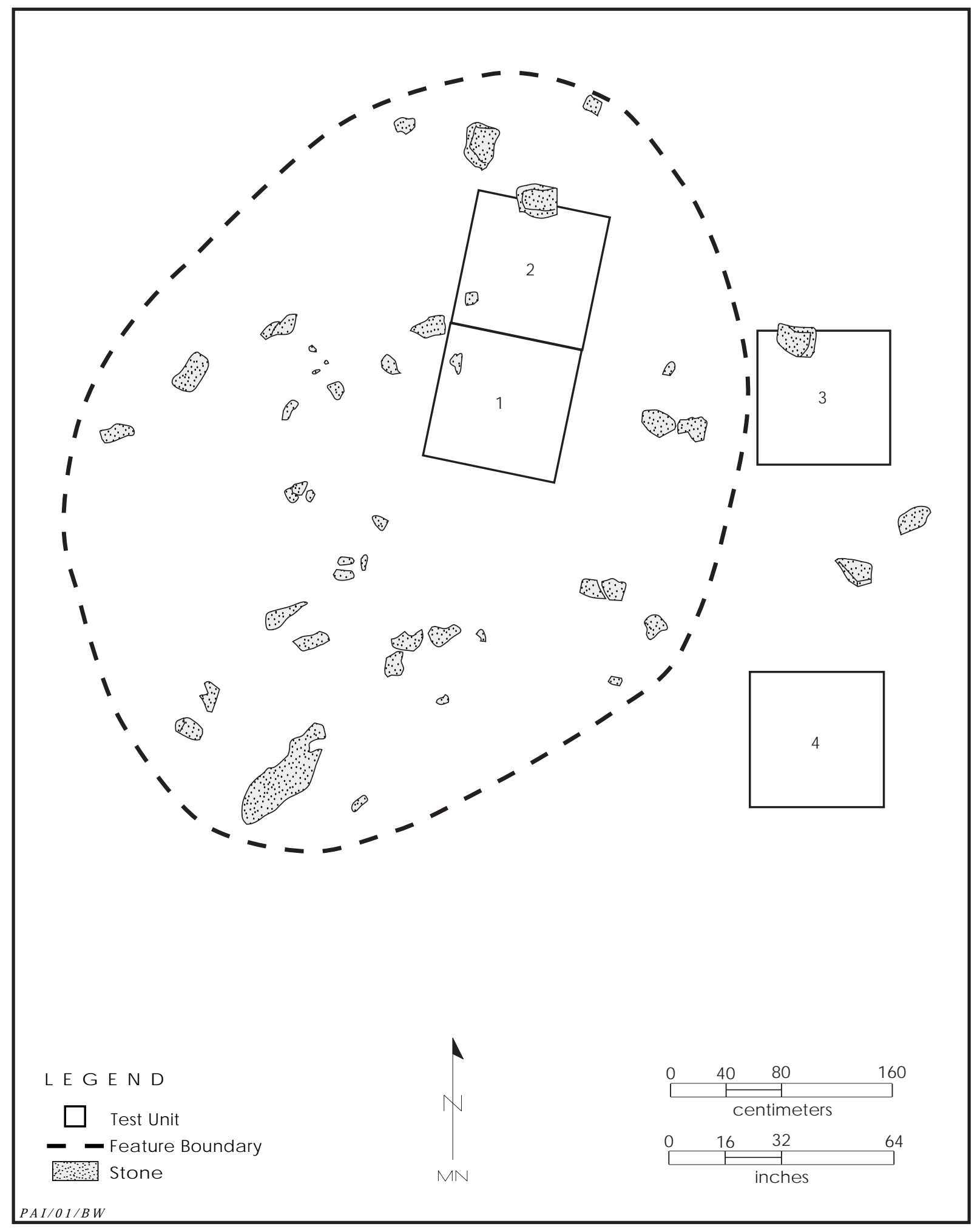

Figure 29. Plan view of Feature 1 at the Shed Farmstead, 41ML179.

75 
artifacts, and little stone or mortar covered the eastern half of the unit. At $30-40 \mathrm{~cm}$, the rocks in the western half of Test Unit 1 were larger (30×30 cm and larger) and mortared together in courses (Figure 30), representing the intact base of the foundation. Little intrusive sediment/debris or thermal fracturing was noted. Test U nit 2 had few stones or mortar across its entire extent at this level but yiel ded many more artifacts in a burned and ashy matrix. Little rubble and few artifacts were found below the large stones in either unit, and most appeared to be resting immediately bel ow the bottom layer of stones. The chimney foundation probably was set into a builder's trench, although no evidence of this could be seen in the dark sediments.

The maximum thickness of Feature 1 is approximately $45 \mathrm{~cm}$, with most of that being the ca. 35-cm-high rubble mound. Within this, a burned layer containing large amounts of charcoal, melted glass, and burned domestic artifacts extends in an 8-cm-thick lens across Test Units 1 and 2 at a depth of $32-40 \mathrm{~cm}$. This destruction debris deposit presumably overlies an unobserved builder's trench and clearly relates to destruction of the house by fire. Deposits below the feature are culturally sterile. No artifacts were recovered in Test Unit 1 at 50$60 \mathrm{~cm}$ and Test Unit 2 at $45-60 \mathrm{~cm}$. Of the 603 artifacts collected from Feature 1 , including glass, nails, miscellaneous metal, ceramics, and door hardware, few are diagnostic of a short timespan; nonetheless, they surely relate to the 1866-1877 Sneed occupation.

\section{Materials Recovered}

Artifacts recovered from 41ML 179 consist of ceramics $(n=24)$, glass $(n=376)$, metal $(n=405)$, faunal remains $(n=6)$, and other materials $(n=3)$ (Table 11$)$.

\section{CERAMICS}

Of the 24 ceramic sherds, 17 are whiteware, 3 are stoneware, 1 is porcelain, 2 are porcelain buttons, and 1 is a ceramic door knob.

\section{Whiteware}

The 17 whiteware sherds exhibit the following decorative types: undecorated $(n=5)$, burned $(n=7)$, transfer printed $(n=4)$, and gilded $(n=1)$. The most diagnostic and significant of these arethetransfer-printed whiteware sherds (Figure 31). None are associated with Feature 1.

Transfer-printed ceramics typically are highly diagnostic because they can be dated accurately to short spans of time based on their patterns. Although these sherds are the same pattern as those recovered during the previous phase of work (K vernes et al. 2000:58), this floral pattern is not identifiable. However, dating information is available based on the color and style of the print. The design is a floral motif around the vessel rim printed in a light greentraits commonly found in the late nineteenth century (Majewski and O'Brien 1987:145). This is consistent with the Sneed occupation from 1866 to 1877.

\section{Stoneware}

The three sherds of stoneware represent three different types, and at least that many vessels. Stoneware glaze types are Bristol and Albany $(n=1)$, Albany $(n=1)$, and alkaline $(n=$ 1). Stoneware sherds were recovered from both Test U nit 2 (on Feature 1) and Test U nit 4 (off Feature 1). The presence of alkaline-glazed stoneware is particularly notable because it was produced primarily by Southern folk potters in the nineteenth century (Lebo 1987:131).

\section{Porcelain}

The one sherd of porcelain is bone china, a kind of soft-paste porcelain commonly manufactured in the nineteenth century and later (Majewski and O'Brien 1987:126-127). It was recovered from Level 4 of Feature 1, the destruction debris layer.

\section{Other Ceramics}

The remainder of the ceramics assemblage consists of two porcelain buttons $(n=2)$, one black and one white. Both are four-hole sewthrough types. A mottled-ware ceramic door knob $(n=1)$ also was recovered.

\section{GLASS}

Glass artifacts fall into six general catego- 


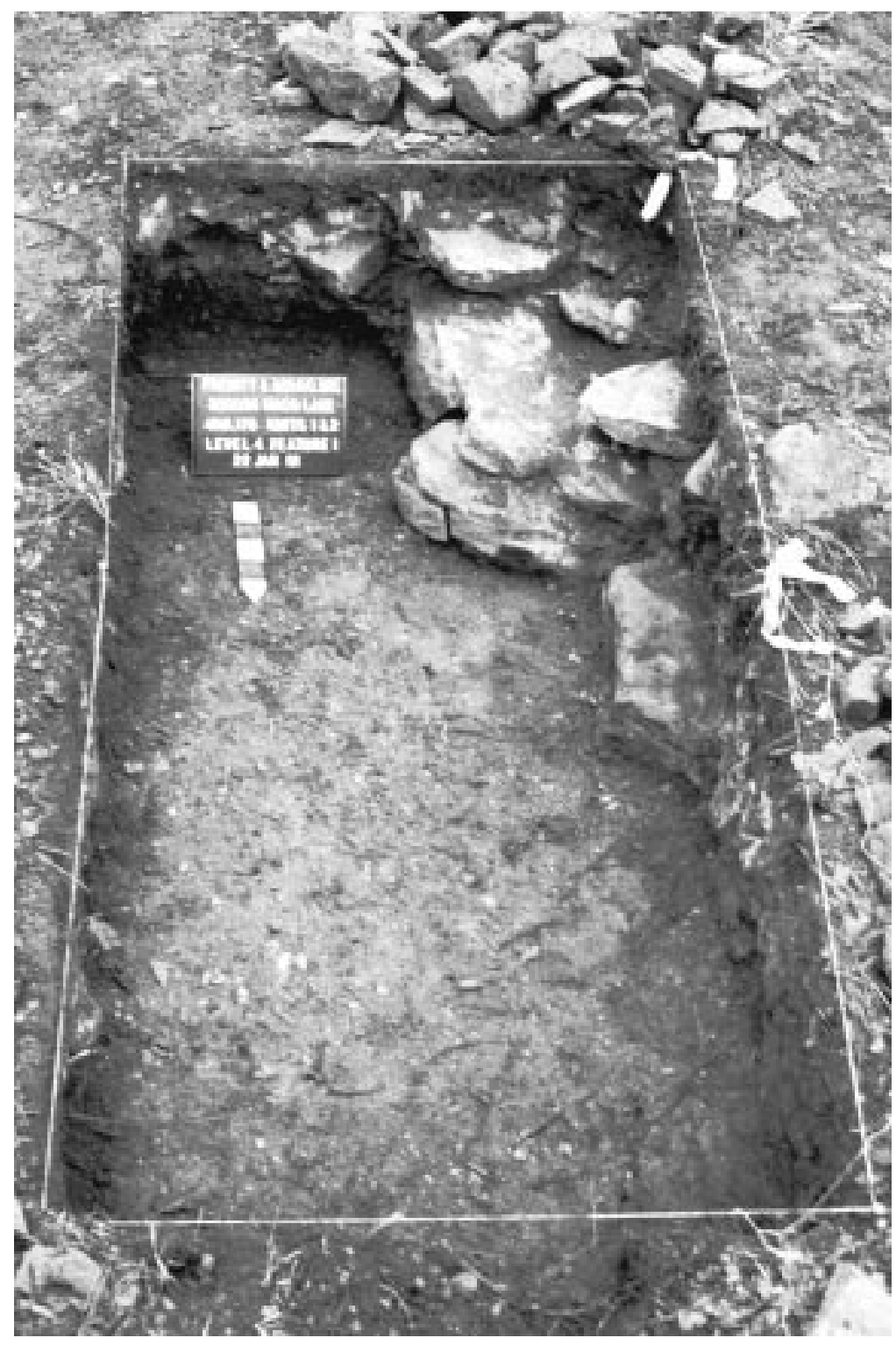

Figure 30. Photograph of Feature 1 as exposed in Test Units 1 and 2 (Level 4) at the Sneed Farmstead, 41ML179. View is to the south.

1989:127). The 13 sherds recovered are opaque white/milk glass $(n=2)$, clear/colorless glass $(n=9)$, and clear/colorless pressed glass $(n=2)$. Of particular note is the pressed soda-lime glass tableware, most commonly found on sites postdating 1860 ( $\mathrm{J}$ ones and Sullivan 1989:12). All of the pressed glass tableware sherds were recovered from the upper $20 \mathrm{~cm}$ of Test Unit 4, located off Feature 1.

\section{Kerosene Lamp Chimney Glass}

Two sherds of glass from the chimney portion of kerosene lamps were recovered. Only lead glass specimens are represented. Although lead glass was replaced by sodalime glass in the 1860s for the manufacture of tableware, lead glass continued to be used for making lamp chimneys through the latter portion of the nineteenth century (Woodhead et al. 1984:61).

\section{Container Glass}

Eighty-two sherds of container glass (primarily from bottles and jars) were recovered. Colors represented are aqua $(n=30)$, cl ear/col orless $(n=42)$, brown $(n=5)$, solarized $(n=4)$, and green $(n=1)$. Most of the col ors of glass recovered are not tightly diag-

ries: table glass ( $n=13$ ), kerosene lamp chimney glass $(n=2)$, container glass $(n=82)$, window glass $(n=86)$, unidentified/melted glass ( $n=$ 192), and other glass $(n=1)$.

\section{Table Glass}

Table glass is defined as "glassware used on the table and associated with food and drink, as well as some items of decorative glassware, such as vases" (J ones and Sullivan nostic because of the long span of their use in container production. The exception is solarized glass, which was made primarily from ca. 1875 to 1914 (J ones and Sullivan 1989:13).

\section{Window Glass}

Eighty-six window glass sherds were recovered. The greatest concentration occurred in the test units off Feature 1. 
Table 11. Summary of cultural materials from 41ML 179

\begin{tabular}{|c|c|c|c|c|c|c|}
\hline Provenience & 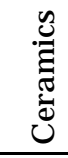 & $\frac{\mathscr{U}}{\stackrel{O}{0}}$ & $\begin{array}{l}\bar{\sigma} \\
\bar{d} \\
\Sigma\end{array}$ & $\begin{array}{l}\bar{\sigma} \\
\sqsubseteq \\
\bar{\sigma} \\
\amalg \\
\end{array}$ & 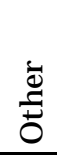 & $\begin{array}{l}\frac{n}{0} \\
\frac{0}{0} \\
\vdash\end{array}$ \\
\hline \multicolumn{7}{|l|}{ TEST UNIT 1} \\
\hline Level $1(0-10 \mathrm{~cm})$ & - & 7 & 1 & - & - & 8 \\
\hline Level 2 (10-20 cm) & - & 18 & 3 & - & 2 & 23 \\
\hline Level $3(20-30 \mathrm{~cm})$ & - & 1 & 2 & - & - & 3 \\
\hline Level 4 (30-40 cm) & 6 & 104 & 85 & 2 & - & 197 \\
\hline Level $5(40-50 \mathrm{~cm})$ & - & 7 & 2 & 3 & - & 12 \\
\hline Level 6 (50-60 cm) & 1 & 1 & - & 1 & - & 3 \\
\hline Subtotals & 7 & 138 & 93 & 6 & 2 & 246 \\
\hline \multicolumn{7}{|l|}{ TEST UNIT 2} \\
\hline Level $1(0-10 \mathrm{~cm})$ & - & 1 & - & - & - & 1 \\
\hline Level 2 (10-20 cm) & - & 4 & - & - & - & 4 \\
\hline Level $3(20-30 \mathrm{~cm})$ & 2 & 26 & 50 & - & - & 78 \\
\hline Level 4 (30-40 cm) & 2 & 24 & 119 & - & 1 & 146 \\
\hline Level $5(40-50 \mathrm{~cm})$ & - & 3 & - & - & - & 3 \\
\hline Subtotals & 4 & 58 & 169 & 0 & 1 & 232 \\
\hline \multicolumn{7}{|l|}{ TEST UNIT 3} \\
\hline Level 2 (10-20 cm) & 3 & 46 & 22 & - & - & 71 \\
\hline \multicolumn{7}{|l|}{ TEST UNIT 4} \\
\hline Level 1 (0- $10 \mathrm{~cm})$ & 8 & 113 & 108 & - & - & 229 \\
\hline Level 2 (10-20 cm) & 2 & 18 & 11 & - & - & 31 \\
\hline Level $3(20-30 \mathrm{~cm})$ & - & 3 & 2 & - & - & 5 \\
\hline Subtotals & 10 & 134 & 121 & 0 & 0 & 265 \\
\hline TOTALS & 24 & 376 & 405 & 6 & 3 & 814 \\
\hline
\end{tabular}

METAL

Metal artifacts constitute the largest material type recovered. Artifact types consist of cut nails ( $n=301)$, wire nails $(n=33)$, screws/bolts $(n=7)$, wire $(n=3)$, fencing staples $(n=2)$, tin can fragments $(n=15)$, clothing fasteners $(n=2)$, buttons $(n=4)$, and miscellaneous metal $(n=38)$.

Cut Nails

Cut nails ( $n=301$ ) represent the dominant type of structural fastener utilized at 41ML179. Occupation of the property reportedly took place between 1866 and 1877. That implies that the initial construction at this location took place in the immediate postbellum period. The presence of cut nails in large numbers is consistent with a mid-nineteenth-century construction episode with no reoccupation after the house burned.

Wire Nails

Only 33 wire nails were re covered from the site. They probably represent small repairs to the existing structure under the

\section{Unidentified/Melted Glass}

The artifacts in this category ( $n=192)$ are glass fragments that have been melted or otherwise distorted by fireso that identification beyond material typeis impossible. Melted glass is heavily concentrated in Level 4 of Feature 1, which correlates well with other evidence of the Sneed house being destroyed by fire.

\section{Other Glass}

One glass artifact that does not fit into any of the other categories is a circular piece ( 2 inches in diameter) of clear glass recovered from Level 4 of Feature 1. It appears to be either a small mirror from which the silvering has worn away, or possibly glass from a small photograph frame. ownership of the Sneed family. Wire nails, although invented in 1850, were not widely available until the late nineteenth century (Noël

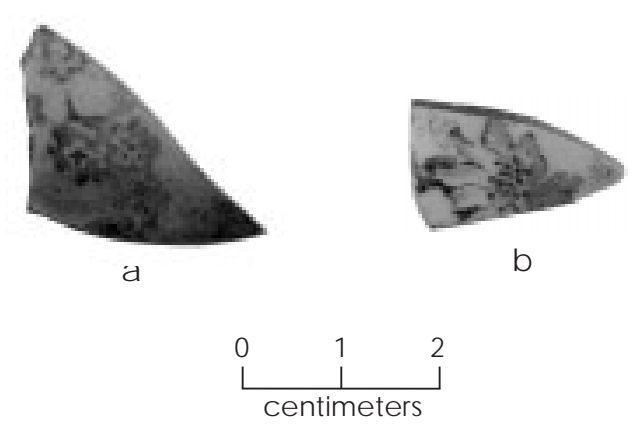

Figure 31. Transfer-printed ceramics from 41ML179. 
Hume 1991:254). Their presence in small numbers at 41ML 179 indicates initial consumer access to wire nails.

\section{Screws/Bolts}

Seven screws and bolts were recovered. All appear to be related to machinery or farm implements rather than architectural fasteners. Specimens were recovered from all of the test units, and no spatial patterning is apparent.

Wire

Wire fragments $(n=3)$ of different gauges (plain only) were recovered. They would have been used for a multitude of tasks on a farm.

\section{Fencing Staples}

Directly related to the use of wire for fencing is the use of staples to secure the wire to support posts. Two fencing staples were recovered, but they probably are not related to the Sneed occupation. Barbed wire fencing was not common until the 1880s, which suggests that fencing on the property probably was not undertaken in any systematic fashion until after the Sneeds sold the property.

\section{Tin Can Fragments}

A small number $(n=15)$ of identifiable tin can fragments was recovered. All came from contexts associated with Feature 1 . The small number suggests that commercial foods were used only minimally and that home preservation and storage of foodstuffs was more commonly practiced.

\section{Clothing Fasteners}

Two metal clothing fasteners were recovered from Test Unit 1 . One is an overalls rivet, and the other is a safety pin. Neither item is particularly diagnostic, but production of work clothing such as overalls began in the 1870s (Psota 1999).

\section{Miscellaneous Metal}

Metal artifacts that do not fit easily into any of the other established categories are classed as miscellaneous metal $(n=37)$. These are a lead fragment (possibly a window sash weight), a cartridge casing, a shotgun shell head, 18 fragments of unidentified metal, 7 pieces of the cast iron base and legs of a sewing machine, a furniture caster, a drawer pull, and 7 fragments of a purse frame.

\section{MISCELLANEOUS ARTIFACTS}

Artifacts that are identifiable in material and/or function but that do not fit easily into any of the other established categories were classed as miscellaneous. These consist of vertebrate faunal remains $(n=6)$ and a slate pencil $(n=1)$.

\section{Vertebrate Faunal Remains}

Vertebrate faunal remains $(n=6)$ were re covered exclusively from Test U nit 1 . I dentified taxa are Mammalia (canid/deer-sized, $n=5$ ) and Artiodactyla (goat/deer-sized, $n=1$ ) (see Appendix C). The bones probably represent random occurrences of food remains in the house at the time of the fire.

Slate Pencil

A single sharpened slate pencil was recovered from Level 4 of Test Unit 2. It probably represents a personal possession lost when the house burned.

Mortar

Two pieces of mortar were collected from Test U nit 1 as samples.

\section{Chronology and Components}

The chronol ogy for 41ML 179 is based on the artifacts recovered and the archival evidence of activity on the property. A single component is present. The component is defined by Feature 1, the collapsed stone chimney. Based on the strong correlation between the archival evidence and the material culture recovered, the site clearly is associated with Sneed family activities from 1866 until 1877, after which the locale was never reoccupied.

With reference to Feature 1, the only feature at the site, archival research suggests that 
the original structure erected by the Sneed family was at this location, and that it was most likely a log cabin with a stone fireplace. Although excavation undertaken to explore the site yiel ded little beyond the immediate feature area, the intact foundation remains uncovered confirm its identification. The presence of large amounts of burned materials (especially glass) also corroborates the identification with Sneed's burned house.

Feature 1 represents only a small portion of the farmstead. It is probable that the family relied on the nearby springs at Hog Creek for water and did not have either a well or a cistern, and it is possible that the isolated farm family did not bother with the formality of digging a privy. In addition, the various components related to agricultural production, particularly a barn or other outbuildings, are not represented at this site. Only the simplest of activities of basic habitation can be interpreted based on the single feature and the small artifact assemblage. The artifacts indicate the use and discard of a common assortment of domestic goods, including table ceramics and container glass. The small number of tin can fragments suggests consumerism on a small scale, with food preparation, preservation, and storage probably taking place within the household. The home was equipped apparently with a sewing machine for the production of family garment and household linen needs. The Sneed family did have some luxury goods, as evidenced by fragments from a purse frame and a partial mirror or frame glass. Beyond these simple interpretations, little can be said. The habitation and its probable water source are in evidence, but other outbuildings or refuse disposal deposits are noticeably absent.

\section{Summary and Assessment}

Site 41ML179 is the 1866-1877 Nicholas and J ennett Sneed housesite. It consists of a single identified feature representing a collapsed chimney and an associated artifact scatter. While the artifact assemblage represents a limited span of time consistent with the archivally determined dates for the Sneed occupation, it has little capacity to contribute important information because it exhibits few attributes that would aid in site interpretation. For example, most of the table ceramic sherds are either undecorated or burned, much of the glass is melted beyond identification, and the largest single artifact class-cut nails-has little interpretive value beyond the obvious. Further, the single known feature was sufficiently excavated during testing, leaving little potential for it to yield additional information, and the lack of information on other features at the site limits inquiry into questions about farmstead layout, the use of space, and activity areas. These characteristics indicate that $41 M L 179$ is ineligible for National Register listing under Criterion $D$.

\section{Site 41ML 185}

\section{Description}

Site 41ML 185 is a prehistoric site buried in Holocene alluvium along the south bank of the North Bosque River arm of the lake just downstream from where Davis Branch enters the lake; it is beneath and adjacent to the FM 185 bridge over the upper end of Waco Lake (see Figure 4). The terrace containing the site lies at an elevation of ca. 458-460 ft, whilethefloodplain just to north was at ca. $440 \mathrm{ft}$ prior to inundation by the lake. Vegetation near the banks includes pecan, oak, and hackberry trees; however, much of the site beneath the bridge is open and supports grasses.

\section{Previous Investigations}

Site 41ML 185 was recorded and subjected to minimal testing in 1984 (Prikryl and J ackson 1985:236-237). Prehistoric materials were noted over a distance of ca. $220 \mathrm{~m}$ in cutbanks 2-3 $\mathrm{m}$ high when the lake level was below its normal level due to drought. Debitage, burned rocks, bones, and mussel shells were observed, particularly at the confluence of the North Bosque River and Davis Branch. Three burned rock features were noted near the downstream end, one of which had been modified recently by fishermen to accommodate fire.

Cutbank exposures indicated that two buried zones of cultural materials might be present in the central part of the site. Two profile cuts were cleaned along the cutbank, one near the center of the site under the highway bridge (Profile Cut 1) and the other just to the west immediately downstream from where Davis Branch 
enters the lake (Profile Cut 2). Four stratigraphic zones were identified. Zone 1, about $60 \mathrm{~cm}$ thick in Profile Cut 1 and $20 \mathrm{~cm}$ thick in Profile Cut 2, consisted of dark brown clay loam mixed with concrete and modern debris. A mottled reddish brown clay in Profile Cut 1 extended from $60 \mathrm{~cm}$ to the water table at $250 \mathrm{~cm}$ below the surface and was labeled Zone 2 . Lenses of cultural materials were recorded within Zone 2 at 70-80 cm and 175-195 cm. Zone 2 was absent in Profile Cut 2, which instead had a dark grayish brown silty clay label ed Zone 3 extending from 20 to $80 \mathrm{~cm}$; Zone 3 contained sparse prehistoric artifacts. I mmediately downstream from the profile, Zone 3 contained two lenses of cultural materials between 40 and $78 \mathrm{~cm}$. Zone 4, a tannish brown silty clay, extended from 80 to $115 \mathrm{~cm}$ bel ow the surface only in Profile Cut 2; it yielded one mussel shell.

Site 41ML 185 was revisited in 1999 as part of a site re-location and reassessment effort (Kvernes et al. 2000:55-56). A surface survey of the site area yiel ded two artifacts: one chert flake was found about $5 \mathrm{~m}$ south of a mussel shell cluster in the cutbank ca. $10 \mathrm{~m}$ west of the bridge, and another chert flake was found near the water line at the North Bosque River/ Davis Branch confluence. Because the lake was at its normal conservation pool level of $455 \mathrm{ft}$, the extensive cutbanks visible in 1984 were inundated. The investigators noted limited impacts to the site since 1984 . For example, the presence of willow trees in the same position in 1984 and 1999 near the eastern edge of the site indicates that shoreline erosion has not been extensive. However, the site area had suffered from the construction of the FM 185 bridge, as well as use of the area as a boat launching facility and fishing area. Gravel was dumped on the shore directly beneath the bridge. The shore immediately downstream from the bridge was disturbed badly by construction and use of a boat ramp, and the upper part of the terrace in the vicinity was disturbed by earthmoving and vehicular traffic.

Two shovel tests were excavated. Shovel Test 99-1 was placed approximately 60 m south of the North Bosque/Davis Branch confluence$10 \mathrm{~m}$ from the shoreline. This area was recorded in 1984 as yielding significant amounts of burned rocks and mussel shell fragments along the cutbanks. The shovel test was excavated to a depth of $40 \mathrm{~cm}$, consisting entirely of gray loam. It produced no cultural materials. Shovel Test 99-2 was placed $10 \mathrm{~m}$ southwest of Shovel Test 99-1 parallel to the shoreline. The test similarly produced no artifacts, and a soil matrix of gray loam. The investigators concluded that the cultural deposits in this area were too deeply buried to be exposed through shovel testing.

\section{Work Accompl ished}

During the 2000-2001 investigations, a wooden stake was used as the primary datum and was given an arbitrary elevation of $100.00 \mathrm{~m}$. The datum was placed ca. $11 \mathrm{~m}$ south of Trench 1 . A second datum (wooden stake) was placed near a largetreeca. 7 m southeast of Trench 1 and $9.5 \mathrm{~m}$ northeast of the primary datum.

Two backhoetrenches were excavated (Figure 32). It became evident during trenching operations that a thick, recent sandy mantle covered the old stable Holocene surface. This made trenching difficult and precluded trenching on the western end of the site. One trench was dug in the wooded portion of the site and one in the open terrace. Trench 1 was placed midway along the Davis Branch inlet at an orientation of $320^{\circ}$. It measured $2.6 \times 1.6 \times 2.5 \mathrm{~m}$ and yielded a few pieces of charcoal from 94 to $154 \mathrm{~cm}$. Trench 2 was located out on the open point where Davis Branch enters Waco Lake. It was aligned at $16^{\circ}$ and measured $2.7 \times 1.5 \times 3.0 \mathrm{~m}$. At approximately $80-125 \mathrm{~cm}$, mussel shell fragments, burned rocks, a few charcoal pieces, and a few pieces of debitage were observed in the buried A horizon. The Bw horizon yielded burned rocks at $148 \mathrm{~cm}$ (Feature 1 ) and $239 \mathrm{~cm}$. A few mussel shells also were noted in these areas. A bulk sediment sample for radiocarbon dating was collected from the profile at $101-109 \mathrm{~cm}$.

Five test units were excavated. All wereterminated when the targeted cultural zone was investigated or the water table was reached. Test Units 1 and 2, which formed a 1×2-m unit, were on the western end of the site near the confluence of an unnamed drainage with Davis Branch. Excavation began at the modern ground surface and stopped at $200 \mathrm{~cm}$ (Level 20 ) in both units. The first eight levels in Test Unit 1 were removed as overburden and not screened. Test U nits 3 and 4 were excavated on the southwest safety bench of Trench 1 . The first levels began $90 \mathrm{~cm}$ below the modern ground 
National Register Testing of NineArcheol ogical Sites at Waco Lake

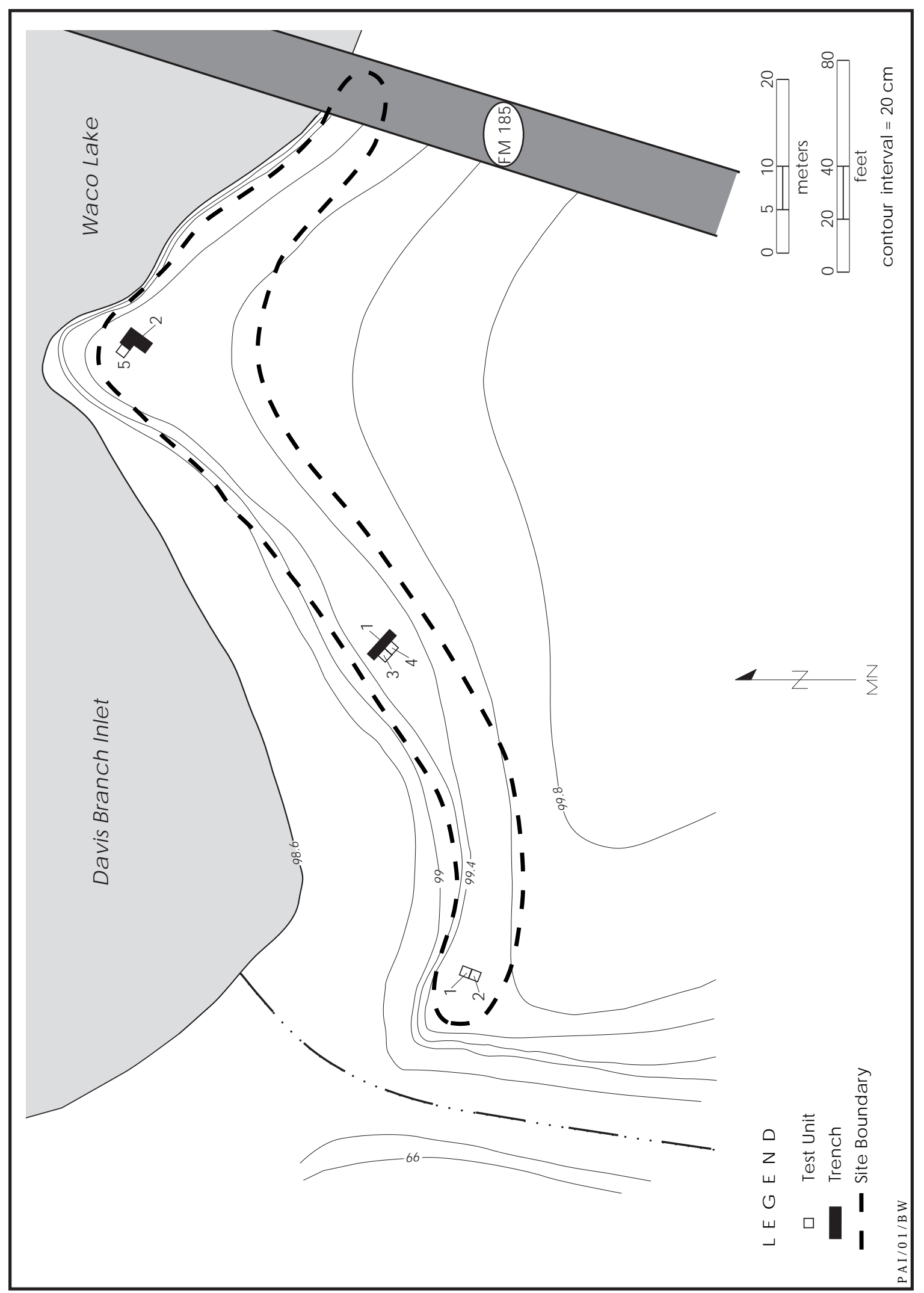

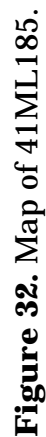


surface, and excavations ceased at Level 14 $(230 \mathrm{~cm})$. Finally, Test Unit 5 was placed over the burned rocks discovered in Trench 2 . The overburden was removed by hand, and the first level began $90 \mathrm{~cm}$ below the modern ground surface. Excavation stopped when the water table was encountered at the base of Level 11 $(200 \mathrm{~cm})$. I $\mathrm{n}$ total, $6.9 \mathrm{~m}^{3}$ were hand excavated.

\section{Site Extent and Depth}

In 1984, prehistoric materials were observed over a distance of ca. $220 \mathrm{~m}$ in the cutbanks east and west of the FM 185 bridge during low lake levels (Prikryl and J ackson 1985:236-237). A revisit in 1999 (Kvernes et al. 2000:59-60) noted that the portion of the site on the east side of the bridge had been impacted from the construction of a boat ramp and the FM 185 bridge and road maintenance activities. The current investigations focused on the ca. 100-m-long western portion of the site, west of the bridge, where relatively limited surface impacts were noted al ong the Davis Branch inlet of the lake.

The vertical extent of $41 M L 185$ varies. The westernmost portion of the site near the unnamed Davis Branch tributary contains cultural materials between 1.0 and $1.7 \mathrm{~m}$ below the surface in Test U nits 1 and 2. Excavations ceased in these units at $2 \mathrm{~m}$ below the surface after three sterile levels had been removed. The vertical extent of the site near the confluence of Davis Branch and the North Bosque River, however, is deeper. Cultural materials were encountered as deep as $2 \mathrm{~m}$ bel ow the surface, as was the water table.

\section{Sediments and Stratigraphy}

The sediments and stratigraphy at 41ML 185 were examined through the profiles and soil-stratigraphic descriptions of two trenches (see Appendix A). The site is situated on a Holocene alluvial terrace that, prior to the construction of Waco Lake, stood ca. $6 \mathrm{~m}$ above the North Bosque channel. Soils on the terrace surface bel ong to the Catalpa series (Templin et al. 1958). Catal pa soils are calcareous grayish brown to dark grayish brown clay loam to clayey soils formed on recent alluvium.

The terrace surface at 41ML185, which is located at the upper end of Waco Lake in the
North B osque valley, is blanketed by an almost 1-m-thick deposit of recent alluvium, the result of base level changes and back flooding since the construction of the lake (Figure 33). This recent deposit consists of alternating thin laminaeto medium beds of pale brown very finesand and dark gray mud. Tin and steel cans, plastic, and other modern debris were observed throughout this deposit. The recent alluvial deposit has essentially sealed off the prehistoric and early historic surface occupied by Native American groups in the past.

Alluvial deposits below the recent mantle are late $\mathrm{H}$ olocene in age and consist of silty clay loams imprinted with an Ab-Bwkb or Ab-Bwb soil profile. In Trench 1, the Ab horizon (94$154 \mathrm{~cm}$ ) is a very dark grayish brown silty clay Ioam. A few pieces of charcoal were observed throughout the soil, which is moderately bioturbated (microfaunal burrowing). The underlying Bwkb horizon (154-254+ cm) is a yellowish brown silty clay loam displaying a moderate prismatic structure that breaks to a moderate angular bl ocky structure.

In Trench 2, the Ab horizon $(80-125 \mathrm{~cm})$ is a very dark grayish brown silty day loam. Many freshwater mussel shell fragments, common burned rocks, and common pieces of charcoal were observed throughout the soil. A bulk soil sample collected at $101-109 \mathrm{~cm}$ yielded a conventional radiocarbon age of $1130 \pm 80$ B.P. (Beta-154295). The underlying Bwb horizon $(125-300+\mathrm{cm})$ is a yellowish brown silty day loam. A few freshwater mussel shell fragments and burned rocks wereobserved at 148 and $239 \mathrm{~cm}$ bel ow the surface. Both profiles suggest that the terrace surface aggraded rapidly throughout the lateH ol oceneand then sl owed around ca. 1100 B.P., facilitating the development of a thick, dark A horizon, which was occupied by late Late Archaic and Late Prehistoric groups.

\section{Cultural Features}

\section{FEATURE 1}

Feature 1 is a cluster of burned rocks and other cultural materials situated in the southeast corner of Test Unit 5, Levels 6 and 7 (146$157 \mathrm{~cm}$ ). The feature originally was observed in the west wall of Trench 2. The excavated portion measures ca. $65 \mathrm{~cm}$ north-south by $40 \mathrm{~cm}$ east-west (Figure 34). The plan shaperesembles 
National Register Testing of NineArcheol ogical Sites at Waco Lake

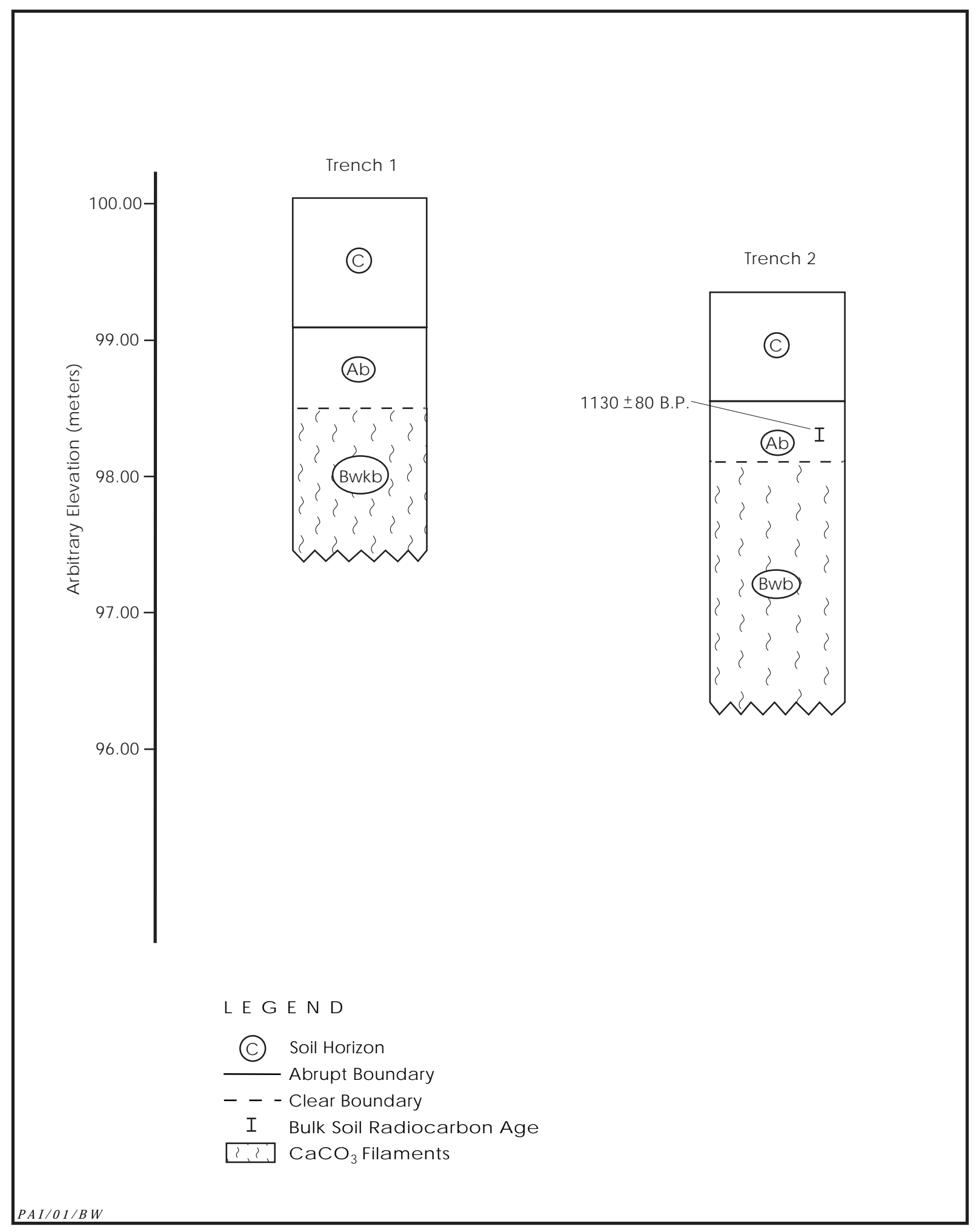

Figure 33. Profiles of Trenches 1 and 2, 41ML 185. 


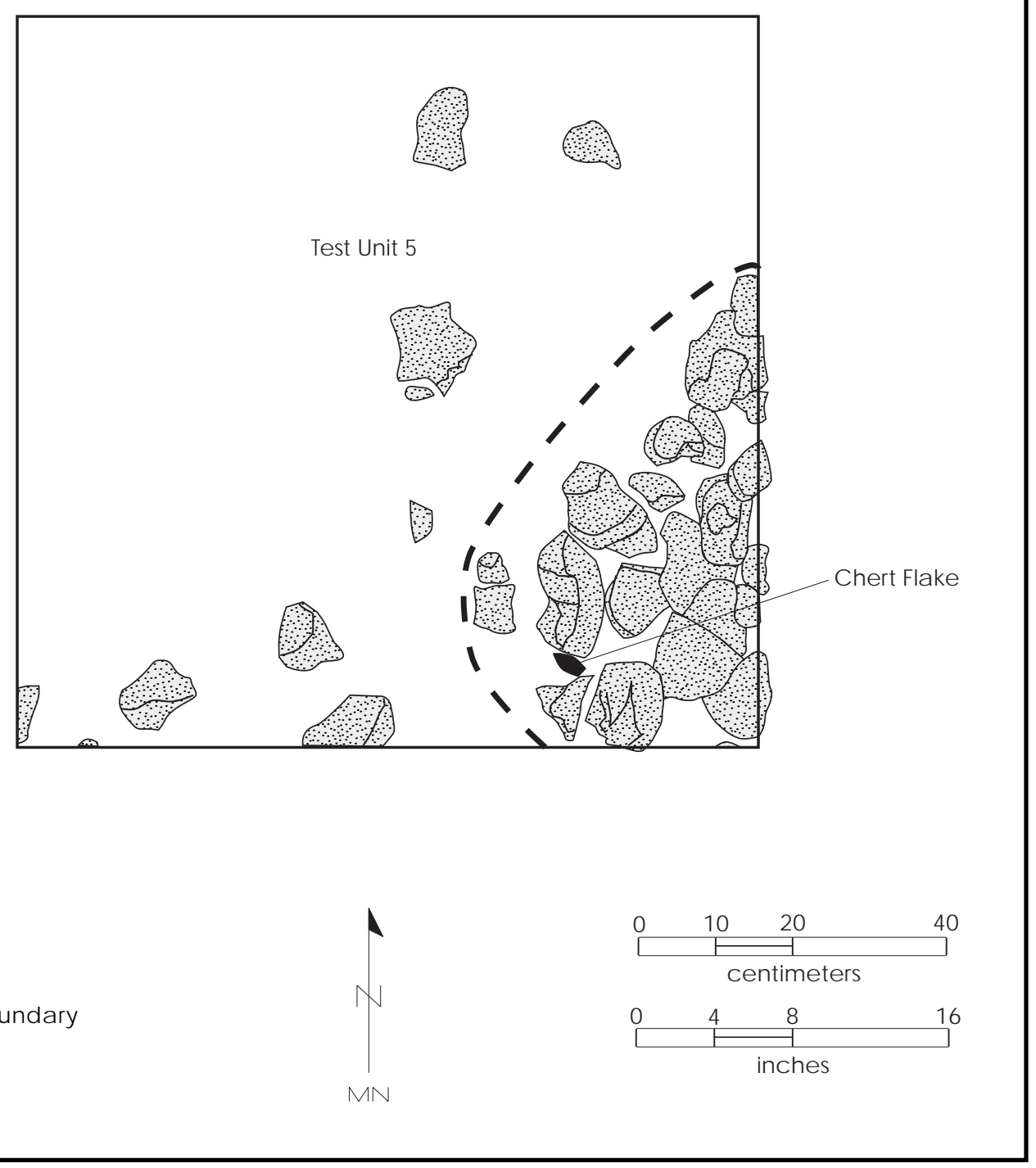

Figure 34. Plan of Feature 1, 41ML 185.

a portion of an irregular circle. In cross section, the feature has no distinct shape and is rather flat. Mostly containing small burned rocks, the feature is ca. $11 \mathrm{~cm}$ thick. No charred materials or oxidized sediment were observed.

The feature contains ca. 39 burned rocks, 1 piece of lithic debitage, Rabdotus sp. shells, and mussel shells, some of which are burned. Some of the burned rocks are fractured in place and
1 fist-sized rock is not burned at all. In total, $8 \mathrm{~kg}$ of burned rocks were excavated. The rocks vary in size from ca. $20 \mathrm{~cm}$ to less than $5 \mathrm{~cm}$ and do not appear to be oriented in any particular direction. The feature may have been disturbed by bioturbation.

Approximately 4.5 liters of featurefill were collected for flotation. F lotation failed to recover any charred botanical remains; only burned 
rocks, weighing less than $1 \mathrm{~kg}, 3$ pieces of lithic debitage, and numerous mussel and snail shell fragments were recovered.

Feature 1 represents a portion of a larger burned rock feature, possibly a prepared hearth. Burned rocks present in the eastern wall of the trench at the same elevation suggest that the feature may have been even larger; thus, it appears that much of the feature was removed during trenching. Because only a portion of the feature was excavated, its exact size, morphology, and function are unclear.

\section{FEATURE 2}

Feature 2 is a small, loosely clustered group of burned rocks located in the northwest corner of Test Unit 5, Levels 7 and $8(153-161 \mathrm{~cm})$. The excavated portion measures ca. $30 \mathrm{~cm}$ north-south by $40 \mathrm{~cm}$ east-west (Figure 35). The plan shape is circular. It appears that only about one-quarter of the feature was encountered. In cross section, the feature slopes downward to the west, suggesting a basin-shaped bottom. The feature averages about $8 \mathrm{~cm}$ thick. No charred botanical or faunal remains or oxidized sediment were observed during excavation of the feature.

Feature 2 contains mainly burned rocks, however, Rabdotus sp. and mussel shell fragments were observed. Lithic debitage was collected outside the feature in the general level recovery. Sixteen burned rocks, all of which are less than $10 \mathrm{~cm}$ in size, were removed. I n total, the burned rocks weigh $2.5 \mathrm{~kg}$. The small size of the rocks suggests that they may have been heated multiple times and their usefulness exhausted. None of the rocks are fractured in place, and because of their loosely spaced arrangement, they may have been disturbed by bioturbation.

About 5.3 liters of feature fill werecollected for flotation. Flotation recovered ca. $14 \mathrm{~g}$ of burned rocks, 3 pieces of lithic debitage, and numerous fragments of snail and mussel shells. No carbonized materials were recovered.

Feature 2 appears to have functioned as a prepared hearth pit based on the configuration of the rocks, gently sloping in cross section. Despite the lack of charred materials, the feature was probably a cooking device. Since only a portion of the feature was exposed, its actual size and function cannot be fully ascertained.

\section{Materials Recovered}

A total of 430 artifacts (426 chipped stone artifacts; 1 ground, pecked, and battered stone tool; and 3 pottery sherds), 209 invertebrate faunal specimens, and 24 vertebrate faunal remains were collected from 41ML 185 (Table 12). Other materials include burned rocks, which were noted but not collected. Furthermore, assorted modern debris such as glass, nails, tin cans, and fishing tackle was found in a few of thelevels (from the ground surface to ca. $100 \mathrm{~cm}$ ) in Test U nits 2-5. None of these materials were quantified or collected.

\section{CHIPPED STONE ARTIFACTS}

The chipped stone artifacts consist of 1 dart point, 6 bifaces, 1 uniface, 1 cobbletool, 21 pieces of edge-modified debitage, and 396 pieces of unmodified debitage.

\section{Dart Point}

One nearly complete dart point was found in Test Unit 3, Level $14(220-230 \mathrm{~cm})$ (Figure 36). It has a slender, triangular blade with straight margins, moderate unbarbed shoulders, and straight stem with a subtle expansion at the base. The blade is gently beveled showing some reworking, and the stem is beveled with moderately ground edges. A small part of the tip and a portion of the base are missing. Dimensions for the point are as follows: $66.7 \mathrm{~mm}$ for present length, $20.3 \mathrm{~mm}$ for blade width, $11.6 \mathrm{~mm}$ for neck width, $11.9 \mathrm{~mm}$ for base width, $14.2 \mathrm{~mm}$ for haft length, and $7.0 \mathrm{~mm}$ for thickness.

The point does not fall into a traditionally defined type; however, it closel y resembles Provisional Type 1 (see 41ML 162, Materials Recovered, for a more-detailed discussion of this type). As Kleinbach et al. (1999:337) suggest, these points were utilized ca. 30002000 B.C.

\section{Bifaces}

Six biface fragments, consisting of one proximal and three distal portions and two indeterminate edges, were collected. Only one biface tool type, a knife, could be identified. The remaining specimens are indeterminate fragments. Stages of reduction for the bifaces are 


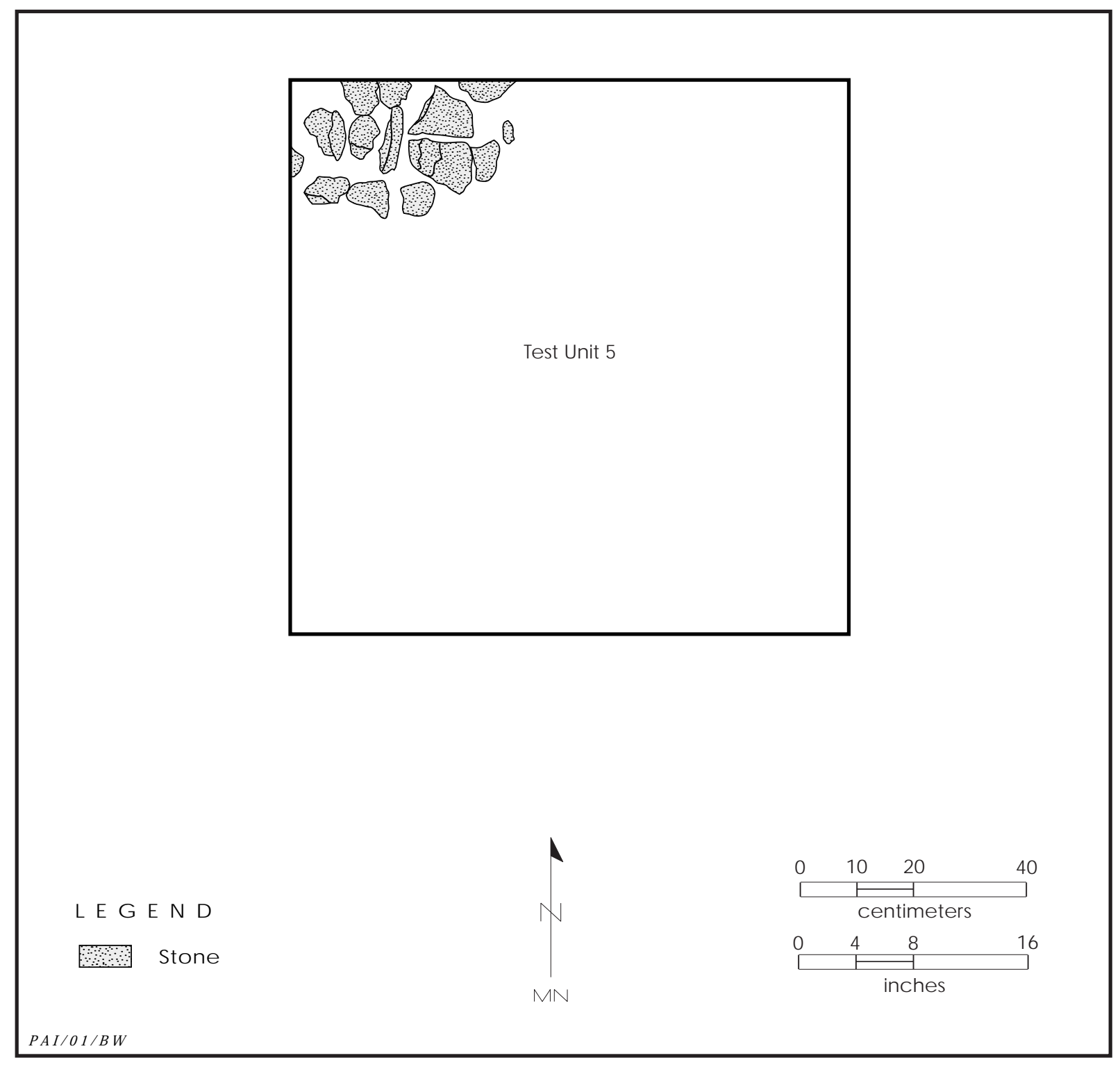

Figure 35. Plan of Feature 2, 41ML185.

early $(n=1)$, middle $(n=4)$, and finished $(n=1)$. Because of their fragmentary condition, only thickness and occasionally width could be measured. Provenience and metric data are presented in Table 13.

\section{Uniface}

One uniface, an intact end/side scraper, was recovered from Test Unit 2, Level 13 (120-130 cm). The specimen retains much cortex. Reworking on its distal end has created an almost graverlike tool with multiple, short protrusions at the scraping surface. Dimensions for the uniface are as follows: length, $48.2 \mathrm{~mm}$; width, $31.3 \mathrm{~mm}$; and thickness, $19.4 \mathrm{~mm}$.

\section{Cobble Tool}

One cobble tool was collected from Test Unit 2, Level $14(130-140 \mathrm{~cm})$. It is a proximal fragment of a chopper with much use wear on one end. Cortex is present over most of the specimen. The tool is $51.9 \mathrm{~mm}$ long, $47.9 \mathrm{~mm}$ wide, and $23.7 \mathrm{~mm}$ thick. 


\section{TEST UNIT 1}

Provenience

Level $9(80-90 \mathrm{~cm})$ Level $10(90-100 \mathrm{~cm})$ Level $11(100-110 \mathrm{~cm})$ Level $12(110-120 \mathrm{~cm})$ Level $13(120-130 \mathrm{~cm})$ Level $14(130-140 \mathrm{~cm})$ Level $15(140-150 \mathrm{~cm})$ Level $16(150-160 \mathrm{~cm})$ Level $17(160-170 \mathrm{~cm})$

Subtotals

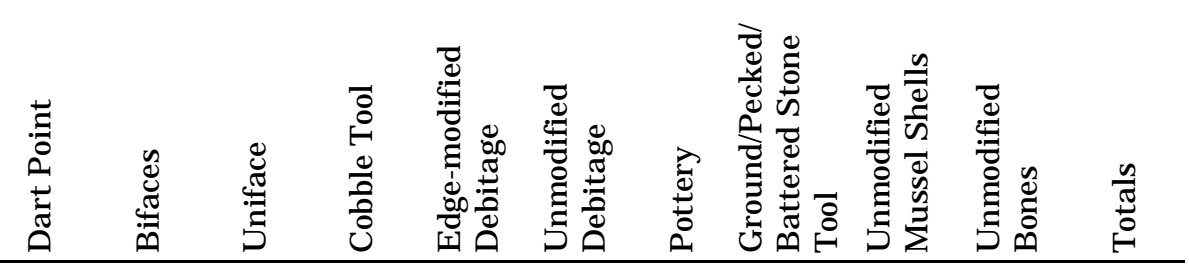

TEST UNIT 2

\begin{tabular}{llllllllllrr} 
Level $11(100-110 \mathrm{~cm})$ & - & 1 & - & - & 1 & 3 & 1 & - & 1 & 4 & 11 \\
Level $12(110-120 \mathrm{~cm})$ & - & - & - & - & - & - & - & - & 1 & - & 1 \\
Level $13(120-130 \mathrm{~cm})$ & - & - & 1 & - & 1 & 3 & - & - & - & - & 5 \\
Level $14(130-140 \mathrm{~cm})$ & - & - & - & 1 & - & 3 & - & - & 1 & - & 5 \\
Subtotals & 0 & 1 & 1 & 1 & 2 & 9 & 1 & 0 & 3 & 4 & 22 \\
\hline
\end{tabular}

TEST UNIT 3

Level $2(100-110 \mathrm{~cm})$ Level $3(110-120 \mathrm{~cm})$ Level $4(120-130 \mathrm{~cm})$ Level $5(130-140 \mathrm{~cm})$ Level $6(140-150 \mathrm{~cm})$ Level $7(150-160 \mathrm{~cm})$ Level $8(160-170 \mathrm{~cm})$ Level $9(170-180 \mathrm{~cm})$ Level $10(180-190 \mathrm{~cm})$ Level $11(190-200 \mathrm{~cm})$ Level $12(200-210 \mathrm{~cm})$ Level $13(210-220 \mathrm{~cm})$ Level $14(220-230 \mathrm{~cm})$

Subtotals

\begin{tabular}{rrrrrrrrrrr}
- & - & & - & - & - & - & - & - & 3 & 3 \\
- & - & - & - & - & 2 & - & - & 1 & - & 3 \\
- & - & - & - & 3 & - & 2 & - & 3 & 1 & 9 \\
- & - & - & - & - & 1 & - & - & 1 & - & 2 \\
- & - & - & - & 1 & - & - & - & 1 & - & 2 \\
- & - & - & - & 1 & 7 & - & - & 3 & - & 11 \\
- & - & - & - & - & 3 & - & - & 1 & 13 & 17 \\
- & - & - & - & - & 7 & - & - & - & - & 7 \\
- & - & - & - & - & 2 & - & - & 1 & - & 3 \\
0 & 0 & 0 & 0 & 5 & 22 & 2 & 0 & 11 & 17 & 57 \\
\hline
\end{tabular}

\section{TEST UNIT 4}

Level $1(90-100 \mathrm{~cm})$ Level $2(100-110 \mathrm{~cm})$ Level $3(110-120 \mathrm{~cm})$ Level $4(120-130 \mathrm{~cm})$ Level $5(130-140 \mathrm{~cm})$ Level $6(140-150 \mathrm{~cm})$ Level $7(150-160 \mathrm{~cm})$ Level $8(160-170 \mathrm{~cm})$ Level $11(190-200 \mathrm{~cm})$ Level $12(200-210 \mathrm{~cm})$

\begin{tabular}{rrrrrrrrrrr}
- & - & - & - & 1 & 2 & - & - & 1 & - & 4 \\
- & - & - & - & 1 & 9 & - & - & 1 & 1 & 12 \\
- & - & - & - & - & 5 & - & - & 2 & - & 7 \\
- & 1 & - & - & - & 5 & - & 1 & 4 & 1 & 12 \\
- & - & - & - & - & 7 & - & - & 7 & - & 14 \\
- & 1 & - & - & - & 5 & - & - & 8 & - & 14 \\
- & - & - & - & - & 1 & - & - & - & - & 1 \\
- & - & - & - & - & 4 & - & - & 1 & - & 5 \\
- & - & - & - & 1 & - & - & - & - & - & 1 \\
- & - & - & - & - & 2 & - & - & 3 & - & 5 \\
- & - & - & - & - & 2 & - & - & 3 & - & 5 \\
- & - & - & - & - & 1 & - & - & 2 & - & 3 \\
1 & - & - & - & 1 & - & - & - & - & - & 2 \\
1 & 2 & 0 & 0 & 4 & 43 & 0 & 1 & 32 & 2 & 85 \\
\hline
\end{tabular}

-
-
-
-
-
-
-
-




\begin{tabular}{|c|c|c|c|c|c|c|c|c|c|c|c|}
\hline Provenience & 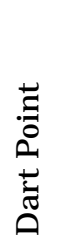 & 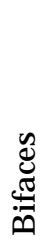 & 亗 & $\begin{array}{l}\frac{8}{\circ} \\
\frac{0}{0} \\
\frac{0}{0}\end{array}$ & 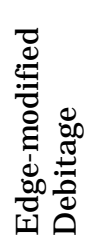 & 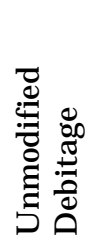 & 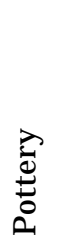 & 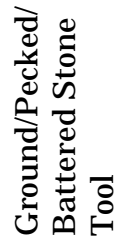 & 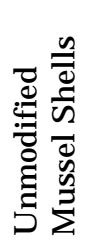 & 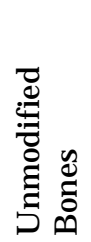 & $\begin{array}{l}\frac{n}{D} \\
\frac{0}{0}\end{array}$ \\
\hline Level $13(210-220 \mathrm{~cm})$ & - & - & - & - & - & 4 & - & - & 2 & - & 6 \\
\hline Level $14(220-230$ cm) & - & - & - & - & - & 5 & - & - & 1 & - & 6 \\
\hline Subtotals & 0 & 2 & 0 & 0 & 2 & 57 & 0 & 0 & 35 & 0 & 96 \\
\hline \multicolumn{12}{|l|}{ TEST UNIT 5} \\
\hline Level $2(100-110 \mathrm{~cm})$ & - & - & - & - & - & 1 & - & - & - & - & 1 \\
\hline Level $3(110-120 \mathrm{~cm})$ & - & - & - & - & 2 & 12 & - & - & 9 & - & 23 \\
\hline Level 4 (120-130 cm) & - & - & - & - & 1 & 32 & - & - & 3 & 1 & 37 \\
\hline Level $5(130-140 \mathrm{~cm})$ & - & 1 & - & - & - & 123 & - & - & 14 & - & 138 \\
\hline Level 6 (140-150 cm) & - & - & - & - & 3 & 75 & - & - & 29 & - & 107 \\
\hline Feature 1 (146-157 cm) & - & - & - & - & - & 3 & - & - & 5 & - & 8 \\
\hline Level $7(150-160 \mathrm{~cm})$ & - & - & - & - & 1 & 7 & - & - & 22 & - & 30 \\
\hline Feature 2 (150-160 cm) & - & - & - & - & - & 3 & - & - & 3 & - & 6 \\
\hline Level 8 (160-170 cm) & - & - & - & - & - & 5 & - & - & 13 & - & 18 \\
\hline Level 9 (170-180 cm) & - & - & - & - & - & 2 & - & - & 20 & - & 22 \\
\hline Level 10 (180-190 cm) & - & - & - & - & 1 & 1 & - & - & 9 & - & 11 \\
\hline Level 11 (190-200 cm) & - & - & - & - & - & 1 & - & - & 1 & - & 2 \\
\hline Subtotals & 0 & 1 & 0 & 0 & 8 & 265 & 0 & 0 & 128 & 1 & 403 \\
\hline TOTALS & 1 & 6 & 1 & 1 & 21 & 396 & 3 & 1 & 209 & 24 & 663 \\
\hline
\end{tabular}

\section{Edge-modified Debitage}

Twenty-one pieces of edge-modified debitage were identified. Forty-three percent $(n=9)$ are complete flakes, 24 percent $(n=5)$ are proximal fragments, 24 percent $(n=5)$ are chips, and 9 percent $(n=2)$ are chunks. Over half have cortex. Most have either one modified edge $(n=10)$ or two modified edges $(n=9)$. The remaining 2 pieces show three worked edges. None of the specimens is smaller than $2 \mathrm{~cm}$ in size. The 19 flakes with one or two modified edges range in size from 2 to $4 \mathrm{~cm}$. The two pieces with three worked edges are 4-6 cm in size. Raw material colors range from light brown-the material most common-to light and dark gray cherts.

\section{Unmodified Debitage}

A total of 396 pieces of unmodified debitage were collected. Of those flakes, 25 percent $(n=100)$ are complete, 34 percent
( $n=134$ ) are proximal fragments, 34 percent $(n=133)$ are chips, and 7 percent $(n=29)$ are chunks. Cortex is absent on 61 percent $(n=243)$ of the assemblage. Only 8 flakes have 100 percent dorsal cortex. These flakes range from less than $1 \mathrm{~cm}$ in size to $7 \mathrm{~cm}$. Sixty-four percent $(n=253)$ are $1-2 \mathrm{~cm}$. The second-most-frequent size range is $2-3 \mathrm{~cm}$, represented by 22 percent $(n=86)$. Seven percent $(n=30)$ are less than $1 \mathrm{~cm}$ in size, and, 7 percent $(n=27)$ are $3-7 \mathrm{~cm}$ in size. Raw material colors vary from light brown to light mottled gray and dark gray chert. A very dark gray to almost black material was noted. Numerous flakes display a pinkish hue from thermal alteration. A few pieces of irregularly banded dark brown and gray chert also were observed.

\section{INVERTEBRATE FAUNAL REMAINS}

Thirty-five of the 209 mussel shells collected are completeenough for taxonomic identification 


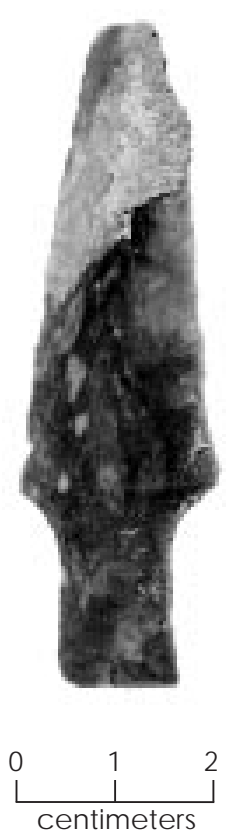

Figure 36. Dart point from 41ML185.

(seeAppendixB).Thetaxa indudeAmblema plicata, Leptodea fragilis, Quadrula petrina, Quadrula sp., and Tritogonia verrucosa. The species A. plicata (threeridge mussel) is the most common.

\section{VERTEBRATE FAUNAL REMAINS}

Of the 24 bone fragments recovered, 23 were analyzed (see Appendix $\mathrm{C}$ ). The remaining unanalyzed bone fragment was inadvertently left out of the analysis. This specimen is burned and less than $2 \mathrm{~cm}$ in size. Although no species were identified in the assemblage, deer probably makes up most of the collection, as one Artiodactyla (medium- or goat/deer-sized) specimen was identified and the remaining fragments are medium-sized/large (canid/ deer-sized) Mammalia ( $n=17)$ or Vertebrata $(n=5)$. Only one specimen is calcined.

\section{OTHER MATERIALS}

Other materials recovered consist of burned rocks; three pottery sherds; and one ground, pecked, and battered stone tool. As noted above, ca. 55 burned rocks were found in Features 1 and 2 . In addition, scattered burned rocks were found occasionally in nonfeature contexts. The presence of these rocks was noted, but they were not quantified.

\section{Pottery}

Three pieces of prehistoric pottery were found. Two crossmend and were analyzed as one piece (Figure 37). This specimen is a $3-4-\mathrm{cm}$ body sherd equally burnished on the interior and exterior. The exterior is decorated with incised lines and a crosshatched field. The sherd is bone tempered and $6.6 \mathrm{~mm}$ thick. Although it resembles Caddoan-style vessels with its zoned crosshatched decoration, the small size of the sherd and the amount of decoration present are insufficient for assigning a specific type origin. Found in the same level in the adjacent unit, the third piece of pottery may be from the same vessel. It is a small (1-2 cm), bone-tempered, undecorated sherd. Both theinterior and exterior surfaces are burnished. The sherd is $5.6 \mathrm{~mm}$ thick.

\section{Ground, Pecked, and Battered Stone Tool}

A ground, pecked, and battered stone tool was recovered from Test Unit 3, Level 5 (130$140 \mathrm{~cm}$ ). The limestone specimen is oblate or disk shaped with an $85.5-\mathrm{mm}$-long by $15.0-\mathrm{mm}$ wide worn surface on one of the margins. It measures $95.4 \times 88.9 \times 35.5 \mathrm{~mm}$ and weighs $357.0 \mathrm{~g}$.

\section{Chronology and Components}

Based on the distribution of cultural materials, features, and radiocarbon ages, two components are defined for 41ML185. The first contains a mix of Late Archaic and Late Prehistoric cultural materials recovered from the buried A horizon, though no unambiguous diagnostic artifacts were recovered. The presence of a Late Prehistoric occupation is based on the recovery of pottery from Test Units 1 and 2. It is possible that the Late Prehistoric constituent of this component represents a Toyah phase occupation based on a radiocarbon age of $160 \pm 50$ B.P. (Beta-154286) on charcoal from Test Unit 4, Level $4(120-130 \mathrm{~cm})$. The radiocarbon age produces a two-sigma calibrated date range of $300(270,200,150,20,0) 0$ B.P., which overlaps temporally with the end of the Toyah phase. This date should be viewed with caution, however, because of deviations and 
Table 13. Provenience and metric data for bifaces from 41ML 185

\begin{tabular}{|c|c|c|c|c|c|c|}
\hline Provenience & Tool Type & $\begin{array}{l}\text { Stage of } \\
\text { Reduction }\end{array}$ & Completeness & 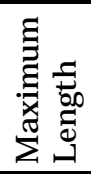 & 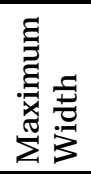 & 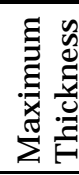 \\
\hline \multicolumn{7}{|l|}{ TEST UNIT 2} \\
\hline Level $11(100-110 \mathrm{~cm})$ & indeterminate & middle & edge & - & - & 4.9 \\
\hline \multicolumn{7}{|l|}{ TEST UNIT 3} \\
\hline Level 5 (130- $140 \mathrm{~cm})$ & indeterminate & finished & edge & - & - & - \\
\hline Level 7 (150-160 cm) & knife & middle & proximal & - & 32.0 & 6.8 \\
\hline \multicolumn{7}{|l|}{ TEST UNIT 4} \\
\hline Level $3(110-120 \mathrm{~cm})$ & indeterminate & middle & distal & - & 21.8 & 6.1 \\
\hline Level 4 (120-130 cm) & indeterminate & middle & distal & - & - & 10.0 \\
\hline \multicolumn{7}{|l|}{ TEST UNIT 5} \\
\hline Level 5 (130-140 cm) & indeterminate & early & distal & - & 39.4 & 17.8 \\
\hline
\end{tabular}

Note All measurements are in millimeters.

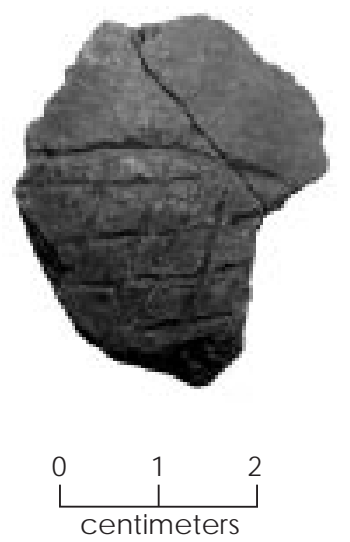

Figure 37. Prehistoric pottery sherd from 41ML 185. imprecision in the calibration curve over this time span. A second radiocarbon age of $1130 \pm 80$ B.P. on soil humates from the buried $A$ horizon indicates that the ca. 45-60-cmthick soil emcompasses a large interval of time and probably includes cultural materials that predate the Late Prehistoric period. A third radiocarbon age on charcoal ca. $30 \mathrm{~cm}$ bel ow the humate date produced a modern radiocarbon age (Beta-154285). This suggests that, al though the A horizon is thick and cumulic in nature, the cultural materials within it are mixed. It appears that the component has been disturbed either by bioturbation or some other means. Late Prehistoric materials cannot be separated stratigraphically from Late Archaic materials, and thus isolating smaller temporal components within the A horizon is not possible.
The second component is more discrete but of unknown age. The presence of the Provisional Type 1 dart point suggests a late Middle Archaic to early Late Archaic age for this component. Previous investigations in central Texas imply that this point style was used by hunters and gatherers around 30002000 B.c. (see Kleinbach et al. 1999). No radiometric data are available from 41ML 185 to provide chronol ogical support. Cultural materials associated with this component were recovered from a 40-cm-thick deposit in Test Units 3 and 4, Levels 11-14 (190-239 cm). These materials consist of 1 dart point, 1 edgemodified flake, 14 pieces of unmodified debitage, 23 mussel shell fragments, and scattered burned rocks. A few isolated burned rocks were observed at $239 \mathrm{~cm}$ in the profile of Trench 2. Given the small amount of artifacts, few interpretations can be given. Nonetheless, it is likely that chipped stone tool production, hunting, and game processing are represented by this component.

\section{Summary and Assessment}

Test excavations at 41ML 185 discovered 430 artifacts and other cultural materials, including a dart point and pottery, and two burned 
rock features. Based on the distributions of these materials and radiocarbon ages, two components are defined. The later component is L ate Archaic to Late Prehistoric in age. Prehistoric pottery sherds are associated with this component and may or may not represent a Toyah phase occupation. These LatePrehistoric artifacts cannot be separated from the Late Archaic materials. The earlier component contains few artifacts and is undated, but it probably dates to the late Middle Archaic to early Late Archaic periods. Comparatively, the earlier component is more discrete, appears to have good contextual integrity, and likely could contribute important information. For these reasons, it is recommended that $41 \mathrm{ML} 185$ be considered eligible for listing in the National Register of Historic Places.

\section{Site 41ML 186}

\section{Description}

Prehistoric site 41ML 186 is situated on the southern bank of the North Bosque River at the bend near the old Eichel berger Crossing bridge (see Figure 4). The site is located about $100 \mathrm{~m}$ south of the north bank, where Spring Branch and the North Bosque River meet. Surface elevation is approximately $470 \mathrm{ft}$. Vegetation includes oak, elm, pecan, and juniper trees with various shrubs and greenbriers making up the understory.

\section{Previous I nvestigations}

Site 41ML 186 was first located during the geomorphological and archeological surveys conducted in 1984 (Prikryl and J ackson 1985:96-98, 237-238). The lake level was $10 \mathrm{ft}$ below normal when the site was first discovered and $5 \mathrm{ft}$ below normal when the archeological crew returned to formally record the site. An examination of the cutbank revealed that the site extended for approximately $50 \mathrm{~m}$, with most of the cultural materials in a 10-12-mlong stretch at the southwestern end. Two lenses of cultural materials were observed in this area. The first consisted of burned rocks, mussel shells, and charcoal at a depth of ca. $2.9 \mathrm{~m}$ bel ow the ground surface, whil ethe second consisted of a basin-shaped hearth and a $15-\mathrm{cm}$ thick zone with burned rocks, mussel shells, and charcoal at ca. $3.6 \mathrm{~m}$. Another possible feature consisting of a thin lens of burned sediment was noted at ca. $4.2 \mathrm{~m}$. No artifacts were located within any of the lenses.

Site 41ML 186 was revisited by boat as part of a site re-location and reassessment effort in 1999 (K vernes et al., 2000:60-61). An examination of the 4.5-m-high cutbank was limited by dense vegetation. However, the examination did reveal a 20-30-cm-thick lens of mussel shells, burned rocks, and charcoal ca. $3 \mathrm{~m}$ below the surface. No shovel tests were excavated because of the deeply buried materials.

\section{Work Accomplished}

During the 2000-2001 investigations, a long rebar stake was used as the primary datum and was given an arbitrary elevation of $100.00 \mathrm{~m}$. The datum was placed near a large oak tree ca. $10 \mathrm{~m}$ west of the cutbank edge and ca. $4 \mathrm{~m}$ north of Trench 2. A second datum (rebar) was placed $18 \mathrm{~m}$ east of Trench 3.

Five trenches were excavated (Figure 38). Trench 1 in the northern part of the site was oriented at $336^{\circ}$ and measured $4.1 \times 2.5 \times 3.5 \mathrm{~m}$. An examination of the trench revealed a few small pieces of charcoal scattered between 83 and $104 \mathrm{~cm}$ and one mussel shell fragment at $204 \mathrm{~cm}$. Aligned at $314^{\circ}$, Trench 2 was ca. $13 \mathrm{~m}$ southwest of Trench 1 . It measured $4 \times 2.5 \times 3.7 \mathrm{~m}$ and contained no cultural materials. Cultural materials al so were not seen in Trench 3 , which was aligned at $324^{\circ}$, measured $4 \times 2.7 \times 3.7 \mathrm{~m}$, and was located $13 \mathrm{~m}$ southwest of Trench 2. Trench $4(2.8 \times 2.1 \times 1.9 \mathrm{~m})$ was placed $25 \mathrm{~m}$ south of Trench 3, and Trench $5(4 \times 2.8 \times 3.5 \mathrm{~m})$ was located $21 \mathrm{~m}$ southwest of Trench 4 . Neither Trench 4 nor 5 contained cultural materials. They were located in the southern part of the site at an orientation of $304^{\circ}$ and $302^{\circ}$, respectively.

Four test units were excavated. Test Units 1 and 2 were placed on the southwest side of Trench 1 . The first level in each unit began ca. $80 \mathrm{~cm}$ below the modern ground surface, near the bottom of the recent alluvial cap. Excavations were terminated at Level $30(380 \mathrm{~cm})$. Test Units 3 and 4 were placed on the southwest side of Trench 2 . The first levels in these units began at $75 \mathrm{~cm}$ bel ow the surface, and the excavations ceased at Level $31(385 \mathrm{~cm})$. In total, $12.2 \mathrm{~m}^{3}$ of fill were excavated. 


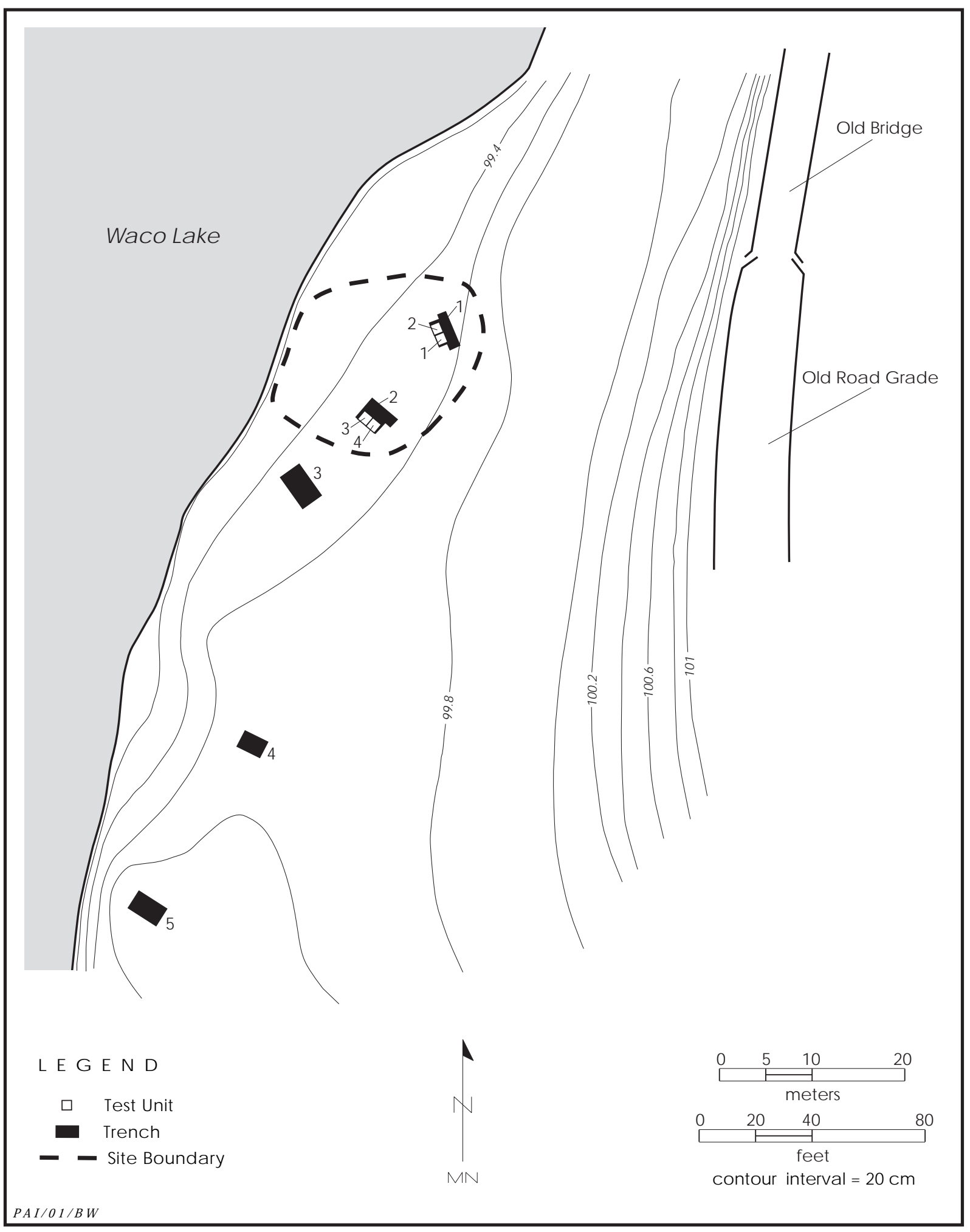

Figure 38. Map of 41ML186. 


\section{Site Extent and Depth}

In 1984, cultural materials (i.e., bones, burned rocks, mussel shells, and charcoal) were observed at depths of 2.9, 3.6, and $4.2 \mathrm{~m}$ below the ground surface along a 50-60 m stretch of cutbank (Prikryl and J ackson 1985:96-98, 237238). During the revisit in 1999 (Kvernes et al. 2000:60-61), only a 20-30-cm-thick lens of burned rocks, mussel shells, and charcoal at ca. $3 \mathrm{~m}$ bel ow the surface was identified. The trenches and test units excavated in 2000-2001 did not encounter any of the cultural zones mentioned above, only sparsely scattered cultural materials at $1.75-3.65 \mathrm{~m}$ (the water table was reached at 3.80-3.85 m). The remaining cultural deposits appear to be located in the northern part of the site area as originally defined, covering an estimated area of $20 \times 20 \mathrm{~m}$. It appears that most of the site has been lost to erosion by the North Bosque River.

\section{Sediments and Stratigraphy}

The sediments and stratigraphy at 41ML 186 were examined through the profiles of five trenches and descriptions of the soil stratigraphy of three of the trench profiles (see Appendix A). The site is situated on a Hol ocene alluvial terrace that stands ca. 4-5 m above the North Bosque channel. Soils on the terrace surface belong to the Catalpa series (Templin et al. 1958). Catalpa soils are calcareous grayish brown to dark grayish brown clay loam to clayey soils formed on recent alluvium.

As at other localities examined along the North Bosque River, the terrace at 41ML186 is mantled by a deposit of recent unmodified alluvium. This alluvial cap is $30-58 \mathrm{~cm}$ thick and consists of alternating horizontal beds and laminae of yellowish brown sand and grayish brown to dark grayish brown mud (Figure 39). It is estimated that these sediments postdate EuroAmerican settlement with the drainage basin. The underlying terrace deposits consist of channel fill and floodplain facies with multiple soil imprints. The degree of soil development throughout these deposits suggests that they are late $\mathrm{Hol}$ ocene in age.

Channel fill facies, observed in the profile of Trench 5, exhibit an upward-fining sequence. These deposits display an Ab-C-2Ab-2Bb soil profile. The Ab horizon $(55-120 \mathrm{~cm})$ is a dark grayish brown sandy clay loam containing a few poorly preserved thin sand beds. The $C$ horizon $(120-254 \mathrm{~cm})$ is an unmodified brown silt loam also containing a few poorly preserved sand beds. A second soil is imprinted on the underlying deposits. The $2 A b$ horizon $(254-288 \mathrm{~cm})$ is a dark grayish brown silty clay loam with a thin gravel bed at $276 \mathrm{~cm}$, while the underlying $2 \mathrm{Bb}$ horizon (288-352+ cm) is a very gravelly silty clay. Granule- to cobble-sized, rounded to subrounded gravels increase in frequency between 324 and $352+\mathrm{cm}$.

Overbank facies are represented in the profile of Trench 1 and display multiple soils. Trench 1 exhibits an AC-Ab-C-2Ab-2Bkb soil profile. The AC horizon $(30-83 \mathrm{~cm})$ is a brown finesandy clay loam. TheAb horizon (83-104 cm) consists of a grayish brown silty clay, while the C horizon (104-140 cm) is a brown fine sandy clay loam. The lowest buried soil (2Ab-2Bkb) consists of a dark grayish brown silty clay overlying a brown silty clay loam with common $\mathrm{CaCO}_{3}$ filaments.

\section{Materials Recovered}

Few cultural materials were recovered from 41ML 186: 2 chipped stone artifacts, 17 inverte brate faunal remains, and 4 burned rocks. None of thetest units encountered any cultural features.

\section{CHIPPED STONE ARTIFACTS}

Two pieces of unmodified lithic debitage were found. One is from Test Unit 3, Level 12 (185-195 cm). It is a complete flake $2-3 \mathrm{~cm}$ in size with some dorsal cortex present. The second piece of debitage is from Test U nit 4, Level $11(175-185 \mathrm{~cm})$. It is a proximal fragment measuring 3-4 cm in size and is completely covered with cortex on the dorsal surface.

\section{INVERTEBRATE FAUNAL REMAINS}

Of the 17 mussel shell fragments recovered, only 5 specimens are identifiable (Table 14) (see Appendix B). The remaining 12 pieces are too eroded or fragmented for identification.

\section{OTHER MATERIALS}

Two small burned rocks were observed in 


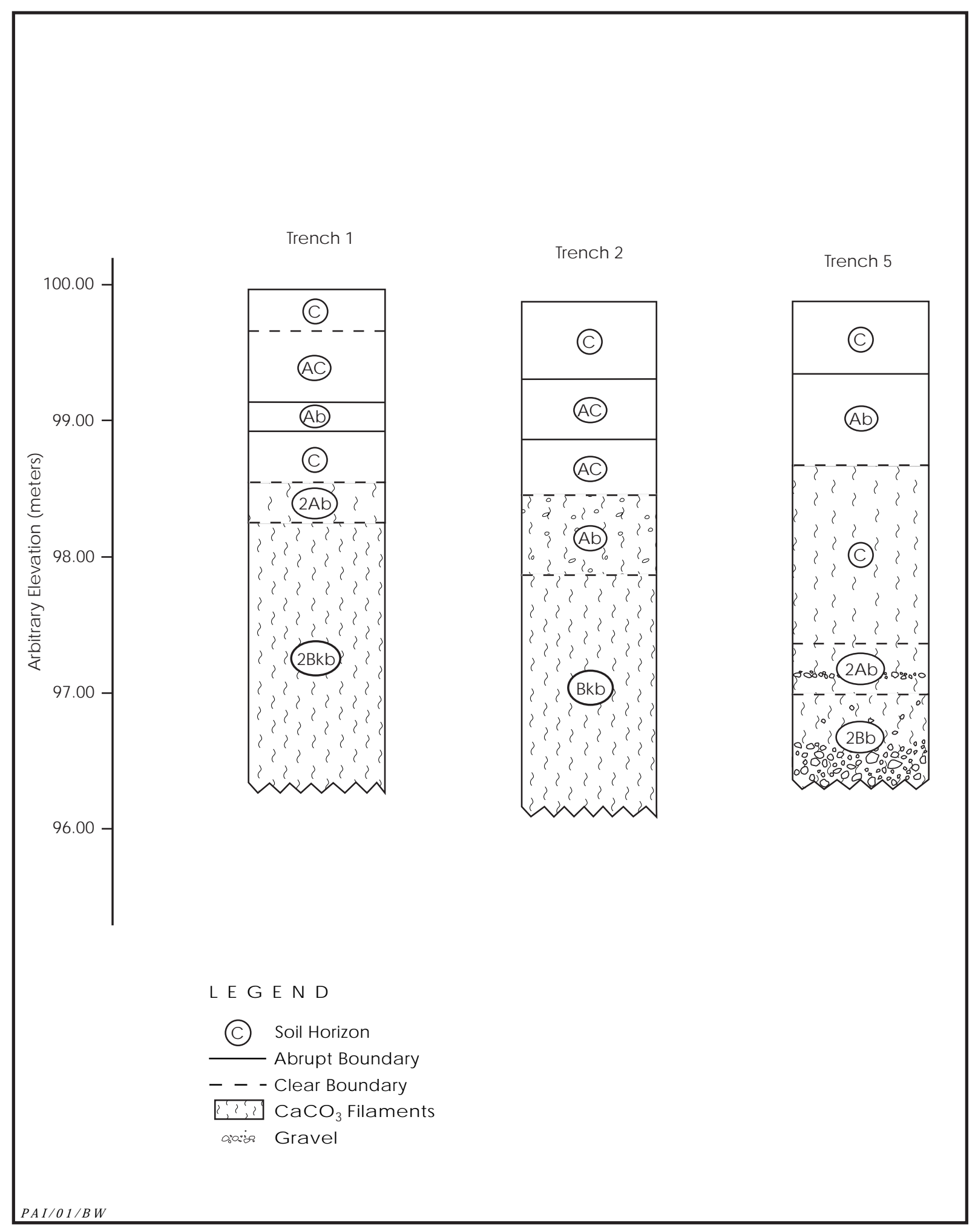

Figure 39. Profiles of Backhoe Trenches 1, 2, and 5, 41ML 186. 
Table 14. Provenience of mussel shells from 41ML 186

\begin{tabular}{lcl}
\hline Provenience & Quantity & I dentification \\
\hline TEST UNIT 1 & & \\
Level $12(190-200 \mathrm{~cm})$ & 3 & Unidentified \\
\hline TEST UNIT 2 & & \\
Level $11(180-190 \mathrm{~cm})$ & 1 & Unidentified \\
\hline TEST UNIT 3 & & \\
Level $11(175-185 \mathrm{~cm})$ & 2 & Unidentified \\
Level $13(195-205 \mathrm{~cm})$ & 1 & Quadrula sp. \\
Level $14(205-215 \mathrm{~cm})$ & 1 & Cyrtonaisas tampicoensis \\
Level $15(215-225 \mathrm{~cm})$ & 1 & Unidentified \\
\hline TEST UNIT 4 & & \\
Level $12(185-195 \mathrm{~cm})$ & 1 & Tritogonia verrucosa \\
Level $15(215-225 \mathrm{~cm})$ & 2 & Unidentified \\
Level $27(335-345 \mathrm{~cm})$ & 1 & Quadrula petrina \\
Level $28(345-355 \mathrm{~cm})$ & 1 & Quadrula sp. \\
Level $29(355-365 \mathrm{~cm})$ & 3 & Unidentified \\
\hline TOTAL & 17 & \\
\hline
\end{tabular}

\section{Site 41ML 194}

\section{Description}

Site 41ML194 is a prehistoric site situated on the eastern bank of the North Bosque River upstream from the upper end of Waco Lake (see Figure 4). The area around the site is a terrace between the modern channel to the west and an old partially filled channel to the east-northeast. A small unnamed drainage is opposite the site on the west side of the river. The current ground surface is at an elevation of ca. $470 \mathrm{ft}$. Vegetation in the area includes oak, pecan, elm, and juniper trees with a thick understory of greenbriers and various shrubs.

\section{Previous I nvestigations}

Site 41ML 194 was located and recorded in 1984 (Prikryl and J ack-

Test Unit 2, Level $13(200-210 \mathrm{~cm})$; and two were noted in Test Unit 4, Levels 28-29 (345$365 \mathrm{~cm}$ ). Collectively, the burned rocks weigh less than $1 \mathrm{~kg}$.

\section{Chronology and Components}

The cultural chronology of $41 M L 186$ is based on the distribution of few cultural materials closely related in space. Carbon samples collected from the site were insufficient for radiocarbon dating, and no diagnostics were re covered. Neverthel ess, an undated component is present between 175 and $365 \mathrm{~cm}$, based on the recovery of two flakes, four burned rocks, and mussel shells.

\section{Summary and Assessment}

Site $41 M L 186$ is an undated prehistoric site situated on the south bank of the North Bosque River. Little material was recovered from testing, and much of the site appears to have been lost to erosion. The site lacks the capacity to yield important information. Therefore, it is recommended that 41ML 186 be considered ineligible for listing in the $\mathrm{Na}$ tional Register of Historic Places. son 1985:245-246). During a boat survey, burned rocks, mussel shells, and bone fragments were noted at depths of 3.0 to $3.75 \mathrm{~m}$ al ong ca. $85 \mathrm{~m}$ of cutbank. Approximately $3 \mathrm{~m}$ bel ow the surface, a 10-cm-thick lens of horizontally bedded silt, clay, and gravel was noted as containing the majority of the cultural materials. Above the lens, clay or clay loam deposits were bedded horizontally. Beneath this lens, dipping beds of clay, silt, and gravel suggesting channel filling were observed; sparse, probably redeposited cultural materials were observed in these lower deposits.

As part of a revisitation and reassessment effort in 1999, 41ML 194 was relocated by boat and the cutbank was reexamined (Kvernes et al. 2000:64-65). A lens of mussel shells and burned rocks was noted al ong a ca. 50-m section of the cutbank around the same depth recorded in 1984. No shovel tests were excavated because of the deeply buried materials.

\section{Work Accompl ished}

During the 2000-2001 investigations, a long rebar stake was used as the primary datum and was given an arbitrary elevation of $100.00 \mathrm{~m}$. The datum was placed near a large pecan tree 
a few meters east of the cutbank edge and south of Trench 2. A second datum (rebar) was placed $12 \mathrm{~m}$ north between Trenches 1 and 2 .

Six trenches were excavated (Figure 40). Trench $1(4.9 \times 2.5 \times 3.5 \mathrm{~m})$, placed to the north of the site, was oriented at $60^{\circ}$ and encountered gravels at ca. $200 \mathrm{~cm}$. Trench 2, located $19 \mathrm{~m}$ southeast of Trench 1, measured $6.6 \times 3.5 \times 3.3 \mathrm{~m}$ and was oriented at $70^{\circ}$. A thin gravel bed was encountered at $314 \mathrm{~cm}$. About $12 \mathrm{~m}$ southwest of Trench 2, Trench 3 was oriented at $120^{\circ}$ and measured $4.7 \times 3.4 \times 2.6 \mathrm{~m}$. A burned surface was noted in the profile at $206 \mathrm{~cm}$. F urthermore, a thin lens of oxidized sediment, charcoal, and ash was observed at $217 \mathrm{~cm}$. No cultural materials were observed in the burned lenses.

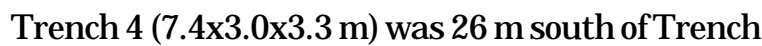
3 and was oriented at $100^{\circ}$. Twenty-five meters to the southwest lies Trench 5, oriented at $116^{\circ}$ and measuring $7.5 \times 4.0 \times 3.3 \mathrm{~m}$. Finally, Trench 6 (oriented at $102^{\circ}$ ) was placed in an area where the nearby cutbank showed a deeply buried lens of gravel and mussel shells. Thetrench measured $8.6 \times 3.0 \times 3.3 \mathrm{~m}$ but failed to encounter the deeply buried lens or yield any cultural materials. A bulk sediment sample for radiocarbon dating was collected from the wall at $114-122 \mathrm{~cm}$.

Six test units were placed at 41ML 194. Test Units 1 and 2 were on the north side safety bench of Trench 2 . The upper $130 \mathrm{~cm}$ in these units were discarded without screening because they appeared to be culturally sterile. These units were taken to Level $9(220 \mathrm{~cm})$ before efforts were redirected to focus on potentially better areas of the site. Test Units 3 and 4 were on the south side safety bench of Trench 3 . The first levels began $150 \mathrm{~cm}$ bel ow the modern ground surface. The units were situated over Feature 1, the thin lens of oxidized sediment, charcoal, and ash observed at $217 \mathrm{~cm}$. Excavations were halted at Level $23(380 \mathrm{~cm})$. Finally, Test Units 5 and 6 , which examined the southern portion of the site area where cutbank exposures showed mussel shells, were on the south side safety bench of Trench 6 . The first levels in these units began at $135 \mathrm{~cm}$ bel ow the modern ground surface. Excavations were concluded at Level $24(375 \mathrm{~cm})$. A total of $11.2 \mathrm{~m}^{3}$ of fill were hand excavated at 41ML 194.

\section{Site Extent and Depth}

Site 41ML 194 originally was discovered in the cutbank of the North Bosque River during a boat survey in 1984 (Prikryl and J ackson 1985:245-246). Cultural materials such as burned rocks, mussel shells, and bone fragments were recorded along an 85-m stretch of the cutbank at depths of 3.0 to $3.75 \mathrm{~m}$. The few cultural materials observed in the cutbank and recovered in the trenches and test units in 2000-2001 indicate a north-south dimension of ca. $100 \mathrm{~m}$ and an east-west dimension of $10 \mathrm{~m}$ or less. Apparently, most of the site has eroded away. Archeol ogical materials were documented from ca. $2.0 \mathrm{~m}$ to $3.75 \mathrm{~m}$ bel ow the surface.

\section{Sediments and Stratigraphy}

The sediments and stratigraphy at 41ML 194 were examined through the profiles of six trenches and descriptions of the soil stratigraphy of three of the trench profiles (see Appendix A). The site is situated on a Hol ocene alluvial terrace that stands ca. $7 \mathrm{~m}$ above the North Bosque channel. Portions of the terrace cutbank appear to have slumped recently. Soils on the terrace surface bel ong to the Catalpa and Patrick series (Templin et al. 1958). Catalpa soils are cal careous grayish brown to dark grayish brown clay loam to clayey soils formed on recent alluvium, while Patrick soils are shallow, calcareous, dark brown to dark grayish brown dayey alluvial soils overlying limestone gravels.

Trench exposures reveal that the terrace is a composite of channel margin (levee and crevasse splay) and interchannel floodbasin (floodplain) facies. Multiple soils are imprinted on these deposits, and the soil stratigraphy is fairly consistent across the site (Figure 41). The site is mantled by a thin (ca. $16-18 \mathrm{~cm}$ ) deposit of brown to grayish brown silty clay that is pedogenically unmodified, suggesting that it was deposited recently. Levee and crevasse splay deposits consisting of alternating beds of fine to coarse quartz sand and dark silty clay underlie the recent mantle. These deposits range from $69 \mathrm{~cm}$ thick in Trench 6 to $286 \mathrm{~cm}$ thick in Trench 2, with some displaying multiple buried soils. Floodplain deposits underlie the levee and crevasse splay deposits at depths of 85 to $304 \mathrm{~cm}$ bel ow the surface. These deposits consist of dark silty clay loams imprinted with A or A-Bw-B soil profiles.

The profile of Trench 6 is typical of the previously noted sequence. $A$ recent unmodified 
National Register Testing of NineArcheol ogical Sites at Waco Lake

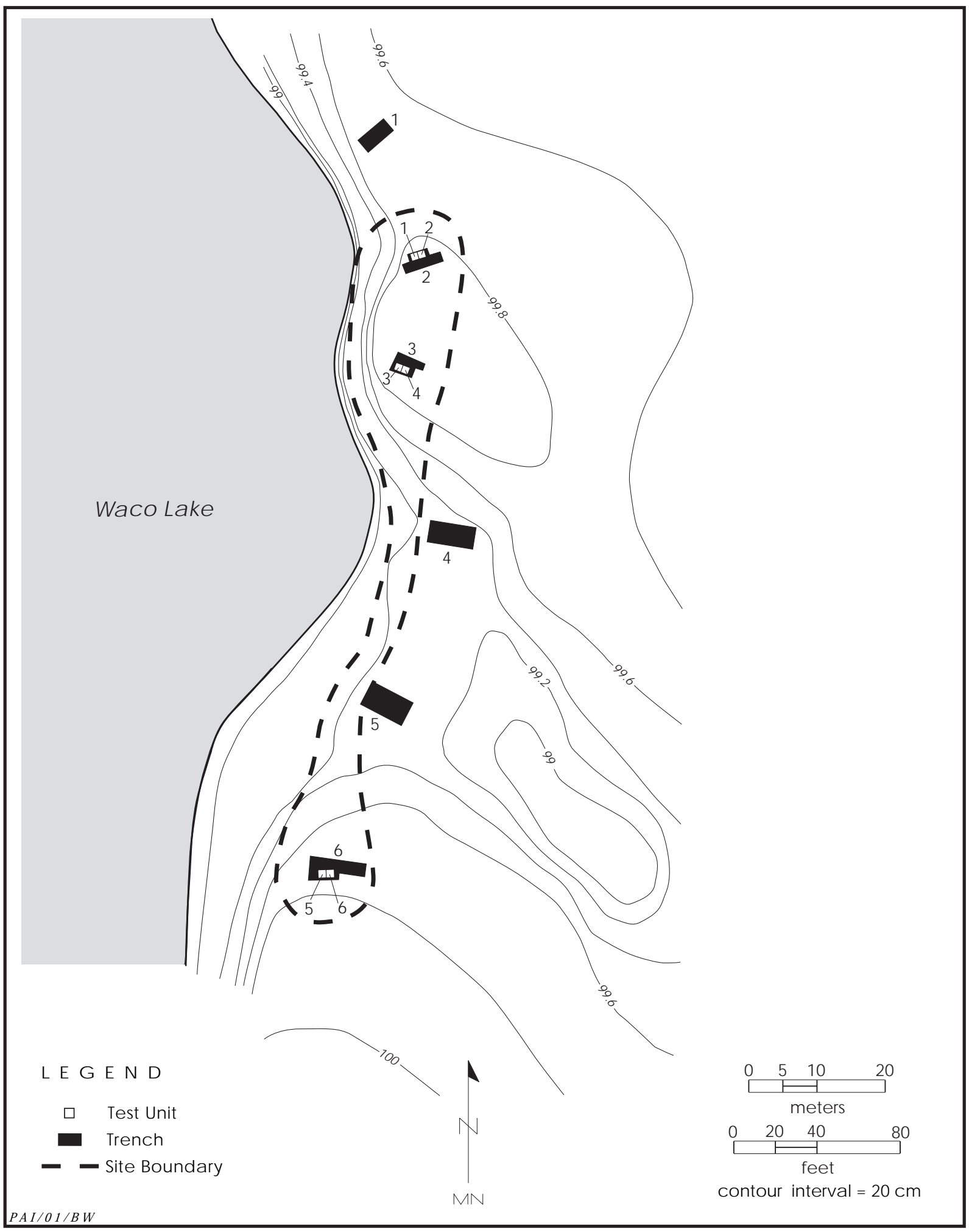

Figure 40. Map of 41ML 194. 


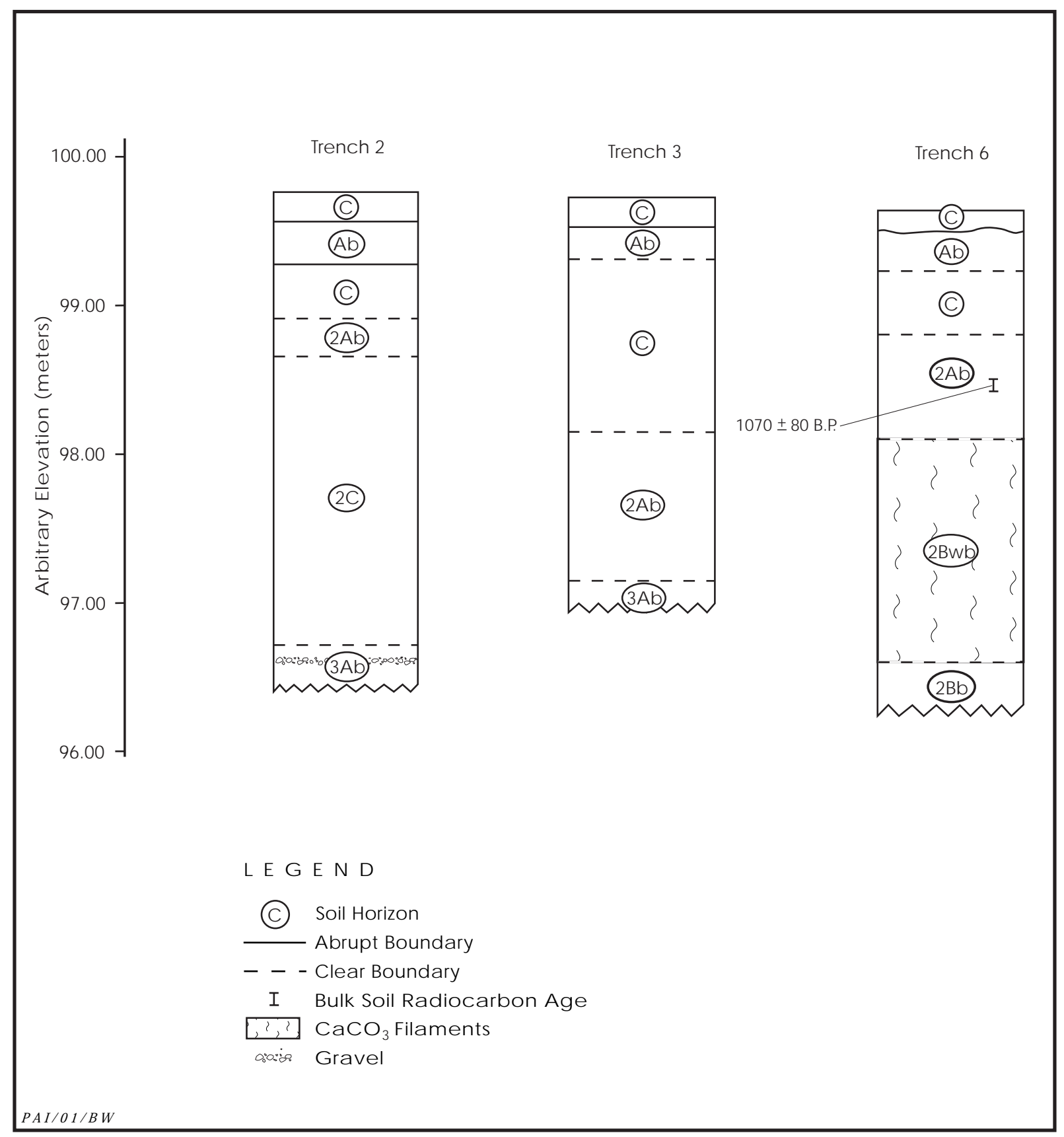

Figure 41. Profiles of Trenches 2, 3, and 6, 41ML 194.

alluvial deposit of brown silty clay $(0-16 \mathrm{~cm})$ caps the soil-stratigraphic profile. A thin bed of fine to medium sand marks the wavy boundary between it and the underlying levee deposit. The levee deposit $(16-85 \mathrm{~cm})$ is imprinted with an $\mathrm{Ab}-\mathrm{C}$ soil profile. TheAb horizon is a $25-\mathrm{cm}$-thick dark grayish brown silty clay loam. The $C$ horizon is a 44-cm-thick brown silty clay with a few poorly preserved very thin to thin beds of fine to medium quartz sands. The underlying floodplain deposits $(85-330+\mathrm{cm})$ exhibit a $2 \mathrm{Ab}$ $2 \mathrm{Bwb}-2 \mathrm{Bb}$ soil profile. The $2 \mathrm{Ab}$ horizon $(85-156 \mathrm{~cm})$ is a dark gray silty clay loam. A bulk soil sample collected from the $2 A b$ horizon at 114- $122 \mathrm{~cm}$ produced a conventional radiocarbon age of $1070 \pm 80$ B.P. (Beta-154296). 
The 2Bwb horizon (156-306 cm) is a dark grayish brown silty clay, while the 2Bb horizon (306$330+\mathrm{cm})$ is a dark grayish brown silty clay loam. The radiocarbon age of the buried soil in Trench 6 and the degree of development observed in all of the buried soils throughout the site suggest that the alluvial deposits composing the terrace are late $\mathrm{H}$ ol ocene in age.

\section{Cultural Feature}

Feature 1, a thin lens of oxidized sediment, charcoal, and ash, was discovered in the wall of Trench 3. The feature covers most of Test $U$ nits 3 and 4 at a depth of ca. 203-212 cm. The excavated portion measures ca. $2.0 \times 0.75 \mathrm{~m}$ (Figure 42). The lens is approximately $7-9 \mathrm{~cm}$ thick. It contains concentrations of ash, charcoal, and oxidized sediment; however, none are discrete, isolable layers. The lens exhibits a broad, slightly basin-shaped profile across Test Unit 3 , but that shape is not reflected elsewhere in the feature cross section. In general, the cross section is gently undulating, showing no evidence of a prepared surface. No cultural materials were observed during excavation of the feature. Approximately 42.8 liters of sediment were collected from the feature for flotation processing (see Materials Recovered).

While the exact function of Feature 1 is unclear, it is reasonable to think that the feature is an unprepared heating/cooking surface. This is suggested by the presence of charcoal, ash, and oxidized sediment; the lack of burned rocks; and the recovery of charred faunal re mains from the fill. The age of the feature is unknown, but a Late Archaic age is inferred based on its provenience and a radiocarbon age on bulk soil collected fromTrench 6 in the same soil-stratigraphic zone.

\section{Materials Recovered}

A single chipped stone artifact and 31 invertebrate faunal remains were recovered during hand excavations at 41ML 194. Materials also were recovered from the flotation of Feature 1 fill.

\section{CHIPPED STONE ARTIFACT}

One pi ece of unmodified lithic debitage was recovered from Test Unit 5, Level 19 (315-
$325 \mathrm{~cm}$ ). The specimen is a $5-6-\mathrm{cm}$ chunk of dark gray chert. Most of the specimen is covered with cortex, and it may represent a tested cobble fragment.

\section{INVERTEBRATE FAUNAL REMAINS}

Of the 31 pieces of mussel shell recovered from the site, only 3 specimens are identifiable (Table 15) (see Appendix B). The remaining 28 are too eroded or fragmented for identification.

\section{OTHER MATERIALS}

Flotation sampling from Feature 1 recovered 11 small (less than $1 \mathrm{~cm}$ ) unidentified bone fragments and a minute quantity of charcoal. Seven of the bones are burned or calcined.

\section{Chronology and Components}

Based on the distribution and depths of cultural materials and a radiocarbon assay, one component is defined for 41ML 194. A radiocarbon age of $1070 \pm 80$ B.P. on a bulk soil sample from Trench 6 suggests that the cultural deposit, which is stratigraphically bel ow the dated soil sample, is Late Archaic in age (assuming, of course, that this assay does not suffer from the kinds of problems that often are associated with dated soil humates). One feature, an unprepared heating/cooking surface, and a small number of cultural materials are associated with this component. The site probably represents a short-term, specialized task site such as a hunting camp, where small game was processed, cooked, and consumed by a small party of hunters.

\section{Summary and Assessment}

Site 41ML 194 is a LateArchaic sitenestled in a bend of the North B osque River. It appears that much of the site has been lost to erosion. What is left is represented by a handful of cultural materials and a heating/cooking feature on an unprepared surface. Because of the very low density of artifacts and other cultural remains, including datable materials, 41ML 194 lacks the capacity to yield important archeological information. The site is considered ineligible for listing in the National Register of Historic Places. 


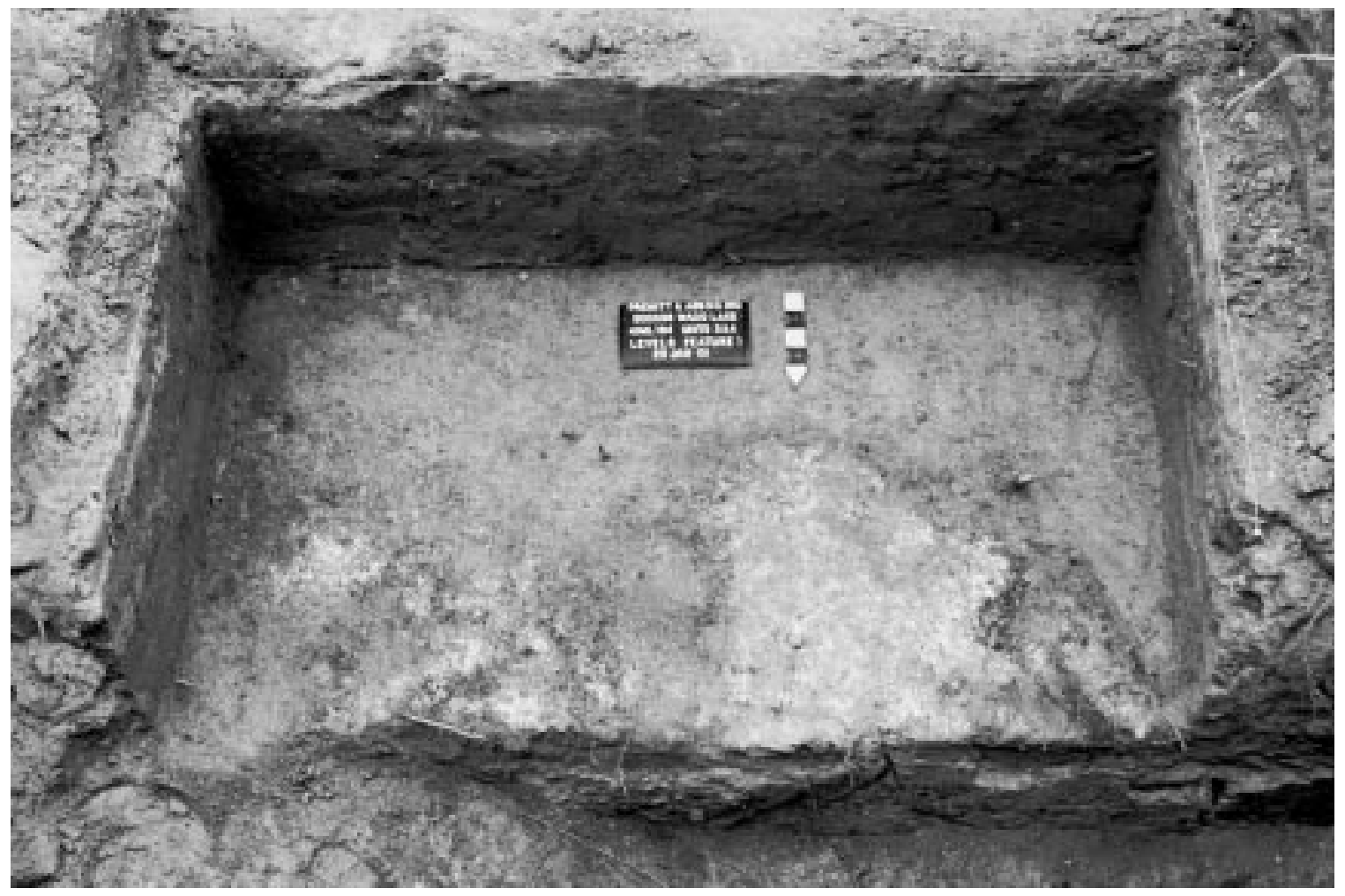

Figure 42. Photograph of Feature 1, Test Units 3 and 4, 41ML 194. View is south.

\section{Site 41ML 195}

\section{Description}

Site 41ML 195 is a prehistoric site deeply buried in Holocene alluvium on the north bank of the North Bosque River upstream from the upper end of Waco Lake (see F igure 4). The site occupies a Hol ocene terrace, the surface of which is at an el evation of ca. $470 \mathrm{ft}$, between themodern channel to the south and an old partially filled channel ca. $200 \mathrm{~m}$ to the north. Vegetation consists of a dense oak, pecan, elm, and juniper forest with a thick understory of brush and greenbriers.

\section{Previous Investigations}

Site 41M L 195 was located and recorded in 1984 (Prikryl and J ackson 1985:246). Investigations were limited to inspection of a 6-7-m-high cutbank, where cultural materials were observed over a distance of ca. $60 \mathrm{~m}$. Scattered mussel shell fragments and one chert flake were noted at $70-80 \mathrm{~cm}$ below the surface, and another lens of mussel shells and burned rocks was observed at ca. $3 \mathrm{~m}$. B oth lenses were recor ded as dipping down to the east. Scattered mussel shell fragments, but no artifacts, were noted between the lenses.

Site 41ML 195 was revisited in 1999 as part of a site re-location and reassessment effort (Kvernes et al. 2000:65-66). The cutbank, with the Waco Lake conservation pool at its normal 455-ft level, was approximately $5.5 \mathrm{~m}$ high. Visibility generally was good, except for the upper $20 \mathrm{~cm}$ where poison oak and weeds partially obscured the bank. Mussel shell fragments were observed in the cutbank around $80 \mathrm{~cm}$ below the surface. A second lens of mussel shells approximately $5 \mathrm{~cm}$ thick was noted at a depth of $3 \mathrm{~m}$, extending for a distance of about $40 \mathrm{~m}$. Some evidence of erosion was noted, but intact cultural deposits clearly were present. No shovel tests were excavated because of the depth of the cultural deposits. 
Table 15. Provenience of mussel shells from 41ML 194

\begin{tabular}{lcl}
\hline Provenience & Quantity & I dentification \\
\hline TEST UNIT 3 & & \\
Level 22 $(360-370 \mathrm{~cm})$ & 8 & Unidentified \\
\hline TEST UNIT 4 & & \\
Level 17 $(310-320 \mathrm{~cm})$ & 1 & Tritogonia verrucosa \\
Level 19 $(330-340 \mathrm{~cm})$ & 1 & Unidentified \\
Level 21 $(350-360 \mathrm{~cm})$ & 2 & Unidentified \\
\hline TEST UNIT 5 & & \\
Level $5(175-185 \mathrm{~cm})$ & 1 & Unidentified \\
Level $17(295-305 \mathrm{~cm})$ & 2 & Unidentified \\
Level $18(305-315 \mathrm{~cm})$ & 1 & Amblema plicata \\
Level $19(315-325 \mathrm{~cm})$ & 3 & Unidentified \\
Level 22 $(345-355 \mathrm{~cm})$ & 2 & Unidentified \\
Level $24(365-375 \mathrm{~cm})$ & 1 & Unidentified \\
\hline TEST UNIT 6 & & \\
Level $16(285-295 \mathrm{~cm})$ & 1 & Unidentified \\
Level $17(295-305 \mathrm{~cm})$ & 3 & Unidentified \\
Level $18(305-315 \mathrm{~cm})$ & 1 & Quadrula sp. \\
& 1 & Unidentified \\
Level $19(315-325 \mathrm{~cm})$ & 3 & Unidentified \\
\hline TOTAL & 31 & \\
\hline
\end{tabular}

Situated ca. $25 \mathrm{~m}$ north of the cutbank on the eastern end of the site area, Trench 3 also encountered cultural materials between 230 and $240 \mathrm{~cm}$. Aligned at $80^{\circ}$, the trench measured $5.3 \times 3.1 \times 2.4 \mathrm{~m}$ and was ca. $40 \mathrm{~m}$ from Trench 1.

Four test units were hand excavated. Test Units 1 and 2 were placed on the western safety bench of Trench 1 . Level 1 in each of the units began $75 \mathrm{~cm}$ below the modern ground surface. The excavation was terminated at Level $21(285 \mathrm{~cm})$. Test Units 3 and 4 were placed on the southern safety bench of Trench 3. The first level in these units began $85 \mathrm{~cm}$ bel ow modern ground surfaceand thelast was Level $19(275 \mathrm{~cm})$. A total of $8.0 \mathrm{~m}^{3}$ were hand excavated.

\section{Site Extent and Depth}

As originally recorded in 1984 (Prikryl and J ackson 1985:246), 41ML 195 consisted of an 80-m-long exposure of chert flakes, burned

\section{Work Accomplished}

During the 2000-2001 investigations, a long rebar stake was used as the primary datum and was given an arbitrary elevation of $100.00 \mathrm{~m}$. The datum was placed near a large tree a few meters north of the cutbank edge and between Trenches 1 and 2. A U.S. Army Corps of Engineers benchmark is present at the site, a few meters from the cutbank. Part of the notation reads, "COE 1-3-3 1965." Its location was recorded during site mapping and designated as the secondary datum. The primary datum is $15.5 \mathrm{~m}$ due west of the Corps benchmark.

Threetrenches were excavated (Figure 43). Trench 1 , located on the western edge of the site, was aligned at $356^{\circ}$ and measured $5.2 \times 2.9 \times 2.6 \mathrm{~m}$. It was just behind the cutbank. The trench yielded mussel shells, burned rocks, and charcoal at 235-240 cm, while debitage and a projectile point were recovered from the backdirt pile. Trench 2, excavated near the cutbank 20 m east of Trench 1, was aligned at $330^{\circ}$ and measured $5.0 \times 3.0 \times 2.4 \mathrm{~m}$. Burned rocks and mussel shells were observed at $230-240 \mathrm{~cm}$. rocks, and mussel shells in the terrace cutbank along the North Bosque River. Cultural materials were observed at depths of up to ca. $3 \mathrm{~m}$ bel ow the surface. Test excavations in 2000-2001 found that cultural materials extend a substantial distance in from the cutbank, at least $30 \mathrm{~m}$. Based on this and current observations of the materials exposed in the cutbanks, it is estimated that the site covers an area that is roughly $50 \times 30 \mathrm{~m}$.

Although small numbers of mussel shells and shell fragments were encountered throughout the upper deposits during testing, unquestionable cultural materials (lithic debitage) were not encountered until ca. 185 and $205 \mathrm{~cm}$ in Test Units 2 and 1, respectively. The frequency of cultural materials substantially decreased between ca. 265 and $275 \mathrm{~cm}$. Although mussel shell fragments were encountered at $285 \mathrm{~cm}$, they were not associated with any obvious cultural materials.

\section{Sediments and Stratigraphy}

Thesediments and stratigraphy at 41ML 195 


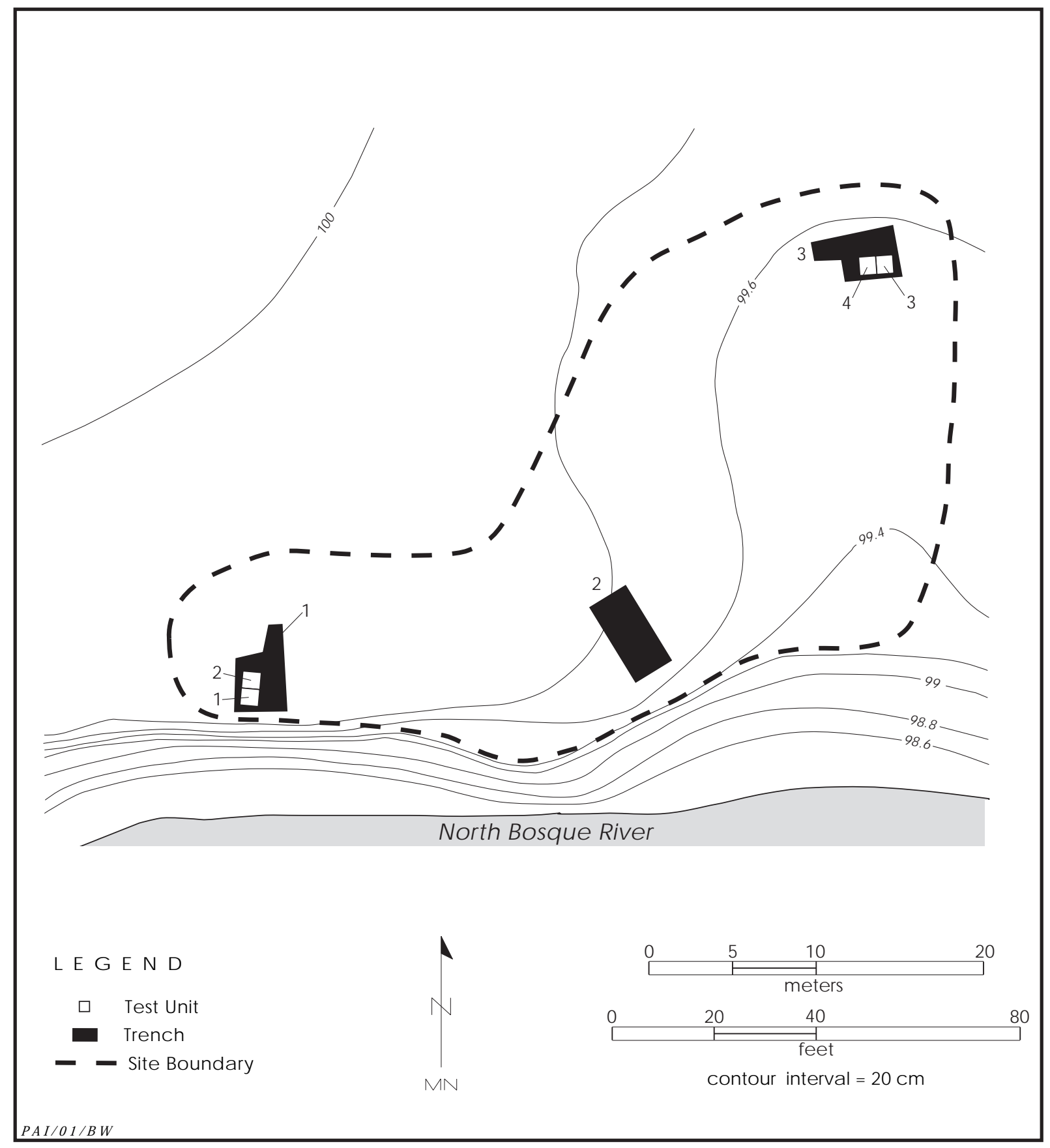

Figure 43. Map of 41ML 195.

were examined through the profiles of three trenches and descriptions of the soil stratigraphy of two of the trench profiles (see Appendix A). The site is situated on a Holocene alluvial terrace that stands ca. $6 \mathrm{~m}$ above the North Bosque channel. Soils on the terrace surface belong to the Catalpa series (Templin et al. 1958). Catal pa soils are calcareous grayish brown to dark grayish brown clay loam to clayey soils formed on recent alluvium.

The terrace surface is covered by an 1819-cm-thick veneer of recent grayish brown to 
dark grayish brown loamy alluvium (Figure 44). A very thin to thin bed of medium to coarse sand-sized quartz and carbonate clasts is present at the base of this deposit. The recent alluvium overlies late Holocene alluvium that is imprinted with multiple soils. Trench 1 expresses an Ab-Bwb-Bwb2-2Ab soil profile, and Trench 3 displays an $A b-B w b-2 A b$ soil profile. The upper buried soil (Ab-Bwb and Ab-Bwb-Bwb2) in both profiles is imprinted on upward-fining channel fill deposits. In Trench 1, the Ab horizon $(18-46 \mathrm{~cm})$ consists of very dark grayish brown sandy clay loam with a discontinuous thin bed of coarse sand-sized quartz, carbonate clasts, and fossilized shell fragments. The underlying Bwb horizon (46-96 cm) is a dark grayish brown very fine sandy clay loam, and the B wb2 horizon $(96-200 \mathrm{~cm})$ is a very dark grayish brown fine to medium sandy loam. In Trench 3 , the Ab horizon $(19-36 \mathrm{~cm})$ consists of a very dark grayish brown silty clay loam, while the underlying Bwb horizon (36-190 cm) is a dark grayish brown coarse to very coarse sandy clay loam with 2 percent limestone gravels.

The previously described channel fill deposits overliea second buried soil that is imprinted on dark loamy alluvium (overbank sediments). The 2Ab horizon of Trench $1(200-250+\mathrm{cm})$ consists of a dark grayish brown silty clay loam, while the $2 \mathrm{Ab}$ horizon of Trench $3(190-242+\mathrm{cm})$ is a dark grayish brown clay loam. The soil contains a rich assemblage of cultural materials.

\section{Cultural Feature}

One discrete cluster of burned rocks was discovered and designated Feature 1 (Figure 45). Feature 1 is located in Test U nit 1, Level $19(255-261 \mathrm{~cm})$, and measures ca. $50 \times 50 \mathrm{~cm}$. It is a single layer of mostly flat-lying tabular burned rocks, averaging about $15-20 \mathrm{~cm}$ in size and weighing $5.5 \mathrm{~kg}$. In cross section, the feature measures about $6 \mathrm{~cm}$ in thickness and has a slight basin-shaped base, which is accentuated by the tilting of the burned rocks toward the center of the feature. Some of the rocks, particularly the bases or bottoms, are fire reddened or oxidized. No ash or oxidized sediment was observed, however, a charcoal sample was collected from below one of the rocks. Laboratory analysis found that this sample is a mix of a small amount of charred wood and organic sediment. The sample pro- duced a radiocarbon age of $3130 \pm 40$ B.P. (Beta-154287). Two other charcoal samples (one of which was identified as oak wood) were collected from just outside the feature in Test Unit 2. These two samples yiel ded radiocarbon ages of $2740 \pm 40$ B.P. (Beta-154290) and $2870 \pm 40$ B.P. (Beta-154288). It is believed that these two radiocarbon ages are a better estimate of the age of Feature 1 than the radiocarbon age of $3130 \pm 40$ B.P. from the feature itself because they are on charcoal rather than a mix of charcoal and organic sediment.

No artifacts were observed during excavation of the feature; however, mussel shells were found in association with the burned rocks, and three dart points were found in Level 18 of the adjacent test unit (see Materials Recovered). Approximately 13.5 liters of feature fill were collected for flotation. Flotation processing recovered $0.036 \mathrm{~kg}$ of small burned rocks, 19 pieces of lithic debitage, 9 bone fragments, some charred botanical remains, and 8 mussel shell fragments. The faunal remains were included in the vertebrate faunal analyses (see Materials Recovered).

Feature 1 represents a small hearth or baking pit as suggested by its basin shape. It is probable that the ground surface was prepared by digging a shallow pit and lining it with a single layer of tabular rocks so that heat could be stored and cooking time increased.

\section{Materials Recovered}

Modest amounts of cultural materials were recovered from 41M L 195: 141 chi pped stone artifacts, 760 invertebrate faunal remains, 14 vertebrate faunal remains, and some burned rocks. Provenience data are presented in Table 16.

\section{CHIPPED STONE ARTIFACTS}

The 141 chipped stone artifacts consist of 4 dart points, 2 bifaces, 14 pieces of edge-modified debitage, and 121 pieces of unmodified debitage.

Dart Points

\section{Carrollton}

One specimen is classified as a Carrollton dart point (Turner and Hester 1993:85) (Figure 46a). Thetriangular bladeis broad, and 


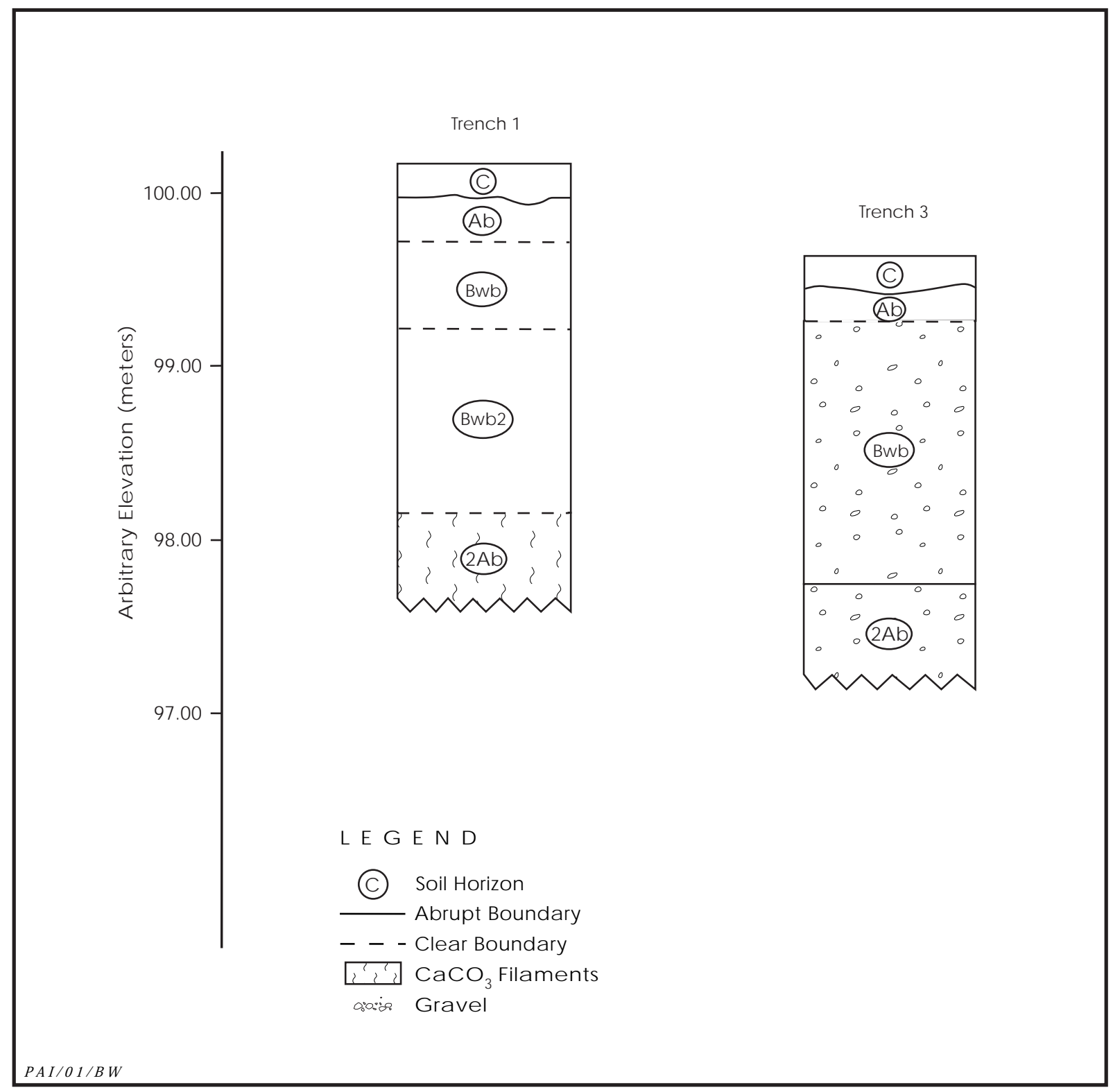

Figure 44. Profiles of Trenches 1 and 3, 41ML 195.

the shoulders are prominent with moderate barbs. The stem is slightly contracting, and its base is straight. The raw material is a light grayish brown chert with some pinkish hues along the basal edge. Provenience and metric data for this and the other dart points recovered are provided in Table 17.

\section{Ellis}

Two specimens areidentified as Ellis points
(Turner and Hester 1993:113) (Figure 46b-c). The first is nearly complete and has a small triangular blade with serrated edges. The shoulders are prominent and barbed. The stem is expanding, and the base is convex. Basal grinding is evident, which is unusual for Ellis points (Elton Prewitt, personal communication 2001). The material is a black chert with lighter gray inclusions and small crystalline vugs. The second specimen is a nearly intact point, missing the tip, one lateral blade edge, and a barb. The 


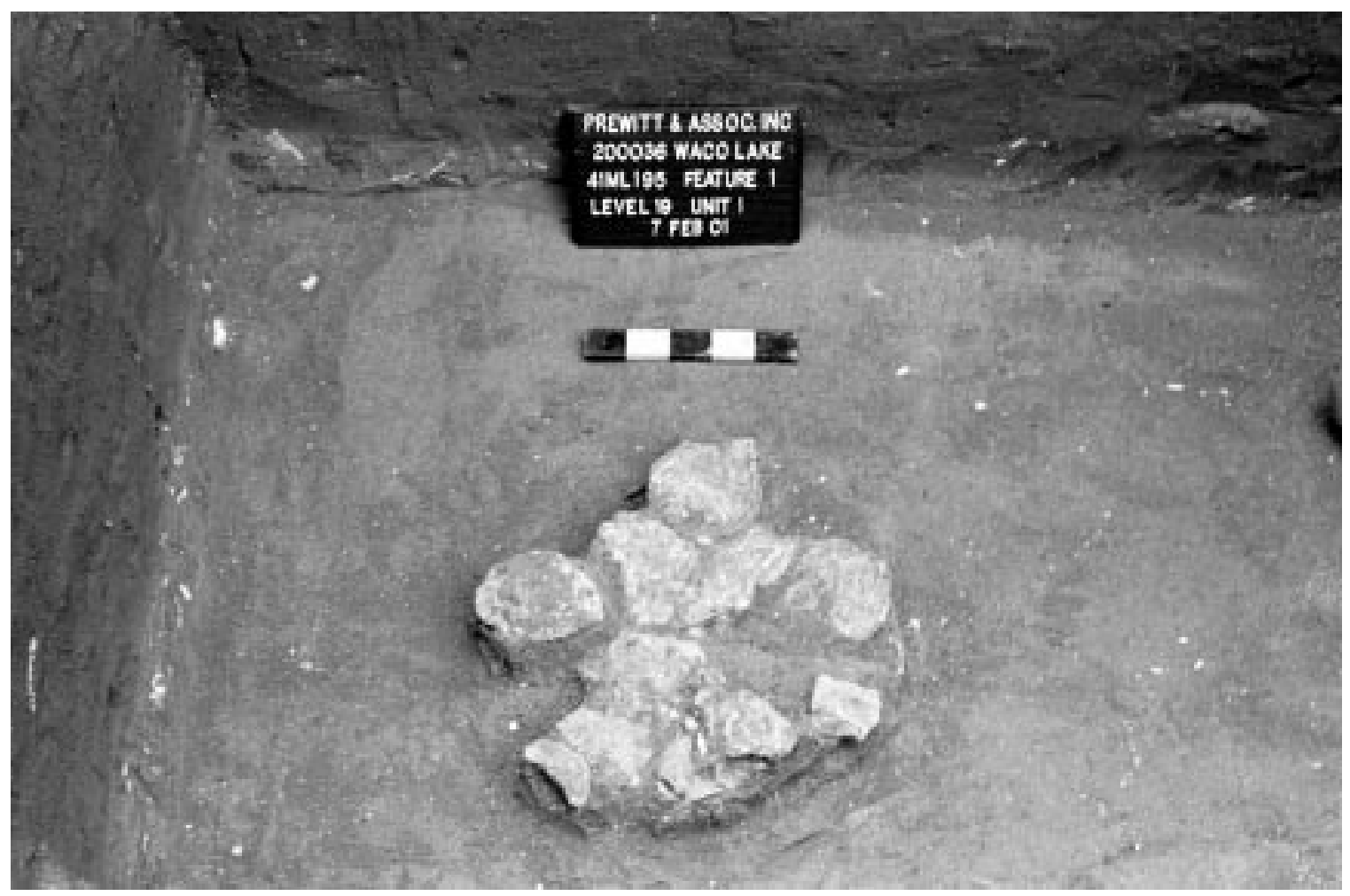

Figure 45. Photograph of Feature 1, 41ML 195.

blade is small and triangular with moderate barbed shoulders. The stem is short and expanding, and the base is convex. The material is a light gray chert with lighter gray mottles.

\section{Untyped}

One specimen could not be typed (Figure 46d). It is a distal fragment. The intact portion of thebladedisplays alternate left beveling. The material is a gray chert with white speckles.

\section{Bifaces}

Two bifaces were recovered, an intact adze (Figure 46e) and a proximal bifacial fragment. Collected fromTest Unit 1, Level $18(245-255 \mathrm{~cm})$, the adze is in an early stage of reduction; it measures $64.4 \mathrm{~mm}$ long by $53.4 \mathrm{~mm}$ wide by and $20.2 \mathrm{~mm}$ thick. The raw material is a light to dark brown chert with gray mottling; cortex is present on the dorsal side of the tool.

The proximal fragment is from Test U nit 2, Level $18(245-255 \mathrm{~cm})$, and is in the middle stage of reduction and likely a manufacturing failure. Theonly measurable attributeis its thickness, which is $8.7 \mathrm{~mm}$. Thematerial is a light gray chert with fine white speckled inclusions.

\section{Edge-modified Debitage}

Fourteen pieces of edge-modified debitage were identified. Fifty percent $(n=7)$ are complete flakes, 21 percent $(n=3)$ are proximal fragments, and 29 percent $(n=4)$ are chips. Over half of the specimens (57 percent, $n=8$ ) have dorsal cortex. The majority of the utilized flakes have one working edge $(n=8)$, and 4 specimens have two working edges. The remaining 2 pieces display three working edges. None of the specimens are smaller than $2 \mathrm{~cm}$ in size, and the largest piece is $4-5 \mathrm{~cm}$. The two edgemodified flakes with three working edges are 2$3 \mathrm{~cm}$ in size. Overall, 50 percent $(n=7)$ of the assemblage are $2-3 \mathrm{~cm}$ in size and 43 percent $(n=6)$ are $3-4 \mathrm{~cm}$. The remaining specimens $(7$ percent) are $4-5 \mathrm{~cm}$. Raw material colors range from gray to light gray and brown cherts. 
Table 16. Summary of cultural materials from 41ML 195

\begin{tabular}{|c|c|c|c|c|c|c|c|}
\hline Provenience & Bifaces & $\begin{array}{c}\text { Dart } \\
\text { Points } \\
\end{array}$ & $\begin{array}{c}\text { Edge- } \\
\text { modified } \\
\text { Debitage }\end{array}$ & $\begin{array}{c}\text { Unmodified } \\
\text { Debitage }\end{array}$ & $\begin{array}{c}\text { Unmodified } \\
\text { Bones }\end{array}$ & $\begin{array}{c}\text { Unmodified } \\
\text { Mussel Shells } \\
\end{array}$ & Totals \\
\hline TRENCH 1 (backdirt) & - & 1 & - & - & - & - & 1 \\
\hline \multicolumn{8}{|l|}{ TEST UNIT 1} \\
\hline Level 2 (85-95 cm) & - & - & - & - & - & 1 & 1 \\
\hline Level $5(115-125 \mathrm{~cm})$ & - & - & - & - & - & 1 & 1 \\
\hline Level $6(125-135 \mathrm{~cm})$ & - & - & - & - & - & 1 & 1 \\
\hline Level $8(145-155 \mathrm{~cm})$ & - & - & - & - & - & 1 & 1 \\
\hline Level $11(175-185 \mathrm{~cm})$ & - & - & - & - & - & 2 & 2 \\
\hline Level $12(185-195 \mathrm{~cm})$ & - & - & - & - & - & 3 & 3 \\
\hline Level $14(205-215 \mathrm{~cm})$ & - & - & 1 & 1 & - & 3 & 5 \\
\hline Level $15(215-225 \mathrm{~cm})$ & - & - & - & 2 & - & 9 & 11 \\
\hline Level $16(225-235 \mathrm{~cm})$ & - & - & - & - & - & 8 & 8 \\
\hline Level $17(235-245 \mathrm{~cm})$ & - & - & - & 5 & - & 10 & 15 \\
\hline Level $18(245-255 \mathrm{~cm})$ & 1 & - & - & 15 & - & 113 & 129 \\
\hline F eature $1(255-261 \mathrm{~cm})$ & - & - & - & 19 & 9 & 8 & 36 \\
\hline Level $19(255-265 \mathrm{~cm})$ & - & - & 1 & 26 & 1 & 66 & 94 \\
\hline Level $20(265-275 \mathrm{~cm})$ & - & - & - & - & - & 69 & 69 \\
\hline Level 21 (275-285 cm) & - & - & - & - & - & 11 & 11 \\
\hline Subtotals & 1 & 0 & 2 & 68 & 10 & 306 & 387 \\
\hline \multicolumn{8}{|l|}{ TEST UNIT 2} \\
\hline Level $8(145-155 \mathrm{~cm})$ & - & - & - & - & - & 1 & 1 \\
\hline Level $11(175-185 \mathrm{~cm})$ & - & - & - & - & - & 3 & 3 \\
\hline Level $12(185-195 \mathrm{~cm})$ & - & - & 1 & - & - & 2 & 3 \\
\hline Level $13(195-205 \mathrm{~cm})$ & - & - & - & 1 & - & 1 & 2 \\
\hline Level $14(205-215 \mathrm{~cm})$ & - & - & - & - & - & 2 & 2 \\
\hline Level $15(215-225 \mathrm{~cm})$ & - & - & - & 1 & - & 60 & 61 \\
\hline Level $16(225-235 \mathrm{~cm})$ & - & - & - & 1 & - & 3 & 4 \\
\hline Level $17(235-245 \mathrm{~cm})$ & - & - & - & 4 & - & 22 & 26 \\
\hline Level $18(245-255 \mathrm{~cm})$ & 1 & 3 & 5 & 32 & 4 & 158 & 203 \\
\hline Level $19(255-265 \mathrm{~cm})$ & - & - & 4 & 14 & - & 13 & 31 \\
\hline Level $20(265-275 \mathrm{~cm})$ & - & - & - & - & - & 26 & 26 \\
\hline Level $21(275-285 \mathrm{~cm})$ & - & - & - & - & - & 4 & 4 \\
\hline Subtotals & 1 & 3 & 10 & 53 & 4 & 295 & 366 \\
\hline \multicolumn{8}{|l|}{ TEST UNIT 3} \\
\hline Level $5(125-135 \mathrm{~cm})$ & - & - & - & - & - & 4 & 4 \\
\hline Level $6(135-145 \mathrm{~cm})$ & - & - & - & - & - & 1 & 1 \\
\hline Level $9(165-175 \mathrm{~cm})$ & - & - & - & - & - & 5 & 5 \\
\hline Level $10(175-185 \mathrm{~cm})$ & - & - & - & - & - & 2 & 2 \\
\hline Level 11 (185-195 cm) & - & - & - & - & - & 3 & 3 \\
\hline Level $12(195-205 \mathrm{~cm})$ & - & - & - & - & - & 1 & 1 \\
\hline Level $13(205-215 \mathrm{~cm})$ & - & - & - & - & - & 4 & 4 \\
\hline Level $14(215-225 \mathrm{~cm})$ & - & - & - & - & - & 3 & 3 \\
\hline Level $15(225-235 \mathrm{~cm})$ & - & - & 2 & - & - & 10 & 12 \\
\hline Level $16(235-245 \mathrm{~cm})$ & - & - & - & - & - & 16 & 16 \\
\hline Level $17(245-255 \mathrm{~cm})$ & - & - & - & - & - & 7 & 7 \\
\hline Level $18(255-265 \mathrm{~cm})$ & - & - & - & - & - & 27 & 27 \\
\hline Level $19(265-275 \mathrm{~cm})$ & - & - & - & - & - & 5 & 5 \\
\hline Subtotals & 0 & 0 & 2 & 0 & 0 & 88 & 90 \\
\hline
\end{tabular}


National Register Testing of NineArcheol ogical Sites at Waco L ake

Table 16, continued

\begin{tabular}{|c|c|c|c|c|c|c|c|}
\hline Provenience & Bifaces & $\begin{array}{c}\text { Dart } \\
\text { Points } \\
\end{array}$ & $\begin{array}{c}\text { Edge } \\
\text { modified } \\
\text { Debitage }\end{array}$ & $\begin{array}{c}\text { Unmodified } \\
\text { Debitage }\end{array}$ & $\begin{array}{c}\text { Unmodified } \\
\text { Bones }\end{array}$ & $\begin{array}{c}\text { Unmodified } \\
\text { Mussel Shells }\end{array}$ & Totals \\
\hline \multicolumn{8}{|l|}{ TEST UNIT 4} \\
\hline Level $1(85-95 \mathrm{~cm})$ & - & - & - & - & - & 1 & 1 \\
\hline Level $4(115-125 \mathrm{~cm})$ & - & - & - & - & - & 1 & 1 \\
\hline Level $6(135-145 \mathrm{~cm})$ & - & - & - & - & - & 1 & 1 \\
\hline Level $7(145-155 \mathrm{~cm})$ & - & - & - & - & - & 1 & 1 \\
\hline Level $8(155-165 \mathrm{~cm})$ & - & - & - & - & - & 1 & 1 \\
\hline Level $9(165-175 \mathrm{~cm})$ & - & - & - & - & - & 3 & 3 \\
\hline Level $10(175-185 \mathrm{~cm})$ & - & - & - & - & - & 3 & 3 \\
\hline Level 11 (185-195 cm) & - & - & - & - & - & 3 & 3 \\
\hline Level $12(195-205 \mathrm{~cm})$ & - & - & - & - & - & 1 & 1 \\
\hline Level $13(205-215 \mathrm{~cm})$ & - & - & - & - & - & 5 & 5 \\
\hline Level $14(215-225 \mathrm{~cm})$ & - & - & - & - & - & 8 & 8 \\
\hline Level $15(225-235 \mathrm{~cm})$ & - & - & - & - & - & 14 & 14 \\
\hline Level $16(235-245 \mathrm{~cm})$ & - & - & - & - & - & 11 & 11 \\
\hline Level $17(245-255 \mathrm{~cm})$ & - & - & - & - & - & 6 & 6 \\
\hline Level $18(255-265 \mathrm{~cm})$ & - & - & - & - & - & 12 & 12 \\
\hline Subtotals & 0 & 0 & 0 & 0 & 0 & 71 & 71 \\
\hline TOTALS & 2 & 4 & 14 & 121 & 14 & 760 & 915 \\
\hline
\end{tabular}

\section{Unmodified Debitage}

A total of 121 pieces of unmodified debitage were recovered. Of thoseflakes, 31 percent $(n=38)$ are complete, 34 percent $(n=41)$ are proximal fragments, 28 percent $(n=34)$ are chips, and 7 percent $(n=8)$ are chunks. Cortex is absent on 49 percent $(n=60)$. Only 6 flakes have 100 percent of their dorsal surfaces covered with cortex. The unmodified debitage ranges from less than $1 \mathrm{~cm}$ to $5 \mathrm{~cm}$ in size. A maximum size of $1-2 \mathrm{~cm}$ is represented by 36 percent $(n=44)$ of the debitage. The most frequent size range is $2-3 \mathrm{~cm}$ as represented by 38 percent $(n=46)$ of the debitage. Fourteen percent $(n=17)$ are less than $1 \mathrm{~cm}$, the majority of which are from Feature 1. Finally, 12 percent $(n=14)$ are $3-5 \mathrm{~cm}$. Raw material colors vary from a light gray to a dark gray chert (the more common color) to variations of brown or tan. An almost black chert was noted. A few flakes exhibit a pinkish hue from thermal alteration.

\section{INVERTEBRATE FAUNAL REMAINS}

Of the 760 mussel shells collected, 409 are complete enough for taxonomic identification (see Appendix B). The identified taxa consist of Amblema pl icata, Cyrtonaias tampicoensis,
Cyrtonaias sp., Leptodea fragil is, Leptodea sp., Potamilus purpuratus, Potamilus sp., Quadrula apiculata, Quadrula petrina, Quadrula sp., and Tritogonia verrucosa (one fossilized oyster [Cretaceous] was identified as well). The most common species identified is Amblema plicata, also known as threeridge mussel ( $n=274$, or 67 percent).

\section{VERTEBRATE FAUNAL REMAINS}

Fourteen animal bones were recovered, including those from the flotation samples (see Appendix C). The specimens are too incomplete to be identified to the species, genus, or family level. Eleven specimens are identified simply as Vertebrata, while the remaining three are identified as medium-sized tolarge mammalian elements. Five specimens are charred. The assemblage is too small and incomplete to draw any clear conclusions about subsistence practices, other than the fact that the medium-sized to large mammalian elements may represent deer.

\section{OTHER MATERIALS}

Besides the burned rocks from Feature 1, 


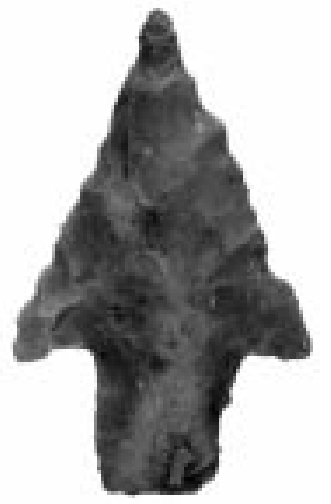

a

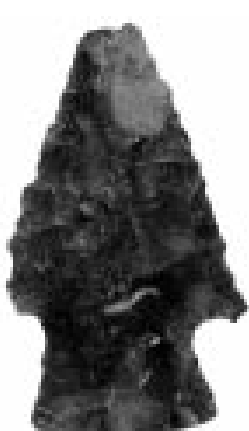

b

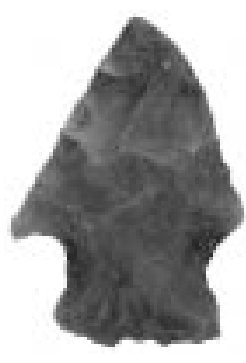

C

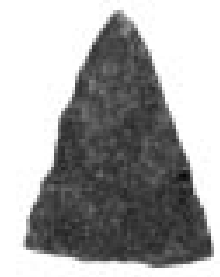

d

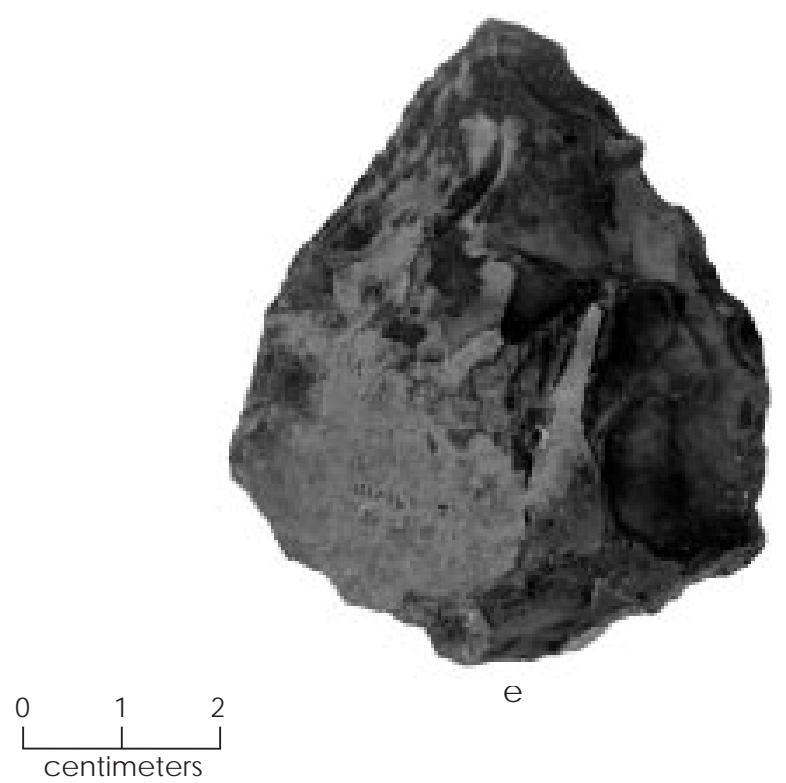

Figure 46. Dart points and a biface from 41ML 195. (a) Carrollton; (b-c) Ellis; (d) untyped; (e) adze.

fewer than 30 other burned rocks weighing under $10 \mathrm{~kg}$ total were observed during testing. Test U nits 1 and 2 yielded about $15(6 \mathrm{~kg})$ nonfeature burned rocks, whileTest Units 3 and 4 yiel ded about 11 (3 kg).

\section{Chronology and Components}

Radiocarbon ages, soil stratigraphy, and the distribution of the cultural materials allow for the delineation of a single component. Although a small number of artifacts were recovered from the upper deposits (ca. 0-200 cm), their age and associations remain unclear. The vast majority of the artifacts and other cultural materials were recovered from a ca. 30-40-cm-thick zone within the buried soil or $2 \mathrm{Ab}$ horizon (Levels
17-20 of Test Units 1 and 2, and Levels 15-18 of Test Units 3 and 4).

Three diagnostic artifacts are associated with this component, but they do not provide much clarity in regards to the age of the component. The artifacts are darts typed as Carrollton and Ellis points. The Carrollton point was found on the backdirt pile of Trench 1 with numerous mussel shells shortly after they came out of the backhoe bucket. The mussel shells were part of a discrete zone of shells associated with the buried cultural deposit. Although the dart point was found out of context, there is little doubt that it is associated with the buried component. Carrollton points are assigned to the MiddleArchaic period (6000-3500 B.P.) in northcentral Texas (see Prikryl 1990). A fairly un- 
National Register Testing of NineArcheol ogical Sites at Waco L ake

Table 17. Provenience and metric data for dart points from $41 \mathrm{ML} 195$

\begin{tabular}{|c|c|c|c|c|c|c|c|c|}
\hline Provenience & $\begin{array}{l}\text { Point } \\
\text { Type }\end{array}$ & Tool Completeness & 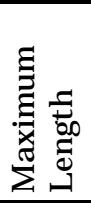 & 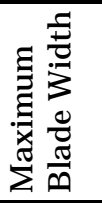 & 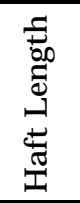 & 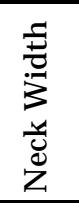 & 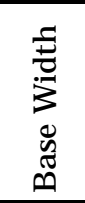 & 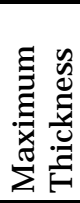 \\
\hline \multicolumn{9}{|l|}{ TRENCH 1 (backdirt) } \\
\hline & Carrollton & intact/nearly complete & 48.5 & 29.7 & 12.2 & 14.1 & 11.6 & 8.9 \\
\hline \multicolumn{9}{|l|}{ TEST UNIT 2} \\
\hline Level $18(245-255 \mathrm{~cm})$ & Ellis & intact/nearly complete & 41.2 & 23.3 & 8.3 & 14.7 & 18.6 & 7.0 \\
\hline Level $18(245-255 \mathrm{~cm})$ & Ellis & intact/nearly complete & - & - & 8.1 & 14.0 & 16.9 & 7.0 \\
\hline Level $18(245-255 \mathrm{~cm})$ & Untyped & distal & - & - & - & - & - & 4.7 \\
\hline
\end{tabular}

Note: All measurements are in millimeters.

common point style, few Carrollton points are known from excavated contexts or associated with radiocarbon ages. Site 41FT226, al ong the Trinity River in F reestone County, yielded a Carrollton point with an associated radiocarbon age of $3786 \pm 56$ B.P. (Richner and Bagot 1978:232). Ellis points are common in northcentral Texas and are assigned to the Late Archaic period (3500-1250 B.P.) (see Prikryl 1990). At $41 \mathrm{CO} 141$ along the EIm Fork of the Trinity, an Ellis-like point was associated with a raw radiocarbon age of $1810 \pm 90$ B.P. (Prikryl and Yates 1987:83). As previously noted, the presence of thesetwo projectilepoint types does not providemuch darity in terms of the age of the component, given that the two styles are not well dated.

Four radiocarbon ages associated with the component provide a less nebulous picture and suggest the cultural materials represent a single occupation. Three of the radiocarbon ages are on charcoal and produced two-sigma calibrated date ranges that overlap significantly (see Appendix D). Two of these ( $2740 \pm 40$ and $2870 \pm 40$ B.P.) are believed to be associated with Feature 1 (see Cultural Features), while the third (2790 \pm 40 B.P., Beta-154289) is on scattered el $m$ wood charcoal collected from Test U nit 4, Level 19. The fourth radiocarbon age, which is on a mix of charcoal and organic sediment from Feature 1, is slightly ol der, at $3130 \pm 40$ B.P. Based on the first three radiocarbon assays, the age of the buried component is estimated to be ca. $2800-3000$ B.P.

Component artifacts and other materials consist of 4 dart points, 2 bifaces (including an adze), 12 pieces of edge-modified debitage, 115 pieces of unmodified debitage, 588 mussel shells, and 14 pieces of bone. The debitage assemblage indicates that the reduction of cortical materials (chert cobbles) took place at the site, probably for the production of bifacial tools. Flake byproducts were used to complete expedient tasks. Along with the small burned rock feature (Feature 1), the formal and expedient tools suggest that hunting, game processing, and woodworking took place. The small vertebrate faunal assemblage includes three medium-sized to large mammalian elements (the other 11 specimens are identified as Vertebrata) and suggests that deer may have been consumed at the site. Aside from possibly deer, mussels also appear to have been part of the diet. The species Amblema plicata (threeridge mussel) dominates the assemblage.

\section{Summary and Assessment}

Site 41MI195 contains a discrete, buried cultural zone that is ca. $30-40 \mathrm{~cm}$ thick. A tight series of radiocarbon ages indicates that the cultural zone may represent a single occupation dating to ca. $2800-3000$ B.P. Although cultural materials are dispersed vertically over 30-40 cm (probably through bioturbation), the cultural zone has been buried and sealed by ca. $200 \mathrm{~cm}$ of alluvium, preserving and protecting its contextual integrity. The contextual integrity, the discreteness of the cultural zone, and the preservation of organic remains, in conjunction with the chronological data, indicate that 
the site has the capacity to yield important information. The prehistoric inhabitants of the site utilized the locality as a base camp judging from the variety of activities and tasks indicated, induding the consumption of mussels and possibly deer and the production of chipped stone tools. The site appears to have the ability to yiel d a more-detailed picture of these activities. A more-specific issuethat can beaddressed is subsistence and diet of the inhabitants based on the recovery of faunal remains and other organic materials, which in addition may serve as an indicator of environmental change. The recovery of a discrete tool assemblage from a well-dated context may allow identification of diagnostic assemblage characteristics. The same can be said for features at the site, in terms of their function, morphology, and composition. The temporal placement and range of Carrollton and Ellis dart points also can be addressed. On a larger scale, the site may contribute useful information for comparisons be tween archeological manifestations in central Texas and north-central Texas. Overall, the site offers a rare opportunity to examine a discrete interval of time, possibly a single occupation, and its associated cultural materials. For this reason, it is recommended that $41 \mathrm{ML} 195$ be considered eligible for listing in the National Register of Historic Places. 


\section{ASSESSMENTS AND RECOMMENDATIONS}

\section{NATIONAL REGISTER ASSE SSME NTS}

National Register of Historic Places testing was completed at seven prehistoric sites and two historic sites at Waco Lake in McLennan County, Texas, in 2000-2001. The project was prompted by plans to raise the level of the lake by $7 \mathrm{ft}$, with the testing undertaken to identify important sites that might need data recovery excavations before they are impacted by rising lake waters. As explained below, three of the prehistoric sites (41ML135, 41ML 186, and 41ML 194) and the two historic sites (41ML 140 and 41ML 179) are considered ineligible for listing in the National Register, while four prehistoric sites (41ML 160, 41ML 162, 41ML 185, and 41ML 195) are considered eligible for listing.

A site's significance is evaluated based on the criteria identified by the National Park Service(1995:2). Cultural resources are eligiblefor listing in the National Register of Historic Places, and thus worthy of avoidance, protection, or mitigation through data recovery, if they aresignificant in American history, architecture, engineering, or culture (National Park Service 1995:2). Significant properties are those that possess integrity of location, design, setting, materials, workmanship, feeling, and association and:

A. are associated with events that have made a significant contribution to the broad patterns of our history; or

B. are associated with the lives of persons significant in our past; or
C. embody the distinctive characteristics of a type, period, or method of construction, or that represent the works of a master, or that possess high artistic values, or that represent a significant and distinguishable entity whose components may lack individual distinction; or

D. have yielded or may likely yield information important in prehistory or history [National Park Service 1995:2].

Criterion $D$ as defined abovereadily applies to both prehistoric and historic archeological sites. It is against this criterion that the sites tested in 2000-2001 are evaluated.

Neither of the tested historic sites appears to be eligible for $\mathrm{N}$ ational Register listing. Site 41ML 140, the location of the housesite occupied by George Erath (1850-1868) and Duncan McLennan (1868-1930), and perhaps subsequently by tenants of Nannie Sinclair, has at least eight cultural features and numerous artifacts associated with this occupation span. However, only part of one investigated feature (a trash disposal area) yielded intact, archeologically important, mid-nineteenthcentury deposits of artifacts and faunal remains. Approximately two-thirds of this feature was excavated during testing, leaving little potential for it to yield additional information. Elsewhere on the site, the cultural materials representing the various occupations are mixed together, offering little opportunity to isolate early assemblages that could contribute important information. The features provide limited 
information on the general layout of the immediate house area, and 41ML 140 represents only the core habitation; the larger plantation/farming complex of which the residence was a part remains unidentified archeologically. Hence, $41 \mathrm{ML} 140$ has little capacity to contribute important information concerning the use of space and activity areas. The sparseness of contexts containing isolable early assemblages and the inability to address issues related to overall plantation/farmstead layout render the site ineligible for National Register listing.

Site 41ML179 is the 1866-1877 Nicholas and J ennett Sneed housesite. It consists of a single identified feature representing a collapsed chimney and an associated artifact scatter. While the artifact assemblage represents a limited span of time consistent with the archivally determined dates for the Sneed occupation, it has little capacity to contribute important information because it exhibits few attributes that would aid in site interpretation. For example, most of the table ceramic sherds are either undecorated or burned, much of the glass is melted beyond identification, and the largest single artifact class-cut nails-has little interpretive value beyond the obvious. Further, the single known feature was sufficiently excavated during testing, leaving little potential for it to yield additional information, and the lack of information on other features at the site limits inquiry into questions about farmstead layout, the use of space, and activity areas. These characteristics indicate that 41ML 179 is ineligible for National Register listing.

Prehistoric sites 41ML 135, 41ML 186, and 41ML 194 are judged to be ineligible for $\mathrm{Na}$ tional Register listing because they yiel ded so few artifacts (only 60 chipped stone artifacts for all three sites combined) and other cultural materials that they lack the capacity to yield any important information about prehistory. Few interpretations can be made, and only limited insights on chronology and site activities can be gained from the small assemblages. In some cases, the small numbers of artifacts were recovered from disturbed contexts, further limiting interpretations.

Prehistoric sites 41ML 160, 41ML 162, 41ML 185, and 41ML 195 are considered el igible for listing in the National Register of Historic Places because they contain cultural deposits with the following characteristics: good contextual integrity; stratigraphically isolablecomponents; and sufficient quantities of artifacts and other materials for interpretation. These four sites date from the latter part of the Middle Archaic period (ca. 5000 B.P.) to the Late Prehistoric period. At 41ML160, cultural materials are deeply buried and part of a single discrete component. Though undated, the artifacts, feature, and other materials indicate the site was occupied briefly, probably as a hunting camp. Multiple dated components characterize 41ML 162. The components are discrete and rich in artifacts, indicating use of the locale as a habitation sitefrom thelatter part of the Middle Archaic period through the Toyah phase of the Late Prehistoric period. Artifacts and other materials recovered from 41ML 185 indicate that it also was used as a habitation site. While the contextual integrity of the LateArchaic-Late Prehistoric component is somewhat compromised, a more-discrete, less-disturbed late MiddleArchaic to early LateArchaic component is present in the deeper deposits. A single dated, discrete early Late Archaic component characterizes 41ML195. Artifacts and other materials are deeply buried and suggest the locale was utilized as a habitation site. In short, these sites have the potential to contribute high-resolution data sets that can be used to address a variety of important research issues, resulting in a reliable reconstruction of hunter and gatherer lifeways and adaptive strategies for the Waco Lake area during the late Holocene.

\section{DATA RE COVERY RE COMME NDATIONS AND GENERAL RE SEARCH ISSUES AT WACO LAKE}

Two of the four prehistoric sites recommended as being eligible for National Register listing-41ML 162 and 41ML 195-are especially good candidates for data recovery excavations. While judged to be eligible based on the contextual integrity and discreteness of their cultural deposits, 41ML 160 and 41ML 185 are not as suited for data recovery excavations because they are not as well-dated as the components at 41ML 162 and 41ML 195 (i.e., questions remain about their chronologies) and their cultural deposits are not as rich or dense. Further, these sites appear not to represent time peri- 
ods or activities that are poorly represented at 41ML 162 and 41ML195, and all four sites are located fairly d ose to one another along a 5.6-km stretch of the North Bosque River. In short, 41ML160 and 41ML 185 are likely to be less productive than 41ML162 and 41ML 195 and to yield information that is largely redundant.

Along with 41ML 162 and 41ML 195, it also is recommended that data recovery excavations be conducted at 41ML35 (Baylor site) and 41ML 37 (Britton site). Moderately extensive test excavations were conducted at the Baylor and Britton sites in the 1960s (Story and Shafer 1965), and they are considered eligible for listing in the $\mathrm{National}$ Register of Historic Places (see Kvernes et al. 2000:70). These four sites have the ability to address issues of how prehistoric hunters and gatherers utilized the riparian zone along the North Bosque River throughout the late $\mathrm{H}$ olocene. On a site by site basis, the data recovery excavations should focus on what types of activities took place, what resources were utilized, and, if possible, during what seasons the sites were occupied. Collectively, the sites may address how the riparian zone of the North Bosque River was utilized within the larger context of the Grand Prairie landscape. Was the North Bosque river valley utilized strictly as a base for foraging activities within and outside the riparian zone? Was it utilized as a corridor for movement between the Grand Prairie and the Blackland Prairie to the east? Information gained from data recovery excavations and analyses should be compared to data from sites in similar riparian environments, such as the Leon River at Fort Hood (see Mehalchick et al. 1999), to address these and similar questions.

The four sites also have the ability to address interregional contacts and movement of groups through the comparison of artifact assemblages and distributions of specific artifact types. The sites at Waco Lake are located along the northern periphery of what traditionally is considered the central Texas archeological regi on (e.g., Prewitt 1981; Suhm 1960). The archeological record of this area (Waco Lake) contains el ements that suggest influences and contacts to varying degrees over time with areas to the north and east. Comparisons of artifact assemblages, particularly projectile points, recovered from the four Waco Lake sites to those from central Texas sites should provide some insights into the movement of groups from surrounding regions into central Texas. In addition, some of the more poorly dated projectile point styles, such as Carrollton and Ellis, can be placed more securely in time.

These research questions and others can be addressed through extensive block excavations at all four sites. At 41ML 162, block excavations should focus on the western half of the site, where cultural materials were recovered from discrete, well-dated components. At the Higginbothamsite(41ML195), theupper ca. $200 \mathrm{~cm}$ should be removed mechanically before data recovery excavations are undertaken in the vicinity of Trenches 1 and/or 3. For the Baylor and Britton sites, the collections and records at the Texas Archeological Research Laboratory should be reviewed prior to developing specific data recovery plans, e.g., to determine what kinds of information are needed to make morecomplete interpretations, to determinethesizes and locations of the block excavations, etc.

Ageestimates for all excavated components should be determined through radiocarbon dating of organic materials (preferably charcoal) from secure contexts, such as features. This will provide a chronol ogical framework for the placement of artifacts and assemblages into interpretable contexts. Site activities can be interpreted through the artifact and feature assemblages recovered. Multicomponent sites, such as 41ML162, Baylor, and Britton, provide the added dimension of depicting how these assemblages, and hence site activities, varied or stayed static over time. Analyses of the chi pped stone tools and debitage recovered can provideinsights into the acquisition and reduction of lithic raw materials and the onsite tasks completed with lithic tools. Diversity in tool assemblages will offer indications of site activities, as well as clues about the duration of occupations.

Burned rock features also can provide information on the intensity of site use through evidence of recycling and reheating of feature rocks. Size grading of burned rocks, careful observations and documentation of feature constituents, and archeomagnetic data from feature rocks can provide clues about feature reuse and rock recycling. Analyses of faunal and charred botanical remains and residues on tools and burned rocks will provide information on what resources were utilized at the sites, what sub- 
sistence strategies were employed by the sites' occupants, and possibly during what season(s) the sites were occupied. These data also may serve as proxy indicators for determining past environmental conditions and, al ong with sedimentological and isotopic data from soils, bones, etc., provide a better understanding of environmental constraints and resource availability. Geomorphological investigations should beconducted at the sites, as well as at other local ities along the lower portion of the North Bosque River valley, to provide information on site formation processes and, on a larger scale, provide a picture of past environments and resource availability. It is recommended that these investigations involve personnel in the Department of Geology at Baylor University because of their extensive knowledge of the Quaternary geol ogy of the Brazos River basin.

In addition, Waco Lake is an area where professional and avocational archeological investigations have taken place over several decades, involving work by some of Texas's most prominent archeologists. Many of these individuals retain an active research interest in the central Texas region, and they may be able to provide important insights into the role these earlier investigations had in the development of central Texas archeology and where research should be directed today. It is recommended that the Corps of Engineers sponsor a one-day meeting while the data recovery excavations are ongoing (e.g., during work at 41ML 162 and/ or 41ML195 but before work commences at the Baylor and Britton sites) to explore these issues.

Lastly, such a publicly funded project so close to a large urban area offers many opportunities to share the story of archeology and prehistoric lifeways with a large segment of the public. It is recommended that the Corps of Engineers support and sponsor such measures, which could include the production of a popular report for local distribution, the devel opment of an interpretive display or exhibit, the preparation of an archeol ogy-based curriculum for use in local schools, and/or the sponsorship of public tours or digs. Such activities likely could be coordinated with and carried out partly by local entities or organizations such as the Central Texas Archeol ogical Society or the Strecker Museum at Baylor University. 
Abbott, J ames T., and W. Nicholas Trierweiler (editors)

1995 NRHP Significance Testing of 57 Prehistoric Archeol ogical Sites on Fort Hood, Texas: Volumes I \& II. Archeological Resource Management Series, Research $\mathrm{Re}$ port No. 34. United States Army, Fort Hood.

Baker, Walter

1936 Political History of MCLennan County. Unpublished Master's thesis, Baylor University, Waco.

Barber, J ohn L.

1987 The Rimfire Cartridge in the United States and Canada: An Illustrated History of its Manufacturers and Their Products, 1857 to 1984. Armory Publications, Tacoma, Washington.

Black, Stephen L., Linda W. Ellis, Darrell G. Creel, and Glenn T. Goode

1997 Hot Rock Cooking on theGreater Edwards Plateau: Four Burned Rock Midden Sites in West Central Texas, Volumes 1 and 2. Studies in Archeology 22. Texas Archeological Research Laboratory, The University of Texas at Austin. Archeology Studies Program, Report 2. Environmental Affairs Department, Texas Department of Transportation, Austin.

Blair, W. Frank

1950 The Biotic Provinces of Texas. The Texas J ournal of Science2(1):93-117.

Blake, Marie E., and Martha Doty Freeman

1998 Nineteenth-Century Transfer-Printed Ce ramics from the Texas Coast: The Quintana Collection. Prepared for theU.S. Army Corps of Engineers, Galveston District, by Prewitt and Associates, Inc., Austin.

Brown, David O. (compiler)

1987 Archeology at Aquilla Lake: 1978-1982 Investigations. Research Report 81. Texas Archeological Survey, The University of Texas Austin.
Bryan, Frank

1936 A Preliminary Report on the Archeology of Western Limestone County. Central Texas Archeol ogist 2:81-95.

1937 A Preliminary Report on the Archeology of Western Navarro County and Some Camp Sites in $\mathrm{Hill}$ and McLennan Counties. Central Texas Archeologist 3:70-79.

Buice, Calvin

1985 Interview with Calvin Buice at the Speegleville store on J anuary 24, 1985, conducted by J ack M. J ackson.

Burket, J. M.

1965 Geology of Waco. In Urban Geology of Greater Waco, Part 1: Geol ogy, by Peter T. Flawn and J. M. Burket. Baylor Geological Studies Bulletin No. 8. Bayl or University, Waco.

Collins, Michael B. (assembler and editor)

1998 Wilson-Leonard; An 11,000-Year Archeological Record of Hunter-Gatherers in Central Texas, Volumes I-V. Studies in Archeology 31. Texas Archeological Re search Laboratory, The University of Texas at Austin. Archeol ogy Studies Program, Report 10. Environmental Affairs Division, Texas Department of Transportation, Austin.

Collins, Michael B.

1990 The Archaeol ogical Sequence of Kincaid Rockshel ter, U val de County, Texas. Transactions of the Twenty-fifth Regional Archeological Symposium for Southeastern New Mexico and Western Texas, pp. 2534.

1995 Forty Years of Archeology in Central Texas. Bulletin of theTexas Archeological Society 66:361-400.

Collins, Michael B., and Kenneth M. Brown

2000 The Gault Gisement; Some Preliminary Observations. Current Archeology in Texas 2(1):8-11. 
Collins, Michael B., Bruce Ellis, and Cathy Dodt-Ellis 1990 Excavations at the Camp Pearl Wheat Site (41KR243): An Early Archaic Campsiteon Town Creek, Kerr County, Texas. Studies in Archeology 6. Texas Archeological Research Laboratory, The University of Texas at Austin.

Collins, Michael B., Thomas R. Hester, and Pamela J . Headrick

1992 Engraved Cobbles from the Gault Site, Central Texas. Current Research in the Pleistocene 9:3-4.

Collins, Michael B., and Vance T. Holliday 1985 Geoarchaeology in the Lower Bosque Basin, McLennan County, Texas. Report submitted to theU.S. Army Engineer District, Fort Worth.

Cutrer, Thomas W.

1996 Erath, GeorgeBernard. In TheNew Handbook of Texas, Vol . 2:880. The Texas State Historical Association, Austin.

Duffield, Lathel F.

1959 Appraisal of the Archeological Resources of Waco Lake, McLennan County Texas. Report submitted to the National Park Service by the Texas Archeological Salvage Project, The University of Texas at Austin.

Evans, Howard E., and Mary J ane West Eberhard 1970 TheWasps. University of Michigan Press, Ann Arbor.

Ferring, C. Reid

1986 Rate of Fluvial Sedimentation: Implications for Archaeological Variability. Geoarchaeol ogy 1:259-274.

2001 The Archaeology and Pal eoecology of the Aubrey Clovis Site (41DN479), Denton County, Texas. Center for Environmental Archaeology, Department of Geography, University of North Texas, Denton.

Fields, Ross C., Eloise F. Gadus, L. Wayne Klement, C. Britt Bousman, and Jerrilyn B. McLerran

1993 Excavations at the Tick, Spike, J ohns Creek, and Peerless Bottoms Sites, Cooper LakeProject, Delta and Hopkins Counties, Texas. Reports of I nvestigations No. 91. Prewitt and Associates, Inc., Austin.

Goode, Glenn T.

1991 Late Prehistoric Burned Rock Middens in
Central Texas. In The Burned Rock Middens of Texas: An Archeological Symposium, edited by Thomas R. Hester, pp. 71-93. Studies in Archeology 13. Texas Archeological Research Laboratory, The University of Texas at Austin.

Goode, Glenn T., and Robert J . Mallouf

1991 The Evant Cores: Polyhedral Blade Cores from North-Central Texas. Current Re search in the Pleistocene 8:67-70.

Hatfield, Virginia L.

1997 Paleoindian Evidence at the Triple S Ranch Site, Hamilton County, Texas. Current Research in thePleistocene 14:32-34.

Hays, Thomas R., and Foster E. Kirby

1977 Hog Creek Testing Project: Preliminary Results. Report submitted to the U.S. Department of Agriculture, Soil Conservation Service, Temple, Texas.

Hayward, O. T.

1988 Gulfian Rocks, Western Margin of the East Texas Basin. In South-Central Section of the Geological Society of America, Centennial Field Guide Volume 4, edited by O. T. Hayward, pp. 329-334. The Geological Society of America, Boulder, Colorado.

Henry, Donald O.

1995 Cultural and Paleoenvironmental Successi ons Revealed by the Hog Creek Archeological Investigation, Central Texas. In Advances in Texas Archeology: Contributions from Cultural Resources Manage ment, edited by J ames E. Bruseth and Timothy K. Perttula, pp. 51-79. Cultural Resource Management Report 5. Division of Antiquities Protection, Texas Historical Commission, Austin.

Henry, Donald O., Foster E. Kirby, and AnneB.J usten 1980 The Prehistory of Hog Creek: An Archaeological I nvestigation of Bosque and Coryel I Counties, Texas. Laboratory of Archeology, Department of Anthropology, University of Tulsa.

Hester, Thomas R.

1989 Historic NativeAmerican Populations. In From the Gulf to the Rio Grande: Human Adaptation in Central, South, and Lower Pecos, Texas, by Thomas R. Hester, Stephen L. Black, D. Gentry Steele, Ben W. Olive, Anne A. Fox, Karl J. Reinhard, and Leland C. Bement, pp. 77-84. Research 
Series 33. Arkansas Archeological Survey, Fayetteville.

Hill, Robert T.

1901 Geography and Geology of the Black and Grand Prairies, Texas, with Detailed Description of the Cretaceous Formations and Special Reference to Artesian Waters. In Twenty-first Annual Report to the United States Geological Survey 18991900, Part 7-Texas.

Horne, Sam N.

n.d. History of Waco and McLennan County. Typescript notes from various published and manuscript sources in rough chronological order. On file, Texas Collection, Baylor University, Waco.

Huebner, J effery A.

1991 Late Prehistoric Bison Populations in Central and South Texas. Plains Anthropologist 36 (137):343-358.

J ackson, J ack M.

1984 An Historic Overview of Waco Lake, McLennan County, Texas. Report submitted to the U.S. Army Corps of Engineers, Fort Worth District.

J elks, Edward B.

1953 Excavations at Blum Rockshelter. Bulle tin of the Texas Archaeological and Paleontologi cal Soci ety 24:189-207.

1962 The Kyle Site: A Stratified Central Texas Aspect Site in Hill County, Texas. Archeology Series No. 5. Department of Anthropology, The University of Texas at Austin.

1970 Documentary E vidence of I ndian Occupation at the Stansbury Site (41-39B 1-1), Appendix B. Bulletin of theTexas Archeological Society 41:277-286.

J ohnson, LeRoy, and Glenn T. Goode

1994 A New Try at Dating and Characterizing Holocene Climates, as Well as Archeological Periods, on the Eastern Edwards Plateau. Bulletin of the Texas Archeological Society 65:1-51.

J ones, Olive R.

1986 Cylindrical English Wine\& Beer Bottles, 1735-1850. Studies in Archaeology, Architecture, and History. National Historic Parks and Sites, Canadian Parks Service, Environment Canada, Ottawa, Ontario.
J ones, Olive, and Catherine Sullivan

1989 The Parks Canada Glass Gl ossary for the Description of Containers, Tableware, Flat Glass, and Closures. Studies in Archaeology, Architecture, and History. National Historic Parks and Sites, Canadian Parks Service, Environment Canada, Ottawa, Ontario.

Kelly, Dayton (editor)

1972 The Handbook of Waco and McLennan County, Texas. Texian Press, Waco.

Kleinbach, Karl, Gemma Mehalchick, J ames T. Abbott, and J. Michael Quigg

1995 Other Analyses. In NRHP Significance Testing of 57 Prehistoric Archeological Sites on Fort Hood, Texas, Volume II, edited by J ames T. Abbott and W. Nicholas Trierweiler, pp. 765-842. Archeological Resource Management Series, Research Report 34. United States Army, Fort Hood.

Kleinbach, Karl W., Gemma Mehalchick, Douglas K. Boyd, and Karl W. Kibler

1999 National Register Testing Of 42 Prehistoric Archeological Sites On Fort Hood, Texas: The 1996 Season. Archeological Resource Management Series, Research Report No. 38. United States Army, Fort Hood.

Krieger, Margery $\mathrm{H}$.

1996 Tawakoni Indians. In TheN ew Handbook of Texas, Vol. 6:213. The Texas State Historical Association, Austin.

K vernes, K imberly K., MarieE . Blake, Karl W. Kibler, J ennifer K. McWilliams, E. Frances Gadus, and Ross C. Fields

2000 Re-Location and U pdated Recordation of 44 Archeological Sites at Waco Lake, McLennan County, Texas. Reports of Investigations No. 127. Prewitt and Associates, Inc., Austin.

Larson, Richard E., and Foster E. Kirby

1976 Test Excavations at the L. E. Robertson Shelter and theStoneR ockshelter, Coryel County, Texas. Research Report 87. Archaeology Research Program, Southern Methodist University, Dallas.

Larson, Richard E., Duane E. Peter, Foster E. Kirby, and S. Alan Skinner

1975 An Evaluation of the Cultural Resources at Hog Creek. Research Report 84. Archaeology Research Program, Southern Methodist University, Dallas. 
Lebo, Susan A.

1987 Local Utilitarian Stonewares:A Diminishing Artifact Category. In Historic Buildings, Material Culture, and People of the Prairie Margin: Architecture Artifacts, and Synthesis of Historic Archaeology, edited by David $\mathrm{H}$. J urney and Randall W. Moir, pp. 121-142. Richland Creek Technical Series, Vol. V. Archaeology Research Program, Institute for the Study of Earth and Man, Southern Methodist University, Dallas.

Lewis Publishing Co.

1893 A Memorial and a Biographical History of McLennan County, Texas. Lewis Publishing Co., Chicago.

Lynott, Mark J ., and Duane E. Peter

1977 Archaeological Investigations at Aquilla Lake, 1975. Research Report 102. Archaeology Research Program, Southern M ethodist University, Dallas.

McKinney, Wilson W.

1981 Early Holocene Adaptations in Central and Southwestern Texas: The Problem of the Paleoindian-Archaic Transition. Bulletin of the Texas Archeology Society 52:91-120.

Majewski, Teresita, and Michael J . O'Brien

1987 The Use and Misuse of Nineteenth-Century English and American Ceramics in Archaeological Analysis. In Advances in Archaeol ogical Method and Theory, vol. 11, edited by Michael B. Schiffer, pp. 97-209. Academic Press, Inc., San Diego.

Mehalchick, Gemma, Karl Kleinbach, Douglas K. Boyd, SteveA. Tomka, and Karl W. Kibler

1999 National Register Testing of 19 Prehistoric Sites at Fort Hood, Texas: The 1995 Season. Archeological Resource Management Series, Research Report No. 37. United States Army, Fort Hood.

Mehalchick, Gemma, Karl Kleinbach, Douglas K. Boyd, and Karl W. Kibler

2000 Geoarcheological Investigations and National Register Testing of 52 Prehistoric Archeological Sites on Fort Hood, Texas: The 1997 Season. Archeological Resource Management Series, Research Report No. 39. United States Army, Fort Hood.

Miller, E. O., and Edward B. J elks

1952 Archeological Excavations at the Belton Reservoir, Coryell County, Texas. Bulletin of the Texas Archeol ogical and Paleontological Society 23:168-217.

National Park Service

1995 How to Apply the National Register Criteria for Evaluation. National Register Bulletin 15. U.S. Department of Interior, National Park Service, National Register Division, Washington, D.C.

Natural Fibers Information Center

1987 The Climates of Texas Counties. Natural Fibers Information Center, The University of Texas at Austin, in cooperation with the Office of the State Climatologist, Texas A\&M U niversity.

Newcomb, W. W., J r.

1961 The Indians of Texas. University of Texas Press, Austin.

Noël Hume, I vor

1991 A Guide to Artifacts of Colonial America. Vintage Books, N ew York.

Poage, W. R.

1981 MCLennan County Before 1980. Texian Press, Waco.

Pollan, Sandra D., W. Sue Gross, Amy C. Earls, J ohnneyT. Pollan J r., and J ames L. Smith

1996 Nineteenth-Century Transfer-Printed Ce ramics from the Townsite of Old Velasco (41BO125), Brazoria County, Texas: An Illustrated Catalogue. Prepared for the U.S. Army Corps of Engineers, Galveston District, by Prewitt and Associates, Inc., Austin.

Prewitt, Elton R.

1981 Cultural Chronology in Central Texas. Bulletin of the Texas Archeol ogical Society 52:65-89.

1985 From Circleville to Toyah: Comments on Central Texas Chronology. Bulletin of the Texas Archeol ogical Society 54:201-238.

Prikryl, Daniel J .

1990 Lower Elm Fork Prehistory: A Redefinition of Cultural Concepts and Chronologies along the Trinity River, North-Central Texas. Office of the State Archeologist Report 37. Texas Historical Commission, Austin.

Prikryl, Daniel J ., and J ack M. J ackson

1985 Waco Lake, McLennan County, Texas: An Inventory and Assessment of Cultural 
Resources. Reports of I nvestigations No. 39. Prewitt and Associates, Inc., Austin.

Prikryl, Daniel J ., and Elton R. Prewitt

1984 An Overview of the NativeAmerican Cultural Resources at Waco Lake, McLennan County, Texas. Letter Report No. 278. Prewitt and Associates, Inc., Austin.

Prikryl, Daniel J ., and Bonnie C. Yates

1987 Test Excavations at 41CO141, Ray Roberts Reservoir, Cooke County, Texas. Contributions in Archaeology N o. 4. Institute of Applied Sciences, North Texas State University, Denton.

Proctor, C. V., J r., J . H. McGowen, and W. T. Haenggi

1970 Geologic Atlas of Texas, Waco Sheet. Bureau of Economic Geology, The University of Texas at Austin.

Psota, Sunshine

1999 Can't Bust 'Em:TheWorker's Clothing and Footwear from the Alabama Gates Work Camp. Paper presented at the Society for California Archaeology Annual Meeting, Sacramento.

Redder, Albert J .

1985 Horn Shelter Number 2: The South End, A Preliminary Report. Central Texas Archeol ogist 10:37-65.

Richner, J effrey J ., and J oe Bagot (assemblers)

1978 A Reconnaissance Survey of the Trinity River Basin. Research Report 113, Archaeology Research Program, Southern M ethodist University, Dallas.

Shafer, Harry J .

1963 Test Excavations at the Youngsport Site: A Stratified Terrace Site in Bell County, Texas. Bulletin of theTexas Archeological Society 34:57-81.

1977 Late Prehistory of Central Texas. Bulle tin of the South Plains Archeological Society 3:18-24.

Shafer, Harry J ., DeeAnn Suhm, and J . Dan Scurlock 1964 An Investigation and Appraisal of the Archeological Resources of Belton Reservoir, Bell and Coryell Counties, Texas. Miscellaneous Papers 2. Texas Archeological Salvage Project, The University of Texas at Austin.

Skinner, S. Alan, and Mark L. Henderson 1972 Archeological Resources of the Aquilla
Creek Watershed. In TheNatural and Cultural Environmental Resources of Aquilla Creek Watershed, Hill County, Texas, assembled by S. Alan Skinner, pp. 3-62. Institute for the Study of Earth and Man, Southern Methodist University, Dallas.

Skinner, S. Alan, C. Shaw, K. Huckaby, and M. L. Bartsch

1978 An Evaluation of Archeol ogical Research at Aquilla Lake Archaeology Research Program, Southern Methodist University, Dallas.

Smryl, Vivian Elizabeth

1996a McLennan County. In TheNew Handbook of Texas, Vol. 4:430-433. The Texas State Historical Association, Austin.

1996b Speegleville. In The New Handbook of Texas, Vol. 6:24. The Texas State Historical Association, Austin.

Sorrow, William, Harry J . Shafer, and Richard Ross 1967 Excavations at Stillhouse Hollow Reservoir. Papers of the Texas Archaeological Salvage Project, No. 11. The University of Texas at Austin.

Speegle, Arthur R.

1985 Interview with Arthur R. Speegle at site 41ML 150 on J anuary 24, 1985, by J ack M. J ackson.

Steinbomer, Robert A.

1982 Brickmaking in Texas: A History of the Industry and I ts Product. Manuscript on file, the Texas Historical Commission, Austin.

Stephenson, Robert L.

1947 Archeological Survey of Whitney Basin: A Preliminary Report. Bulletin of the Texas Archeological and Paleontological Society 18:129-142.

1970 Archeological Investigations in the Whitney Reservoir Area, Central Texas. Bulletin of the Texas Archeological Society $41: 37-277$.

Story, Dee Ann

1985 Adaptive Strategies of Archaic Cultures of the West Gulf Coastal Plain. In Prehistoric Food Production in North America, edited by Richard I. Ford, pp. 19-56. Anthropological Papers No. 75. Museum of Anthropology, University of Michigan, Ann Arbor. 
1990 Cultural History of the NativeAmericans. In The Archeology and Bioarcheology of the Gulf Coastal Plain, by DeeAnn Story, J anice A. Guy, Barbara A. Burnett, Martha Doty Freeman, J erome C. Rose, D. Gentry Steele, Ben W. Olive, and Karl J . Reinhard, pp. 163-366. Research Series No. 38. Arkansas Archeological Survey, Fayetteville.

Story, Dee Ann, and Harry Shafer

19651964 Excavations at Waco Reservoir, McLennan County, Texas: TheBaylor and Britton Sites. Miscellaneous Papers No. 6. Texas Archeol ogical Salvage Project, The University of Texas at Austin.

Suhm, Dee Ann

1960 A Review of Central Texas Archeology. Bulletin of the Texas Archeological Society 29:63-107.

Suhm, Dee Ann, and Edward B. J elks

1962 Handbook of Texas Archeology: Type Descriptions. Texas Archeological Society Special Publication No. 1 and Texas Memorial Museum Bulletin No. 4. Austin.

Templin, E. H., A. L. Nabors, T. R. Atkins, A. W. Crain, I. C. Mowery, D. T. Horton, J . S. Williams, and R. M. Voigtel

1958 Soil Survey of McLennan County, Texas. U.S. Department of Agriculture, Soil Conservation Service, in cooperation with Texas Agricultural Experiment Station.

Toomey, Richard S., III, Michael D. Blum, and Salvatore Valastrof $r$.

1993 Late Quaternary Climates and Environments of the Edwards Plateau, Texas. Global and Planetary Change 7:299-320.

Trierweiler, W. Nicholas (editor)

1994 Archeological Investigations on 571 Pre historic Sites at Fort Hood, Bell and Coryell Counties, Texas. Archaeological Resource Management Series, Research Report No. 31. United States Army, Fort Hood.

1996 Archeological Testing of 56 Prehistoric Sites at Fort Hood, 1994-1995. Archeological Resource Management Series, Research Report N o. 35. United States Army, Fort Hood.
Turner, Sue Ellen, and Thomas R. Hester

1993 A Field Guide to Stone Artifacts of Texas Indians. 2nd ed. Texas Monthly Field Guide Series, Houston.

Vinson, Carlos

1968 Collecting Shotshells. Gun Digest, 22nd Year Issue.

Watt, Frank $\mathrm{H}$.

1936 A Prehistoric Shelter Burial in Bell County, Texas. Bulletin of the Central Texas Archeol ogical Society 2:5-27.

1941 Preliminary Report on Potsherds from the Chupik Site. Central Texas Archeol ogi cal Society Newsl etter 2(4):17-19.

1956 Archeological Materials from the Asa Warner Site. Central Texas Archeologist 7:7-29.

1965 Notes on the Clark Site, McLennan County, Texas. Bulletin of the Texas Archeological Society 36:99-110.

1969 The Waco I ndian Village and I ts Peoples. Central Texas Archeol ogist 9.

1978 Radiocarbon Chronology of Sites in the Central Brazos Valley. Bulletin of the Texas Archeol ogical Society 49:111-138.

Weir, Frank A.

1976 The Central Texas Archaic. Unpublished Ph.D. dissertation, Department of Anthropology, Washington State University, Pullman.

Willey, Gordon R., and Philip Phillips

1958 Method and Theory in American Archaeology. University of Chicago Press, Chicago.

Williams, Petra, and Marguerite R. Weber

1998 StaffordshirellI: RomanticTransfer Patterns, Cup Plates and Early Victorian China. Fountain House East, J effersontown, Kentucky.

Woodhead, E. I., C. Sullivan, and G. Gusset

1984 Lighting Devices in theN ational Reference Collection, Parks Canada. National Historic Parks and Sites Branch, Parks Canada, Ottawa, Ontario. 
APPENDIX A: SOIL-STRATIGRAPHIC DESCRIPTIONS

Karl W. Kibler 

Each soil-stratigraphic description is based on a $50-100-\mathrm{cm}$-wide exposure within the trench or test unit wall. Soil-stratigraphic descriptions use the neutral term "zone" to describe pedogenic and stratigraphic variations within the profile under a single term. Zones are numbered sequentially from the top (surface) down. For each zone the depth, thickness, color, consistence, texture, soil structure, mottles, inclusions (e.g., gravel content), and the nature of the lower boundary are described according to the proce dures and criteria presented by Buol et al. (1980:21-43) and theSoil Survey Staff (1996).

The color (Munsell Soil Col or Chart) and consistence (loose, very friable, friable, firm, very firm, and extremely firm) of a zone or sediment were recorded from a moist condition. Textural classifications are based on fiel d estimates (see Olson 1976:19) of the relative proportions of particle sizes less than $2.0 \mathrm{~mm}$ in diameter (i.e., sand, silt, and clay). Twelve textural classes based on theUSDA textural classification of soils (Soil Survey Staff 1996:631) are used: sand, loamy sand, sandy loam, loam, silt loam, silt, sandy clay loam, clay loam, silty clay loam, sandy clay, silty clay, and clay. The textural name is prefaced by the term gravel ly if 20-50 percent of the sediment by volume is of gravel size (2$76 \mathrm{~mm}$ ), or very gravelly if 50-90 percent of the sediment is of gravel size. In some instances textural classes based on the percentages of gravels and the ratio of sand to mud (silt and clay) (see Folk 1974) are more appropriate to describe the textural properties of zones. This classification scheme has 15 textural classes: gravel, muddy gravel, muddy sandy gravel, sandy gravel, gravelly mud, gravelly muddy sand, gravelly sand, slightly gravelly mud, slightly gravelly sandy mud, slightly gravelly muddy sand, slightly gravelly sand, mud, sandy mud, muddy sand, and sand.

Soil structure characteristics include grade, size, and type. The gradeis shown as weak, moderate, or strong. The size of the peds is shown as fine, medium, or coarse, depending on ped morphology or type. The type, referring to the shape of the peds, is identified as blocky (subangular and angular), platy, prismatic, columnar, or granular. Soil horizons not containing these characteristics are considered structureless. If preserved, sedimentary structures are noted and described.

Mottles are described by color, abundance, contrast, and size. Abundance is shown as few ( $<2$ percent), common (2-20 percent), and many (>20 percent), while contrast is described as faint, distinct, or prominent. Size ranges are given as fine $(\varangle 0.5 \mathrm{~cm})$, medium $(0.5-1.5 \mathrm{~cm})$, or coarse $(>1.5 \mathrm{~cm})$. The lower boundary of each zone is described in terms of distinctivenessvery abrupt $(\varangle 0.1 \mathrm{~cm})$, abrupt $(0.1-2.5 \mathrm{~cm})$, clear $(2.5-6.4 \mathrm{~cm})$, gradual $(6.4-12.7 \mathrm{~cm})$, and diffuse $(>12.7 \mathrm{~cm})$-and topography - smooth, wavy, irregular, and broken. Final soil horizon designations are based on the guidelines and criteria of Birkeland (1984) and the Soil Survey Staff (1996). 


\section{Site 41ML 135}

Trench 1

Zone $1 \quad 0-29 \mathrm{~cm}$

Zone 2 29-81+cm

\section{Trench 4}

Zone $1 \quad 0-36 \mathrm{~cm}$

Zone $2 \quad 36-103+c m$ matic breaking to moderate fine angular blocky structure, $10 \%$ limestone gravels (matrix-supported, subangular to subrounded, granule to pebblesized), boundary not observed. Bw horizon, late Holocene all uvium.

\section{Site 41ML 160}

Trench 1

Zone $1 \quad 0-11 \mathrm{~cm}$

Zone $2 \quad 11-54 \mathrm{~cm}$

dark gray (10YR 3/1) and very dark grayish brown (10YR 3/2) silty day loam, firm, moderate medi um subangular blocky structure, $2 \%$ limestone gravels (dispersed stringer at $35 \mathrm{~cm}$, rounded, granule-sized), gradual smooth boundary. Ab horizon, late Holocene alluvium.

Zone 3 54-219 cm Dark grayish brown (10YR 4/2) silty clay loam, firm, moderate medium subangular blocky structure, few $\mathrm{CaCO}_{3}$ filaments, clear smooth boundary. Bwb horizon, late Holocene alluvium.

Zone 4 219-329+cm Brown (10YR 5/3) silt loam, friable, weak medium prismatic breaking to moderate medium angular blocky structure, common $\mathrm{CaCO}_{3}$ filaments, boundary not observed. Bkb horizon, late Holocene alluvium.

\section{Trench 3}

Zone $1 \quad 0-27 \mathrm{~cm}$

Alternating horizontal beds and laminae of pale brown (10YR 6/3) sand and dark gray (10Y R 4/1) mud, abrupt smooth boundary. C horizon, recent alluvium.

Zone 2 27-50 cm Grayish brown (10YR 5/2) fine sandy clay loam, firm, weak fine subangular blocky structure, few poorly preserved beds and laminae of sand and mud, heavily bioturbated (microfaunal burrowing), clear smooth boundary. AC 
horizon, late Holocene alluvium.

Zone $3 \quad 50-86 \mathrm{~cm} \quad$ Very dark grayish brown (10YR 3/2) silty clay loam, firm, moderate medium subangular blocky structure, gradual smooth boundary. Ab horizon, late Holocene alluvium.

Zone 4 86-406 cm Brown (10YR 5/3) silt loam, firm, moderate medium prismatic structure, few $\mathrm{CaCO}_{3}$ filaments, thin bed of gravel, very coarse and coarse sand at $286 \mathrm{~cm}$, very abrupt smooth boundary. Bwb horizon, late Holocene alluvium.

Zone 5 406-420+cm Brown (7.5YR 4/4) clay loam, firm, moderatemedium angular blocky structure, common prominent coarse (7.5YR 6/6) mottles, boundary not observed. $2 \mathrm{Bb}$ horizon, early(?) Holocene alluvium.

\section{Trench 5}

Zone $1 \quad 0-32 \mathrm{~cm}$

Alternating beds and laminae of pale brown (10YR 6/3) fine to medium sand and grayish brown (10YR 5/2) mud, abrupt smooth boundary. C horizon, recent alluvium.

Zone 2 32-68 cm Dark grayish brown (10YR 4/2) silty clay loam to fine sandy clay loam, friable, weak fine subangular blocky structure, clear smooth boundary. AC horizon, late Holocene alluvium.

Zone 3 68-92 cm Dark gray (10YR 4/1) silty clay loam, firm, moderate medium subangular blocky structure, gradual smooth boundary. Ab horizon, late Holocene alIuvium.

Zone 4 92-295 cm Dark grayish brown (10YR 4/2) silty clay loam, firm, weak medium prismatic breaking to moderate medium angular blocky structure, few $\mathrm{CaCO}_{3}$ filaments, gravel stringer (slightly dispersed, granule-sized) at $184 \mathrm{~cm}$, clear smooth boundary. Bb horizon, late Holocene al luvium.

Zone 5 295-425+cm Brown (10YR 5/3) silty clay loam, firm, weak medium prismatic breaking to moderate medium angular blocky structure, few $\mathrm{CaCO}_{3}$ filaments, boundary not observed. Bwb horizon, late Holocene alluvium.

\section{Site 41ML 162}

\section{Trench 1}

Zone $1 \quad 0-36 \mathrm{~cm}$

Grayish brown (10YR 5/2) silty clay loam, firm, moderate fine subangular blocky structure, common preserved horizontal laminae, abrupt smooth boundary. AC horizon, recent alluvium.

Zone 2 36-52 cm Dark gray (10YR 4/1) silty clay loam, firm, moderatefine subangular blocky structure, $10 \%$ limestone gravels (matrix-supported, subangular to subrounded, granule-sized), abrupt smooth boundary. Ab horizon, late Holocene alluvium.

Zone 3 52-64 cm Dark grayish brown (10YR 4/2) gravelly sandy clay loam, firm, weak fine granular structure, 50\% limestone gravels (matrix- and clast-supported, angular to subangular, granule- to pebble-sized), Zone 3 pinches out to the 
National Register Testing of NineArcheol ogical Sites at Waco Lake

north, abrupt smooth boundary. Bwb horizon, late Holocene colluvium.

Zone 4 64-72 cm Dark grayish brown (10YR 4/2) silty clay loam, firm, moderate fine subangular blocky structure, Zone 4 pinches out to the south, abrupt smooth boundary. Bwb2 horizon, late Holocene alluvium.

Zone 5 72-96 cm Dark grayish brown (10YR 4/2) gravelly sandy clay loam, firm, weak fine granular structure, 50\% limestone gravels (matrix- and clast-supported, subangular to subrounded, granule- to pebble-sized), Zone 5 pinches out to the north, abrupt smooth boundary. Bwb3 horizon, late Holocene colluvium.

Zone 6 96-116 cm Dark grayish brown (10YR 4/2) silty clay loam, firm, moderate fine subangular blocky structure, Zone 6 pinches out to the south, abrupt smooth boundary. Bwb4 horizon, late Holocene alluvium.

Zone 7 116-141+cm Dark grayish brown (10YR 4/2) gravelly sandy clay loam, firm, weak fine granular structure, 50\% limestone gravels (matrix- and clast-supported, subangular tosubrounded, granule-to pebble-sized), boundary not observed. $\mathrm{C}$ horizon, late Holocene colluvium.

Trench 3

Zone 1 0-19 cm

Dark grayish brown (10YR 4/2) silty clay loam, firm, moderate fine granular structure, few preserved horizontal laminae, abrupt smooth boundary. AC horizon, recent alluvium.

Zone 2 19-93 cm Black (10YR 2/1) silty clay loam, firm, moderate medium subangular blocky structure, $5 \%$ limestone gravels (matrix-supported, angular to subangular, granule- to pebble-sized), few freshwater mussel shell fragments, common burned rocks, gradual smooth boundary. Ab horizon, late Holocene alluvium.

Zone 3 93-143+cm Yell owish brown (10YR 5/4) silty clay, firm, moderatemedium angular blocky structure, 2 percent limestone gravels (matrix-supported, angular, granule to pebble-sized), boundary not observed. Bwb horizon, late Holocene alluvium.

\section{Trench 4}

Zone $1 \quad 0-18 \mathrm{~cm}$

Dark gray (10YR 4/1) silty clay loam, firm, weak medium granular structure, abrupt smooth boundary. AC horizon, recent alluvium.

Zone 2 18-77 cm Very dark gray (10YR 3/1) silty clay loam, very firm, moderate medium subangular blocky structure, common freshwater mussel shell fragments, common burned rocks, clear smooth boundary. Radiocarbon age on bulk soil from $50-60 \mathrm{~cm}$ of $1720 \pm 60$ B.P. Ab horizon, late Holocene alluvium.

Zone 3 77-105 cm Dark grayish brown (10YR 4/2) clay loam, very firm, moderate medium angular blocky structure, 2\% limestone gravel (matrix-supported, angular to subangular, granule to pebble-sized), clear smooth boundary. Bwb horizon, late Holocene alluvium.

Zone $4 \quad$ 105-127 cm Very dark grayish brown (10YR 3/2) clay loam, very firm, moderate medium angular blocky structure, many burned rocks, common freshwater 
mussel shells, few pieces of charcoal, few pieces of lithic debitage, clear smooth boundary. Radiocarbon age on bulk soil from 107-117 cm of $3400 \pm$ 70 B.P. 2Ab horizon, late Holocene alluvium.

Zone 5 127-153 cm Brown (10YR 5/3) silty clay loam, firm, moderate fine angular blocky structure, $5 \%$ limestonegravels (matrix-supported, angular to subangular, granuleto pebble-sized), clear smooth boundary. 2Bb horizon, late Holocene alluvium and colluvium.

Zone 6 153-180+cm Dark grayish brown (10YR 4/2) silty clay loam, firm, moderate medium angular blocky structure, common freshwater mussel shells, common snail (Rabdotus sp.) shells, 10\% limestone gravels (matrix-supported, angular to subangular, granule-sized), boundary not observed. 3ABb horizon, late Holocene alluvium and colluvium.

\section{Site 41ML 185}

\section{Trench 1}

Zone $1 \quad 0-94 \mathrm{~cm}$

Zone $2 \quad 94-154 \mathrm{~cm}$

Zone 3 154-254+cm Yellowish brown (10YR 5/4) silty clay loam, firm, moderate medium prismatic breaking to moderate medium angular blocky structure, many distinct coarse (10YR 5/2) mottles, common $\mathrm{CaCO}_{3}$ filaments, boundary not observed. Bwkb horizon, late Holocene all uvium.

\section{Trench 2}

Zone $1 \quad 0-80 \mathrm{~cm}$

Zone 2 80-125 cm Very dark grayish brown (10YR 3/2) silty clay loam, firm, moderate me dium subangular blocky structure, common faint fine (10YR 4/3) mottles, many snail (Rabdotus sp.) shells, many freshwater mussel shell fragments, common burned rocks, common pieces of charcoal, heavily bioturbated (microfaunal burrowing), clear smooth boundary. Radiocarbon age on bulk soil from $101-109 \mathrm{~cm}$ of $1130 \pm 80$ B.P. Ab horizon, late Holocene alluvium.

Zone 3 125-300+cm Yellowish brown (10YR 5/4) silty clay loam, firm, moderate medium subangular blocky structure, many distinct coarse (10YR 5/2) mottles that become more prominent with depth, few $\mathrm{CaCO}_{3}$ filaments, few freshwater mussel shell fragments, individual burned rocks at 148 and $239 \mathrm{~cm}$, boundary not observed. Bwb horizon, late Holocene alluvium. 
National Register Testing of NineArcheol ogical Sites at Waco Lake

\section{Site 41ML 186}

Trench 1

Zone $1 \quad 0-30 \mathrm{~cm}$

Zone $2 \quad 30-83 \mathrm{~cm}$

Zone $3 \quad 83-104 \mathrm{~cm}$

Zone 4 104-140 cm Brown (10YR 5/3) fine sandy clay loam, friable, moderate fine subangular blocky structure, few poorly preserved sand and mud laminae, clear smooth boundary. $\mathrm{C}$ horizon, late $\mathrm{H}$ ol ocene alluvium.

Zone 5 140-170 cm Dark grayish brown (10YR 4/2) silty clay loam, firm, moderate medium subangular blocky structure, few $\mathrm{CaCO}_{3}$ filaments, clear smooth boundary. $2 \mathrm{Ab}$ horizon, late Holocene alluvium.

Zone 6 170-357+cm Brown (10YR 5/3) silty clay loam, firm, moderate medium angular blocky structure, common $\mathrm{CaCO}_{3}$ filaments, one freshwater mussel shell fragment at $204 \mathrm{~cm}$, boundary not observed. 2B kb horizon, late Holocene alluvium.

\section{Trench 2}

Zone $1 \quad 0-58 \mathrm{~cm}$

Zone $2 \quad 58-102 \mathrm{~cm}$

Zone $3 \quad 102-143 \mathrm{~cm}$

Zone $4 \quad 143-201 \mathrm{~cm}$

Very dark grayish brown (10YR 3/2) silty clay loam, firm, moderate medium angular blocky structure, $2 \%$ limestone gravels (matrix-supported, subangular, granule to pebble-sized), few $\mathrm{CaCO}_{3}$ filaments, clear smooth boundary. Ab horizon, late Holocene alluvium.

Zone 5 201-369+cm Pale brown (10YR 6/3) silty clay, firm, weak medium prismatic breaking to moderate medium angular blocky structure, common $\mathrm{CaCO}_{3}$ filaments, boundary not observed. Bkb horizon, late $\mathrm{H}$ olocene alluvium.

\section{Trench 5}

Zone $1 \quad 0-55 \mathrm{~cm}$
Alternating horizontal beds of yellowish brown (10YR 5/4) sand and dark grayish brown (10YR 4/2) mud, abrupt smooth boundary. C horizon, recent alluvium.

Brown (10YR 5/3) fine sandy clay loam, friable, weak fine subangular blocky structure, poorly preserved beds of sand and mud, heavily bioturbated, abrupt smooth boundary. AC horizon, late Holocene alluvium.

subanguyish brown (10YR 4/2) silty clay loam, firm, moderate fine subangular blocky structure, few poorly preserved thin sand beds, clear smooth boundary. AC horizon, late Holocene alluvium.
Alternating beds and laminae of yellowish brown (10YR 5/4) fine to medium sand and grayish brown (10YR 5/2) mud, abrupt smooth boundary. C horizon, recent alluvium. 
Zone 2 55-120 cm Dark grayish brown (10YR 4/2) sandy clay loam, firm, weak fine subangular blocky structure, few poorly preserved thin sand beds, few pieces of charcoal, clear smooth boundary. Ab horizon, late Hol ocene alluvium.

Zone 3 120-254 cm Brown (10YR 5/3) silt loam, friable, moderate medium subangular blocky structure, few poorly preserved sand beds, few $\mathrm{CaCO}_{3}$ filaments, few pieces of charcoal, clear smooth boundary. $\mathrm{C}$ horizon, late Holocene alluvium.

Zone $4 \quad 254-288 \mathrm{~cm} \quad$ Dark grayish brown (10YR 4/2) silty clay loam, firm, weak medium prismatic breaking to moderate fine angular blocky structure, few $\mathrm{CaCO}_{3}$ filaments, thin bed of granule- to pebble-sized, subrounded to rounded gravels at $276 \mathrm{~cm}$, clear smooth boundary. 2Ab horizon, late Holocene alluvium.

Zone 5 288-352+cm Brown (10YR 5/3) very gravelly silty clay loam, firm, weak medium prismatic breaking to moderate fine angular blocky structure, common $\mathrm{CaCO}_{3}$ filaments, $>50 \%$ limestone gravels (granule- to cobble-sized, rounded to subrounded) at $324-352+\mathrm{cm}$, boundary not observed. 2Bb horizon, late Holocene alluvium.

\section{Site 41ML 194}

\section{Trench 2}

Zone $1 \quad 0-18 \mathrm{~cm}$

Zone $2 \quad 18-48 \mathrm{~cm}$

Zone $3 \quad 48-84 \mathrm{~cm}$

Zone $4 \quad 84-110 \mathrm{~cm}$

Zone $5 \quad 110-304 \mathrm{~cm}$

Zone $6 \quad 304-324+c m$

Dark grayish brown (10YR 4/2) silty clay loam, firm, moderate medium
subangular blocky structure, thin bed of gravel at $314 \mathrm{~cm}$, boundary not observed. 3Ab horizon, late Holocene al luvium.

\section{Trench 3}

Zone $1 \quad 0-18 \mathrm{~cm}$

Zone $2 \quad 18-41 \mathrm{~cm}$

Grayish brown (10YR 5/2), silty clay, firm, weak fine subangular blocky structure, few very thin beds of fine to coarse sand, very abrupt smooth boundary. $\mathrm{C}$ horizon, recent alluvium.

Dark gray (10YR 4/1) silty clay loam, firm, moderate medium subangular blocky structure, abrupt smooth boundary. Ab horizon, late Holocene alluvium.

Brown (10YR 5/3) sandy loam, friable, weak medium subangular blocky structure, clear smooth boundary. $\mathrm{C}$ horizon, late Holocene alluvium.

Dark grayish brown (10YR 4/2) silty clay loam, friable, moderate medium subangular blocky structure, clear smooth boundary. 2Ab horizon, late Holocene alluvium.

Brown (10YR 5/3) silt loam, friable, weak finesubangular blocky structure, common poorly preserved thin beds of fine to medium (10YR 7/4) sand, clear smooth boundary. $2 \mathrm{C}$ horizon, late Holocene alluvium.

Grayish brown (10YR 5/2) silty day, firm, weak fine subangular blocky structure, few thin beds of fine to coarse sand, abrupt smooth boundary. $C$ horizon, recent alluvium.

Dark grayish brown (10YR 4/2) silty clay loam, firm, weak medium subangular blocky structure, clear smooth boundary. Ab horizon, late Ho- 
National Register Testing of NineArcheol ogical Sites at Waco Lake

locene alluvium.

Zone 3 41-155 cm Brown (10YR 4/3) sandy clay loam, friable, weak fine subangular blocky structure, few poorly preserved very thin to thin beds of fine to medium quartz sand, clear smooth boundary. $\mathrm{C}$ horizon, late Holocene all uvium.

Zone 4 155-255 cm Dark grayish brown (10YR 4/2) silty clay loam, firm, moderate medium subangular blocky structure, two thin lenses of ash, charcoal, and oxidized sediment at 206 and $217 \mathrm{~cm}$, clear smooth boundary. 2Ab horizon, late Holocene alluvium.

Zone 5 255-270+cm Dark gray (10YR 4/1) silty clay loam, firm, moderatemedium angular blocky structure, many insect burrow casts, boundary not observed. 3Ab horizon, late Holocene alluvium.

\section{Trench 6}

Zone $1 \quad 0-16 \mathrm{~cm} \quad$ Brown (10YR 5/3) silty clay, firm, weak fine subangular blocky structure, thin bed of fineto medium sand at $16 \mathrm{~cm}$, abrupt wavy boundary. $\mathrm{C}$ horizon, recent alluvium.

Zone 2 16-41 cm Dark grayish brown (10YR 4/2) silty clay loam, firm, moderate fine subangular blocky structure, clear smooth boundary. Ab horizon, late Holocene alluvium.

Zone 3 41-85 cm Brown (10YR 5/3) silty clay, firm, weak fine subangular blocky structure, few poorly preserved very thin to thin beds of fine to medium quartz sand, clear smooth boundary. C horizon, late Holocene alluvium.

Zone 4 85-156 cm Dark gray (10YR 4/1) silty clay loam, firm, moderate medium angular blocky structure, clear smooth boundary. Radiocarbon age on bulk soil from 114$122 \mathrm{~cm}$ of $1070 \pm 80$ B.P. $2 \mathrm{Ab}$ horizon, late Holocene alluvium.

Zone 5 156-306 cm Dark grayish brown (10YR 4/2) silty clay, friable, moderate medium angular blocky structure, few $\mathrm{CaCO}_{3}$ filaments, clear smooth boundary. 2Bwb horizon, late Holocene alluvium.

Zone 6 306-330+cm Dark grayish brown (10YR 4/2) silty clay loam, firm, moderate medium prismatic breaking to moderate medium angular blocky structure, few $\mathrm{CaCO}_{3}$ filaments, boundary not observed. 2Bb horizon, late Holocene alluvium.

\section{Site41ML 195}

\section{Trench 1}

Zone $1 \quad 0-18 \mathrm{~cm}$

Zone $2 \quad 18-46 \mathrm{~cm}$
Dark grayish brown (10YR 4/2) silty clay loam, firm, weak finesubangular blocky structure, discontinuous very thin bed of medium to coarse sandsized quartz and carbonate clasts at $18 \mathrm{~cm}$, abrupt wavy boundary. $\mathrm{C}$ horizon, recent alluvium.

Very dark grayish brown (10YR 3/2) sandy clay loam, friable, weak medium subangular blocky structure, discontinuous thin bed of coarse sand-sized quartz, carbonate clasts, and fossilized shell, clear smooth boundary. Ab 
horizon, late Holocene alluvium.

Zone 3 46-96 cm Dark grayish brown (10YR 4/2) very fine sandy clay loam, firm, weak medium subangular blocky structure, sand component coarsens down profile to a coarse sand, clear smooth boundary. B wb horizon, late Holocene alluvium.

Zone 4 96-200 cm Very dark grayish brown (10YR 3/2) fine to medium sandy loam, friable, weak fine subangular blocky structure, cl ear smooth boundary. Bwb2 horizon, late Holocene alluvium.

Zone 5 200-250+cm Dark grayish brown (10YR 4/2) silty clay loam, firm, moderate fine subangular blocky structure, few $\mathrm{CaCO}_{3}$ filaments, common freshwater mussel shells, common pieces of charcoal, and common burned rocks at 235- $240 \mathrm{~cm}$, boundary not observed. 2Ab horizon, late H ol ocene all uvium.

Trench 3

Zone 1 0-19 cm Grayish brown (10YR 5/2) clay loam, firm, weak fine subangular blocky structure, thin bed of medium to coarse sand-sized quartz and carbonate clasts at $19 \mathrm{~cm}$, abrupt wavy boundary. $\mathrm{C}$ horizon, recent alluvium.

Zone 2 19-36 cm Very dark grayish brown (10YR 3/2) silty clay loam, firm, moderate fine subangular blocky structure, clear smooth boundary. Ab horizon, late Holocene alluvium.

Zone 3 36-190 cm Dark grayish brown (10YR 4/2) coarse to very coarse sandy clay loam, friable, moderate medium angular blocky structure, $2 \%$ limestone gravels (slightly bedded, subrounded to rounded, granule-sized), abrupt smooth boundary. Bwb horizon, late Holocene alluvium.

Zone 4 190-242+cm Dark grayish brown (10YR 4/2) clay loam, very firm, moderate medium angular blocky structure, few $\mathrm{CaCO}_{3}$ filaments, $2 \%$ limestone gravels (matrix-supported, rounded, granule-sized), boundary not observed. 2Ab horizon, late Holocene alluvium. 
National Register Testing of NineArcheol ogical Sites at Waco Lake

\section{REFERE NCES CITED}

Birkeland, Peter W.

1984 Soils and Geomorphol ogy. Oxford University Press, Oxford, England.

Buol, S. W., F. D. Hole, and R. J . McCracken

1980 Soil Genesis and Classification. 2nd ed. lowa State University Press, Ames.

Folk, Robert L.

1974 Petrol ogy of Sedimentary Rocks. Hemphill Publishing, Austin.

Olson, Gerald W.

1976 Criteria for Making and Interpreting a Soil Profile Description: A Compilation of the Official USDA Procedureand Nomenclaturefor Describing Soils. Bulletin 212. University of Kansas Publications, Lawrence.

Soil Survey Staff

1996 Keys to Soil Taxonomy. 7th ed. U.S. Department of Agriculture, Natural Resources Conservation Service, Washington D.C. 


\section{APPENDIX B: INVERTEBRATE FAUNAL ANALYSIS}

Karen M. Gardner 

This analysis focuses on the invertebrate faunal remains, specifically the freshwater mussel shells recovered during the excavations (Table 18). All of the shells recovered from each site were reviewed, but only complete valves or umbo fragments were looked at more closely for species identification. Fragments, tooth fragments, and umbo fragments that are too fragmentary for identification (whether due to breakage or poor preservation) werequantified, but no attempt at identification was made. All of the mussel shells were examined for evidence of cultural modification.

\section{Amblema plicata (Threeridge)}

Amblema plicata, a member of the family U nionidae, is a common species, ranging from the San Antonio and Guadal upe River systems through central, north, and east Texas. It typically is found on a variety of substrates ranging from silt and mud to gravel and cobbles at water depths of $2.5 \mathrm{~cm}$ to $3.0 \mathrm{~min}$ small streams, the headwaters and shallower sections of larger rivers, and reservoirs. This species is known to tolerate a lower water quality than other species (Howells et al. 1996:33-35; Parmalee 1967:26).

\section{Cyrtonaiastampicoensis (Tampico Pearlymussel)}

Cyrtonaias tampicoensis, a member of the family Unionidae, is found in many of the major river systems of Texas, including the B razos and Trinity. It usually is found on mud, mud and sand, or mud and gravel substrates, and occasionally those of cobble or rock. It prefers slow-flowing, mud-bottomed rivers or gravelbottomed streams with swifter currents, and it has been known to adapt well to some reservoir environments (Howells et al. 1996:48-50).

\section{Leptodea fragil is (F ragile Papershell)}

Leptodea fragilis, a member of the family Unionidae, is a common species in central, north, and east Texas. It is found on mud, gravel, mud and gravel, and occasionally sand, silt, or rocky substrates, in both shallow and deep waters. It is an adaptable species and is found in a variety of environments, ranging from small streams to large rivers, in clear or murky waters, and in still to swiftly flowing waters, although it is more common in quieter waters (Howells et al. 1996:75-76; Parmalee 1967:72).

\section{Potamilus pupuratus (Bleufer)}

Potamilus purpuratus, a member of the family Unionidae, is found in Texas from the Guadalupe River basin into the north and east. It is found in deep-water streams or rivers with slow to moderate currents, or in reservoirs or slow-moving sloughs at depths from ca. 0.5 to $3.0 \mathrm{~m}$. It favors mud substrates or a fine to medium gravel interspersed with mud (Howells et al. 1996:100-102).

\section{Quadrula apiculata (Southern Mapleleaf)}

Quadrula api culata, a member of thefamily Unionidae, is a common species in Texas and has been documented in all major river drainages. It is found on a variety of substrates, including mud, mud and sand, mud and gravel, and mud, gravel, and cobbles. It occurs in flowing waters in rivers and streams, as well as in slow-moving canals and still-water reservoirs. It can be found at depths of up to $4.6 \mathrm{~m}$, but also is common in much shallower waters (Howells et al. 1996:105-106).

\section{Quadrula petrina (Texas pimpleback)}

Quadrula petrina, a member of the family Unionidae, is found primarily in the Guadalupe and Col orado River systems, but it also has been noted el sewhere. It prefers mud and gravel substrates in slow-moving water, but al so has been found on sand and gravel substrates in shall ow flowing waters. It typically is found in shallow waters, at depths of 0.5 to $1.0 \mathrm{~m}$ (Howells et al. 1996:119-120).

\section{Tritogonia verrucosa (Pistolgrip)}

Tritogonia verrucosa, a member of the family Unionidae, has been noted from the San Antonio River drainage into east and north Texas. It has been noted on a variety of substrates, 
National Register Testing of NineArcheol ogical Sites at Waco Lake

Table 18. Provenience of invertebrate faunal remains

\begin{tabular}{lcll}
\hline Provenience & Quantity & Taxon & Description \\
\hline 41ML135 & & & \\
Test Unit 4, Level 1 & 2 & unidentified & fragments \\
\hline 41ML140 & & & \\
Test Unit 1, Feature 5, Level 2 & 6 & unidentified & fragments, 1 fossilized \\
Test Unit 1, Feature 5, Level 3 & 1 & $\begin{array}{l}\text { unidentified } \\
\text { fossilized oyster }\end{array}$ & fragment \\
Test Unit 1, Feature 5, Level 3 & 1 & umbo fragment \\
Test Unit 6, Feature 5, Level 2 & 3 & unidentified & fragments, possibly cut (?) \\
Test Unit 6, Feature 5, Level 3 & 6 & unidentified & fragments, possibly cut (?) \\
\hline
\end{tabular}

$41 M L 160$

Test Unit 1, Level 5

Test Unit 1, Level 10

Test Unit 1, Level 10

Test Unit 1, Level 18

Test Unit 1, Level 22

Test Unit 1, Level 27

Test Unit 1, Level 30

Test Unit 1, Level 34

Test Unit 1, Level 34

Test Unit 2, Level 32

Test Unit 2, Level 32

Test Unit 3, Level 12

Test Unit 3, Level 14

Test Unit 3, Level 15

Test Unit 3, Level 16

Test Unit 3, Level 21

Test Unit 3, Level 21

Test Unit 4, Level 5

Test Unit 4, Level 14

Test Unit 4, Level 14

Test Unit 4, Level 14

Test Unit 4, Level 15

Test Unit 4, Level 16

Test Unit 4, Level 16

Test Unit 4, Level 20

Test Unit 4, Level 20

Test Unit 4, Level 21

Test Unit 4, Level 22

\section{ML162}

Test Unit 1, Level 5

Test Unit 1, Level 5

Test Unit 1, Level 6

Test Unit 1, Level 6

Test Unit 1, Level 7

Test Unit 1, Level 8

Test Unit 1, Level 8

Test Unit 1, Level 9

Test Unit 1, Level 9

Test Unit 1, Level 10

Test Unit 1, Level 10

Test Unit 1, Level 10

Test Unit 1, Level 10

Test Unit 1, Level 11

Test Unit 1, Level 11

Test Unit 1, Level 11

Test Unit 1, Level 11

Test Unit 1, Level 11

Test Unit 1, Level 12

Test Unit 1, Level 12 unidentified

Quadrula sp.

unidentified

Amblema plicata

Amblema plicata

unidentified

unidentified

Quadrula petrina

unidentified

Leptodea fragilis

Amblema plicata

Amblema plicata

Amblema plicata

Amblema plicata

unidentified

Amblema plicata

Quadrula petrina

Cyrtonaias tampicoensis

Tritogonia verrucosa

Amblema plicata

unidentified

unidentified

Amblema plicata

unidentified

Amblema plicata

Quadrula sp.

Quadrula petrina

Amblema plicata

Amblema plicata unidentified

Amblema plicata

unidentified

unidentified

Amblema plicata

unidentified

Amblema plicata

unidentified

Leptodea fragilis

Tritogonia verrucosa

Amblema plicata

unidentified

Amblema plicata

Potamilus purpuratus

Leptodea fragilis

Quadrula sp.

unidentified

Amblema plicata

unidentified eroded umbo fragment

umbo fragment

fragment

umbo fragment (in two pieces)

nearly complete valve

fragments

fossilized fragment

1 complete valve, 1 umbo fragment

fragment

complete valve

umbo fragment

nearly complete valve

umbo fragments

umbo fragments, weathered

umbo fragments, too eroded to ID

umbo fragments

complete valve

nearly complete valve

nearly complete valve

umbo fragments

fragments

umbo fragment, too eroded to ID

umbo fragment

umbo fragments, too eroded to ID

umbo fragments

umbo fragment

complete valve

umbo fragment

umbo fragment

umbo fragments, too eroded to ID

umbo fragment

1 umbo fragment/ 5 fragments, too eroded to ID

1 umbo fragment/14 fragments, too eroded to ID

umbo fragments

umbo fragment, too small to ID

nearly complete valve

3 umbo fragments/3 fragments, too eroded to ID

umbo fragment

umbo fragments

umbo fragments

umbo fragments, too small/eroded to ID

umbo fragments

umbo fragment

umbo fragment

umbo fragment

umbo fragments/fragments, too eroded to ID

eroded umbo fragment

umbo fragments, too eroded to ID 
Table 18, continued

\begin{tabular}{|c|c|c|c|}
\hline Provenience & Quantity & Taxon & Description \\
\hline Test Unit 1, Level 13 & 1 & Amblema plicata & umbo fragment \\
\hline Test Unit 1, Level 14 & 1 & Amblema plicata & umbo fragment \\
\hline Test Unit 1, Level 14 & 1 & Quadrula sp. & umbo fragment \\
\hline Test Unit 1, Level 14 & 1 & unidentified & umbo fragment, too eroded to ID \\
\hline Test Unit 1, Level 15 & 1 & Amblema plicata & umbo fragment \\
\hline Test Unit 2, Level 3 & 2 & Amblema plicata & umbo fragments \\
\hline Test Unit 2, Level 3 & 3 & unidentified & umbo fragments, too eroded to ID \\
\hline Test Unit 7, Level 4 & 27 & Amblema plicata & umbo fragments \\
\hline Test Unit 7, Level 4 & 8 & Quadrula petrina & umbo fragments \\
\hline Test Unit 7, Level 4 & 1 & Potamilus purpuratus & umbo fragment \\
\hline Test Unit 7, Level 4 & 2 & Tritogonia verrucosa & umbo fragments \\
\hline Test Unit 7, Level 4 & 19 & unidentified & umbo fragments/fragments, too eroded to ID \\
\hline Test Unit 2, Level 5 & 24 & Amblema plicata & umbo fragments \\
\hline Test Unit 2, Level 5 & 6 & Quadrula petrina & umbo fragments \\
\hline Test Unit 2, Level 5 & 3 & Quadrula sp. & umbo fragments \\
\hline Test Unit 2, Level 5 & 3 & Tritogonia verrucosa & umbo fragments \\
\hline Test Unit 2, Level 5 & 4 & Potamilus sp. & umbo fragments \\
\hline Test Unit 2, Level 5 & 2 & Leptodea fragilis & umbo fragments \\
\hline Test Unit 2, Level 5 & 13 & unidentified & umbo fragments/fragments, too eroded to ID \\
\hline Test Unit 2, Level 6 & 1 & Amblema plicata & umbo fragment \\
\hline Test Unit 2, Level 6 & 2 & Tritogonia verrucosa & umbo fragments \\
\hline Test Unit 2, Level 6 & 1 & Quadrula sp. & umbo fragment \\
\hline Test Unit 2, Level 8 & 1 & Quadrula petrina & umbo fragment \\
\hline Test Unit 2, Level 10 & 2 & unidentified & umbo fragments/fragments, too eroded to ID \\
\hline Test Unit 2, Level 12 & 1 & Quadrula sp. & umbo fragment \\
\hline Test Unit 2, Level 14 & 3 & unidentified & umbo fragments, too eroded to ID \\
\hline Test Unit 3, Level 3 & 84 & Amblema plicata & umbo fragments \\
\hline Test Unit 3, Level 3 & 6 & Leptodea fragilis & umbo fragments, nearly complete valves \\
\hline Test Unit 3, Level 3 & 2 & Potamilus purpuratus & umbo fragments \\
\hline Test Unit 3, Level 3 & 8 & Tritogonia verrucosa & umbo fragments \\
\hline Test Unit 3, Level 3 & 16 & Quadrula petrina & umbo fragments \\
\hline Test Unit 3, Level 3 & 18 & unidentified & umbo fragments/fragments, too eroded to ID \\
\hline Test Unit 3, Level 4 & 18 & Amblema plicata & umbo fragments \\
\hline Test Unit 3, Level 4 & 7 & Quadrula petrina & umbo fragments \\
\hline Test Unit 3, Level 4 & 1 & Tritogonia verrucosa & umbo fragment \\
\hline Test Unit 3, Level 4 & 4 & unidentified & umbo fragments/fragments, too eroded to ID \\
\hline Test Unit 3, Level 5 & 19 & Amblema plicata & umbo fragments \\
\hline Test Unit 3, Level 5 & 5 & Quadrula petrina & umbo fragments \\
\hline Test Unit 3, Level 5 & 1 & Cyrtonaias tampicoensis & umbo fragment \\
\hline Test Unit 3, Level 5 & 3 & Tritogonia verrucosa & umbo fragments \\
\hline Test Unit 3, Level 5 & 1 & Leptodea fragilis & umbo fragment \\
\hline Test Unit 3, Level 5 & 1 & unidentified & umbo fragments/fragments, too eroded to ID \\
\hline Test Unit 3, Level 6 & 10 & Amblema plicata & umbo fragments \\
\hline Test Unit 3, Level 6 & 1 & Leptodea fragilis & umbo fragment \\
\hline Test Unit 3, Level 6 & 1 & Tritogonian verrucosa & umbo fragment \\
\hline Test Unit 3, Level 7 & 19 & Amblema plicata & umbo fragments, nearly complete valves \\
\hline Test Unit 3, Level 7 & 2 & Tritogonia verrucosa & umbo fragments \\
\hline Test Unit 3, Level 7 & 4 & Quadrula petrina & umbo fragments \\
\hline Test Unit 3, Level 7 & 5 & Leptodea fragilis & umbo fragments \\
\hline Test Unit 3, Level 7 & 4 & unidentified & umbo fragments/fragments, too eroded to ID \\
\hline Test Unit 3, Level 8 & 12 & Amblema plicata & umbo fragments, nearly complete valves \\
\hline Test Unit 3, Level 8 & 3 & Quadrula petrina & umbo fragments \\
\hline Test Unit 3, Level 8 & 4 & Leptodea fragilis & nearly complete valves \\
\hline Test Unit 3, Level 8 & 2 & Tritogonia verrucosa & umbo fragments \\
\hline Test Unit 3, Level 8 & 7 & unidentified & umbo fragments/fragments, too eroded to ID \\
\hline Test Unit 3, Level 9 & 4 & Amblema plicata & umbo fragments \\
\hline Test Unit 3, Level 9 & 1 & Tritogonia verrucosa & umbo fragment \\
\hline Test Unit 3, Level 9 & 1 & unidentifed & umbo fragment/fragments, too eroded to ID \\
\hline Test Unit 3, Level 10 & 4 & unidentifed & umbo fragments/fragments, too eroded to ID \\
\hline Test Unit 3, Level 11 & 2 & Amblema plicata & umbo fragments \\
\hline Test Unit 3, Level 12 & 1 & Amblema plicata & umbo fragment \\
\hline Test Unit 4, Level 3 & 1 & Amblema plicata & umbo fragment \\
\hline Test Unit 4, Level 4 & 2 & Quadrula petrina & umbo fragments \\
\hline Test Unit 4, Level 4 & 11 & unidentified & umbo fragments/fragments, too eroded to ID \\
\hline
\end{tabular}


Table 18, continued

\begin{tabular}{|c|c|c|c|}
\hline Provenience & Quantity & Taxon & Description \\
\hline Test Unit 4, Level 5 & 9 & Amblema plicata & umbo fragments \\
\hline Test Unit 4, Level 5 & 3 & Quadrula petrina & umbo fragments \\
\hline Test Unit 4, Level 5 & 3 & Potamilus purpuratus & umbo fragments \\
\hline Test Unit 4, Level 5 & 1 & Leptodea fragilis & complete valve \\
\hline Test Unit 4, Level 5 & 17 & unidentified & umbo fragments/fragments, too eroded to ID \\
\hline Test Unit 4, Level 6 & 7 & Amblema plicata & umbo fragments \\
\hline Test Unit 4, Level 6 & 4 & Quadrula petrina & umbo fragments \\
\hline Test Unit 4, Level 6 & 1 & Tritogonia verrucosa & umbo fragment \\
\hline Test Unit 4, Level 6 & 17 & unidentified & umbo fragments/fragments, too eroded to ID \\
\hline Test Unit 4, Level 7 & 1 & Tritogonia verrucosa & nearly complete valve \\
\hline Test Unit 4, Level 7 & 4 & Quadrula petrina & umbo fragments \\
\hline Test Unit 4, Level 7 & 6 & Amblema plicata & umbo fragments \\
\hline Test Unit 4, Level 7 & 43 & unidentified & umbo fragments/fragments, too eroded to ID \\
\hline Test Unit 4, Level 8 & 1 & unidentified & umbo fragment/fragments, too eroded to ID \\
\hline Test Unit 4, Level 9 & 5 & unidentified & umbo fragment/fragments, too eroded to ID \\
\hline Test Unit 4, Level 10 & 5 & unidentified & umbo fragment/fragments, too eroded to ID \\
\hline Test Unit 4, Level 11 & 4 & Quadrula sp. & umbo fragments \\
\hline Test Unit 4, Level 11 & 1 & Amblema plicata & umbo fragment \\
\hline Test Unit 4, Level 11 & 1 & Tritogonia verrucosa & umbo fragment \\
\hline Test Unit 4, Level 11 & 20 & unidentified & umbo fragments/fragments, too eroded to ID \\
\hline Test Unit 4, Level 12 & 3 & Amblema plicata & umbo fragments \\
\hline Test Unit 4, Level 12 & 1 & Quadrula apiculata & complete valve \\
\hline Test Unit 4, Level 12 & 1 & Leptodea fragilis & umbo fragment \\
\hline Test Unit 4, Level 12 & 9 & Quadrula sp. & umbo fragments \\
\hline Test Unit 4, Level 12 & 17 & unidentified & umbo fragments/fragments, too eroded to ID \\
\hline Test Unit 4, Level 13 & 7 & Amblema plicata & umbo fragments \\
\hline Test Unit 4, Level 13 & 8 & unidentified & umbo fragments/fragments, too eroded to ID \\
\hline Test Unit 4, Level 14 & 1 & Tritogonia verrucosa & umbo fragment \\
\hline Test Unit 4, Level 14 & 1 & Quadrula sp. & umbo fragment \\
\hline Test Unit 4, Level 14 & 2 & Amblema plicata & umbo fragments \\
\hline Test Unit 4, Level 14 & 10 & unidentified & umbo fragments/fragments, too eroded to ID \\
\hline Test Unit 4, Level 15 & 14 & unidentified & umbo fragments/fragments, too eroded to ID \\
\hline Test Unit 4, Level 16 & 24 & unidentified & umbo fragments/fragments, too eroded to ID \\
\hline Test Unit 4, Level 17 & 1 & Amblema plicata & umbo fragment \\
\hline Test Unit 4, Level 17 & 1 & Tritogonia verrucosa & umbo fragment \\
\hline Test Unit 4, Level 17 & 12 & unidentified & umbo fragments/fragments, too eroded to ID \\
\hline Test Unit 4, Level 18 & 22 & unidentified & umbo fragments/fragments, too eroded to ID \\
\hline Test Unit 5, Level 5 & 1 & Leptodea fragilis & umbo fragment \\
\hline Test Unit 5, Level 5 & 1 & Quadrula petrina & umbo fragment \\
\hline Test Unit 5, Level 5 & 1 & Amblema plicata & umbo fragment \\
\hline Test Unit 5, Level 6 & 5 & Amblema plicata & umbo fragments \\
\hline Test Unit 5, Level 6 & 1 & Potamilus sp. & umbo fragment \\
\hline Test Unit 5, Level 7 & 2 & unknown & umbo fragments, cannot ID \\
\hline Test Unit 5, Level 8 & 1 & unidentified & umbo fragment \\
\hline Test Unit 5, Level 9 & 3 & Quadrula petrina & umbo fragments \\
\hline Test Unit 5, Level 9 & 3 & Tritogonia verrucosa & umbo fragments \\
\hline Test Unit 5, Level 9 & 11 & Amblema plicata & umbo fragments \\
\hline Test Unit 5, Level 9 & 17 & unidentified & umbo fragments/fragments, too eroded to ID \\
\hline Test Unit 5, Level 10 & 1 & Leptodea fragilis & umbo fragment \\
\hline Test Unit 5, Level 10 & 4 & Amblema plicata & umbo fragments \\
\hline Test Unit 5, Level 10 & 1 & oyster & umbo fragment \\
\hline Test Unit 5, Level 10 & 3 & unidentified & umbo fragments/fragments, too eroded to ID \\
\hline Test Unit 5, Level 11 & 1 & Tritogonia verrucosa & umbo fragment \\
\hline Test Unit 5, Level 11 & 1 & Amblema plicata & umbo fragment \\
\hline Test Unit 5, Level 11 & 2 & unidentified & umbo fragments, too small to ID \\
\hline Test Unit 3, Feature 1, Level 5 & 4 & unidentified & umbo fragments, too small to ID \\
\hline \multicolumn{4}{|l|}{ 41ML185 } \\
\hline Test Unit 1, Level 10 & 1 & unidentified & umbo fragment, too small to ID \\
\hline Test Unit 1, Level 11 & 3 & unidentified & umbo fragments, too small to ID \\
\hline Test Unit 1, Level 12 & 1 & unidentified & umbo fragment, too small to ID \\
\hline Test Unit 1, Level 13 & 1 & unidentified & umbo fragment/fragments, too small to ID \\
\hline Test Unit 1, Level 14 & 3 & Amblema plicata & umbo fragments \\
\hline Test Unit 1, Level 15 & 1 & unidentified & umbo fragment/fragments, too small to ID \\
\hline Test Unit 1, Level 17 & 1 & unidentified & umbo fragment/fragments, too small to ID \\
\hline
\end{tabular}


Table 18, continued

\begin{tabular}{|c|c|c|c|}
\hline Provenience & Quantity & Taxon & Description \\
\hline Test Unit 2, Level 11 & 1 & unidentified & umbo fragment, too small to ID \\
\hline Test Unit 2, Level 12 & 1 & unidentified & umbo fragment/fragments, too small to ID \\
\hline Test Unit 2, Level 14 & 1 & unidentified & umbo fragment, too small to ID \\
\hline Test Unit 3, Level 2 & 1 & unidentified & umbo fragment/fragments, too small to ID \\
\hline Test Unit 3, Level 3 & 1 & unidentified & umbo fragment/fragments, too small to ID \\
\hline Test Unit 3, Level 4 & 2 & unidentified & umbo fragments/fragments, too small to ID \\
\hline Test Unit 3, Level 5 & 4 & unidentified & umbo fragments/fragments, too small to ID \\
\hline Test Unit 3, Level 6 & 7 & unidentified & umbo fragments/fragments, too small to ID \\
\hline Test Unit 3, Level 7 & 8 & unidentified & umbo fragments/fragments, too small to ID \\
\hline Test Unit 3, Level 8 & 5 & unidentified & fragments \\
\hline Test Unit 3, Level 9 & 1 & unidentified & umbo fragment/fragments, too small to ID \\
\hline Test Unit 3, Level 10 & 1 & unidentified & fragment \\
\hline Test Unit 3, Level 11 & 3 & unidentified & umbo fragments/fragments, too small to ID \\
\hline Test Unit 3, Level 12 & 3 & unidentified & umbo fragments/fragments, too eroded to ID \\
\hline Test Unit 3, Level 13 & 2 & unidentified & umbo fragments/fragments, too small to ID \\
\hline Test Unit 3, Level 14 & 10 & unidentified & fragments \\
\hline Test Unit 4, Level 1 & 1 & unidentified & cardinal tooth fragment \\
\hline Test Unit 4, Level 2 & 8 & unidentified & umbo fragments, too eroded to ID \\
\hline Test Unit 4, Level 3 & 2 & unidentified & umbo fragments/fragments, too small to ID \\
\hline Test Unit 4, Level 4 & 3 & unidentified & umbo fragments/fragments, too eroded to ID \\
\hline Test Unit 4, Level 5 & 1 & unidentified & umbo fragment/fragments, too small to ID \\
\hline Test Unit 4, Level 6 & 5 & unidentified & umbo fragments/fragments, too small to ID \\
\hline Test Unit 4, Level 7 & 3 & Tritogonia verrucosa & umbo fragments, extremely weathered \\
\hline Test Unit 4, Level 7 & 6 & unidentified & umbo fragments/fragments, too eroded to ID \\
\hline Test Unit 4, Level 8 & 1 & unidentified & umbo fragment/fragments, too small to ID \\
\hline Test Unit 4, Level 9 & 4 & unidentified & fragments \\
\hline Test Unit 4, Level 10 & 1 & unidentified & fragment \\
\hline Test Unit 4, Level 11 & 1 & unidentified & umbo fragment/fragments, too small to ID \\
\hline Test Unit 4, Level 12 & 1 & unidentified & umbo fragment/fragments, too small to ID \\
\hline Test Unit 4, Level 13 & 2 & unidentified & umbo fragments/fragments, too small to ID \\
\hline Test Unit 4, Level 14 & 1 & unidentified & umbo fragment/fragments, too small to ID \\
\hline Test Unit 5, Level 3 & 2 & Amblema plicata & umbo fragments \\
\hline Test Unit 5, Level 3 & 2 & Quadrula sp. & umbo fragments \\
\hline Test Unit 5, Level 3 & 5 & unidentified & umbo fragments/fragments, too small to ID \\
\hline Test Unit 5, Level 4 & 3 & unidentified & umbo fragments/fragments, too small to ID \\
\hline Test Unit 5, Level 5 & 1 & Tritogonia verrucosa & nearly complete valve \\
\hline Test Unit 5, Level 5 & 2 & Amblema plicata & umbo fragments \\
\hline Test Unit 5, Level 5 & 11 & unidentified & umbo fragments/fragments, too eroded to ID \\
\hline Test Unit 5, Level 6 & 1 & Amblema plicata & umbo fragment \\
\hline Test Unit 5, Level 6 & 1 & Quadrula petrina & umbo fragment \\
\hline Test Unit 5, Level 6 & 1 & Leptodea fragilis & umbo fragment \\
\hline Test Unit 5, Level 6 & 26 & unidentified & umbo fragments/fragments, too small/eroded to ID \\
\hline Test Unit 5, Level 7 & 2 & Amblema plicata & umbo fragments \\
\hline Test Unit 5, Level 7 & 20 & unidentified & umbo fragments/fragments, too small/eroded to ID \\
\hline Test Unit 5, Level 8 & 4 & Amblema plicata & umbo fragments, badly weathered \\
\hline Test Unit 5, Level 8 & 2 & Tritogonia verrucosa & umbo fragments, badly weathered \\
\hline Test Unit 5, Level 8 & 7 & unidentified & umbo fragments/fragments, too eroded to ID \\
\hline Test Unit 5, Level 9 & 7 & Amblema plicata & umbo fragments, weathered with deposit buildup \\
\hline Test Unit 5, Level 9 & 2 & Tritogonia verrucosa & umbo fragments, weathered with deposit buildup \\
\hline Test Unit 5, Level 9 & 11 & unidentified & $\begin{array}{l}\text { umbo fragments/fragments, too eroded/too much } \\
\text { deposit buildup to ID }\end{array}$ \\
\hline Test Unit 5, Level 10 & 1 & Amblema plicata & umbo fragments \\
\hline Test Unit 5, Level 10 & 8 & unidentified & umbo fragments, too eroded to ID \\
\hline Test Unit 5, Level 11 & 1 & Amblema plicata & umbo fragment \\
\hline $\begin{array}{l}\text { Test Unit 5, Feature } 1 \text {, } \\
\text { Levels 6-7, flotation sample }\end{array}$ & 5 & unidentified & umbo fragments, too small and eroded to ID \\
\hline $\begin{array}{l}\text { Test Unit 5, Feature } 2, \\
\text { Level } 7 \text {, flotation sample }\end{array}$ & 3 & unidentified & umbo fragments, too small and eroded to ID \\
\hline \multicolumn{4}{|l|}{ 41ML 186} \\
\hline Test Unit 1, Level 12 & 3 & unidentified & 1 umbo fragment, 2 fragments too eroded to ID \\
\hline Test Unit 2, Level 11 & 1 & unidentified & umbo fragment, too eroded to ID \\
\hline Test Unit 3, Level 11 & 2 & unidentified & fragments, too eroded to ID \\
\hline Test Unit 3, Level 13 & 1 & Quadrula sp. & umbo fragment \\
\hline
\end{tabular}


National Register Testing of NineArcheol ogical Sites at Waco Lake

Table 18, continued

\begin{tabular}{|c|c|c|c|}
\hline Provenience & Quantity & Taxon & Description \\
\hline Test Unit 3, Level 14 & 1 & Cyrtonaias tampicoensis & umbo fragment \\
\hline Test Unit 3, Level 15 & 1 & unidentified & umbo fragment, too eroded to ID \\
\hline Test Unit 4, Level 12 & 1 & Tritogonia verrucosa & umbo fragment \\
\hline Test Unit 4, Level 15 & 2 & unidentified & 1 umbo fragment, 1 fragment too eroded to ID \\
\hline Test Unit 4, Level 27 & 1 & Quadrula petrina & umbo fragment \\
\hline Test Unit 4, Level 29 & 1 & Quadrula sp. & umbo fragment \\
\hline Test Unit 4, Level 29 & 3 & unidentified & umbo fragments, too eroded to ID \\
\hline \multicolumn{4}{|l|}{ 41ML 194} \\
\hline Test Unit 3, Level 22 & 8 & unidentified & fragments \\
\hline Test Unit 4, Level 17 & 1 & Tritogonia verrucosa & umbo fragment \\
\hline Test Unit 4, Level 19 & 1 & unidentified & umbo fragment, too eroded to ID \\
\hline Test Unit 4, Level 21 & 2 & unidentified & umbo fragments, too eroded to ID \\
\hline Test Unit 5, Level 5 & 1 & unidentified & umbo fragment, too eroded to ID \\
\hline Test Unit 5, Level 17 & 2 & unidentified & umbo fragments, too eroded to ID \\
\hline Test Unit 5, Level 18 & 1 & Amblema plicata & umbo fragment \\
\hline Test Unit 5, Level 19 & 3 & unidentified & 2 umbo fragments, 1 fragment too eroded to ID \\
\hline Test Unit 5, Level 22 & 2 & unidentified & fragments \\
\hline Test Unit 5, Level 24 & 1 & unidentified & umbo fragment, too eroded to ID \\
\hline Test Unit 6, Level 16 & 1 & unidentified & umbo fragment, too eroded to ID \\
\hline Test Unit 6, Level 17 & 3 & unidentified & fragments \\
\hline Test Unit 6, Level 18 & 1 & Quadrula sp. & umbo fragment \\
\hline Test Unit 6, Level 18 & 1 & unidentified & umbo fragment, too eroded to ID \\
\hline Test Unit 6, Level 19 & 3 & unidentified & fragments \\
\hline \multicolumn{4}{|l|}{ 41ML195 } \\
\hline Test Unit 1, Level 2 & 1 & unidentified & umbo fragment, too small to ID \\
\hline Test Unit 1, Level 5 & 1 & unidentified & fragment \\
\hline Test Unit 1, Level 6 & 1 & Amblema plicata & umbo fragment \\
\hline Test Unit 1, Level 8 & 1 & unidentified & umbo fragment, too small to ID \\
\hline Test Unit 1, Level 11 & 1 & Quadrula apiculata & umbo fragment \\
\hline Test Unit 1, Level 11 & 1 & Cyrtonaias tampicoensis & umbo fragment, eroded \\
\hline Test Unit 1, Level 12 & 1 & Amblema plicata & umbo fragment \\
\hline Test Unit 1, Level 12 & 1 & Quadrula petrina & umbo fragment \\
\hline Test Unit 1, Level 12 & 1 & unidentified & umbo fragment/fragments, too small to ID \\
\hline Test Unit 1, Level 14 & 1 & Amblema plicata & umbo fragment \\
\hline Test Unit 1, Level 14 & 2 & unidentified & umbo fragments, too eroded to ID \\
\hline Test Unit 1, Level 15 & 3 & Amblema plicata & umbo fragments \\
\hline Test Unit 1, Level 15 & 1 & Tritogonia verrucosa & umbo fragment \\
\hline Test Unit 1, Level 15 & 1 & Quadrula apiculata & umbo fragment \\
\hline Test Unit 1, Level 15 & 1 & Leptodea sp. & umbo fragment \\
\hline Test Unit 1, Level 15 & 2 & Quadrula sp. & umbo fragments \\
\hline Test Unit 1, Level 15 & 1 & unidentified & umbo fragment, too eroded to ID \\
\hline Test Unit 1, Level 16 & 3 & Amblema plicata & umbo fragments \\
\hline Test Unit 1, Level 16 & 5 & unidentified & umbo fragments, too eroded to ID \\
\hline Test Unit 1, Level 17 & 4 & Amblema plicata & umbo fragments \\
\hline Test Unit 1, Level 17 & 1 & Leptodea fragilis & umbo fragment \\
\hline Test Unit 1, Level 17 & 1 & oyster & umbo fragment \\
\hline Test Unit 1, Level 17 & 4 & unidentified & umbo fragments/fragments, too eroded to ID \\
\hline Test Unit 1, Level 18 & 45 & Amblema plicata & umbo fragments \\
\hline Test Unit 1, Level 18 & 4 & Tritogonia verrucosa & umbo fragments \\
\hline Test Unit 1, Level 18 & 2 & Quadrula apiculata & umbo fragments \\
\hline Test Unit 1, Level 18 & 9 & Quadrula sp. & umbo fragments \\
\hline Test Unit 1, Level 18 & 1 & Leptodea fragilis & umbo fragment \\
\hline Test Unit 1, Level 18 & 52 & unidentifed & umbo fragments/fragments, too small/eroded to ID \\
\hline Test Unit 1, Level 19 & 12 & Amblema plicata & umbo fragments \\
\hline Test Unit 1, Level 19 & 1 & Leptodea fragilia & umbo fragment \\
\hline Test Unit 1, Level 19 & 1 & Quadrula apiculata & umbo fragment \\
\hline Test Unit 1, Level 19 & 1 & Potamilus sp. & umbo fragment \\
\hline Test Unit 1, Level 19 & 5 & Quadrula sp. & umbo fragments \\
\hline Test Unit 1, Level 19 & 46 & unidentified & umbo fragments/fragments, too small/eroded to ID \\
\hline Test Unit 1, Level 20 & 30 & Amblema plicata & umbo fragments \\
\hline Test Unit 1, Level 20 & 1 & Potamilus purpuratus & umbo fragment \\
\hline Test Unit 1, Level 20 & 1 & Leptodea fragilis & umbo fragment \\
\hline Test Unit 1, Level 20 & 1 & Tritogonia verrucosa & umbo fragment \\
\hline
\end{tabular}


Table 18, continued

\begin{tabular}{|c|c|c|c|}
\hline Provenience & Quantity & Taxon & Description \\
\hline Test Unit 1, Level 20 & 4 & Quadrula sp. & umbo fragments \\
\hline Test Unit 1, Level 20 & 2 & Quadrula petrina & umbo fragments \\
\hline Test Unit 1, Level 20 & 30 & unidentified & umbo fragments/fragments, too small/eroded to ID \\
\hline Test Unit 1, Level 21 & 5 & Amblema plicata & umbo fragments \\
\hline Test Unit 1, Level 21 & 1 & Leptodea fragilis & umbo fragment \\
\hline Test Unit 1, Level 21 & 5 & unidentified & umbo fragments, too eroded to ID \\
\hline Test Unit 2, Level 8 & 1 & Tritogonia verrucosa & umbo fragment \\
\hline Test Unit 2, Level 11 & 2 & Amblema plicata & umbo fragments \\
\hline Test Unit 2, Level 11 & 1 & Quadrula sp. & umbo fragment \\
\hline Test Unit 2, Level 12 & 2 & Leptodea fragilis & nearly complete valves \\
\hline Test Unit 2, Level 13 & 1 & unidentified & umbo fragment \\
\hline Test Unit 2, Level 14 & 1 & Potamilus sp. & umbo fragment \\
\hline Test Unit 2, Level 14 & 1 & unidentified & umbo fragment \\
\hline Test Unit 2, Level 15 & 21 & Amblema plicata & umbo fragments \\
\hline Test Unit 2, Level 15 & 3 & Tritogonia verrucosa & umbo fragments \\
\hline Test Unit 2, Level 15 & 1 & Leptodea fragilis & umbo fragment \\
\hline Test Unit 2, Level 15 & 17 & Cyrtonaias sp. & umbo fragments \\
\hline Test Unit 2, Level 15 & 18 & unidentified & umbo fragments/fragments, too small to ID \\
\hline Test Unit 2, Level 16 & 1 & Amblema plicata & umbo fragment \\
\hline Test Unit 2, Level 16 & 1 & Leptodea sp. & umbo fragment \\
\hline Test Unit 2, Level 16 & 1 & unidentified & umbo fragment, too eroded to ID \\
\hline Test Unit 2, Level 17 & 12 & Amblema plicata & umbo fragments \\
\hline Test Unit 2, Level 17 & 2 & Quadrula sp. & umbo fragments \\
\hline Test Unit 2, Level 17 & 8 & unidentified & umbo fragments/fragments, too eroded to ID \\
\hline Test Unit 2, Level 18 & 73 & Amblema plicata & umbo fragments \\
\hline Test Unit 2, Level 18 & 6 & Tritogonia verrucosa & umbo fragments \\
\hline Test Unit 2, Level 18 & 4 & Quadrula apiculata & umbo fragments \\
\hline Test Unit 2, Level 18 & 12 & Quadrula sp. & umbo fragments \\
\hline Test Unit 2, Level 18 & 4 & Quadrula petrina & umbo fragments \\
\hline Test Unit 2, Level 18 & 1 & Leptodea fragilis & umbo fragment \\
\hline Test Unit 2, Level 18 & 58 & unidentified & umbo fragments/fragments, too small/eroded to ID \\
\hline Test Unit 2, Level 19 & 2 & Quadrula sp. & umbo fragments \\
\hline Test Unit 2, Level 19 & 2 & Quadrula apiculata & umbo fragments \\
\hline Test Unit 2, Level 19 & 5 & Amblema plicata & umbo fragments \\
\hline Test Unit 2, Level 19 & 4 & unidentified & umbo fragments \\
\hline Test Unit 2, Level 20 & 11 & Amblema plicata & umbo fragments \\
\hline Test Unit 2, Level 20 & 3 & Tritogonia verrucosa & umbo fragments \\
\hline Test Unit 2, Level 20 & 1 & Quadrula sp. & umbo fragment \\
\hline Test Unit 2, Level 20 & 1 & Leptodea fragilis & umbo fragment \\
\hline Test Unit 2, Level 20 & 10 & unidentified & umbo fragments, too eroded to ID \\
\hline Test Unit 2, Level 21 & 1 & Amblema plicata & umbo fragment \\
\hline Test Unit 2, Level 21 & 2 & Quadrula sp. & umbo fragments \\
\hline Test Unit 2, Level 21 & 1 & unidentified & umbo fragment, too eroded to ID \\
\hline Test Unit 3, Level 5 & 4 & unidentified & umbo fragments/fragments \\
\hline Test Unit 3, Level 6 & 1 & Amblema plicata & umbo fragment \\
\hline Test Unit 3, Level 9 & 1 & Quadrula petrina & umbo fragment \\
\hline Test Unit 3, Level 9 & 1 & Cyrtonaias sp. & umbo fragment \\
\hline Test Unit 3, Level 9 & 3 & unidentified & umbo fragments, too eroded to ID \\
\hline Test Unit 3, Level 10 & 1 & Amblema plicata & umbo fragment \\
\hline Test Unit 3, Level 10 & 1 & unidentified & umbo fragment/fragment, too small to ID \\
\hline Test Unit 3, Level 11 & 3 & unidentified & umbo fragments, too eroded to ID \\
\hline Test Unit 3, Level 12 & 1 & Amblema plicata & umbo fragment \\
\hline Test Unit 3, Level 13 & 2 & Amblema plicata & umbo fragments \\
\hline Test Unit 3, Level 13 & 2 & unidentified & umbo fragments, too eroded to ID \\
\hline Test Unit 3, Level 14 & 1 & Amblema plicata & umbo fragment \\
\hline Test Unit 3, Level 14 & 2 & unidentified & umbo fragments, too eroded to ID \\
\hline Test Unit 3, Level 15 & 1 & Leptodea fragilis & umbo fragment \\
\hline Test Unit 3, Level 15 & 3 & Amblema plicata & umbo fragments \\
\hline Test Unit 3, Level 15 & 6 & unidentified & umbo fragments, too eroded to ID \\
\hline Test Unit 3, Level 16 & 6 & Amblema plicata & umbo fragments \\
\hline Test Unit 3, Level 16 & 10 & unidentified & umbo fragments/fragments, too eroded to ID \\
\hline Test Unit 3, Level 17 & 4 & Amblema plicata & umbo fragments \\
\hline Test Unit 3, Level 17 & 3 & unidentified & umbo fragments/fragments, too eroded to ID \\
\hline Test Unit 4, Level 18 & 3 & Quadrula petrina & umbo fragments \\
\hline
\end{tabular}


Table 18, continued

\begin{tabular}{|c|c|c|c|}
\hline Provenience & Quantity & Taxon & Description \\
\hline Test Unit 4, Level 18 & 3 & Quadrula apiculata & umbo fragments \\
\hline Test Unit 4, Level 18 & 5 & Amblema plicata & umbo fragments \\
\hline Test Unit 4, Level 18 & 3 & Leptodea fragilis & umbo fragment, nearly complete valves \\
\hline Test Unit 4, Level 18 & 13 & unidentified & umbo fragments/fragments, too eroded to ID \\
\hline Test Unit 3, Level 19 & 1 & Leptodea fragilis & umbo fragment \\
\hline Test Unit 3, Level 19 & 2 & Amblema plicata & umbo fragments \\
\hline Test Unit 3, Level 19 & 2 & unidentified & umbo fragments/fragments, too eroded to ID \\
\hline Test Unit 4, Level 1 & 1 & Amblema plicata & umbo fragment \\
\hline Test Unit 4, Level 4 & 1 & unidentified & umbo fragment/fragments \\
\hline Test Unit 4, Level 6 & 1 & unidentified & umbo fragment/fragments, too small to ID \\
\hline Test Unit 4, Level 7 & 1 & unidentified & umbo fragment \\
\hline Test Unit 4, Level 8 & 1 & Amblema plicata & umbo fragment \\
\hline Test Unit 4, Level 9 & 2 & Amblema plicata & umbo fragments \\
\hline Test Unit 4, Level 9 & 1 & unidentified & umbo fragment/fragment, too small to ID \\
\hline Test Unit 4, Level 10 & 1 & Amblema plicata & umbo fragment \\
\hline Test Unit 4, Level 10 & 2 & unidentified & umbo fragments/fragments \\
\hline Test Unit 4, Level 11 & 3 & unidentified & umbo fragments/fragments \\
\hline Test Unit 4, Level 12 & 1 & unidentified & umbo fragment/fragments \\
\hline Test Unit 4, Level 13 & 3 & Amblema plicata & umbo fragments \\
\hline Test Unit 4, Level 13 & 2 & unidentified & umbo fragments, too eroded to ID \\
\hline Test Unit 4, Level 14 & 8 & unidentified & umbo fragments, too eroded to ID \\
\hline Test Unit 4, Level 15 & 3 & Amblema plicata & umbo fragments, nearly complete valve \\
\hline Test Unit 4, Level 15 & 2 & Leptodea fragilis & umbo fragment, nearly complete valve \\
\hline Test Unit 4, Level 15 & 1 & Quadrula petrina & umbo fragment \\
\hline Test Unit 4, Level 15 & 1 & Quadrula apiculata & umbo fragment \\
\hline Test Unit 4, Level 15 & 1 & Tritogonia verrucosa & umbo fragment \\
\hline Test Unit 4, Level 15 & 6 & unidentified & umbo fragments/fragments \\
\hline Test Unit 4, Level 16 & 3 & Amblema plicata & umbo fragments \\
\hline Test Unit 4, Level 16 & 1 & Quadrula petrina & umbo fragment \\
\hline Test Unit 4, Level 16 & 1 & Quadrula apiculata & umbo fragment \\
\hline Test Unit 4, Level 16 & 6 & unidentified & umbo fragments/fragments, too eroded to ID \\
\hline Test Unit 4, Level 17 & 1 & Leptodea fragilis & nearly complete valve \\
\hline Test Unit 4, Level 17 & 1 & Quadrula sp. & nearly complete valve \\
\hline Test Unit 4, Level 17 & 4 & unidentified & umbo fragments, too eroded to ID \\
\hline Test Unit 4, Level 18 & 3 & Amblema plicata & umbo fragments \\
\hline Test Unit 4, Level 18 & 1 & Leptodea fragilis & nearly complete valve \\
\hline Test Unit 4, Level 18 & 1 & Quadrula sp. & umbo fragment \\
\hline Test Unit 4, Level 18 & 7 & unidentified & umbo fragments/fragments, too eroded to ID \\
\hline $\begin{array}{l}\text { Test Unit 1, F eature 1, } \\
\text { Level } 19 \text {, flotation sample }\end{array}$ & 8 & unidentified & umbo fragments/fragments, too eroded to ID \\
\hline
\end{tabular}

including rock and hard mud or silty soft bottoms. Found in medium tolarge rivers, it is common in both shallow and deeper waters at depths ranging from several centimeters to several meters (Howel Is et al. 1996:136-137; Parmalee 1967:43-44). 


\section{REFERE NCES CITED}

Howells, Robert G., Raymond W. Neck, and Harold D. Murray

1996 Freshwater Mussel s of Texas. Texas Parks and Wild life Department, I nland Fisheries Division.
Parmalee, Paul W.

1967 The Fresh-Water Mussel s of IIlinois. IIlinois State Museum, Popular Science Series, Volume VIII. Springfield, IIIinois. 


\section{APPENDIX C: VERTEBRATE FAUNAL ANALYSIS}

Brian S. Shaffer 

Vertebrate faunal remains recovered were analyzed to identify the taxa present and discern taphonomic processes that had impacted the assemblages (Tables 19-21). I dentifications were made to the most specific taxon possible given the condition of the assemblage and analyst skill. Remains were tabulated by simple bone counts.

Taphonomic processes addressed include weathering, breakage, burning, chemical dissolution, rodent gnawing, and cut marks. In terms of surface exposure (weathering) that typically results in bleaching, fine-line cracking, and flaking in planes of the surface of the bone, the assemblages are in good shape. Chemical etching produced by roots or matrix acidity can result in dendritic patterns on the surface of the bone (root etching), or pitting over the entire surface (extensive root etching and matrix acidity). Specimens from 41ML 160, 41ML 179, and 41ML 195 exhibit significant chemical dissolution affecting all specimens from those sites.

Breakage was addressed by recording specimens as unbroken, angular fractures, and spiral fractures. Only a few specimens are unbroken. Most of the breakage is the result of angular fractures. Angular fractures typically occur in flat bones of the skeleton such as on portions of the scapulae and ribs, and also on the cranium and pelvis. In long bones and other elements with thick cortical bone, angular fractures typically occur after the specimen has lost its collagen or become "dry." This can result from the processes of cooking that leach collagen from the bone, burning, weathering, and degradation over time. Spiral fractures occur in I ong bones and other el ements with thick cortical bone while the bone still contains collagen or is "fresh." "Fresh" is a relative term since bonemay remain fresh for an extended amount of time given favorable conditions of preservation. Spiral fractures of fresh bone may occur during the processing of carcasses for their meat, through the intentional breakage of the bone to gain access to the marrow, or through breaking of the bone into small pieces to process for grease. Processing of bone for marrow or grease may be evidenced by the presence of impact points. Five specimens from 41M L 160 and 41ML 162 exhibit impact points. I mpact points are where the bone suffered an impact from an object that fractured the bone. Impact points are characterized by a cone of percussion and concentric fractures around the point of impact.

Burning was recorded as unburned, charred, and calcined. Charred bone is bonethat has been incompletely combusted and may be black or brown in col or. Calcined bone is more completely combusted bone that has turned white (sometimes blue as well, but none are noted in this analysis). Combustion beyond calcination results in complete destruction of the bone.

Another taphonomic result observed is the presence of rodent gnawing. Rodent gnawing is evidenced by the closely spaced parallel groove marks produced on the bone's surface by rodent teeth. These marks are differentiated from carnivore gnawing that typically does not produce parallel grooves. Rodent gnawing is differentiated from cut marks by the typical " $U$ " shape of the grooves as compared to the " $V$ " shape of cut marks. Five specimens from 41ML162 exhibit rodent gnawing.

Nine specimens from 41ML 140 and $41 \mathrm{ML} 179$ have cut marks. All were identified as chop marks. With one exception, all of the chop marks completely transect the bone. Where discernible, the cut marks were made with a smooth-bladed implement such as a cleaver. 
National Register Testing of NineArcheol ogical Sites at Waco Lake

Table 19. Summary of vertebrate faunal remains

\begin{tabular}{|c|c|c|}
\hline Site & Taxon & Totals \\
\hline 41ML 135 & Mammalia (Canid/deer-sized) & 4 \\
\hline \multirow[t]{9}{*}{$41 M L 140$} & Vertebrata (Vertebrates) & 24 \\
\hline & Bufo sp. (Toads) & 1 \\
\hline & Aves (Duck/turkey-sized) & 3 \\
\hline & Mammalia (Canid/deer-sized) & 102 \\
\hline & Mammalia (Deer/bison-sized) & 24 \\
\hline & Artiodactyla (Goat/deer-sized) & 2 \\
\hline & Sus scrofa (Pig) & 25 \\
\hline & Bos/ Bison (Cow/bison) & 1 \\
\hline & Ovis/ Capra (Sheep/goat) & 1 \\
\hline Subtotal & & 183 \\
\hline \multirow[t]{3}{*}{ 41ML 160} & Vertebrata (Vertebrates) & 11 \\
\hline & Mammalia (Canid/deer-sized) & 75 \\
\hline & Artiodactyla (Goat/deer-sized) & 7 \\
\hline Subtotal & & 93 \\
\hline \multirow[t]{12}{*}{ 41ML 162} & Vertebrata (Vertebrates) & 46 \\
\hline & Osteichthyes (Medium-sized, $>6$ inches) & 2 \\
\hline & Sciaenidae (Drum) & 1 \\
\hline & Testudinata (Turtles) & 11 \\
\hline & Mammalia (Rabbit/canid-sized) & 1 \\
\hline & Mammalia (Canid/deer-sized) & 114 \\
\hline & Mammalia (Large/very large) & 26 \\
\hline & Sylvilagus sp. (Cottontail rabbits) & 2 \\
\hline & Artiodactyla (Goat/deer-sized) & 21 \\
\hline & Artiodactyla (Cow/bison-sized) & 3 \\
\hline & Odocoileus sp. (Deer) & 2 \\
\hline & Bos/ Bison (Cow/bison) & 1 \\
\hline Subtotal & & 230 \\
\hline \multirow[t]{2}{*}{ 41ML179 } & Mammalia (Canid/deer-sized) & 5 \\
\hline & Artiodactyla (Goat/deer-sized) & 1 \\
\hline Subtotal & & 6 \\
\hline \multirow[t]{3}{*}{ 41ML 185} & Vertebrata (Vertebrates) & 5 \\
\hline & Mammalia (Canid/deer-sized) & 17 \\
\hline & Artiodacyla (Goat/deer-sized) & 1 \\
\hline Subtotal & & 23 \\
\hline \multirow[t]{2}{*}{ 41ML 195} & Vertebrata (Vertebrates) & 11 \\
\hline & Mammalia (Canid/deer-sized) & 3 \\
\hline Subtotal & & 14 \\
\hline TOTALS & & 553 \\
\hline
\end{tabular}


Table 20. Vertebrate faunal taphonomy

\begin{tabular}{|c|c|c|c|c|c|c|c|c|c|c|c|c|}
\hline \multirow[b]{2}{*}{ Site } & \multicolumn{2}{|c|}{ Weathering } & \multicolumn{3}{|c|}{ Breakage } & \multicolumn{3}{|c|}{ Burning } & \multirow[b]{2}{*}{ 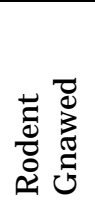 } & \multirow[b]{2}{*}{ 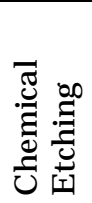 } & \multirow[b]{2}{*}{$\begin{array}{l}\overline{8} \\
\frac{0}{8} \\
\frac{1}{\cup}\end{array}$} & \multirow[b]{2}{*}{ 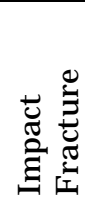 } \\
\hline & 节 & 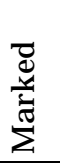 & 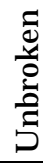 & $\begin{array}{l}\frac{1}{\sigma} \\
\frac{7}{5} \\
\frac{1}{4}\end{array}$ & $\begin{array}{l}\overline{0} \\
\text { 음 } \\
\text { n. }\end{array}$ & 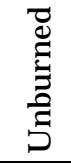 & $\begin{array}{l}\bar{d} \\
\frac{d}{0} \\
\frac{\tau}{U}\end{array}$ & $\frac{\bar{d}}{\frac{C}{\sigma}}$ & & & & \\
\hline 41ML 135 & 4 & - & - & - & 4 & 4 & - & - & - & - & - & - \\
\hline $41 M L 140$ & 182 & 1 & 6 & 143 & 29 & 140 & 16 & 24 & - & - & 8 & 3 \\
\hline 41ML 160 & 93 & - & - & 47 & 46 & 81 & 11 & 1 & - & 93 & - & 2 \\
\hline 41ML 162 & 224 & 2 & 2 & 147 & 77 & 172 & 28 & 26 & 5 & 1 & - & - \\
\hline 41ML179 & 5 & - & - & 5 & - & 5 & - & - & - & 5 & 1 & - \\
\hline 41ML 185 & 23 & - & 1 & 12 & 10 & 20 & - & 3 & - & 10 & - & - \\
\hline 41ML 195 & 14 & - & - & 12 & 2 & - & 5 & - & - & 9 & - & - \\
\hline
\end{tabular}


Table 21. Provenience of vertebrate faunal remains

\begin{tabular}{lcll}
\hline Provenience & Quantity & Taxon & Comments \\
\hline 41ML135 & & & \\
Test Unit 4, Level 1 & 4 & Mammalia (medium/large) & light weathering, spiral break, unburned \\
\hline $41 M L 140$ & &
\end{tabular}

\section{ML 140}

Test Unit 1, F eature 5, Level 2

Test Unit 1, F eature 5, Level 2

Test Unit 1, Feature 5, Level 2

Test Unit 1, F eature 5, Level 2

Test Unit 1, Feature 5, Level 2

Test Unit 1, Feature 5, Level 2

Test Unit 1, Feature 5, Level 3

Test Unit 1, Feature 5, Level 3

Test Unit 1, Feature 5, Level 4

Test Unit 1, Feature 5, Level 4

Test Unit 1, Feature 5, Level 4

Test Unit 1, Feature 5, Level 4

Test Unit 1, Feature 5, Level 4

Test Unit 1, Feature 5, Level 5

Test Unit 1, F eature 5, Level 5

Test Unit 1, Feature 5, Level 5

Test Unit 1, Feature 5, Level 5

Test Unit 1, Feature 5, Level 5

Test Unit 1, Feature 5, Level 5

Test Unit 1, F eature 5, Level 5

Test Unit 1, Feature 5, Level 5

Test Unit 1, Feature 5, Level 5

Test Unit 1, Feature 5, Level 5

Test Unit 1, F eature 5, Level 5

Test Unit 1, F eature 5, Level 6

Test Unit 1, Feature 5, Level 6

Test Unit 1, Feature 5, Level 6

Test Unit 1, Feature 5, Level 6

Test Unit 1, Feature 5, Level 7

Test Unit 1, F eature 5, Level 7

Test Unit 2, F eature 2, Level 1

Test Unit 2, Feature 2, Level 2

Test Unit 2, Feature 2, Level 2

Test Unit 2, Feature 2, Level 2

\section{Vertebrata}

Aves (large)

Mammalia (medium/large)

Mammalia (medium/large)

Mammalia (medium/large)

Sus scrofa

Vertebrata

Mammalia (medium/large)

Vertebrata

Mammalia (medium/large)

Mammalia (medium/large)

Mammalia (medium/large)

Sus scrofa

Mammalia (medium/large)

Mammalia (medium/large)

Mammalia (medium/large)

Mammalia (medium/large)

Mammalia (medium/large)

Mammalia (medium/large)

Mammalia (large/very large)

Mammalia (large/very large)

Mammalia (large/very large)

Artiodactyla (large)

Bos/ Bison

Mammalia (medium/large)

Mammalia (medium/large)

Mammalia (medium/large)

Mammalia (medium/large)

Mammalia (large/very large)

Artiodactyla (medium)

Aves (large)

Vertebrata

Mammalia (medium/large)

Sus scrofa light weathering, angular break, unburned light weathering, angular break, unburned light weathering, angular break, unburned light weathering, angular break, calcined

light weathering, angular break, charred

light weathering, angular break, unburned light weathering, angular break, calcined

light weathering, angular break, unburned light weathering, angular break, unburned

light weathering, angular break, unburned, 2 chop marks

light weathering, angular break, unburned

light weathering, spiral break, unburned

light weathering, unbroken, unburned

light weathering, angular break, charred

light weathering, spiral break, charred

light weathering, spiral break, calcined

light weathering, angular break, calcined

light weathering, spiral break, unburned

light weathering, angular break, unburned

geathering, spiral break, unburned

ight weathering, angular break, unburned, chopped

light weathering, angular break, unburned

light weathering, spiral break, unburned

light weathering, angular break, charred

light weathering, angular break, calcined

light weathering, spiral break, calcined

light weathering, angular break, unburned, chopped at least 2 times

marked weathering, angular break, calcined

light weathering, unbroken, unburned

light weathering, angular break, unburned

light weathering, angular break, unburned

light weathering, angular break, unburned 
Table 21, continued

\begin{tabular}{|c|c|c|c|}
\hline Provenience & Quantity & Taxon & Comments \\
\hline Test Unit 2, Feature 2, Level 2 & 2 & Sus scrofa & light weathering, unbroken, unburned \\
\hline Test Unit 2, Feature 2, Level 3 & 3 & Vertebrata & light weathering, angular break, unburned \\
\hline Test Unit 2, Feature 2, Level 3 & 5 & Sus scrofa & light weathering, angular break, unburned \\
\hline Test Unit 2, Feature 2, Level 3 & 2 & Sus scrofa & light weathering, unbroken, unburned \\
\hline Test Unit 3, Feature 3, Level 1 & 1 & Vertebrata & light weathering, spiral break, unburned \\
\hline Test Unit 3, Feature 3, Level 2 & 3 & Mammalia (medium/large) & light weathering, angular break, unburned \\
\hline Test Unit 3, Feature 3, Level 2 & 1 & Mammalia (large/very large) & light weathering, spiral break, unburned \\
\hline Test Unit 3, Feature 3, Level 2 & 2 & Sus scrofa & light weathering, angular break, unburned \\
\hline Test Unit 5, Feature 6, Level 2 & 3 & Vertebrata & light weathering, angular break, charred \\
\hline Test Unit 5, Feature 6, Level 2 & 2 & Mammalia (medium/large) & light weathering, spiral break, charred \\
\hline Test Unit 6, Feature 5, Level 2 & 1 & Bufo sp. & light weathering, angular break, unburned \\
\hline Test Unit 6, Feature 5, Level 2 & 1 & Mammalia (medium/large) & light weathering, angular break, calcined \\
\hline Test Unit 6, Feature 5, Level 3 & 1 & Vertebrata & light weathering, spiral break, unburned \\
\hline Test Unit 6, Feature 5, Level 3 & 1 & Mammalia (medium/large) & light weathering, spiral break, unburned \\
\hline Test Unit 6, Feature 5, Level 3 & 8 & Mammalia (medium/large) & light weathering, angular break, unburned \\
\hline Test Unit 6, Feature 5, Level 3 & 4 & Sus scrofa & light weathering, angular break, unburned \\
\hline Test Unit 6, Feature 5, Level 4 & 1 & Mammalia (medium/large) & light weathering, angular break, unburned, chopped \\
\hline Test Unit 6, Feature 5, Level 5 & 1 & Mammalia (medium/large) & light weathering, angular break, calcined \\
\hline Test Unit 6, Feature 5, Level 5 & 10 & Mammalia (medium/large) & light weathering, angular break, unburned \\
\hline Test Unit 6, Feature 5, Level 5 & 3 & Mammalia (large/very large) & light weathering, angular break, unburned \\
\hline Test Unit 6, Feature 5, Level 5 & 1 & Mammalia (large/very large) & light weathering, angular break, unburned, chopped \\
\hline Test Unit 6, Feature 5, Level 5 & 3 & Mammalia (large/very large) & light weathering, spiral break, unburned \\
\hline Test Unit 6, Feature 5, Level 5 & 1 & Ovis/Capra & light weathering, angular break, unburned \\
\hline Test Unit 6, Feature 5, Level 6 & 11 & Mammalia (medium/large) & light weathering, angular break, unburned \\
\hline Test Unit 6, Feature 5, Level 6 & 1 & Mammalia (medium/large) & light weathering, angular break, unburned, chopped \\
\hline Test Unit 6, Feature 5, Level 6 & 2 & Mammalia (large/very large) & light weathering, angular break, unburned, chopped \\
\hline Test Unit 6, Feature 5, Level 6 & 1 & Mammalia (large/very large) & light weathering, spiral break, charred \\
\hline Test Unit 6, Feature 5, Level 6 & 6 & Mammalia (large/very large) & light weathering, angular break, unburned \\
\hline Test Unit 6, Feature 5, Level 7 & 1 & Mammalia (medium/large) & light weathering, angular break, unburned \\
\hline Test Unit 6, F eature 5, Level 7 & 1 & Mammalia (medium/large) & light weathering, angular break, calcined \\
\hline
\end{tabular}

\section{$41 \mathrm{ML} 160$}

Test Unit 3, Feature 1, Level 18

Test Unit 3, Feature 1, Level 18

Test Unit 3, Feature 1, Level 18

Test Unit 3, Level 18

Test Unit 3, Level 18

Mammalia (medium/large)

2 Mammalia (medium/large)

1 Artiodactyla (medium)

$7 \quad$ Vertebrata

1 Vertebrata light weathering, spiral break, unburned, marked chemical etching light weathering, spiral break, charred, marked chemical etching light weathering, angular break, unburned, marked chemical etching, deer-sized

light weathering, angular break, unburned, marked chemical etching light weathering, angular break, calcined 
Table 21, continued

Provenience

Test Unit 3, Level 18

Test Unit 3, Level 18

Test Unit 3, Level 18

Test Unit 3, Level 18

Test Unit 3, Level 18

Test Unit 3, Level 18

Test Unit 3, Level 18

Test Unit 4, Level 18

Test Unit 4, Level 18

Test Unit 4, Level 18

Test Unit 4, Level 18

Test Unit 4, Level 18

\section{ML162}

Test Unit 1, Level 4

Test Unit 1, Level 7

Test Unit 1, Level 7

Test Unit 1, Level 7

Test Unit 1, Level 10

Test Unit 1, Level 11

Test Unit 1, Level 12

Test Unit 1, Level 13

Test Unit 2, Level 3

Test Unit 2, Level 3

Test Unit 2, Level 3

Test Unit 2, Level 3

Test Unit 2, Level 3

Test Unit 2, Level 3

Test Unit 2, Level 3

Test Unit 2, Level 4

Test Unit 2, Level 4

Test Unit 2, Level 4

Test Unit 2, Level 4

Test Unit 2, Level 4

Test Unit 2, Level 4

Test Unit 2, Level 4

Test Unit 2, Level 4

Test Unit 2, Level 5

Quantity Taxon

8 Mammalia (medium/large)

2 Mammalia (medium/large)

Mammalia (medium/large)

Mammalia (medium/large)

Artiodactyla (medium)

Artiodactyla (medium)

Artiodactyla (medium)

3 Vertebrata

26 Mammalia (medium/large)

22 Mammalia (medium/large)

2 Artiodactyla (medium)

$1 \quad$ Artiodactyla (medium)

light weathering, spiral break, unburned

light weathering, angular break, charred

light weathering, spiral break, charred

light weathering, angular break, unburned

light weathering, spiral break, charred, marked chemical etching

light weathering, spiral break, unburned, marked chemical etching

light weathering, spiral break, unburned, marked chemical ethcing, impact fracture

light weathering, angular break, unburned, marked chemical etching

light weathering, angular break, unburned, marked chemical etching

light weathering, spiral break, unburned, marked chemical etching

light weathering, spiral break, unburned, marked chemical etching,

impact fracture

light weathering, angular break, unburned, marked chemical etching

1

12

5

1

1

1

6

2

1

15

3

6

3
Artiodactyla (medium) Mammalia (medium/large)

Mammalia (large/very large) light weathering, angular break, unburned

Mammalia (large/very large) light weathering, angular break, unburned

Testudinata

Vertebrata

Mammalia (medium/large)

Artiodactyla (medium)

Mammalia (medium/large)

Mammalia (medium/large)

Mammalia (medium/large)

Mammalia (large/very large)

Sylvilagus sp.

Artiodactyla (large)

Artiodactyla (large)

Vertebrata

Testudinata

Mammalia (medium/large)

Mammalia (medium/large)

Mammalia (medium/large)

Mammalia (large/very large)

Artiodactyla (medium)

Bos/Bison

Osteichthyes (medium) light weathering, angular break, unburned

light weathering, angular break, calcined

light weathering, spiral break, unburned

light weathering, spiral break, unburned, rodent gnawed

light weathering, spiral break, calcined

light weathering, angular break, unburned

light weathering, spiral break, unburned

light weathering, spiral break, unburned

light weathering, angular break, unburned

light weathering, spiral break, unburned

light weathering, angular break, unburned, rodent gnawed

light weathering, angular break, unburned

light weathering, angular break, unburned

light weathering, spiral break, unburned

light weathering, angular break, charred

light weathering, angular break, calcined

light weathering, spiral break, unburned

light weathering, angular break, unburned

marked weathering, spiral break, unburned

light weathering, angular break, unburned 
Table 21, continued

\section{Provenience}

Test Unit 2, Level 5

Test Unit 2, Level 5

Test Unit 2, Level 5

Test Unit 2, Level 5

Test Unit 2, Level 5

Test Unit 2, Level 5

Test Unit 2, Level 6

Test Unit 3, Level 3

Test Unit 3, Level 3

Test Unit 3, Level 3

Test Unit 3, Level 3

Test Unit 3, Level 3

Test Unit 3, Level 3

Test Unit 3, Level 4

Test Unit 3, Level 4

Test Unit 3, Level 4

Test Unit 3, Level 4

Test Unit 3, Level 4

Test Unit 3, Feature 1, Level 5

Test Unit 3, Feature 1, Level 5

Test Unit 3, Feature 1, Level 5

Test Unit 3, Feature 1, Level 5

Test Unit 3, Feature 1, Level 5

Test Unit 3, Feature 1, Level 5

Test Unit 3, F eature 1, Level 5

Test Unit 3, Feature 1, Level 6

Test Unit 3, Feature 1, Level 6

Test Unit 3, Feature 1, Level 6

Test Unit 3, Feature 1, Level 6

Test Unit 3, Feature 1, Level 6

Test Unit 3, Feature 1, Level 7

Test Unit 3, Feature 1, Level 7

Test Unit 3, Feature 1, Level 7

Test Unit 3, Feature 1, Level 7

Test Unit 3, Feature 1, Level 8

Test Unit 3, F eature 1, Level 8

Test Unit 3, Feature 1, Level 9

Test Unit 3, Feature 1, Level 9

Test Unit 4, Level 4

Quantity

$\begin{array}{ll}1 & \text { Sciaenidae } \\ 6 & \text { Mammalia (medium/large) } \\ 7 & \text { Mammalia (medium/large) } \\ 2 & \text { Mammalia (medium/large) } \\ 1 & \text { Artiodactyla (medium) } \\ 4 & \text { Testudinata } \\ 1 & \text { Vertebrata }\end{array}$

Comments

light weathering, angular break, unburned

light weathering, angular break, unburned

light weathering, spiral break, unburned

light weathering, angular break, charred

light weathering, spiral break, unburned, impact fracture

light weathering, angular break, unburned light weathering, angular break, charred light weathering, angular break, unburned

Vertebrata

Testudinata

Mammalia (medium/large)

Mammalia (medium/large)

Mammalia (medium/large)

Artiodactyla (medium)

Vertebrata

Vertebrata

Mammalia (medium/large)

Mammalia (medium/large)

Mammalia (large/very large)

Odocoileus sp.

Vertebrata

Mammalia (Small/medium)

Mammalia (medium/large)

Mammalia (medium/large)

Mammalia (medium/large)

Artiodactyla (medium)

Artiodactyla (medium)

Mammalia (medium/large)

Artiodactyla (medium)

Artiodactyla (medium)

Artiodactyla (medium)

Artiodactyla (medium)

Mammalia (medium/large)

Mammalia (medium/large)

Sylvilagus sp.

Artiodactyla (medium)

Vertebrata

Mammalia (medium/large)

Vertebrata

Mammalia (medium/large)

Vertebrata light weathering, angular break, calcined

light weathering, angular break, unburned marked weathering, spiral break, unburned light weathering, angular break, unburned light weathering, angular break, calcined

light weathering, spiral break, unburned, rodent gnawed ight weathering, spiral break, unburned

light weathering, spiral break, unburned light weathering, unbroken, unburned light weathering, angular break, charred

light weathering, angular break, unburned light weathering, spiral break, calcined light weathering, angular break, charred light weathering, spiral break, unburned light weathering, angular break, calcined light weathering, angular break, unburned light weathering, angular break, calcined light weathering, unbroken, unburned light weathering, spiral break, unburned

light weathering, spiral break, unburned, impact fracture light weathering, angular break, unburned

light weathering, spiral break, unburned

light weathering, angular break, charred light weathering, angular break, unburned light weathering, spiral break, unburned light weathering, angular break, unburned light weathering, spiral break, unburned light weathering, angular break, calcined light weathering, angular break, unburned light weathering, angular break, charred 
Table 21, continued

Provenience

Test Unit 4, Level 4

Test Unit 4, Level 5

Test Unit 4, Level 5

Test Unit 4, Level 5

Test Unit 4, Level 6

Test Unit 4, Level 6

Test Unit 4, Level 6

Test Unit 4, Level 7

Test Unit 4, Level 7

Test Unit 4, Level 7

Test Unit 4, Level 7

Test Unit 4, Level 10

Test Unit 4, Level 10

Test Unit 4, Level 12

Test Unit 4, Level 14

Test Unit 4, Level 14

Test Unit 4, Level 14

Test U nit 4, Level 14

Test Unit 4, Level 16

Test Unit 4, Level 16

Test Unit 4, Level 16

Test Unit 4, Level 17

Test Unit 4, Level 17

Test Unit 4, Level 18

Test Unit 4, Level 18

Test Unit 5, Level 4

Test Unit 5, Level 4

Test Unit 5, Level 5

Test Unit 5, Level 5

Test Unit 5, Level 6

Test Unit 5, Level 7

Test Unit 5, Level 9

Test Unit 5, Level 9

\section{ML 179}

Test Unit 1, Feature 1, Level 4

Test Unit 1, F eature 1, Level 4

Test Unit 1, Feature 1, Level 5

Test Unit 1, Feature 1, Level 6

Quantity Taxon

3 Mammalia (medium/large)

Vertebrata

Mammalia (medium/large)

Mammalia (medium/large)

Vertebrata

Vertebrata

Artiodactyla (medium)

Vertebrata

Mammalia (medium/large)

Mammalia (medium/large)

Odocoileus sp.

Vertebrata

Vertebrata

Mammalia (large/very large) light weathering, angular break, unburned, root etched

Mammalia (medium/large)

Mammalia (medium/large)

Artiodactyla (medium)

Artiodactyla (medium)

Mammalia (medium/large)

Mammalia (medium/large)

Mammalia (medium/large)

Mammalia (medium/large)

Mammalia (medium/large)

Vertebrata

Testudinata

Vertebrata

Mammalia (medium/large)

Artiodactyla (medium)

Mammalia (medium/large)

Artiodactyla (medium)

Artiodactyla (medium)

Mammalia (medium/large)

Mammalia (medium/large)

1

Comments

light weathering, angular break, charred

light weathering, angular break, unburned

ght weathering, angular break, calcined

light weathering, spiral break, unburned

light weathering, angular break, calcined

light weathering, angular break, unburned

light weathering, angular break, unburned

light weathering, angular break, unburned

light weathering, angular break, charred

light weathering, spiral break, unburned

light weathering, spiral break, unburned

light weathering, angular break, calcined

light weathering, angular break, charred

light weathering, angular break, unburned

light weathering, spiral break, unburned

light weathering, spiral break, unburned, rodent gnawed

light weathering, spiral break, unburned

light weathering, spiral break, charred

light weathering, angular break, calcined

light weathering, angular break, charred

light weathering, angular break, charred

light weathering, spiral break, unburned

light weathering, angular break, unburned

light weathering, angular break, unburned

light weathering, angular break, unburned

light weathering, angular break, unburned

light weathering, angular break, unburned

light weathering, angular break, unburned

light weathering, spiral break, unburned

light weathering, angular break, charred

ight weathering, spiral break, unburned, greasy

light weathering, angular break, unburned

$1 \quad$ Mammalia (medium/large)

light weathering, angular break, unburned, chopped, marked chemcial etching

Artiodactyla (medium)

Mammalia (medium/large)

Mammalia (medium/large)

light weathering, angular break, unburned, marked chemical etching

light weathering, angular break, unburned, marked chemical etching 
Table 21, continued

\begin{tabular}{|c|c|c|c|}
\hline Provenience & Quantity & Taxon & Comments \\
\hline \multicolumn{4}{|l|}{ 41ML185 } \\
\hline $\begin{array}{l}\text { Test Unit 2, Level } 11 \\
\text { Test Unit 1, Level } 9 \\
\text { Test Unit 1, Level } 11 \\
\text { Test Unit 1, Level } 15 \\
\text { Test Unit 1, Level } 15 \\
\text { Test Unit 3, Level } 3 \\
\text { Test Unit 3, Level } 5 \\
\text { Test Unit 5, Level } 4 \\
\end{array}$ & $\begin{array}{c}3 \\
3 \\
1 \\
3 \\
10 \\
1 \\
1 \\
1\end{array}$ & $\begin{array}{l}\text { Mammalia (medium/large) } \\
\text { Mammalia (medium/large) } \\
\text { Mammalia (medium/large) } \\
\text { Vertebrata } \\
\text { Mammalia (medium/large) } \\
\text { Vertebrata } \\
\text { Vertebrata } \\
\text { Artiodactyla (medium) } \\
\end{array}$ & $\begin{array}{l}\text { light weathering, angular break, calcined } \\
\text { light weathering, angular break, unburned } \\
\text { light weathering, angular break, unburned } \\
\text { light weathering, angular break, unburned } \\
\text { light weathering, spiral break, unburned, marked chemical etching } \\
\text { light weathering, angular break, unburned } \\
\text { light weathering, angular break, unburned } \\
\text { light weathering, unbroken, unburned }\end{array}$ \\
\hline \multicolumn{4}{|l|}{ 41ML 195} \\
\hline $\begin{array}{l}\text { Test Unit 1, Level } 19 \\
\text { Test Unit 2, Level } 18 \\
\text { Test Unit 2, Level } 18 \\
\text { Test Unit 2, Level } 18 \\
\text { Test Unit 1, Feature 1, Level } 19 \\
\text { Test Unit 1, Feature 1, Level } 19\end{array}$ & $\begin{array}{l}1 \\
2 \\
1 \\
1 \\
4 \\
5\end{array}$ & $\begin{array}{l}\text { Mammalia (medium/large) } \\
\text { Vertebrata } \\
\text { Mammalia (medium/large) } \\
\text { Mammalia (medium/large) } \\
\text { Vertebrata } \\
\text { Vertebrata }\end{array}$ & $\begin{array}{l}\text { light weathering, angular break, unburned, marked chemical etching } \\
\text { light weathering, spiral break, unburned, marked chemical etching } \\
\text { light weathering, angular break, unburned, marked chemical etching } \\
\text { light weathering, angular break, charred, marked chemical etching } \\
\text { light weathering, angular break, charred, marked chemical etching } \\
\text { light weathering, angular break, unburned }\end{array}$ \\
\hline
\end{tabular}




\section{APPENDIX D: SUMMARY OF RADIOCARBON DATES}



Table 22. Summary of radiocarbon dates

\begin{tabular}{|c|c|c|c|c|c|}
\hline Sample & Material & Provenience & F eature & $\begin{array}{l}\text { Conventional } \\
{ }^{14} \mathrm{C} \text { Age B.P. }\left(\delta^{13} \mathrm{C}\right)\end{array}$ & $\begin{array}{l}\text { Two-Sigma Calibrated Age } \\
\text { Range and I ntercept(s)** }\end{array}$ \\
\hline Beta- 154279* & charcoal & 41ML 162, Test Unit 3, Level 6 (50-60 cm) & 1 & $1980 \pm 60(-24.1 \% d$ & 2060 (1920) 1820 B.P. \\
\hline Beta- 154280* & charcoal & 41ML 162, Test Unit 4, Level 7 (69 cm) & 2 & $2830 \pm 40(-26.5 \%)$ & 3050 (2940) 2850 в.P. \\
\hline Beta-154281* & charcoal & 41ML 162, Test Unit 4, Level $8(72 \mathrm{~cm})$ & 2 & $2780 \pm 40(-25.3 \% d)$ & 2960 (2870) 2780 в.Р. \\
\hline Beta- 154282* & charcoal & 41ML 162, Test Unit 4, Level $12(110-120 \mathrm{~cm})$ & - & $3600 \pm 40(-25.5 \% d)$ & 3990 (3900) 3830 в.P. \\
\hline Beta- 154283* & charcoal & 41ML 162, Test Unit 1, Level $12(112 \mathrm{~cm})$ & - & $2210 \pm 40(-22.8 \% d)$ & $2330(2300,2250,2170) 2120$ в.Р. \\
\hline Beta- 154285* & charcoal & 41ML 185, Test Unit 5, Level $8(160-170 \mathrm{~cm})$ & - & $117.5 \pm 0.6(-27.0 \% d$ & modern date \\
\hline Beta- 154286* & charcoal & 41ML 185, Test Unit 4, Level $4(120-130 \mathrm{~cm})$ & - & $160 \pm 50(-29.3 \% d$ & $300(270,200,150,20,0) 0$ в.Р. \\
\hline Beta- 154287* & $\begin{array}{l}\text { bulk soil/ } \\
\text { charcoal }\end{array}$ & 41ML 195, Test Unit 1, Level 19 (259 cm) & 1 & $3130 \pm 40(-25.0 \%)$ & 3440 (3360) 3260 в.P. \\
\hline Beta- 154288* & charcoal & 41ML 195, Test Unit 2, Level 19 (265 cm) & - & $2870 \pm 40(-25.0 \% d)$ & 3090 (2970) 2870 в.P. \\
\hline Beta-154289* & charcoal & 41ML 195, Test Unit 4, Level $19(265-275 \mathrm{~cm})$ & - & $2790 \pm 40(-24.6 \% d)$ & $2970(2870) 2780$ в.Р. \\
\hline Beta- 154290* & charcoal & 41ML 195, Test Unit 2, Level $18(245-255 \mathrm{~cm})$ & - & $2740 \pm 40(-25.0 \%)$ & 2920 (2840) 2760 в.P. \\
\hline Beta-154291* & charcoal & 41ML 162, Test Unit 5, Level 8 (72 cm) & - & $810 \pm 40(-25.5 \% d$ & 780 (710) 670 в.Р. \\
\hline Beta- 154292* & charcoal & 41ML 162, Test Unit 4, Level $13(127 \mathrm{~cm})$ & - & $3490 \pm 40(-24.2 \%)$ & 3860 (3720) 3650 в.P. \\
\hline Beta- 154293 & bulk soil & 41ML 162, Trench 4, Ab horizon $(50-60 \mathrm{~cm})$ & - & $1720 \pm 60(-23.3 \% d$ & 1800 (1610) 1520 в.P. \\
\hline Beta- 154294 & bulk soil & 41ML 162, Trench 4, 2Ab horizon $(107-117 \mathrm{~cm})$ & - & $3400 \pm 70(-22.0 \%)$ & 3840 (3640) 3470 в.P. \\
\hline Beta- 154295 & bulk soil & 41ML 185, Trench 2, Ab horizon (101-109 cm) & - & $1130 \pm 80(-16.4 \% d$ & 1250 (1050) 920 в.Р. \\
\hline Beta- 154296 & bulk soil & 41ML 194, Trench 6, 2Ab horizon (114-122 cm) & - & $1070 \pm 80(-16.3 \% d)$ & $1170(960) 790$ в.Р. \\
\hline
\end{tabular}

* AMS radiocarbon dates

** Calibration database used:

Stuiver, M., and J . van der Plicht

1998 Editorial Comment. Radiocarbon 40(3):xii-xii

Stuiver, M., P. J . Reimer, E. Bard, J . W. Beck, G. S. Burr, K. A. Hughen, B. Kromer, G. McCormac, J . van der Plicht, and M. Spurk 1998 INTCAL98 Radiocarbon Age Calibration. Radiocarbon 40(3):1041-1083.

Talma, A. S., and J . C. Voget

1993 A Simplified Approach to Calibrating C ${ }^{14}$ Dates. Radiocarbon 35(2):317-322. 